\title{
HEAT TRANSFER FROM LOW ASPECT RATIO PIN FINS
}

\author{
Michael E. Lyall
}

Thesis submitted to the Faculty

of the Virginia Polytechnic Institute and State University

in partial fulfillment of the requirements for the degree of

\author{
Master of Science \\ in \\ Mechanical Engineering
}

Dr. K.A. Thole, Chair

Dr. T.E. Diller

Dr. B. Vick

June 2, 2006

Blacksburg, VA

Keywords: pin fins, heat transfer, gas turbines, internal cooling, heat transfer augmentation 


\section{Heat Transfer from Low Aspect Ratio Pin Fins}

\section{Michael E. Lyall}

\section{Abstract}

The performance of many engineering devices from power electronics to gas turbines is limited by thermal management. Pin fins are commonly used to augment heat transfer by increasing surface area and increasing turbulence. The present research is focused on but not limited to internal cooling of turbine airfoils using pin fins. Although the pin fins are not limited to a single shape, circular cross-sections are most common.

The present study examines heat transfer from a single row of circular pin fins with the row oriented perpendicular to the flow. The configurations studied have spanwise spacing to pin diameter ratios of two, four, and eight. Low aspect ratio pin fins were studied whereby the channel height to pin diameter was unity. The experiments are carried out for a Reynolds number range of 5000 to 30,000. Heat transfer measurements are taken on both the pin and on the endwall covering several pin diameters upstream and downstream of the pin row. The results show that the heat transfer augmentation relative to open channel flow is highest for the smallest spanwise spacing for the lowest Reynolds number flows. The results also indicate that the pin fin heat transfer is higher than on the endwall. 


\section{Acknowledgements}

My time here at Virginia Tech has been both a challenging and rewarding experience. I have met so many great people and I'm sure that I will always have fond memories of the friends that I made here. There are many people I would like to thank for making my time more enjoyable. I'll start by recognizing all of my VTEXCCL colleagues that I have known during the past two years (Angela Morris, Erin Elder, Will Colban, Nick Cardwell, Joe Scrittore, Sundar Narayan, Paul Sanders, Scott Walsh, Scott Brumbaugh, Cam Land, Steve Lynch, Seth Lawson, Mike Lawson, Mike Barringer, and Alan Thrift). Although he worked for a different advisor, I would also like to mention Andrew Duggleby who had a workspace in our computer lab. He too is a good friend.

There are certain individuals who I worked with very closely that I feel I need to give special thanks. I'll start off by mentioning Scott Brumbaugh. We started the project together and spent many late nights working in the lab. Your company was appreciated during the hard times. I would also like to thank Seth Lawson who started the project during my final semester. I don't think I could have finished my work on time without your help. I also want to thank Sundar Narayan and Steve Lynch. I enjoyed working on our homework and projects together during my final semester.

In addition, I want to thank Pratt and Whitney for funding the work and Atul Kohli in particular. When things weren't going well, I appreciated your positive outlook. Last but not least, I want to thank my advisor, Karen Thole. After my time at VTEXCCL, I have much more confidence now and feel much more prepared to work as an engineer. I feel your guidance has been very beneficial to me and I thank you for that. I also thank you for being a friend.

Finally, I especially want to acknowledge my wife, Laura. Her job the past year and a half of taking care of our twin sons, Alex and Seth, has been much more important than mine. I don't believe there could possibly be a better wife and mother. I am very blessed to have you for a wife and I look forward to many more years together and seeing our boys grow up. 


\section{Contents}

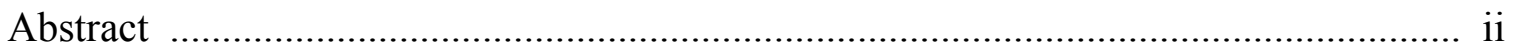

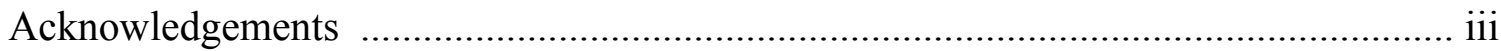

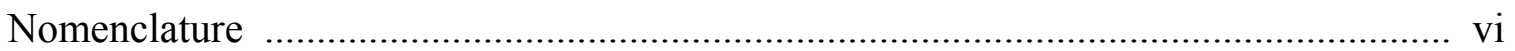

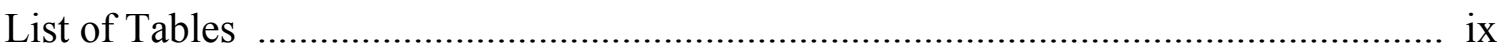

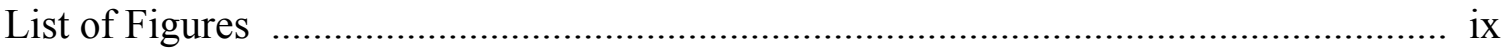

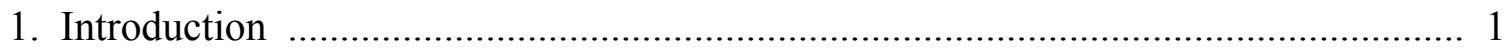

1.1 The Need for Improved Cooling Methods ……………………………….. 3

1.2 Research Objectives .............................................................................. 4

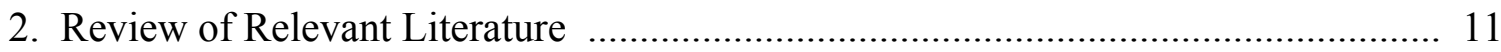

2.1 Pin Fin and Endwall Heat Transfer ............................................................. 12

2.2 Dependency on Location in Array ......................................................... 15

2.3 Pin Spacing Effects ......................................................................... 17

2.4 Effect of Pin Fin Aspect Ratio ............................................................ 18

2.5 Effect of Pin Shape …………………………….............................. 20

2.6 Reynolds Number Effects .................................................................... 22

2.7 Uniqueness of Research ......................................................................... 23

3. Design and Construction of Experimental Facility ……………………………..... 32

3.1 Overall Test Facility .............................................................................. 33

3.2 Test Section Design ............................................................................... 38

3.3 Heat Flux Surfaces and Instrumentation .................................................... 40

3.4 Testing Procedure …………………………………………………….. 52

3.5 Facility Benchmarking ………………………....................................... 54

3.6 Experimental Uncertainty ………………………............................ 57

4. Data Reduction Methodology ……………………......................................... 81

4.1 Endwall Heat Transfer Analysis ............................................................ 81

4.2 Pin Fin Heat Transfer Analysis ............................................................ 90

4.3 Method of Combining Pin and Endwall Results ....................................... 92 


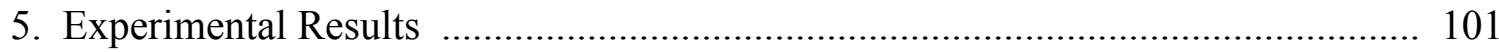

5.1 Heat Transfer from a Single Row of Pin Fins ………………................ 102

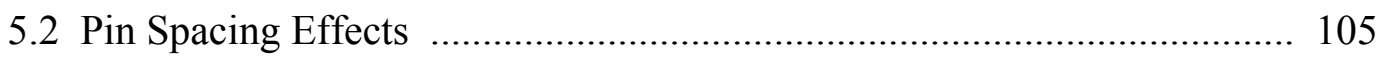

5.3 Reynolds Number Effects ...................................................................... 110

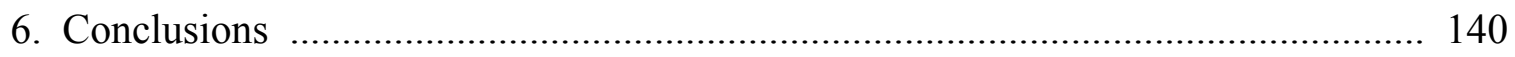

6.1 Overview of Pin Spacing Effects …………………................................ 141

6.2 Overview of Reynolds Number Effects …………................................. 142

6.3 Recommendations for Future Work ........................................................ 144

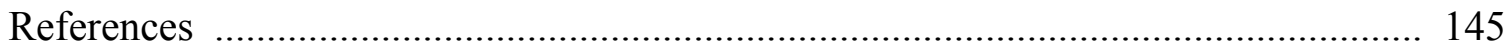

Appendix A: Test Facility Component Information ………................................. 148

Appendix B: Experimental Uncertainty Calculations ……………………………... 154

Appendix C: Duct Heat Loss Calculations ……………….................................. 166

Appendix D: Endwall Heat Transfer Contour Plots for the $\mathrm{S} / \mathrm{d}=4$ and 8 Pin Spacings 


\section{Nomenclature}

\begin{tabular}{|c|c|}
\hline A & $=$ area \\
\hline $\mathrm{C}_{\mathrm{p}}$ & $=$ specific heat \\
\hline $\mathrm{d}$ & $=$ pin diameter \\
\hline $\mathrm{D}_{\mathrm{h}}$ & $=$ unobstructed duct hydraulic diameter \\
\hline $\mathrm{dp} / \mathrm{dx}$ & $=$ pressure gradient in the streamwise direction \\
\hline $\mathrm{E}$ & $=$ total radiation generated from surface \\
\hline $\mathrm{f}$ & $=$ friction factor \\
\hline $\mathrm{G}$ & $=$ total irradiation onto a surface \\
\hline $\mathrm{h}$ & $=$ heat transfer coefficient \\
\hline $\mathrm{H}$ & $=$ channel and pin fin height \\
\hline $\mathrm{k}$ & $=$ thermal conductivity \\
\hline $\mathrm{L}$ & $=$ length \\
\hline $\mathrm{m}$ & $=$ mass flow rate \\
\hline $\mathrm{M}$ & $=$ Mach number \\
\hline $\mathrm{n}$ & $=$ maximum number of points for numerical integration \\
\hline $\mathrm{N}$ & $=$ the number of a quantity \\
\hline $\mathrm{Nu}$ & $=$ Nusselt number based on $\mathrm{D}_{\mathrm{h}}, \mathrm{hD}_{\mathrm{h}} / \mathrm{k}$ \\
\hline $\mathrm{Nu}_{\mathrm{d}}$ & $=$ Nusselt number based on $\mathrm{d}, \mathrm{hd} / \mathrm{k}$ \\
\hline $\mathrm{P}$ & $=$ power; perimeter \\
\hline $\operatorname{Pr}$ & $=$ Prandtl number \\
\hline$q^{\prime \prime}$ & $=$ heat flux \\
\hline Q & $=$ heat rate \\
\hline $\mathrm{R}$ & $=$ electrical resistance \\
\hline $\operatorname{Re}$ & $=$ Reynolds number based on $\mathrm{U}$ and $\mathrm{Dh}, \mathrm{UD}_{\mathrm{h}} / v$ \\
\hline $\mathrm{Re}_{\mathrm{d}}$ & $=$ Reynolds number based on $U_{\max }$ and $\mathrm{d}, \mathrm{U}_{\max } \mathrm{d} / \nu$ \\
\hline $\mathrm{S}$ & $=$ spanwise spacing between pin centers \\
\hline $\mathrm{T}$ & $=$ temperature \\
\hline $\mathrm{u}$ & $=$ uncertainty \\
\hline
\end{tabular}


U

$\mathrm{U}_{\max }$

$\mathrm{V}$

W

$\mathrm{X}$

$\mathrm{X}$

\section{Greek:}

$\varepsilon$

$v$

$\rho$

$\sigma$

\section{Subscripts:}

$\begin{array}{ll}\overline{\text { variable }} & =\text { spanwise averaged value } \\ \overline{\text { variable }} & =\text { area averaged value } \\ 0 & =\text { unobstructed duct baseline condition } \\ \mathrm{amb} & =\text { ambient conditions } \\ \mathrm{b} & =\text { base } \\ \mathrm{bg} & =\text { background relevant to radiation heat transfer } \\ \text { bulk } & =\text { bulk fluid } \\ \text { corr } & =\text { corrected value } \\ \mathrm{d} & =\text { pin diameter } \\ \mathrm{e} & =\text { entrance } \\ \text { endwall } & =\text { endwall of pin fin row } \\ \text { foil } & =\text { inconel foil pin fin heater } \\ \text { heater } & =\text { endwall heater } \\ \text { ins } & =\text { insulation }\end{array}$

$=$ average velocity in unobstructed channel

$=$ maximum average velocity between the pin fins

$=$ voltage

$=$ width of channel and endwall heaters

$=$ streamwise distance

$=$ streamwise spacing between pin centers

$=$ radiation emissivity of a surface

$=$ dynamic viscosity

$=$ density; radiation reflectivity

$=$ Stefan-Boltzman constant 


$\begin{array}{ll}\text { Kapton } & =\text { DuPont brand of polyimide film } \\ \text { loss } & =\text { amount subtracted from a total to give a net value } \\ \max & =\text { maximum value } \\ \text { MDF } & =\text { medium density fiberboard } \\ \min & =\text { value accounting for losses } \\ \text { net } & =\text { pin fin } \\ \text { pin } & =\text { precision resistor } \\ \text { prec } & =\text { radiation } \\ \text { rad } & =\text { value without accounting for losses } \\ \text { total } & =\text { exposed to the flow } \\ \text { W } & \end{array}$




\section{List of Tables}

Table 1-1 Rolls Royce Performance Data Through Time [Saravanamuttoo et al., 2001]

Table 2-1 Summary of Reviewed Pin Fin Geometries From the Literature With Correlations Where Applicable

Table 3-1 Heater Operating Conditions for Single Pin Row Endwall Tests 60

Table 3-2 Inconel Foil Operating Conditions for Balsa Wood Pin Fin Tests 60

Table 3-3 Summary of ANSYS Models with Pin Surface Temperature Results ........ 61

Table 3-4 Summary of Experimental Uncertainties 61

Table 4-1 Calibration Results for $\mathrm{S} / \mathrm{d}=2, \mathrm{Re}=13,072, \mathrm{Re}_{\mathrm{d}}=13,274$ 95

Table 4-2 Summary of Area Fractions for $\mathrm{S} / \mathrm{d}=2$, 4, and 8 Pin Spacings 95

Table 5-1 Test Matrix for the $\mathrm{S} / \mathrm{d}=2$, 4, and 8 Single Row Geometries 118

Table 5-2 Sample $\mathrm{S} / \mathrm{d}=2$ Results at $\mathrm{Re}_{\mathrm{d}}=10,000$ With Literature Comparison ...... 118

\section{List of Figures}

Figure 1-1 Schematic of a turbojet aircraft engine [Hill and Peterson, 1992].

Figure 1-2 Turbofan propulsion engine performance chart [Hill and Peterson, 1992]. .. 7

Figure 1-3 Progression of turbine inlet temperature through time [Clifford, 1985]. ... 8

Figure 1-4 Cutaway section of a gas turbine airfoil showing internal and external cooling schemes [Metzger et al., 1984].

Figure 1-5 Strength to weight ratio versus metal temperature for various turbine airfoil metals [Hill and Peterson, 1992].

Figure 2-1 Comparison of common heat exchanger types [Incropera and Dewitt, 2002].

Figure 2-2 Plot of the comparison of array averaged heat transfer between conductive and non-conductive pin fins [Metzger et al., 1982c]. 
Figure 2-3 Plot of circumferential heat transfer on the surface of a pin fin at different row locations [Ames et al., 2004].

Figure 2-4 Row by row variation of combined pin and endwall heat transfer of a staggered pin fin array [Metzger et al., 1982a].

Figure 2-5 Staggered array, array averaged heat Nusselt versus Reynolds number for different streamwise pin fin spacing [Metzger et al., 1982c]. 28

Figure 2-6 Comparison between inline and staggered pin fin array configurations [Chyu, 1990]. 28

Figure 2-7 Dependency of array averaged heat transfer augmentation over smooth channel heat transfer on pin aspect ratio, H/D [Armstrong and Winstanley, 1988].

Figure 2-8 Comparison of straight cylindrical and filleted pin fins [Chyu, 1990]. .... 29

Figure 2-9 Comparison between cubic and diamond staggered array configurations.

Cubes are rotated $45^{\circ}$ to make the diamond array. 30

Figure 2-10 Staggered array configuration using oblong pins [Metzger et al., 1984]. 30

Figure 2-11 Circular and elliptical pin shapes used by Uzol and Camci [2005]. ....... 31

Figure 3-1 Schematic of overall closed loop test facility. .......................................... 62

Figure 3-2 Photograph of the plenum and test section side of the test rig. ................. 63

Figure 3-3 Photograph of the blower side of the test facility. ...................................... 63

Figure 3-4 Photograph of the inside of the plenum. ………….................................. 64

Figure 3-5 Photograph of the orifice and venturi flow meters. .................................... 64

Figure 3-6 Diagram demonstrating the purpose of the regulator valves. The regulator valves adjusted the test section pressure to atmospheric. ………………………......... 65

Figure 3-7 Schematic of test section for endwall tests using copper pins. ..................66 66

Figure 3-8 Schematic of test section for pin fin tests using balsa wood pins. ............. 67

Figure 3-9 Scaled top view layout of the test section for the $S / d=4$ geometry for endwall and balsa wood pin fin tests. 68

Figure 3-10 Sketch of heater cross-section (Not to scale). ......................................... 69 
Figure 3-11 Diagram of heater and power supply hookup. On the heater, the serpentine inconel strips can be seen on the surface. 69

Figure 3-12 Photograph of ThermaCam P20 infrared camera manufactured by FLIR Systems AB.

Figure 3-13 Diagram of pin fin attachment method.

Figure 3-14 Photograph of the copper pins attached to the test section roof before assembly. The $\mathrm{S} / \mathrm{d}=4$ single row geometry is shown.

Figure 3-15 Diagram of balsa wood pin fin construction [Lawson, 2006]. 71

Figure 3-16 Photograph of completed balsa wood pin. 72

Figure 3-17 Diagram of balsa pin attachment method. 72

Figure 3-18 Diagram of balsa wood pin fin wiring arrangement inside the test section.

Figure 3-19 Comparison of balsa wood test results with the array on, and downstream of the test section heaters. 73

Figure 3-20 Diagram showing the method of installing a thermocouple in the center of a copper pin fin.

Figure 3-21 Comparison of the embedded thermocouple pin fin measurement technique with data from the literature. 74

Figure 3-22 Model 1 results from ANSYS. 75

Figure 3-23 Model 2 results from ANSYS. 75

Figure 3-24 Model 3 results from ANSYS. 76

Figure 3-25 Model 4 results from ANSYS. ......................................................... 76

Figure 3-26 Infrared image with the pin fins lifted off of the test section floor. …… 77

Figure 3-27 Infrared image with the pin fins properly seated on the test section floor. 77

Figure 3-28 Developing pressure profile along the length of the channel $(\operatorname{Re}=13000)$. 78

Figure 3-29 Friction factor results. 78 
Figure 3-30 Test section spanwise uniformity plot.

Figure 3-31 Spanwise Nusselt number line plots extracted from the endwall data one and five pin diameters (d) downstream of the trailing edge of the pin row for $\mathrm{S} / \mathrm{d}=2,4$, and 8 single row geometries. ................................................................................. 79

Figure 3-32 Developing Nusselt number profile along upstream heater surface. ....... 80

Figure 4-1 Raw infrared temperature image of the $\mathrm{S} / \mathrm{d}=4$ single row geometry at $\mathrm{Re}=$ 12,964 . 96

Figure 4-2 Schematic showing the camera orientation to prevent reflection. 96

Figure 4-3 Zinc selenide transmissivity as a function of radiation wavelength [Rohm and Haas, 1999].

Figure 4-4 Sketch showing the difference between a skewed and transformed image.

Figure 4-5 Estimated plain duct flow heat loss and measured channel heat loss for the three single row geometries.

Figure 4-6 Estimated temperature drop across the heater as a function of heat flux over the range of $5000<\operatorname{Re}<30,000$ for the $\mathrm{S} / \mathrm{d}=2$ pin spacing. 98

Figure 4-7 Schematic showing the balsa wood pin fin orientation for increased circumferential resolution.

Figure 4-8 Plot of circumferential pin fin data for $\mathrm{S} / \mathrm{d}=2$ at $\mathrm{Re}_{\mathrm{d}}=30,514$ compared to first row circumferential data from Ames et al. [2004] at $\operatorname{Re}_{d}=30,047$.

Figure 4-9 Drawing of one pin pitch transverse to the flow extending 0.5 pin diameters upstream and downstream of the pin fins.

Figure 5-1 Spanwise average plot of the developing endwall heat transfer at $\operatorname{Re}=13,072$ for the $\mathrm{S} / \mathrm{d}=2$ geometry.

Figure 5-2 Spanwise line plots one and five pin diameters downstream of the pin row at $\operatorname{Re}=13,072$ for the $\mathrm{S} / \mathrm{d}=2$ geometry.

Figure 5-3 Contour of $\mathrm{Nu} / \mathrm{Nu}_{0}$ at $\mathrm{Re}=13,072$ and $\mathrm{Re}_{\mathrm{d}}=13,274$ for the $\mathrm{S} / \mathrm{d}=2$ geometry. 120

Figure 5-4 Contour of $\mathrm{Nu}_{\mathrm{d}}$ at $\mathrm{Re}=13,072$ and $\mathrm{Re}_{\mathrm{d}}=13,274$ for the $\mathrm{S} / \mathrm{d}=2$ geometry. 
Figure 5-5 Plot showing the dependency of $\mathrm{Nu}_{d}$ on $\mathrm{S} / \mathrm{d}$ at a nominal Reynolds number of $\mathrm{Re}_{\mathrm{d}}=5000$.

Figure 5-6 Plot showing the dependency of $\mathrm{Nu}_{\mathrm{d}}$ on $\mathrm{S} / \mathrm{d}$ at a nominal Reynolds number of $\operatorname{Re}_{\mathrm{d}}=17,500$.

Figure 5-7 Normalized combined pin and endwall heat transfer versus the spanwise pin spacing.

Figure 5-8 Normalized line plots showing the developing heat transfer downstream of the pin row both within a pin wake and between the pins for all three geometries at $\mathrm{Re}=$ 5000 .

Figure 5-9 Normalized line plots showing the developing heat transfer downstream of the pin row both within a pin wake and between the pins for all three geometries at $\mathrm{Re}=$ 30,000 .

Figure 5-10 Spanwise averaged developing heat transfer along the streamwise direction for all three geometries at $\operatorname{Re}=5000$.

Figure 5-11 Spanwise averaged developing heat transfer along the streamwise direction for all three geometries at $\mathrm{Re}=30,000$.

Figure 5-12 Spanwise line plots of normalized heat transfer one and five pin diameters downstream of the pin row for the $\mathrm{S} / \mathrm{d}=2,4$ and 8 geometries at $\mathrm{Re}=5000$. 124

Figure 5-13 Spanwise line plots of normalized heat transfer one and five pin diameters downstream of the pin row for the $\mathrm{S} / \mathrm{d}=2,4$ and 8 geometries at $\mathrm{Re}=30,000$. 125

Figure 5-14 Contour plots of $\mathrm{Nu} / \mathrm{Nu}_{0}$ for all three geometries at $\mathrm{Re}=5000$ and $\mathrm{Re}=$ 30,000 .

Figure 5-15 Contour plots of $\mathrm{Nu}_{\mathrm{d}}$ for all three geometries at $\mathrm{Re}=5000$ and $\mathrm{Re}=30,000$.

Figure 5-16 $\mathrm{S} / \mathrm{d}=2,4$, and 8 pin fin heat transfer results presented as $\mathrm{Nu}_{\mathrm{d}}$ versus $\mathrm{Re}_{\mathrm{d}}$ with a comparison with results from the literature. 128

Figure 5-17 Comparison of pin fin heat transfer results showing the dependency of $\mathrm{Nu}_{\mathrm{d}}$ on $\operatorname{Re}$ to investigate different scaling possibilities.

Figure 5-18 $\mathrm{S} / \mathrm{d}=2,4$, and 8 combined pin and endwall heat transfer results plotted as $\mathrm{Nu}_{\mathrm{d}}$ versus $\mathrm{Re}_{\mathrm{d}}$ and compared with data from the literature. 
Figure 5-19 Combined pin and endwall heat transfer augmentation over fully developed open duct flow for the $\mathrm{S} / \mathrm{d}=2,4$, and 8 geometries as a function of Reynolds number, Re.

Figure 5-20 Pin to endwall heat transfer ratio as a function of $\mathrm{Re}_{\mathrm{d}}$. 130

Figure 5-21 Developing endwall heat transfer for the $\mathrm{S} / \mathrm{d}=2$ geometry. 130

Figure 5-22 Developing endwall heat transfer for the $S / d=4$ geometry.

Figure 5-23 Developing endwall heat transfer for the $S / d=8$ geometry.

Figure 5-24 Spanwise line plots of endwall heat transfer downstream of the pin row for the $\mathrm{S} / \mathrm{d}=2$ geometry across the Reynolds number range.

Figure 5-25 Spanwise line plots of endwall heat transfer downstream of the pin row for the $\mathrm{S} / \mathrm{d}=4$ geometry across the Reynolds number range.

Figure 5-26 Spanwise line plots of endwall heat transfer downstream of the pin row for the $\mathrm{S} / \mathrm{d}=8$ geometry across the Reynolds number range. 133

Figure 5-27 Contour plots of $\mathrm{Nu} / \mathrm{Nu}_{0}$ for the $\mathrm{S} / \mathrm{d}=2$ geometry. 134

Figure 5-28 Contour plots of $\mathrm{Nu} / \mathrm{Nu}_{0}$ for the $\mathrm{S} / \mathrm{d}=4$ geometry. 135

Figure 5-29 Contour plots of $\mathrm{Nu} / \mathrm{Nu}_{0}$ for the $\mathrm{S} / \mathrm{d}=8$ geometry. 136

Figure 5-30 Contour plots of $\mathrm{Nu}_{\mathrm{d}}$ for the $\mathrm{S} / \mathrm{d}=2$ geometry. 137

Figure 5-31 Contour plots of $\mathrm{Nu}_{\mathrm{d}}$ for the $\mathrm{S} / \mathrm{d}=4$ geometry. 138

Figure 5-32 Contour plots of $\mathrm{Nu}_{\mathrm{d}}$ for the $\mathrm{S} / \mathrm{d}=8$ geometry. 139 


\section{Chapter 1}

\section{Introduction}

Since the middle of the twentieth century, gas turbines have played a continuously growing role in society. It is well known that the first practical gas turbine engines were developed independently during the World War II era by Whittle in England, and von Ohain in Germany. The first engines were built for military use. As a result of technical advances, gas turbine engine technology eventually transferred to the public sector through air transportation. However, it was quickly realized that gas turbines have potential for many other applications. Today, gas turbines are also used for electrical power generation, ship propulsion, and also high powered pumping stations to name a few. To give insight into how the technology has progressed, consider that military aircraft in the late 1940s and 1950s powered by gas turbine engines had maximum speeds in the subsonic flight regime. Today, the F-22 Raptor has supercruise capability, meaning steady, supersonic flight without afterburners.

In its simplest form, a gas turbine is comprised of three basic components. These are the compressor, the combustor or burner, and the turbine. These components are shown in Figure 1-1, which is a schematic of a turbojet aircraft propulsion engine [Hill and Peterson, 1992]. As shown, air is pulled into the compressor through the diffuser. The work done on the fluid by the compressor causes the air pressure to rise. Energy is then added to the flow in the burner. After the burner, the highly energetic, high pressure flow is expanded through the turbine, which is mechanically interlocked to the compressor to provide power for compression. The available energy in addition to what is required for compression is generally used to produce thrust in aircraft engines, or shaft power for land based gas turbines. In addition, the waste heat from land based gas turbines is also commonly used to produce steam in combined gas and steam cycle power generating plants.

To improve gas turbine performance, research has been driven by two parameters. These parameters are the turbine inlet temperature, and the compressor pressure ratio. Figure 1-2 is a plot of a typical turbofan aircraft engine performance chart that indicates 
the importance of both [Hill and Peterson, 1992]. The plot was produced at a flight mach number of $\mathrm{M}=0.85$. Notice that the specific thrust and the specific fuel consumption are the two dependant variables used to investigate the turbine inlet temperature and pressure ratio. To explain the terminology, the specific thrust is defined as the amount of thrust that is produced per unit mass flow of air. Thus, it is desirable to have a large specific thrust to get the most benefit from a set mass flow. Stated another way, the specific thrust indicates how large an engine must be to produce a given amount of thrust. The specific fuel consumption refers to the mass flow of fuel required per unit thrust. In this case, it is desired to have a low value, which indicates how efficient an engine operates.

As shown in Figure 1-2, the specific thrust increases as the turbine inlet temperature ( $\mathrm{T}_{\max }$ in Figure 1-2) and pressure ratio increase. However, the specific thrust does peak and then decline with increasing pressure ratio for a set turbine inlet temperature. Although not shown on the plot, the overall efficiency keeps on increasing with increasing pressure ratio. Because of this, it is still desirable to operate at higher pressure ratios, even though it may be less than the level required for maximum specific thrust. In addition, the specific fuel consumption decreases with increasing pressure ratio, but increases with higher turbine inlet temperatures. However, the dependency of the specific fuel consumption on the turbine inlet temperature becomes smaller with increasing pressure ratio, again making high pressure ratios more desirable.

As a measure of the progress made over the years, Table 1-1 and Figure 1-3 present the improvements in pressure ratio and turbine inlet temperature respectively. Table 1 presents the thrust and pressure ratios of a series of gas turbine engines built by Rolls Royce [Saravanamuttoo et al., 2001]. As shown, the Avon engine built in 1958 produced $44 \mathrm{kN}$ of thrust with a pressure ratio of ten. Also note that 17 stages were required. However, the Trent engine built in 1995 produces $356 \mathrm{kN}$ of thrust with a pressure ratio of 41 with only 15 stages, which is a vast improvement.

The progress through the years with regard to turbine inlet temperature is equally impressive and is shown in Figure 1-3 [Clifford, 1985]. In the 1950s, turbine blades were uncooled, limiting turbine inlet temperatures to about 1200K. With advanced cooling methods, turbine inlet temperatures today are approaching $2000 \mathrm{~K}$. Also note in Figure 13 that the temperature difference between the allowable metal temperature and the turbine 
inlet temperature became significantly larger through the years. The work presented in this thesis is aimed at providing new knowledge to further increase the turbine inlet temperature to improve performance and also increase the life of turbine components.

\subsection{The Need for Improved Cooling Methods}

One feature common to all modern gas turbine engines is that the internal gas temperatures are hotter than the melting point of various engine components, in particular, the turbine vanes and blades. As a result, gas turbine airfoils must be cooled, at least for the first stages of the turbine. The airfoils are cooled both internally and externally.

Figure 1-4 is a cutaway view of a cooled gas turbine airfoil [Metzger et al., 1984]. For internal cooling, high pressure cooling air bled from the compressor is channeled into the root of the blade, and then split into separate cooling passages. Note the pin fin array at the trailing edge. Due to the taper of the airfoil at the trailing edge section, the pin fin array provides structural support in addition to acting as a turbulence promoter for increasing heat transfer. The cooling air exits the blade at the trailing edge, and through film cooling holes, which are shown in the cross section view on the right of Figure 1-4. The cooling air exiting the film cooling holes is injected under the boundary layer formed by the hot mainstream gas, providing a protective shield to prevent heat transfer from the hot gas to the blade surface. Film cooling is the primary method of external cooling.

Although high combustion gas temperatures increase engine performance, it also has a detrimental effect on turbine component life. As a result, turbine durability drives much of the cooling technology research. Figure 1-5 is a plot that shows the 100 hour rupture stress divided by the density for various materials used in gas turbine airfoils, plotted as a function of temperature. The 100 hour rupture stress divided by the density is also referred to as the strength to weight ratio. Figure 1-5 indicates that the strength of airfoil materials is a strong function of temperature. Thus, operating a gas turbine with excessive turbine inlet temperatures can significantly reduce the life of turbine components. Therefore, effective cooling methods are necessary.

As a result of cooling requirements, extracted coolant flow imparts a penalty on the maximum benefit that can be obtained by operating at higher turbine inlet temperatures. According to Hill and Peterson [1992], more than 10\% of the core engine 
flow may be required to cool the turbine. When considering that other engine components also require cooling, the extracted coolant flow imparts significant losses. The primary loss is that the extracted coolant flow is not heated in the combustor. As the coolant reenters the mainstream flow, the mainstream will be cooled somewhat, thus reducing the amount of work that can be extracted from the turbine. Some of the loss is due to flow friction within the cooling passages. In addition, as the coolant flow rejoins the mainstream, there are losses due to viscous mixing between fluid streams. For a given blade temperature, an improved cooling scheme will require less coolant flow. This will yield greater performance benefits from operating at high turbine inlet temperatures due to fewer losses.

\subsection{Research Objectives}

The work presented in this thesis is part of a larger project with the goal of gaining a better understanding of internal cooling of turbine components. In particular, heat transfer from pin fin arrays is of interest. Pin fin arrays in gas turbine airfoils are unique in that both the pin and endwall make significant contributions to the wetted heat transfer area. Height to diameter ratios (H/d) are on the order of one for many applications for turbine airfoils. For compact heat exchangers, it is common to have $\mathrm{H} / \mathrm{d}$ $<0.5$, where most of the heat transfer occurs on the endwall. For the other extreme, heat exchangers such as those used for steam turbine boilers generally have $\mathrm{H} / \mathrm{d}>4$. In this case, the endwall heat transfer is not as significant. Both low and high $\mathrm{H} / \mathrm{d}$ cases are generally discussed in heat transfer textbooks. Armstrong and Winstanley [1988] claims that interpolating between these two cases does not solve the intermediate problem with $\mathrm{H} / \mathrm{d}$ on the order of one.

As will be discussed in the literature review of Chapter 2, much work has already been done by various investigators on pin fin array heat transfer relevant to gas turbine airfoils. However, there is no clear way based on data found in the literature to develop an optimization scheme for internal cooling. There is too much variability among researchers concerning the geometries tested and also the level of heat transfer enhancement. 
The results presented in this thesis are for single rows of pin fins. These single row measurements serve as a baseline and starting point for moving on to more complicated geometries. The pin fins used had aspect ratios of $\mathrm{H} / \mathrm{d}=1$, where $\mathrm{H}$ is the pin height, and $\mathrm{d}$ is the pin diameter. Measurements were made on the pin and endwall for each row of pin fins. The pin spacings studied were $\mathrm{S} / \mathrm{d}=2,4$, and 8 , with $\mathrm{S}$ representing the spanwise spacing between pin centers. An additional feature is that the endwall heat transfer was studied upstream and downstream of the pin fin row. The basic goal of this part of the overall research project was to provide the data to allow improved predictions for the heat transfer from a single row of pin fins.

The remainder of this thesis is organized as follows. Chapter 2 presents a literature review of pin fin array heat transfer relevant to gas turbine airfoil internal cooling. Chapter 3 gives a detailed description of the test facility used for making both the pin and endwall heat transfer measurements. Due to differences in measurement techniques, the pin and endwall data were obtained during separate tests. In addition, results from facility benchmarking are presented in Chapter 3. In Chapter 4, the data reduction procedure is presented for the endwall and pin heat transfer measurements. The procedure for combining the results is also presented. In Chapter 5, the experimental results are presented. In this chapter, the pin and endwall heat transfer results are presented separately as well as combined. Finally, the conclusions are discussed in Chapter 6, along with recommendations for future work. 
Table 1-1 Rolls Royce Performance Data Through Time [Saravanamuttoo et al. 2001]

\begin{tabular}{lllll}
\hline Engine & Date & $\frac{\text { Thrust }}{[\mathrm{kN}]}$ & $\begin{array}{l}\text { Pressure } \\
\text { ratio }\end{array}$ & Stages \\
\hline Avon & 1958 & 44 & 10 & 17 \\
Spey & 1963 & 56 & 21 & 17 \\
RB-211 & 1972 & 225 & 29 & 14 \\
Trent & 1995 & 356 & 41 & 15 \\
\hline
\end{tabular}




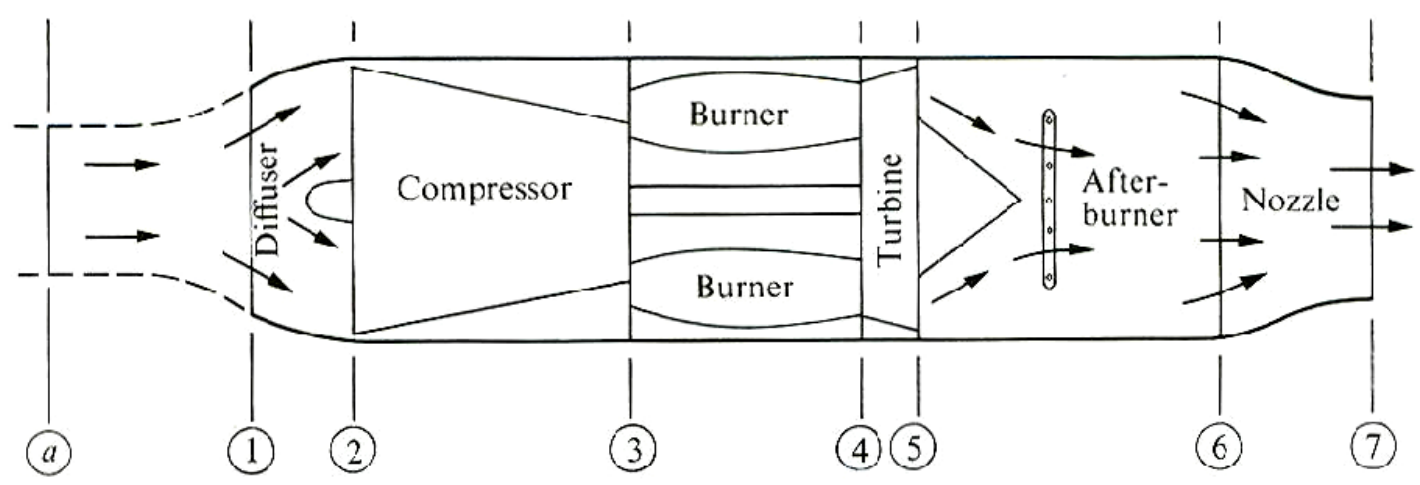

Figure 1-1 Schematic of a turbojet aircraft engine [Hill and Peterson, 1992].

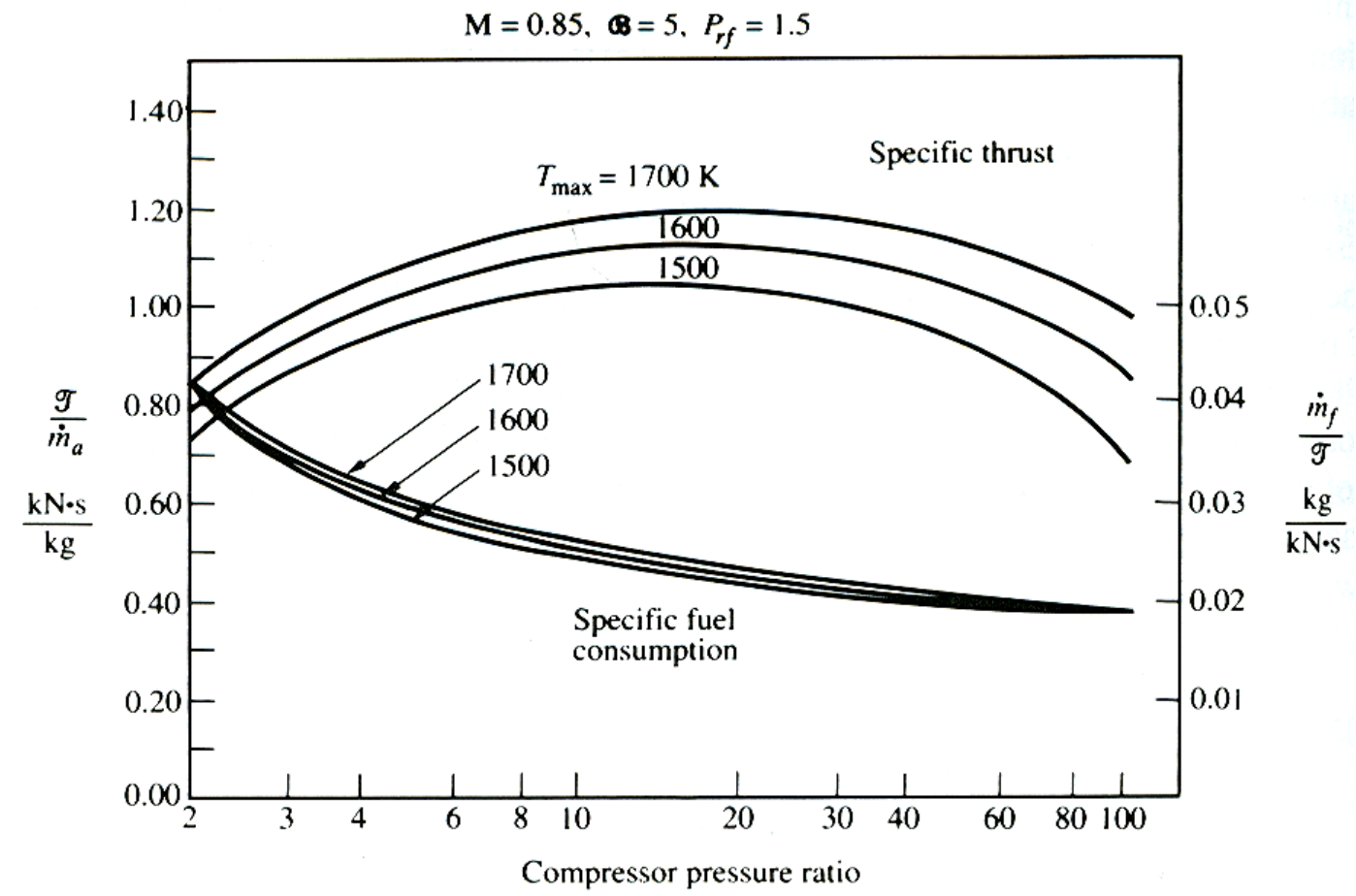

Figure 1-2 Turbofan propulsion engine performance chart [Hill and Peterson, 1992]. 


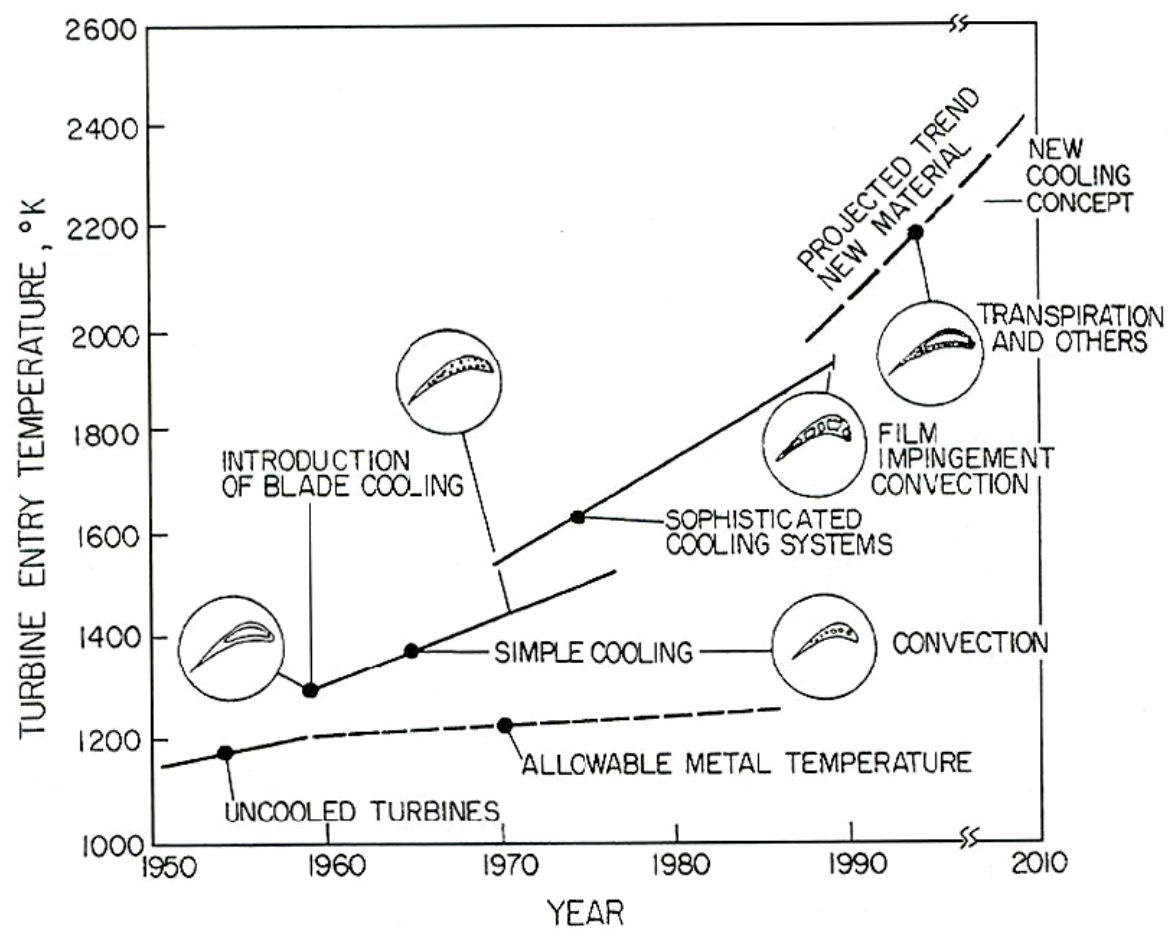

Figure 1-3 Progression of turbine inlet temperature through time [Clifford, 1985]. 


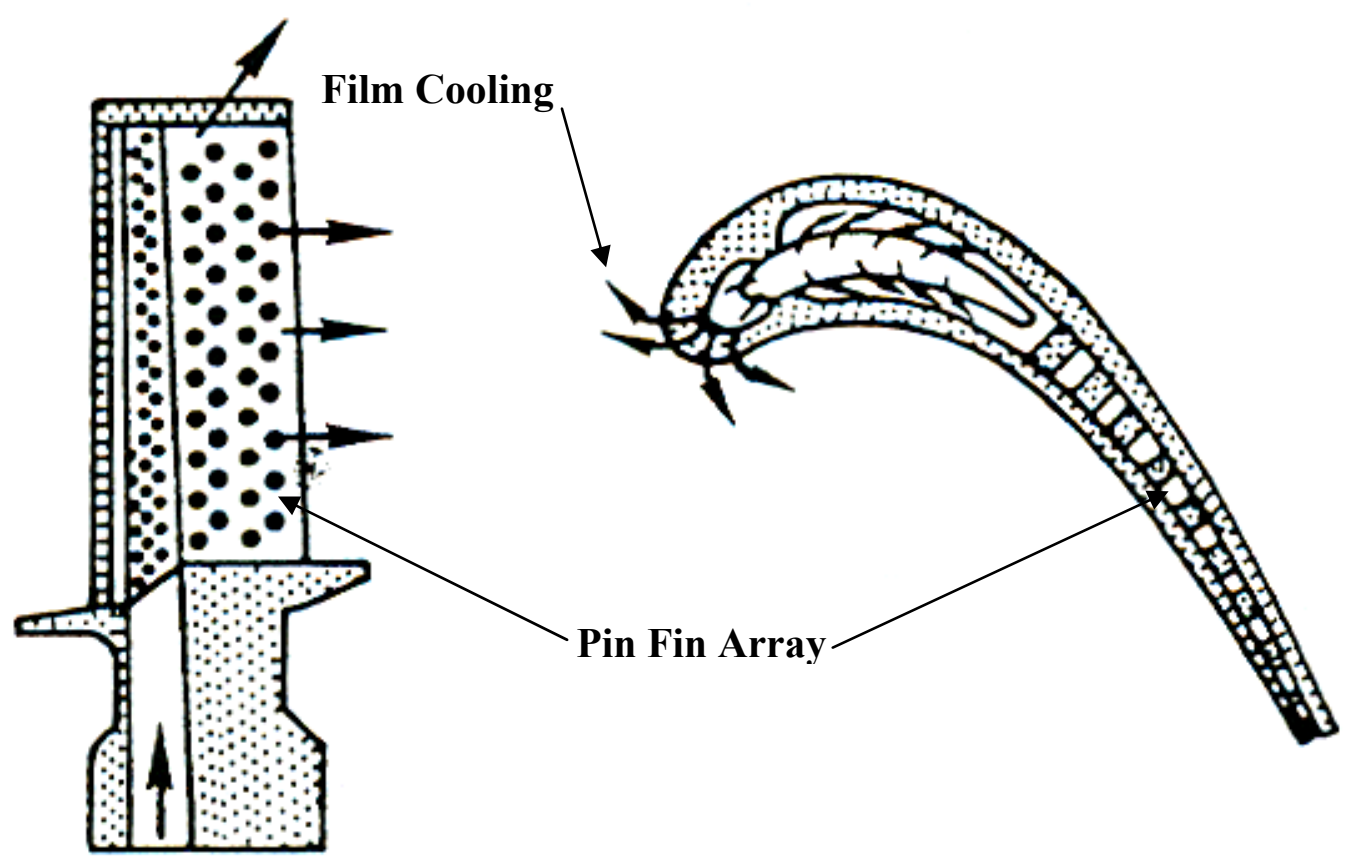

Figure 1-4 Cutaway section of a gas turbine airfoil showing internal and external cooling schemes [Metzger et al., 1984]. 


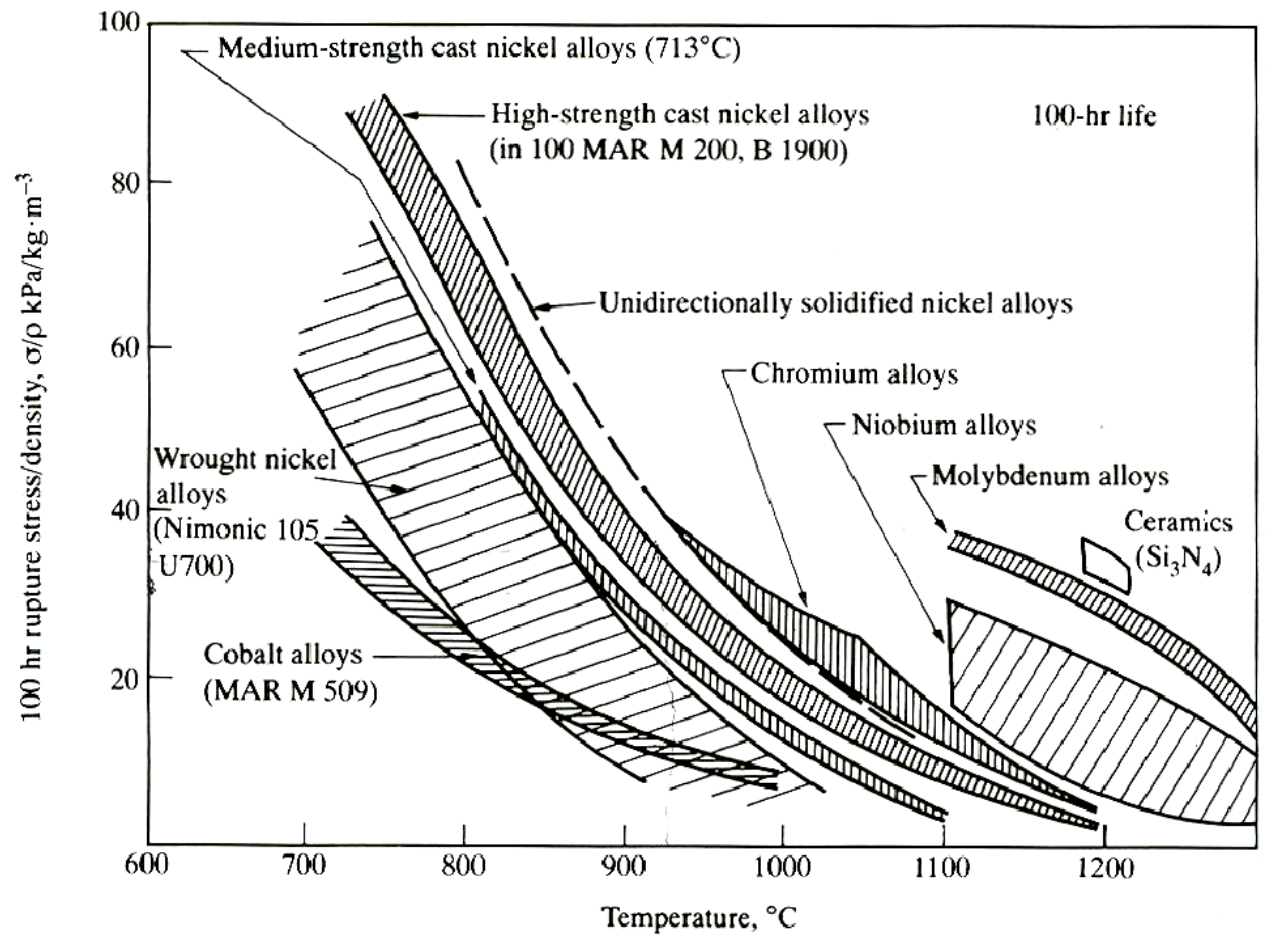

Figure 1-5 Strength to weight ratio versus metal temperature for various turbine airfoil metals [Hill and Peterson, 1992]. 


\section{Chapter 2}

\section{Review of Relevant Literature}

Heat transfer from pin fin arrays is a subject of high importance with many engineering applications. These applications range from compact heat exchangers, boilers for steam turbines, and, being relevant to the current study, convective internal cooling of gas turbine air foils. Accounting for size and manufacturing constraints, pin fins within gas turbine airfoils typically have aspect ratios in the range of $0.5<\mathrm{H} / \mathrm{d}<4$ with $\mathrm{H}$ being the pin height and $\mathrm{d}$ the pin diameter [Lau et al., 1985]. Due to the complex nature of the flow fields, no analytical solution exists that can accurately predict pin fin array heat transfer. As a result, research has been conducted by numerous researchers to investigate how the heat transfer of pin fin arrays change with geometry and flow characteristics.

This chapter is organized into sections that explore key variables relevant to pin fin array heat transfer. Section 2.1 discusses the differences between heat transfer on the pin and the endwall and discusses the effect of combining the two. Research also indicates that pin fin array heat transfer is dependent on location within the array. This is discussed in Section 2.2. In Section 2.3, the effects of varying the spanwise and streamwise pin spacing are explored. The effects of pin aspect ratio are discussed in Section 2.4. Pin shape has also been shown to affect pin fin array heat transfer and this will be presented in Section 2.5. The Reynolds number is the primary flow characteristic of interest for all pin fin array studies. This topic is explored in Section 2.6. Finally in Section 2.7, the current research is compared to work from previous studies in terms of uniqueness. A summary of the geometries investigated by the various researchers discussed in this chapter are presented in Table 2-1.

With regard to nomenclature, it is typical in the literature to present pin fin array heat transfer data using the Reynolds number defined by Equation 2-1:

$$
\operatorname{Re}_{\mathrm{d}}=\frac{\mathrm{U}_{\max } \mathrm{d}}{v}
$$


where $U_{\max }$ is the maximum average velocity between the pins, $v$ is the kinematic viscosity, and $\mathrm{d}$ is the pin diameter. Similarly, the Nusselt number is defined by Equation 2-2:

$$
\mathrm{Nu}_{\mathrm{d}}=\frac{\mathrm{hd}}{\mathrm{k}}
$$

where $\mathrm{h}$ is the convective heat transfer coefficient, $\mathrm{k}$ is the fluid thermal conductivity, and again $\mathrm{d}$ is the pin diameter. In general, these definitions are used by the investigators whose results are discussed in the following sections. Any differences in nomenclature will be discussed in the appropriate section. In addition, to avoid confusion with what has been reported in the literature, both $d$ and un-subscripted $\mathrm{D}$ represent the pin diameter in the following discussion.

\subsection{Pin Fin and Endwall Heat Transfer}

Before heat transfer studies were conducted for pin fin arrays used in gas turbine airfoils, research generally focused on tube bundles of long tubes $(\mathrm{H} / \mathrm{d}>4)$ or bundles of short tubes $(\mathrm{H} / \mathrm{d}<0.5)$. Examples of short and long tube bundles are shown in Figure 2-1 [Incropera and Dewitt, 2002]. A continuous finned-tube heat exchanger is shown in Figure 2-1a. When considering the flow path through any two of the fins, the section of the tube that the flow encounters has a low value of $\mathrm{H} / \mathrm{d}$. The largest heat transfer surface is the fin, which serves as the endwall. Conversely, Figure 2-1b shows a heat exchanger without fins connected to the tubes. The flow passes over long tubes in cross flow with the tubes themselves serving as the primary heat transfer surface. The endwalls are not significant in this case.

Zukauskas [1972] compiled data from 49 different arrangements of long, round tube arrays and produced correlations based on Reynolds number and pin spacing. Endwall effects were not considered. Faulkner [1971] is generally considered to be the first to consider combined pin and endwall effects. Faulkner included endwall effects through the use of the hydraulic diameter defined by Equation 2-3: 


$$
\mathrm{D}_{\mathrm{h}}=\frac{4 \mathrm{~A}_{\min } \mathrm{L}}{\mathrm{A}}
$$

where $\mathrm{A}_{\min }$ is the minimum flow area between the pins, $\mathrm{A}$ is the total heat transfer surface area of the pins and endwall, and $\mathrm{L}$ is the length of the flow passage containing the pin fin array. Faulkner used existing data from both long and short tube heat transfer studies and performed a regression analysis to formulate a general correlation for predicting heat transfer from triangularly spaced pin fin arrays. The goal was to provide a tool for predicting pin fin array heat transfer in gas turbine airfoils. The resulting equation predicted long tube heat transfer better than short tube heat transfer. More recently, Armstrong and Winstanley [1988] claimed that the problem of heat transfer from pin fins of intermediate aspect ratio, such as those found in gas turbine airfoils, cannot be solved by interpolating between short and long tube heat transfer results.

Metzger et al. [1982a] reported combined pin and endwall results for two multiple row arrays with geometries of $\mathrm{S} / \mathrm{d}=\mathrm{X} / \mathrm{d}=2.5, \mathrm{H} / \mathrm{d}=1$, and $\mathrm{S} / \mathrm{d}=2.5, \mathrm{X} / \mathrm{d}=1.5, \mathrm{H} / \mathrm{d}=1$. $\mathrm{S}$ and $\mathrm{X}$ are the spanwise and streamwise distances respectively between pin centers. Metzger's arrays had ten rows in the streamwise direction. In a similar study, VanFossen [1981] also reported combined pin and endwall results. VanFossen [1981] tested two multiple row arrays with geometries of $\mathrm{S} / \mathrm{d}=4, \mathrm{X} / \mathrm{d}=3.46, \mathrm{H} / \mathrm{d}=2$, and $\mathrm{S} / \mathrm{d}=2, \mathrm{X} / \mathrm{d}=$ 1.73 , and $\mathrm{H} / \mathrm{d}=0.5$. Each array had four rows in the streamwise direction. Both researchers used copper to construct the pins and endwalls to obtain the combined pin and endwall results. Metzger et al. [1982a] reported good agreement with VanFossen [1981] for the first four rows in the streamwise direction. The conclusion reached by both researchers was that the combined pin and endwall heat transfer is lower than the heat transfer predicted by Zukauskas [1972] for heat transfer from inner rows of long tubes in a staggered array. Remember that Zukauskas [1972] did not consider endwall effects.

The results vary among researchers concerning the amount of heat transfer on the pin as opposed to the endwall. In the same study mentioned above, VanFossen [1981] replaced the copper pins with non-conducting wooden pins. Using an analytical method 
accounting for the different fin efficiencies of the copper and endwall, he deduced that the heat transfer on the pin is approximately $35 \%$ higher than on the endwall.

However, Metzger and Haley [1982b] also performed separate tests using highly conductive copper and non-conductive wooden pins. The two geometries explored were $\mathrm{S} / \mathrm{d}=2.5, \mathrm{X} / \mathrm{d}=1.5, \mathrm{H} / \mathrm{d}=1$, and $\mathrm{S} / \mathrm{d}=\mathrm{X} / \mathrm{d}=2.5$, and $\mathrm{H} / \mathrm{d}=1$. The endwalls for both copper and wooden pin tests were made of copper. For the copper tests, the total surface area of the pins and endwall exposed to the flow were considered when computing the heat transfer coefficients. For the test results with the wooden pins, only the endwall area was used to compute the heat transfer coefficients. Figure 2-2 is a plot of the results. As shown, the copper pin heat transfer results have a higher Reynolds number dependency than the wooden pin tests. However, there is good overall agreement over most of the Reynolds number range with the highest deviation occurring at low and high Reynolds numbers.

Metzger et al. [1984] used the results provided by Metzger and Haley [1982b] discussed in the above paragraph to estimate the ratio of pin to endwall heat transfer. The heat transfer from the test using non-conductive wooden pins was reanalyzed by using an analytical method to account for the pin thermal conductivity and establish a fin efficiency. It was assumed that the pin heat transfer was proportional to the endwall heat transfer. The proportionality constant was iterated until the wooden pin results matched the copper pin results. Using this method, Metzger et al. [1984] deduced that the pin heat transfer is 1.8 to 2.0 times higher than the heat transfer on the endwall. This difference between pin and endwall heat transfer is much greater than the results indicated by VanFossen [1981], which estimated the ratio to be about 1.35.

Chyu et al. [1998a] reported significantly different results. In their investigation, a naphthalene sublimation technique was used to obtain mass transfer data on the pins and endwalls simultaneously. The pin fin heat transfer was reported to be only 10 to $20 \%$ higher than the endwall heat transfer. The geometry used in their study was defined by $\mathrm{S} / \mathrm{d}=\mathrm{X} / \mathrm{d}=2.5$, and $\mathrm{H} / \mathrm{d}=1$. Although Chyu et al. [1998a] reported a smaller difference between the pin and endwall heat transfer than Metzger et al. [1984] and VanFossen [1981], the overall conclusion is that the heat transfer on the pin fins is higher than on the endwall. 
Only limited work has been done to resolve the heat transfer around the circumference of pin fins with aspect ratios relevant to those found in gas turbine airfoils. Metzger and Haley [1982b] reported circumferential midline heat transfer data from pins mounted in various streamwise locations within an array with a geometry of $\mathrm{S} / \mathrm{d}=2.19$, $\mathrm{X} / \mathrm{d}=1.32$, and $\mathrm{H} / \mathrm{d}=0.875$. Ames et al. [2004] also reported circumferential midline heat transfer data at various streamwise locations within the array. However, the geometry was different in their study with $\mathrm{S} / \mathrm{d}=\mathrm{X} / \mathrm{d}=2.5$, and $\mathrm{H} / \mathrm{d}=2$. Both researchers reported similar trends in heat transfer coefficients around the circumference of the pins.

A sample of the data reported by Ames et al. [2004] is shown in Figure 2-3. In the plot, $0^{\circ}$ indicates the leading edge of the pin fin. As shown, the general trend is that the heat transfer is a maximum at the leading edge of the pin. Between $90^{\circ}$ and $100^{\circ}$ from the leading edge, the heat transfer reaches the minimum value. On the trailing side of the pin fin, the heat transfer recovers from the minimum value. From a fluid mechanics viewpoint, the minimum heat transfer may correspond to the boundary layer separation point on the pin surface. According to Panton [1995], the separation point for a single circular cylinder in cross flow is $80^{\circ}$ from the leading edge at the relevant Reynolds number. However for an array of pin fins, the flow is accelerating upstream of the pin row midline, suppressing boundary layer separation. Downstream of the pin row midline, the flow decelerates, promoting boundary layer separation. This corresponds to the minimum heat transfer being at or downstream of the pin row midline.

\subsection{Dependency on Location in Array}

Based on his review of long tube heat transfer from various researchers, Zukauskas [1972] discussed the effect of location within an array of tubes on the tube surface heat transfer. He reported a 30 to $70 \%$ increase in heat transfer from tubes in downstream rows in comparison to the first row of the array. He also reported that the heat transfer in the array of tubes reaches a fully developed value at about the third row and remains constant downstream. Endwall effects were not considered.

Metzger et al. [1982a] studied the row by row variation of combined pin and endwall heat transfer from staggered pin fin arrays relevant to gas turbine airfoils with geometries of $\mathrm{S} / \mathrm{d}=\mathrm{X} / \mathrm{d}=2.5, \mathrm{H} / \mathrm{d}=1$, and $\mathrm{S} / \mathrm{d}=2.5, \mathrm{X} / \mathrm{d}=1.5$, and $\mathrm{H} / \mathrm{d}=1$. Figure $2-4$ 
shows the combined pin and endwall streamwise variation in heat transfer reported for the $\mathrm{S} / \mathrm{d}=\mathrm{X} / \mathrm{d}=2.5$, and $\mathrm{H} / \mathrm{d}=1$ geometry. Similar to the results for arrays of long tubes, the heat transfer is lowest at the first row, with the maximum heat transfer occurring at the third to fifth row. Contrary to the results for arrays of long tubes, the heat transfer steadily declines at rows downstream of the row with maximum heat transfer. The difference between the maximum heat transfer and the heat transfer of the last row (row 10 ) is about $12 \%$.

Yeh and Chyu [1998] also studied the row by row variation of combined pin and endwall heat transfer for two staggered array arrangements. Both arrays in this study had spanwise and streamwise spacing of $\mathrm{S} / \mathrm{d}=2.8$ and $\mathrm{X} / \mathrm{d}=2.6$ respectively. Only the pin aspect ratio was varied, with $\mathrm{H} / \mathrm{d}=1$ and $\mathrm{H} / \mathrm{d}=2.8$. Similar to Metzger et al. [1982a], the data indicated that the heat transfer level peaks at the third row, followed by a steady decline approaching a fully developed value. The trend was consistent for both pin aspect ratios.

Chyu et al. [1998a] reported the streamwise variation in heat transfer for both inline and staggered arrays with $\mathrm{S} / \mathrm{d}=\mathrm{X} / \mathrm{d}=2.5$, and $\mathrm{H} / \mathrm{d}=1$. The streamwise trend of combined pin and endwall heat transfer for the staggered array corresponded to the results reported by Metzger et al. [1982a], verifying that the maximum heat transfer occurs at about the third to fifth row, followed by a decline in subsequent rows. However the results for the inline array were different. While the heat transfer did reach a maximum at about the third row, the enhancement level remained nearly constant for rows farther downstream.

Simoneau and VanFossen [1984] also studied the row by row variation of heat transfer on the pin surface for both inline and staggered arrays of pin fins. Both arrays had an $\mathrm{S} / \mathrm{d}=\mathrm{X} / \mathrm{d}=2.67$, and $\mathrm{H} / \mathrm{d}=3$ geometry. Similar to Metzger et al. [1982a] and Chyu et al. [1998a], the staggered array heat transfer peaked at the third row with a decline farther downstream. However, the inline array heat transfer peaked at the second row, with subsequent rows maintaining the heat transfer level of row two. 


\subsection{Pin Spacing Effects}

The available literature suggests that pin spacing significantly affects pin fin array heat transfer. For long tube arrays, Zukauskas [1972] reported that reducing the streamwise spacing increases heat transfer, and though less significant, increasing the spanwise spacing increases heat transfer.

Metzger et al. [1982c] studied the effect of streamwise spacing on a staggered array having $\mathrm{S} / \mathrm{d}=2.5$, and $\mathrm{H} / \mathrm{d}=1$. The streamwise spacing was varied from $\mathrm{X} / \mathrm{d}=1.05$ to 5. Figure 2-5 is a plot of the array averaged heat transfer results versus Reynolds number. As shown, the effect of streamwise pin spacing is clear. Reducing the streamwise spacing significantly increases the array averaged heat transfer. Notice that the differences are smaller at the high Reynolds numbers.

Simoneau and VanFossen [1984] studied the effect of spanwise spacing on pin surface heat transfer of a single row of pin fins. Two different pin arrangements were tested. The first row had a geometry of $\mathrm{S} / \mathrm{d}=2.67$, with $\mathrm{H} / \mathrm{d}=3$. The second arrangement had only a single pin with $\mathrm{H} / \mathrm{d}=3$ in the channel. However, the channel width to height aspect ratio was small (2.05), so the tests with a single pin in the channel did not approximate a single cylinder in an infinite duct. Viewed another way, the pin row with $S / d=2.67$ spacing caused $46 \%$ flow blockage. The single pin caused $16 \%$ flow blockage, which is still considerably less than pin fin arrays tested by other researchers. The Reynolds number definition used in this study is defined by Equation 2-4:

$$
\mathrm{Re}=\frac{\mathrm{Ud}}{\mathrm{v}}
$$

Where $\mathrm{U}$ is the unobstructed channel velocity, $v$ is the kinematic viscosity, and $\mathrm{d}$ is the pin diameter. The Nussuelt number for this study is based on Equation 2-2. Note that the maximum velocity between the pins was not used in this study.

Using the Reynolds number definition mentioned above, Simoneau and VanFossen [1984] reported that the pin heat transfer on the single pin was only 7 to $15 \%$ lower than the pin heat transfer of the row with $\mathrm{S} / \mathrm{d}=2.67$ pin spacing. However, the velocity ratio between the two cases was 1.55 . They concluded that the maximum 
velocity was not the proper reference velocity for the Reynolds number. When considering flow blockage and recasting the Reynolds numbers to be based on the maximum velocity between the pins, the heat transfer from the single pin in the channel is higher than the pins from the row with $\mathrm{S} / \mathrm{d}=2.67$ spacing.

Also relevant to pin spacing is array orientation. It is common to configure the pin fins into either an inline or staggered array. Chyu et al. [1998a] studied both inline and staggered arrays having a geometry of $S / d=X / d=2.5$, and $H / d=1$. Figure 2-6 is a schematic that shows both configurations. It was reported that both pin and endwall heat transfer from the staggered array is higher than the inline array heat transfer. This resulted in the combined pin and endwall staggered array heat transfer being 10 to $20 \%$ higher than for the inline array.

This result is most likely attributed to differences in flow characteristics. Inline arrays form separate unobstructed flow passages between the pins in the streamwise direction. When considering a staggered array of pin fins, every row forms a blockage with respect to the row immediately upstream. Due to the additional flow blockage of staggered arrays, the flow is redirected when passing each row of pin fins, which provides better heat transfer enhancement.

\subsection{Effect of Pin Fin Aspect Ratio}

In a review article of staggered pin fin array heat transfer, Armstrong and Winstanley [1988] presented data by Brigham and VanFossen [1984] addressing the effect of pin fin aspect ratio on array averaged heat transfer. The results are shown in Figure 2-7 as a plot of the percent increase in combined pin and endwall heat transfer over an empty smooth channel as a function of pin height to diameter ratio, $\mathrm{H} / \mathrm{d}$, at different Reynolds numbers. As shown, there is no dependency on the array averaged heat transfer for $\mathrm{H} / \mathrm{d} \leq 2$ for the given data. However, there is a large effect for $\mathrm{H} / \mathrm{d}=4$ and 8 , with the heat transfer augmentation increasing with increasing values of $\mathrm{H} / \mathrm{d}$. More resolution may be required to fully answer the question of the effect of aspect ratio on pin fin array heat transfer.

To answer why large aspect ratio pin fins give larger combined pin and endwall heat transfer augmentation, first consider a pin fin array with relatively short pin fins with 
overall geometry of $\mathrm{S} / \mathrm{d}=2.5, \mathrm{X} / \mathrm{d}=2.5$, and $\mathrm{H} / \mathrm{d}=1$. With this configuration, the pin fins make up only $22 \%$ of the heat transfer area in the array. For $\mathrm{H} / \mathrm{d}=4$ the pin fins then contribute $53 \%$ of the total heat transfer area. It has already been discussed that the pin fin heat transfer is higher than the endwall heat transfer for pin fin arrays. As the pin fins become longer, the dominant heat transfer area is changed from the endwall to the pin fins. This is why the area averaged heat transfer of pin fin arrays increases with increasing $\mathrm{H} / \mathrm{d}$.

With respect to the pin fin heat transfer, data from the literature suggest that the heat transfer from pins with aspect ratios relevant to gas turbines $(0.5<\mathrm{H} / \mathrm{d}<4)$ is comparable to long pin heat transfer $(\mathrm{H} / \mathrm{d}>4)$. Metzger and Haley [1982b] obtained pin fin heat transfer measurements from an array with a geometry of $\mathrm{S} / \mathrm{d}=2.19, \mathrm{X} / \mathrm{d}=1.32$, and $\mathrm{H} / \mathrm{d}=0.875$. Measurements were taken from various locations within the array. To make a comparison with long pins or tubes, Metzger and Haley [1982b] compared the first row pin fin data with a correlation by Zukauskas [1972]. The data were within 5\% of the correlation for measurements taken at $\mathrm{Re}_{\mathrm{d}}=10,200,25,000$, and 32,500.

Ames et al. [2004] obtained first row heat transfer measurements from a pin fin array having a geometry of $\mathrm{S} / \mathrm{d}=\mathrm{X} / \mathrm{d}=2.5$, and $\mathrm{H} / \mathrm{d}=2$. Tests were done at $\mathrm{Re}_{\mathrm{d}}=2975$, 10,028 , and 30,047 . The data agree within $5 \%$ of the long tube correlation by Zukauskas [1972] at $\mathrm{Re}_{\mathrm{d}}=2975$ and 30,047. However at $\mathrm{Re}_{\mathrm{d}}=10,028$, the heat transfer is about $11 \%$ less than the long tube correlation.

Chyu et al. [1998a] reported a correlation for the array averaged pin fin heat transfer for an array having $\mathrm{S} / \mathrm{d}=\mathrm{X} / \mathrm{d}=2.5$, and $\mathrm{H} / \mathrm{d}=1$. In addition, multiplying factors were provided to give the pin fin heat transfer on a row by row basis. Using the array averaged correlation along with the multiplying factor for the first row of the pin fin array, comparisons were made with the long tube correlation by Zukauskas [1972]. The data by Chyu et al. [1998a] indicate that the pin fin heat transfer data with $\mathrm{H} / \mathrm{d}=1$ is less than long tube heat transfer, but not by a large amount. Across a Reynolds number range of $5000<\mathrm{Re}_{\mathrm{d}}<30,000$ percent differences between the two predictions range from 10 to $20 \%$. The larger discrepancies occur at the low Reynolds numbers.

To summarize, the heat transfer on the pins for pin fin arrays relevant to gas turbines is comparable to long pin heat transfer. Thus, the pin aspect ratio, $\mathrm{H} / \mathrm{d}$, does not 
have a significant effect on the pin heat transfer. However, it is generally accepted that the endwall heat transfer is less than the pin fin heat transfer. When considering the pin and endwall, the pin aspect ratio has a significant effect on the combined heat transfer. The reason pertains to the heat transfer area contribution from both the pins and endwalls. For pin fin arrays with low pin aspect ratios, the endwall heat transfer area is larger than the pin fin area. The opposite is true for pin fin arrays with large pin fin aspect ratios. As a result, the combined pin and endwall heat transfer increases with increasing $\mathrm{H} / \mathrm{d}$.

\subsection{Effect of Pin Shape}

The straight cylinder is the most commonly studied pin fin geometry. However, other pin shapes have been investigated to see the effect on heat transfer. One such geometry is the straight cylinder with endwall fillets. This geometry was investigated by Chyu [1990]. The filleted pin fin geometry used in this study along with the corresponding cylindrical pin fin geometry is shown in Figure 2-8. The motivation behind their study was related to manufacturing limitations. Although the turbine airfoil manufacturer may intend to cast straight cylindrical pin fins, casting limitations may in fact produce fillets at the pin fin-endwall junction.

Chyu [1990] studied both inline and staggered pin fin arrays with a geometry of $\mathrm{S} / \mathrm{d}=\mathrm{X} / \mathrm{d}=2.5$, and $\mathrm{H} / \mathrm{d}=1$ for a Reynolds number range of $5000<\mathrm{Re}_{\mathrm{d}}<30,000$. Both straight cylindrical and filleted pins were studied for comparison. For the inline array, the endwall fillet had little to no effect on the array averaged pin fin heat transfer. However, the endwall fillets caused significant effects on the staggered configuration. In particular, the filleted pin fin heat transfer coefficients were $25 \%$ less than the straight cylinder array at $\mathrm{Re}_{\mathrm{d}}=5,000$. This difference became less significant at higher Reynolds numbers with only an $8 \%$ difference at $\mathrm{Re}_{\mathrm{d}}=30,000$. For the staggered array, although the endwall fillets reduced the array averaged heat transfer, the enhancement level was still higher than the inline arrangement with straight cylinders.

Chyu et al. [1998b] studied the heat transfer augmentation of pin fin arrays with cubic pin fins. In this study, the cubic pins were oriented both as squares and diamonds with respect to the flow direction. Figure 2-9 shows sketches of both types of arrays. All 
arrays in this study had a geometry of $\mathrm{S} / \mathrm{d}=\mathrm{X} / \mathrm{d}=2.5$, and $\mathrm{H} / \mathrm{d}=1$. Both inline and staggered arrangements were studied.

The major finding in this study was that cubic pin fins produce significantly higher heat transfer than diamond or straight circular pin fins. Chyu et al. [1998b] reported for the staggered array that the array averaged cubic pin fin heat transfer augmentation is 20 to $40 \%$ and 30 to $80 \%$ higher than the diamond and straight cylinder pin fin arrays respectively. The difference is smaller but still significant for the inline arrays with the cubic array averaged pin fin heat transfer being 10 to $20 \%$ and 10 to $40 \%$ higher than the diamond and straight cylinder array respectively.

Metzger et al. [1984] studied the effects of oblong pin fins at different orientation angles, $\gamma$, with respect to the flow direction. Figure 2-10 explains the nomenclature used in studying the oblong pin fin arrays. All geometries for the tests carried out were in the range of $2.5<\mathrm{S} / \mathrm{D}=\mathrm{X} / \mathrm{D}<3.5$, and $\mathrm{H} / \mathrm{D}=1$. The clearance between the pins was maintained constant for all the tests with $\mathrm{A} / \mathrm{D}=\mathrm{B} / \mathrm{D}=1.5$. These clearances correspond to the clearances for the $\mathrm{S} / \mathrm{d}=\mathrm{X} / \mathrm{d}=2.5$, and $\mathrm{H} / \mathrm{d}=1$ cylindrical pin fin geometry.

Metzger et al. [1984] reported the area averaged heat transfer results for the different oblong pin geometries. The orientation angle, $\gamma$, was varied from 0 to $90^{\circ}$. The results indicate that oblong pins can both increase and decrease the array averaged heat transfer relative to a corresponding straight cylindrical pin fin array, depending on the orientation angle. For example, orienting the pins with $\gamma=90^{\circ}$ reduces the heat transfer relative to cylindrical pin fins. Conversely, having $\gamma= \pm 30^{\circ}$ gives the maximum array averaged heat transfer from the oblong pins with about a $20 \%$ increase over a corresponding cylindrical pin fin array. Other orientation angles also increase the array averaged heat transfer relative to cylindrical pin fins, but by a smaller margin.

Uzol and Camci [2005] studied the endwall heat transfer downstream of two rows of pin fins. Cylindrical and two separate elliptical pin shapes were investigated. Figure 2-11 shows sketches of the three pin geometries tested. For all three pin shapes, the pin fin array geometry was defined by $S / D=X / D=2$, and $H / D=1.5$. Measurements were taken starting at 2D downstream of the trailing edge of the second pin row, extending $0.5 \mathrm{D}$ farther downstream. Also note that when testing the elliptical pins, the major axis was aligned with the streamwise direction of the flow. 
The results reported by Uzol and Camci [2005] indicate that both elliptical pin shapes cause about the same level of heat transfer augmentation downstream of the pin rows. However, the circular pin fin augmentation is about $27 \%$ higher than both elliptical pin shapes. These effects were observed over the range of $18,000<\operatorname{Re}_{\mathrm{d}}<86,000$.

Several different pin fin shapes used in pin fin arrays have been investigated by various researchers. Based on results from the literature, pin fin array heat transfer is highly dependent on pin fin shape. How well a particular pin shape enhances heat transfer appears directly related to how well the shape can induce flow separation and generate turbulence within the flow field. Thus, pin fins with a poor aerodynamic shape produce better heat transfer enhancement. As an example, consider a cubic shaped pin fin. Due to the strong inertia forces of the fluid stream surrounding the pin fin, the flow cannot stay attached to the pin surface downstream of the sharp corners. Stated another way, the sudden changes in flow path around the cubic pin fin induce flow separation and turbulent vortex shedding, which augment the heat transfer within the pin fin array.

Now consider an elliptical pin fin with the major axis inline with the streamwise direction of the bulk flow. The flow path outlined by the shape of the pin is defined by gradual changes. In this scenario, it is likely that the flow will stay attached around the outside of the pin longer than with geometries with abrupt flow path changes, such as the cubic pin fins. In support of this claim, Uzol and Camci [2005] obtained flow field measurements downstream of both cylindrical and elliptical pin fins. The results indicated smaller wake patterns for the elliptical pins in comparison to the cylindrical pin fins. The smaller wake patterns correspond to the reduced heat transfer augmentation of the elliptical pins in comparison to the cylindrical pins.

\subsection{Reynolds Number Effects}

Although there is variability among researchers concerning the Reynolds number dependence of pin fin arrays, the dependency arises from the combination of both long pin array and unobstructed duct flow heat transfer. According to Kays and Crawford [1980], the Reynolds number exponent is 0.8 for unobstructed duct flow heat transfer. Zukauskas [1972] reports a Reynolds number exponent of 0.6 for correlating the heat 
transfer from tubes within tube bundles. In general, the Reynolds number dependence is between about 0.6 and 0.8 for pin fin arrays used in gas turbines.

Both Metzger et al. [1982a] and VanFossen [1981] reported Reynolds number exponents of about 0.7 for the combined pin and endwall array averaged heat transfer. Chyu et al. [1998a] reported different Reynolds number dependencies for staggered and inline pin fin arrays. Their study indicated that the staggered array Reynolds number exponent is about 0.6, but the inline array Reynolds number exponent is about 0.7. This range of Reynolds number dependency is typical in the pin fin array literature, even for different pins shapes and array geometries.

\subsection{Uniqueness of Research}

After reviewing the pin fin array literature, it is apparent that most heat transfer studies are focused on multiple row arrays of pin fins. The only exception found is Simoneau and VanFossen [1984], who studied the pin fin heat transfer on a single row of pin fins as a baseline case for multiple row heat transfer studies. The endwalls are not considered in this study. However, several researchers have investigated the heat transfer from the first row of multiple row arrays. In the present study, three single row geometries of straight cylindrical pin fins are considered with $\mathrm{S} / \mathrm{d}=2$, 4, and 8 pin spacing. All three arrangements have a pin aspect ratio of $H / d=1$. Both pin fin and endwall heat transfer are studied.

It is also most common in the literature to focus heat transfer measurements directly within the pin fin array and not on the endwall upstream and downstream of the pin fins. Although the measurements were confined to a narrow strip 0.5 pin diameters long in the streamwise direction, Uzol and Camci [2005] studied the endwall heat transfer downstream of pin fin arrays. For the present study, an infrared thermography technique is used to obtain a temperature map on the endwall across a single row of pin fins extending 3.5 pin diameters upstream and 6 pin diameters downstream of the pin row. Hence, the endwall heat transfer measurements are spatially resolved to allow visualization of the heat transfer patterns on the endwall surface. Heat transfer coefficients are calculated using the temperatures measured across the endwall surface obtained from an infrared camera. 
Table 2-1 Summary of Reviewed Pin Fin Geometries From the Literature With Correlations Where Applicable

\begin{tabular}{|c|c|c|c|c|c|c|c|c|}
\hline & & & & & & & surement & Presented \\
\hline Investigators & S/d & $\mathbf{X} / \mathbf{d}$ & H/d & Pin Shape & Arrangement & Pin & Endwall & Combined \\
\hline Ames et al. [2004] & 2.5 & 2.5 & 2 & Cylindrical & Staggered & yes & no & no \\
\hline $\begin{array}{l}\text { Brigham and } \\
\text { VanFossen [1984] }\end{array}$ & - & - & $\begin{array}{l}0.5- \\
7.7\end{array}$ & Cylindrical & Staggered & no & no & yes \\
\hline Chyu [1990] & 2.5 & 2.5 & 1 & Cylindrical & Staggered & yes & yes & no \\
\hline & 2.5 & 2.5 & 1 & Cylindrical & Inline & yes & yes & no \\
\hline & 2.5 & 2.5 & 1 & Filleted, Cylindrical & Staggered & yes & yes & no \\
\hline & 2.5 & 2.5 & 1 & Filleted, Cylindrical & Inline & yes & yes & no \\
\hline Chyu et al. & 2.5 & 2.5 & 1 & Cylindrical & Staggered & yes & yes & yes \\
\hline [1998a] & 2.5 & 2.5 & 1 & Cylindrical & Inline & yes & yes & yes \\
\hline Chyu et al. & 2.5 & 2.5 & 1 & Cubic & Staggered & yes & no & no \\
\hline [1998b] & 2.5 & 2.5 & 1 & Cubic & Inline & yes & no & no \\
\hline & 2.5 & 2.5 & 1 & Diamond & Staggered & yes & no & no \\
\hline & 2.5 & 2.5 & 1 & Diamond & Inline & yes & no & no \\
\hline Metzger et al. & 2.5 & 1.5 & 1 & Cylindrical & Staggered & no & no & yes \\
\hline [1982a] & 2.5 & 2.5 & 1 & Cylindrical & Staggered & no & no & yes \\
\hline Metzger and & 2.5 & 1.5 & 1 & Cylindrical & Staggered & no & yes & yes \\
\hline Haley [1982b] & 2.5 & 2.5 & 1 & Cylindrical & Staggered & no & yes & yes \\
\hline & 2.19 & 1.32 & 0.875 & Cylindrical & Staggered & yes & no & no \\
\hline & 2.19 & 2.19 & 0.875 & Cylindrical & Staggered & yes & no & no \\
\hline $\begin{array}{l}\text { Metzger et al. } \\
{[1982 \mathrm{c}]}\end{array}$ & 2.5 & $\begin{array}{l}1.05 \\
-5\end{array}$ & 1 & Cylindrical & Staggered & no & yes & no \\
\hline Metzger et al. & 2.5 & 1.5 & 1 & Cylindrical & Staggered & no & no & yes \\
\hline [1984] & 2.5 & 2.5 & 1 & Cylindrical & Staggered & no & no & yes \\
\hline & $\begin{array}{l}2.5- \\
3.5 \\
\end{array}$ & $\begin{array}{l}2.5 \\
-35 \\
\end{array}$ & 1 & Oblong* & Staggered & no & no & yes \\
\hline Simoneau and & 2.67 & 2.67 & 3 & Cylindrical & Staggered & yes & no & no \\
\hline VanFossen [1984] & 2.67 & 2.67 & 3 & Cylindrical & Inline & yes & no & no \\
\hline Uzol and Camci & 2 & 2 & 1.5 & Cylindrical & Staggered & no & yes & no \\
\hline [2005] & 2 & 2 & 1.5 & Elliptical, d x 1.67d & Staggered & no & yes & no \\
\hline & 2 & 2 & 1.5 & Elliptical, d x $2.5 \mathrm{~d}$ & Staggered & no & yes & no \\
\hline VanFossen [1981] & 4 & 3.46 & 2 & Cylindrical & Staggered & yes & yes & yes \\
\hline & 2 & 1.73 & 0.5 & Cylindrical & Staggered & yes & yes & yes \\
\hline Yeh and Chyu & 2.8 & 2.6 & 1 & Cylindrical & Staggered & yes & yes & yes \\
\hline & 2.8 & 2.6 & 2.8 & Cylindrical & Staggered & yes & yes & yes \\
\hline Zukauskas [1972] & $\begin{array}{l}1.3- \\
2.6\end{array}$ & $\begin{array}{c}0.6 \\
- \\
3.9\end{array}$ & Large & Cylindrical & Staggered & yes & no & no \\
\hline & $\begin{array}{c}1.3- \\
2.7\end{array}$ & $\begin{array}{c}1.1 \\
- \\
2.6\end{array}$ & Large & Cylindrical & Inline & yes & no & no \\
\hline
\end{tabular}

\footnotetext{
* The oblong pins were oriented between 0 and $90^{\circ}$ with respect to the flow direction.
} 
Table 2-1(Continued) Summary of Reviewed Pin Fin Geometries From the Literature With Correlations Where Applicable

\begin{tabular}{|c|c|c|c|}
\hline \multicolumn{4}{|c|}{ Correlations } \\
\hline Investigators & Pin & Endwall & Combined \\
\hline Ames et al. [2004] & - & - & - \\
\hline $\begin{array}{l}\text { Brigham and } \\
\text { VanFossen [1984] }\end{array}$ & - & - & - \\
\hline \multirow[t]{4}{*}{ Chyu [1990] } & $\mathrm{Nu}_{\mathrm{d}}=0.690 \mathrm{Re}_{\mathrm{d}}^{0.511} \operatorname{Pr}^{0.4}$ & - & - \\
\hline & $\mathrm{Nu}_{\mathrm{d}}=0.463 \operatorname{Re}_{\mathrm{d}}^{0.537} \operatorname{Pr}^{0.4}$ & - & - \\
\hline & $\mathrm{Nu}_{\mathrm{d}}=0.234 \mathrm{Re}_{\mathrm{d}}{ }^{0.608} \operatorname{Pr}^{0.4}$ & - & - \\
\hline & $\mathrm{Nu}_{\mathrm{d}}=0.403 \operatorname{Re}_{\mathrm{d}}^{0.550} \operatorname{Pr}^{0.4}$ & - & - \\
\hline \multirow{2}{*}{$\begin{array}{l}\text { Chyu et al. } \\
\text { [1998a] }\end{array}$} & $\mathrm{Nu}_{\mathrm{d}}=0.337 \mathrm{Re}_{\mathrm{d}}{ }^{0.585} \mathrm{Pr}^{0.4}$ & $\mathrm{Nu}_{\mathrm{d}}=0.315 \mathrm{Re}_{\mathrm{d}}^{0.582} \operatorname{Pr}^{0.4}$ & $\mathrm{Nu}_{\mathrm{d}}=0.320 \operatorname{Re}_{\mathrm{d}}{ }^{0.583} \operatorname{Pr}^{0.4}$ \\
\hline & $\mathrm{Nu}_{\mathrm{d}}=0.155 \mathrm{Re}_{\mathrm{d}}{ }^{0.658} \operatorname{Pr}^{0.4}$ & $\mathrm{Nu}_{\mathrm{d}}=0.052 \mathrm{Re}_{\mathrm{d}}{ }^{0.759} \operatorname{Pr}^{0.4}$ & $\mathrm{Nu}_{\mathrm{d}}=0.068 \mathrm{Re}_{\mathrm{d}}{ }^{0.733} \mathrm{Pr}^{0.4}$ \\
\hline \multirow{4}{*}{$\begin{array}{l}\text { Chyu et al. } \\
\text { [1998b] }\end{array}$} & $\mathrm{Nu}_{\mathrm{d}}=0.138 \operatorname{Re}_{\mathrm{d}}{ }^{0.704} \operatorname{Pr}^{0.4}$ & - & - \\
\hline & $\mathrm{Nu}_{\mathrm{d}}=0.233 \operatorname{Re}_{\mathrm{d}}^{0.631} \operatorname{Pr}^{0.4}$ & - & - \\
\hline & $\mathrm{Nu}_{\mathrm{d}}=0.084 \operatorname{Re}_{\mathrm{d}}{ }^{0.732} \operatorname{Pr}{ }^{0.4}$ & - & - \\
\hline & $\mathrm{Nu}_{\mathrm{d}}=0.187 \operatorname{Re}_{\mathrm{d}}{ }^{0.639} \operatorname{Pr}^{0.4}$ & - & - \\
\hline \multirow{3}{*}{$\begin{array}{l}\text { Metzger et al. } \\
\text { [1982a], }\end{array}$} & - & - & $\mathrm{Nu}_{\mathrm{d}}=0.092 \mathrm{Re}_{\mathrm{d}}^{0.707}$ \\
\hline & - & - & $\mathrm{Nu}_{\mathrm{d}}=0.069 \mathrm{Re}_{\mathrm{d}}^{0.728}$ \\
\hline & \multicolumn{2}{|c|}{$\begin{array}{l}\text { Combined pin and endwall first row correlations } \\
\text { (Equivalent for both streamwise spacings) }\end{array}$} & $\begin{array}{l}\mathrm{Nu}_{\mathrm{d}}=0.140 \operatorname{Re}_{\mathrm{d}}^{0.611}, \operatorname{Re}<10^{4} \\
\mathrm{Nu}_{\mathrm{d}}=0.022 \operatorname{Re}_{\mathrm{d}}{ }^{0.813}, \operatorname{Re}>10^{4}\end{array}$ \\
\hline \multirow{4}{*}{$\begin{array}{l}\text { Metzger and } \\
\text { Haley [1982b] }\end{array}$} & - & - & - \\
\hline & - & - & - \\
\hline & - & - & - \\
\hline & - & - & - \\
\hline $\begin{array}{l}\text { Metzger et al. } \\
{[1982 \mathrm{c}]}\end{array}$ & - & - & - \\
\hline \multirow{3}{*}{$\begin{array}{l}\text { Metzger et al. } \\
{[1984]}\end{array}$} & - & - & - \\
\hline & - & - & - \\
\hline & - & - & - \\
\hline \multirow{2}{*}{$\begin{array}{l}\text { Simoneau and } \\
\text { VanFossen [1984] }\end{array}$} & - & - & - \\
\hline & - & - & - \\
\hline \multirow{3}{*}{$\begin{array}{l}\text { Uzol and Camci } \\
\text { [2005] }\end{array}$} & - & $\mathrm{Nu}_{\mathrm{d}}=0.0776 \mathrm{Re}_{\mathrm{d}}^{0.7}$ & - \\
\hline & - & $\mathrm{Nu}_{\mathrm{d}}=0.077 \mathrm{Re}_{\mathrm{d}}^{0.678}$ & - \\
\hline & - & $\mathrm{Nu}_{\mathrm{d}}=0.0916 \mathrm{Re}_{\mathrm{d}}{ }_{\mathrm{d}}^{0.661}$ & - \\
\hline \multirow[t]{2}{*}{ VanFossen [1981] } & - & - & - \\
\hline & - & - & - \\
\hline \multirow{2}{*}{$\begin{array}{l}\text { Yeh and Chyu } \\
\text { [1998] }\end{array}$} & $\mathrm{Nu}_{\mathrm{d}}=0.3322 \mathrm{Re}_{\mathrm{d}}^{0.5554}$ & $\mathrm{Nu}_{\mathrm{d}}=0.1344 \mathrm{Re}_{\mathrm{d}}^{0.6341}$ & $\mathrm{Nu}_{\mathrm{d}}=0.1495 \mathrm{Re}_{\mathrm{d}}^{0.6247}$ \\
\hline & $\mathrm{Nu}_{\mathrm{d}}=0.2667 \mathrm{Re}_{\mathrm{d}}^{0.5799}$ & $\mathrm{Nu}_{\mathrm{d}}=0.0639 \mathrm{Re}_{\mathrm{d}}^{0.7107}$ & $\mathrm{Nu}_{\mathrm{d}}=0.944 \mathrm{Re}_{\mathrm{d}}^{0.6747}$ \\
\hline \multirow[t]{3}{*}{ Zukauskas [1972] } & $\begin{array}{l}\mathrm{Nu}_{\mathrm{d}}=0.35(\mathrm{~S} / \mathrm{X})^{0.2} \mathrm{Re}_{\mathrm{d}}^{0.60} \\
\operatorname{Pr}^{0.36}\end{array}$ & \multicolumn{2}{|c|}{ Heat transfer from inner rows } \\
\hline & $\mathrm{Nu}_{\mathrm{d}}=0.27 \operatorname{Re}_{\mathrm{d}}{ }^{0.63} \operatorname{Pr}^{0.36}$ & \multicolumn{2}{|c|}{ Heat transfer from inner rows } \\
\hline & $\mathrm{Nu}_{\mathrm{d}}=0.26 \operatorname{Re}_{\mathrm{d}}^{0.6} \operatorname{Pr}{ }^{0.37}$ & \multicolumn{2}{|c|}{ Heat transfer from first row } \\
\hline
\end{tabular}

Note: Unless stated otherwise, the correlations represent array averages. 


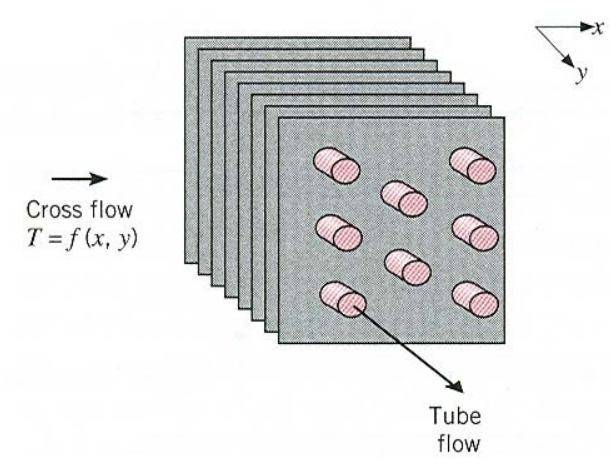

(a) Continuous Finned-Tube

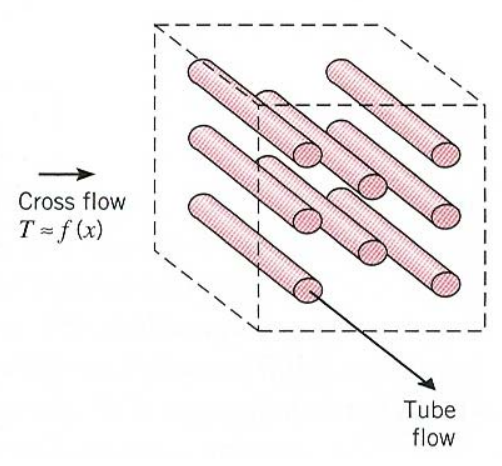

(b) Tubes in Cross Flow

Figure 2-1 Comparison of common heat exchanger types [Incropera and Dewitt, 2002]. In (a), the endwalls dominate the heat transfer. In (b), the dominant heat transfer is on the pin surface. Pin fin arrays in gas turbines are considered to be an intermediate case.

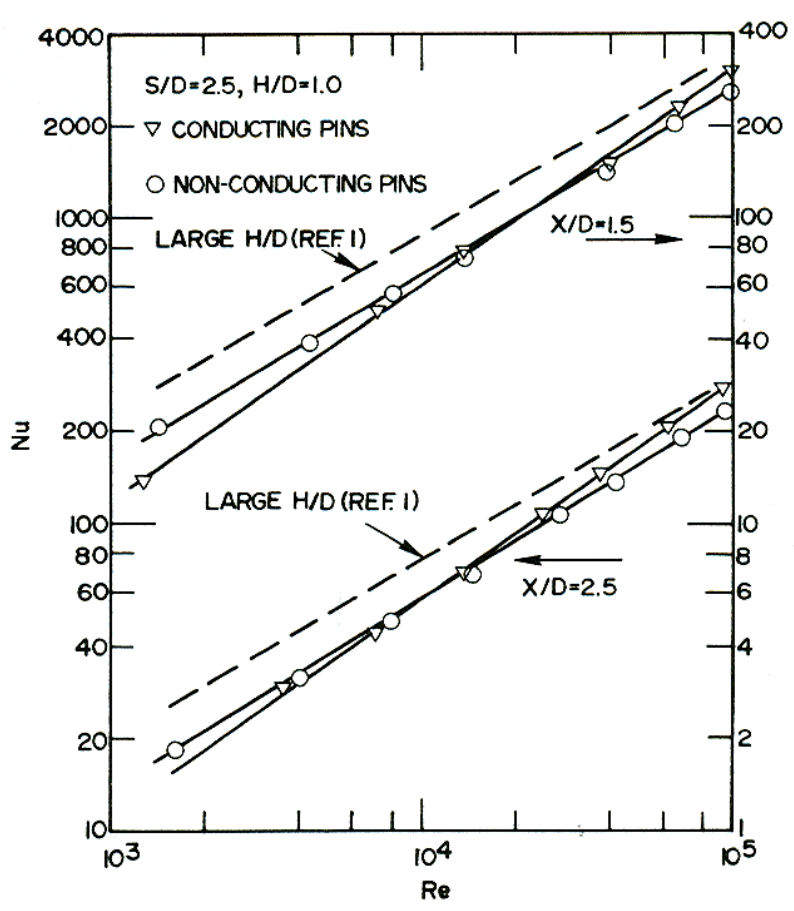

Figure 2-2 Plot of the comparison of array averaged heat transfer between conductive and non-conductive pin fins [Metzger et al., 1982c]. 


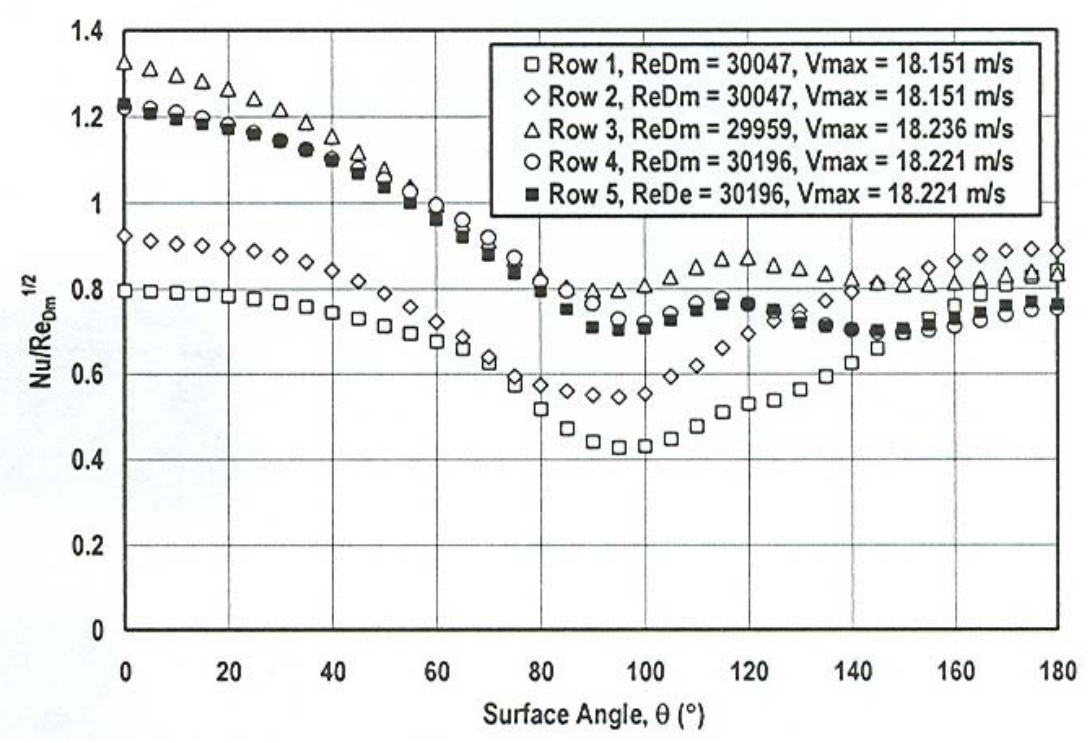

Figure 2-3 Plot of circumferential heat transfer on the surface of a pin fin at different row locations [Ames et al., 2004]. The abscissa indicates the angle from the leading edge of the pin fin.

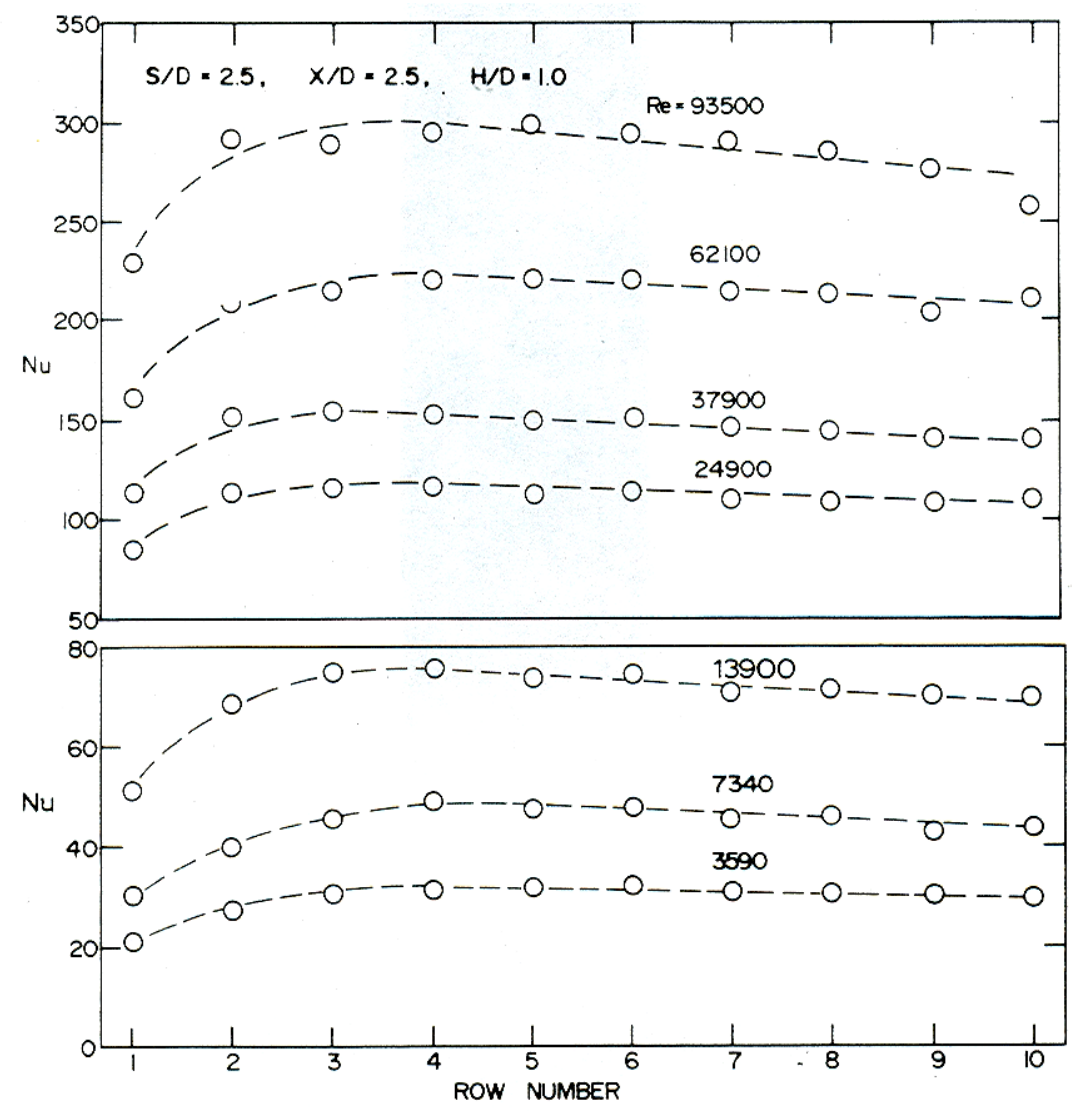

Figure 2-4 Row by row variation of combined pin and endwall heat transfer of a staggered pin fin array [Metzger et al., 1982a]. 


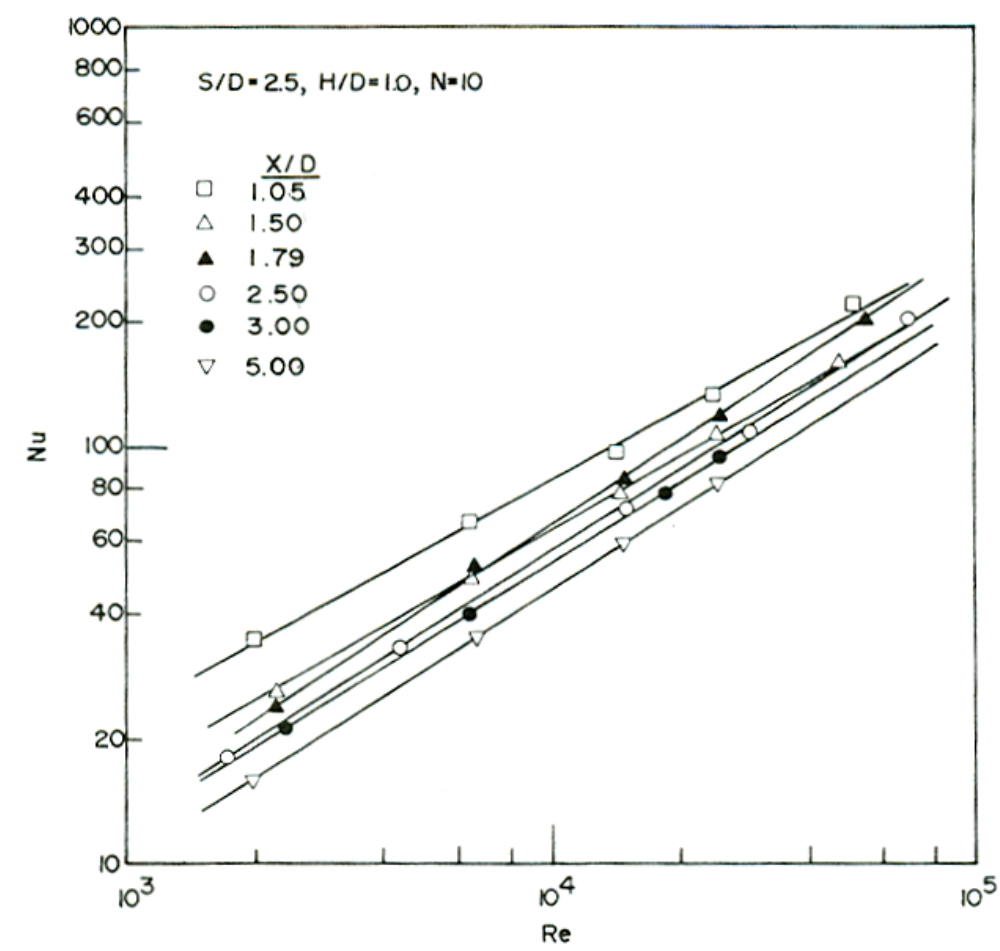

Figure 2-5 Staggered array, array averaged heat Nusselt versus Reynolds number for different streamwise pin fin spacing [Metzger et al., 1982c].

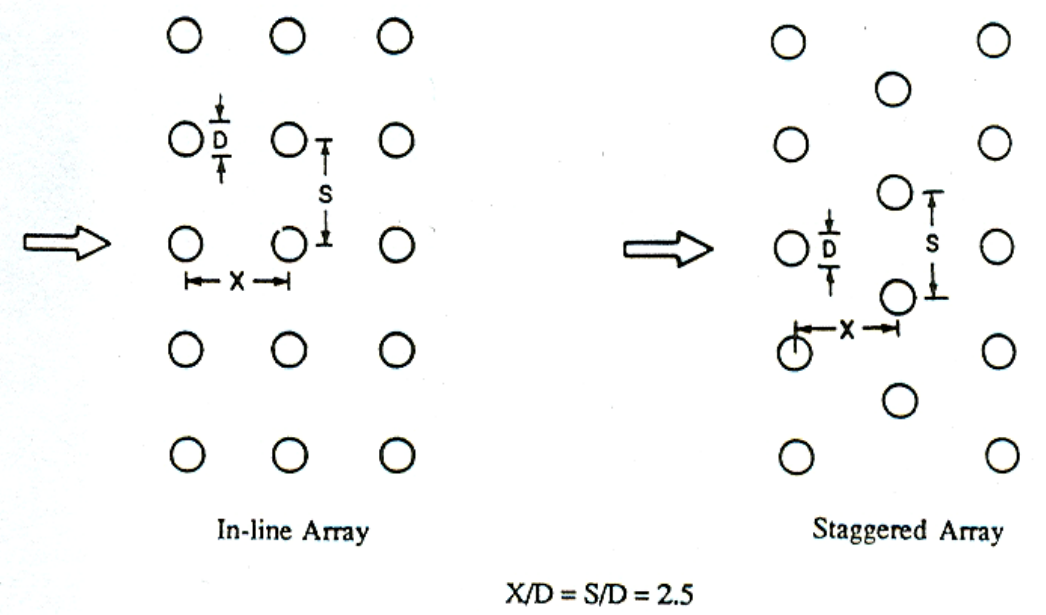

Figure 2-6 Comparison between inline and staggered pin fin array configurations [Chyu, 1990]. 


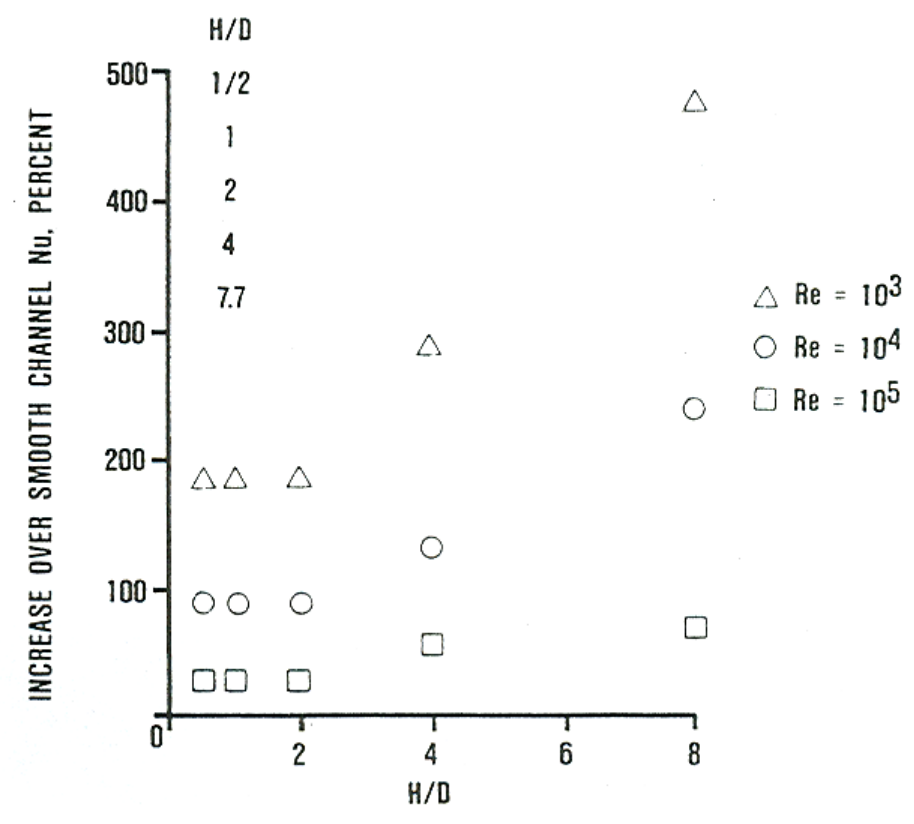

Figure 2-7 Dependency of array averaged heat transfer augmentation over smooth channel heat transfer on pin aspect ratio, H/D [Armstrong and Winstanley, 1988].

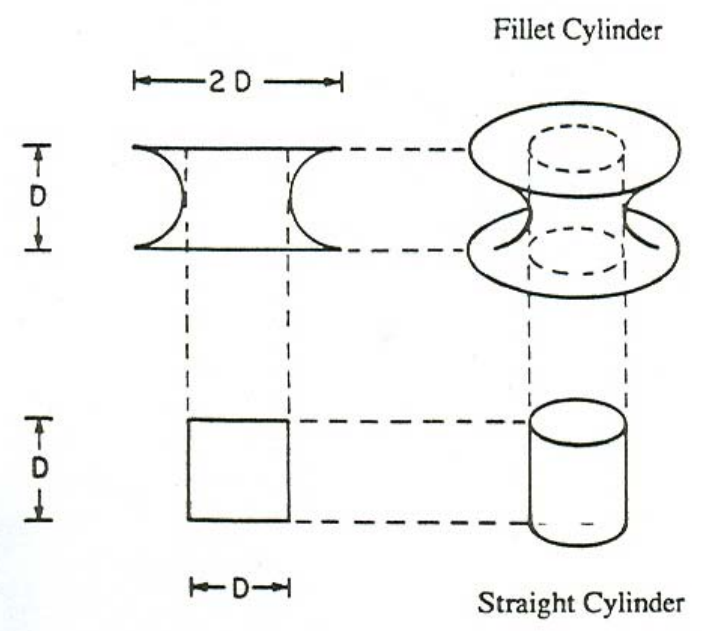

Figure 2-8 Comparison of straight cylindrical and filleted pin fins [Chyu, 1990]. 

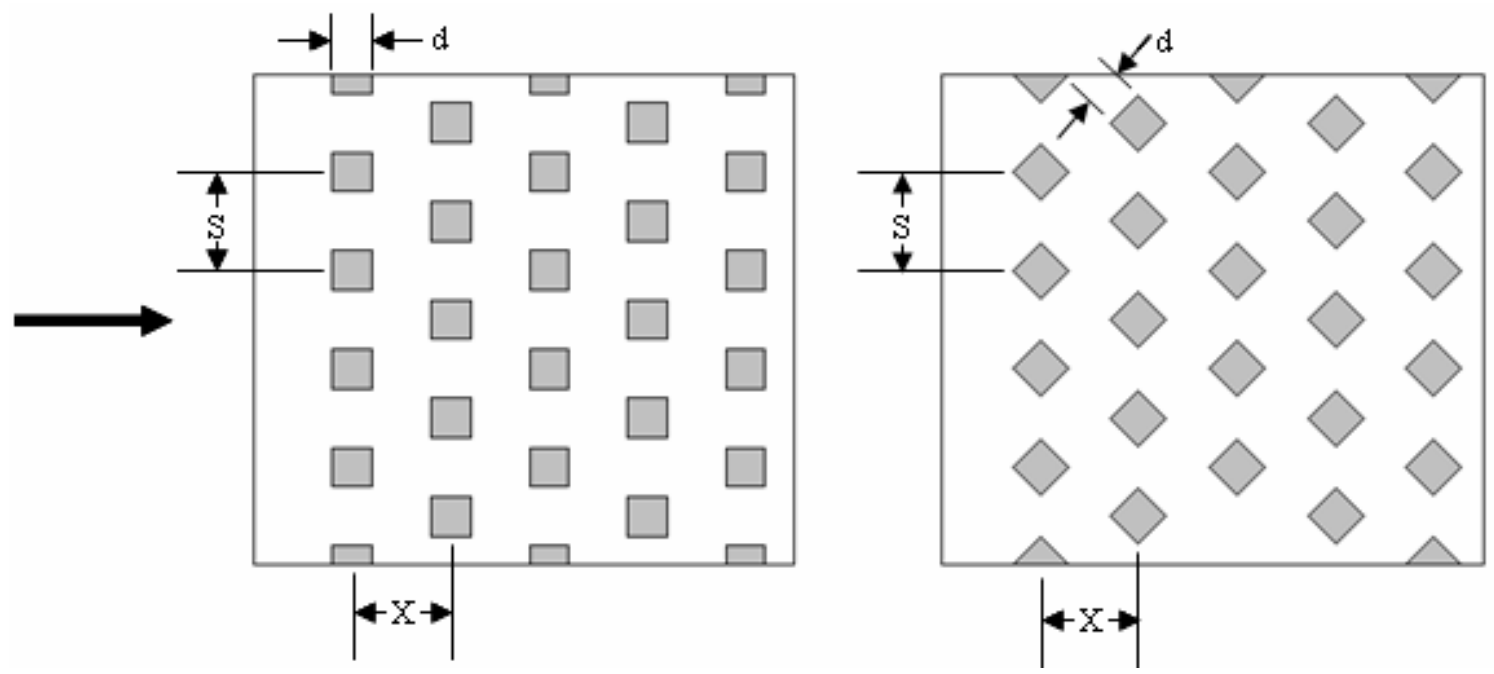

Figure 2-9 Comparison between cubic and diamond staggered array configurations. Cubes are rotated $45^{\circ}$ to make the diamond array.

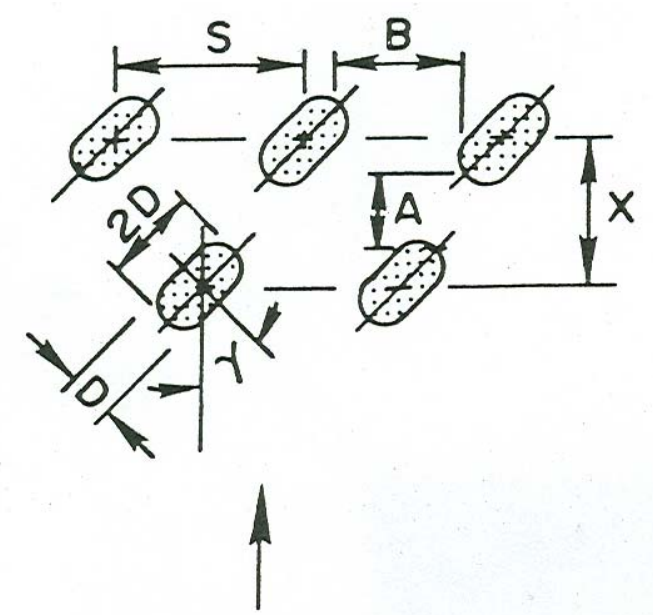

Figure 2-10 Staggered array configuration using oblong pins [Metzger et al., 1984]. 


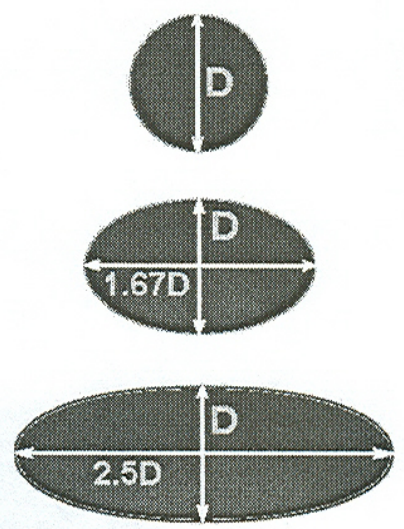

Figure 2-11 Circular and elliptical pin shapes used by Uzol and Camci [2005]. 


\section{Chapter 3}

\section{Design and Construction of Experimental Facility}

The goal of this project required both pin and endwall heat transfer measurements of various configurations of pin fin arrays with pin height to diameter ratio of one. To simplify data collection, a test rig was constructed to gather both pin and endwall heat transfer data, which is the focus of this thesis. To establish the desired measurement resolution, the test section was scaled up from actual engine size. The scale used in this study was 25 times larger than the engine scale. The test section modeled a parallel plate duct with a height of $0.95 \mathrm{~cm}$ and a width of $61 \mathrm{~cm}$. This gave a width to height aspect ratio of $64: 1$. Consequently, all pin fins used in the study had both height and diameter equal to $0.95 \mathrm{~cm}$. Tests were carried out at the range of $5000<\operatorname{Re}<30,000$ on $\mathrm{S} / \mathrm{d}=2,4$, and 8 single pin row geometries.

To establish the required mass flow rates, a high pressure, low flow centrifugal blower was used. In previous work done in the Virginia Tech Experimental and Computational Convection Laboratory (VTExCCL), a combination of compressed air from the building air supply and a compressor from the Aerospace and Ocean Engineering Department served as the primary flow sources [Prausa, 2004; Elder, 2005]. However, in a test section of similar flow area, flows were limited to $\operatorname{Re}<15,000$ using these supplies. Unsteadiness was also a problem due to the cyclic charging and discharging of the air supply system. Thus, using the centrifugal blower gave much more flexibility. In addition, using the blower allowed construction of a closed loop recirculating flow system, providing a buffer to ambient changes in the laboratory.

The focus of this chapter will be to describe in detail all the test rig components and measurement systems. In Section 3.1, all the components of the overall test facility will be discussed with the emphasis being placed on establishing adequate flow conditions for the test section. Section 3.2 focuses on test section design. Section 3.3 discusses the heat transfer surfaces and instrumentation used to run both pin and endwall heat transfer tests. Finally, Section 3.5 describes the testing procedures and Section 3.6 presents the results from facility benchmarking. 


\subsection{Overall Test Facility}

This section describes the components of the test facility. Figure 3-1 is a schematic representation of the overall test facility. As shown in the figure, the flow followed a clockwise path as indicated by the arrows. Consider the inlet of the plenum as a starting point. The flow first passed through the inlet of the plenum and encountered a splash plate. The splash plate was installed to disperse the flow and prevent a jet from propagating through the center of the plenum. The flow then passed through the heat exchanger, which was used to maintain a steady inlet temperature. After the test section, the flow passed through a square-to-round expansion joint to connect with the inlet line of the flow meter. The flow then passed through the flow meter, followed by a butterfly flow control valve and a regulator valve before entering into the blower. Finally, the blower drove the flow back through the return line and into the plenum to complete the loop.

Shown in Figure 3-2 and 3-3 is a pair of photographs that show the actual scale of the rig. The total length of the test rig was $9.6 \mathrm{~m}$, and as a result it is difficult to see detail in a single photograph. Figure 3-2 shows the plenum and test section side of the test facility while Figure 3-3 shows the blower side. The plenum is located at the far left of Figure 3-2, with the test section fitted back inside the front plenum wall. Mounted on the discharge of the test section is the square-to-round diffuser, which was used to transition the flow to the inlet line of the flow meter. Located at the bottom of the photograph is the return line mounted underneath the test section and plenum.

The blower is located at the far right in Figure 3-3. The line feeding the blower was mounted directly above the return line. As shown in the photograph, both the flow meter and the butterfly flow control valve were located in the blower feed line. There was a pressure regulator valve located in both the discharge and suction lines of the blower.

The plenum was the component of the test facility used to condition the flow entering the test section both aerodynamically and thermally. Figure 3-4 shows a photograph of the top view of the plenum with the roof removed. The main components inside the plenum were the splash plate and the heat exchanger. Also shown in Figure 3- 
4 is the inlet contraction of the test section, since it was fitted inside the discharge end wall of the plenum.

In terms of aerodynamics, the plenum conditioned the flow by first using the splash plate to disperse the flow to fill the entire flow area and be more uniform inside the plenum. Secondly, the plenum caused an approximate zero velocity condition by having a much larger flow area than the test section flow area. Accelerating the flow into the test section from a near zero velocity condition inside the plenum aided in producing flow uniformity inside the test section.

In the initial design and construction, a baffle was installed downstream of the splash plate. Flow had to pass through the center of the baffle, where as the flow had to pass around the outside of the splash plate. The idea was that the flow area would be increased in two separate stages before filling the entire plenum flow area, creating more uniform flow in the plenum. However, heat transfer tests were performed both with and without the baffle installed. The results were insensitive to the baffle. As a result, the baffle downstream of the splash plate was omitted.

Because heat transfer tests were done in a closed loop facility, it was necessary to remove the heat that was added during each flow cycle. This thermal conditioning was accomplished by using a heat exchanger. Installing the heat exchanger inside the plenum was primarily a choice of convenience and also to prevent pressure losses. Based on the plenum cross-sectional area, estimated mass flow, and estimated heat rate entering the closed loop system, Super Radiator Coils of Richmond, Virginia built and donated a custom fin and tube multi-pass counter flow heat exchanger. Tap water was used as the coolant, which held the inlet temperature fluctuations to within $0.2^{\circ} \mathrm{C}$ during test runs. Detailed heat exchanger specifications are given in Appendix A.

The inside dimensions of the plenum measured $1.22 \mathrm{~m}$ in the flow direction, 1.22 $\mathrm{m}$ transverse to the flow, and $0.55 \mathrm{~m}$ high. The resulting cross-sectional flow area was $0.67 \mathrm{~m}^{2}$. Furthermore, the ratio of plenum flow area to test section flow area was 115:1. Normally, a ratio of 10:1 is considered acceptable for plenum design, so the size of this plenum was considered more than enough. It was suggested by Prausa [2004] that the flow area around the splash plate be twice the area of the plenum inlet pipe. With this constraint, the splash plate measured $0.50 \mathrm{~m}$ high and $1.20 \mathrm{~m}$ wide, making the splash 
plate aspect ratio approximately equal to the plenum open area aspect ratio. The splash plate was placed $0.20 \mathrm{~m}$ downstream of the plenum inlet and was bolted to aluminum angles for support. The heat exchanger was placed $0.60 \mathrm{~m}$ downstream of the plenum inlet. Finally, the inlet contraction of the test section was located about $0.30 \mathrm{~m}$ downstream of the heat exchanger. To obtain test section inlet temperatures, Type E thermocouples were fed through small brass tubes that projected up into the plenum between the heat exchanger and the test section inlet contraction. The test section will be described in detail in Section 3.2.

As shown in Figure 3-1, the flow rate measurement section was placed immediately downstream of the test section. Depending on the testing flow rate, either an orifice or venturi flow meter was used to measure the mass flow. The orifice flow meter was used in the range of $\operatorname{Re} \leq 17,500$ and the venturi flow meter was used in the range of $\operatorname{Re}>17,500$. An orifice flow meter was used at the low flow rates to give a higher pressure drop, which provided better resolution and accuracy when measuring low mass flows. Conversely, it was desired to limit the pressure drop caused by the flow meter at high mass flow rates. Based on preliminary design estimates, a tightly spaced pin fin array could cause substantial pressure drops comparable to the maximum delivery pressure available from the blower at high mass flows. To attain the maximum desired flow rate for tightly spaced pin fin arrays, a venturi meter was chosen for high mass flow measurements due to a low permanent loss characteristic.

For best flow rate measurement accuracy, the manufacturer suggested at least ten pipe diameters upstream and five pipe diameters downstream of the flow meter for flow development. However, the flow measurement system was installed with 15 pipe diameters upstream of the flow meter and eight pipe diameters downstream to be conservative. Both the venturi and orifice flow meters were manufactured by the Lambda Square Company of Babylon New York.

The orifice meter used in the tests was an Oripac Model 4150-P-06-2.500-150 and the venturi used was a Model 2300-06-3.58 flow meter. Figure 3-5 is a photograph of the flow meters to give a realistic perspective. Both flow meters were built to be interchangeable with the same flow development piping. The piping used in the flow measurement section was standard $15.2 \mathrm{~cm}$ schedule $40 \mathrm{PVC}$ pipe. Both flow meters 
were bolted between the inlet and outlet pipes by means of ASME 150\# flanges. Based on flow equations supplied by Lambda Square, the advertised accuracy of flow rate measurements was within $\pm 0.75 \%$ for the venturi and $\pm 0.6 \%$ for the orifice with no calibration [Lang, 2005]. This assumed proper installation. Typical characteristic curves, flow equations, and sample calculations are given in Appendix A for the orifice and venturi. One major convenience of using these particular flow meters was that the high and low pressure side pressure taps were built into the flanges of the flow meters. This eliminated the possibility of misplacing the pressure tap locations during installation.

To obtain mass flow rate measurements from the equations supplied by the manufacturer, the differential pressure, absolute pressure at the flow meter inlet, and the air temperature all had to be measured. The differential pressure across the flow meters was obtained with a Setra Model 264 differential pressure transducer. The transducer had a range of $0-1.25 \mathrm{kPa}$ with an accuracy of $\pm 0.25 \%$ of full scale [Setra Systems, 1998b]. The atmospheric pressure in the laboratory was measured with a Setra Model 370 barometric pressure gage. This absolute pressure gage had a range of $60-110 \mathrm{kPa}$ with an accuracy of $\pm 0.02 \%$ of full scale [Setra Systems, 1998a]. To obtain the absolute pressure at the inlet of the flow meter, the inlet pressure with respect to the atmospheric pressure was obtained with a Meriam 2110F differential pressure transducer with a $0-5$ $\mathrm{kPa}$ range and $\mathrm{a} \pm 0.1 \%$ of full scale accuracy [Meriam, 2004]. The air temperature was measured with a Type E thermocouple mounted just upstream of the flow meter.

Due to the necessary accuracy of the differential pressure measurement across the flow meter, the voltage signal from the Setra Model 264 transducer was captured and converted to pressure using National Instruments signal conditioning equipment and software. The signal conditioner used was an SCXI 1100 with an SCXI 1303 terminal block for connecting the transducer to the signal conditioner. Both the signal conditioner and terminal block were housed in an SCXI 1000 chassis. The analog signals were digitized utilizing a PCI-6034E 16 bit data acquisition card. The thermocouple signal was captured in the same way as the pressure signal except an SCXI 1102 instead of SCXI 1100 signal conditioner was used. The SCXI 1102 had a built in $2 \mathrm{~Hz}$ low pass filter to reduce unwanted noise and frequency content in the signal. This low cut-off frequency was desirable when capturing steady-state signals. National Instruments 
LabView software controlled the signal conditioning equipment. Both the Setra Model 370 barometric pressure gage and the Meriam 2110F differential pressure transducer had digital readouts to obtain the pressure data.

The piping section was comprised of the components of the test rig necessary to carry the flow from the discharge end of the flow measurement section back to the plenum to repeat the flow cycle. This section included the butterfly flow control valve, the blower, the regulator valves, and the return line. All these components are shown and labeled schematically in Figure 3-1 and in a photograph in Figure 3-3.

The blower was chosen primarily for its high static pressure rise characteristic. Preliminary design calculations indicated very high pressure drops through pin fin geometries previously tested in the VTExCCL at the desired flow rates required in this project. However, mass flow rates were small in the test section due to the narrow parallel plate test section configuration. Since a high flow rate was not a requirement, the blower was selected based on pressure rise capability. After comparing performance and cost data from various manufacturers, a Model D53-J4 high pressure low flow blower built by Chicago Blower was used in this project. The blower data sheet can be found in Appendix A. The blower was powered by a 3-phase, $460 \mathrm{~V} 11.2 \mathrm{~kW}$ Baldor electric motor. The motor was controlled by a Baldor Model ID15H415-E variable frequency drive, allowing blower speed adjustments of $0.01 \mathrm{~Hz}$ increments.

The purpose of the regulator valves was to regulate the operating pressure inside the closed loop flow system relative to the atmospheric pressure. Due to a thin non-rigid heater serving as the pin fin array endwall, the internal test section pressure had to be nearly equal to atmospheric to prevent the heater from bulging in or out. The heater will be discussed in greater detail in Section 3.3. Figure 3-6 gives a graphical explanation of the purpose of the regulator valves. As shown in the figure, the pressure at the discharge of the blower is some value above atmospheric pressure. Conversely, the pressure at the suction side of the blower is some value lower than atmospheric pressure. The regulator valves placed the zero pressure crossing point at the test section.

As an example, consider that the test section pressure is lower than atmospheric pressure and that both regulator valves are open, allowing the extra air that is pulled into the system at the suction of the blower to escape at the blower discharge. To raise the 
pressure in the test section, the valve on the discharge of the blower will be restricted and the valve on the suction side will be opened up. The reason this works is that air can be pulled more freely into the system through the suction valve. However, due to the extra restriction at the blower discharge valve, more pressure is required to remove the excess air from the internal loop. This effect raises the pressure at the discharge of the blower relative to atmospheric pressure.

The butterfly flow control valve was installed to adjust the operating point of the blower. During initial testing of the rig, it was suspected that running the blower too slowly would cause unsteadiness in the flow and the butterfly valve was installed to allow faster blower speeds at low flow rates. Later experience showed that using the variable speed drive provided sufficient flow control for testing.

\subsection{Test Section Design}

The test section was designed as a parallel plate channel with the purpose of measuring pin fin and endwall heat transfer from pin fin arrays. The flow area through the channel had a height of $0.95 \mathrm{~cm}$ and width of $61 \mathrm{~cm}$ across the span. The given dimensions resulted in an open duct hydraulic diameter of $1.87 \mathrm{~cm}$ with a width to height aspect ratio of 64:1. Figure 3-7 is a schematic showing the basic components of the test section used for endwall heat transfer and flow measurements. As shown in the figure, the flow entered the test section through the inlet contraction. Notice near the inlet of the test section, 60 grit sandpaper strips were placed. These strips were installed to promote uniform transition from laminar to turbulent flow across the span of the channel. The required flow development length in the test section was estimated by Equation 3-1:

$$
\mathrm{L}_{\mathrm{e}}=4.4 \mathrm{D}_{\mathrm{h}}(\mathrm{Re})^{1 / 6}
$$

where $D_{h}$ and Re are the open channel hydraulic diameter and Reynolds number respectively [Munson, et al., 2002]. Using Equation 3-1, the required maximum development length at $\operatorname{Re}=30,000$, was 24 hydraulic diameters. The length of 24 hydraulic diameters was allowed in the unheated development length of the channel. 
However to be conservative, there were 45 hydraulic diameters of hydraulic development length leading to the copper pin row.

After the unheated test section entrance region, the flow then passed over the heated region of the channel. This is also shown in Figure 3-9, which is a top view of the test section layout. In the heated region, a symmetric, constant heat flux boundary condition on the roof and floor was imposed by means of two pairs of resistive heaters in the streamwise direction. Thin poster board sheets were placed on the unheated section to prevent a step change in the flow path due to the heater thickness. Within the heated section, the flow passed by the cutaway region of the test section roof. The copper pin row was placed at the cutaway region to allow measuring the pin fin row endwall temperatures with an infrared camera. To prevent excessive thermal losses from the cutaway region, a zinc selenide window was installed to fill the void. Along with this window was an air gap, in which both served as additional thermal resistance. A detailed discussion of measuring the endwall temperatures with an infrared camera is presented in Section 3.3. During the heat transfer tests, both roof and floor were insulated to reduce heat loss.

Figure 3-8 is a schematic showing the basic components of the test section used for pin fin heat transfer and flow measurements. The balsa pin row represents the location of the pin fin row used when taking pin fin heat transfer measurements. In the balsa pin row, selected pin fins were constructed out of balsa wood wrapped with an inconel foil. Electrical current was passed through the foil to provide a constant heat flux boundary condition at the surface of the pin. Thermocouples were mounted underneath the foil to obtain surface temperature measurements for calculating heat transfer coefficients. The balsa pin row was moved downstream of the test section heaters to prevent conduction losses to the thin layer of copper deposited on the Kapton layer of the inconel heaters. Also note that the test section heaters were not turned on during the pin fin heat transfer tests. The balsa wood pins will be discussed in detail in Section 3.3. Also shown in Figure 3-9 is a scale drawing of the top view of the pin fin row layouts for both endwall and balsa wood pin fin heat transfer tests for the $S / d=4$ single row geometry. Note that the heater locations along with the cutaway region are shown in the figure. 
Pressure taps and thermocouples were installed in the duct wall upstream of the cutaway region of the test section to obtain friction factor and developing heat transfer measurements for facility benchmarking. The thermocouples were installed, alternating between the roof and floor to check for symmetry. Note that during the friction factor and pressure drop tests, the upstream heaters were removed to give more pressure data along the length of the channel. Section 3.3 presents a detailed discussion of the instrumentation used for the endwall and pin fin heat transfer measurements.

\subsection{Heat Flux Surfaces and Instrumentation}

The test section heaters used in this study were Kapinex, Model 117875-11245 rectangular shaped electrical resistance heaters manufactured by the Electro-Film Company of Valencia, California. The heaters were measured to be $61 \mathrm{~cm}$ wide and 29 $\mathrm{cm}$ long. When placed in the test section, the heaters covered the entire span of the channel and encompassed approximately 16 hydraulic diameters in the streamwise direction. Being rated at $1320 \mathrm{~W}$ each, the heaters were able to generate a maximum of $7400 \mathrm{~W} / \mathrm{m}^{2}$.

The heaters were comprised of serpentine inconel strips encapsulated by two layers of Kapton. The top layer of Kapton was also covered by a layer of copper. Figure 3-10 shows a sketch of a portion of the heater cross-section. Because of the space between the inconel strips, the copper layer was added to provide a more uniform heat flux distribution. However, the copper side of the heater was painted black to give a highly emissive surface for viewing with the infrared camera during endwall heat transfer tests. Consequently outside of the viewing area, it was also the copper side of the heater that had to be attached to the duct walls. The flow inside the test section was in contact with the Kapton side of the heater. According to the manufacturer, the adhesive used to make the composite of all components of the heater had the same approximate properties as Kapton. Although there were multiple layers used in building the heaters, the total thickness was only $254 \mu \mathrm{m}$.

The heaters were attached to the test section walls outside of the viewing area by means of Model 401B tape manufactured by the 3M Company. The tape had a paper substrate with both sides coated with a silicone based adhesive. The total tape thickness 
was $229 \mu \mathrm{m}$ and the rolls were $2.54 \mathrm{~cm}$ wide. The tape was also lined on the back side to prevent sticking on the roll. The tape adhered very well to both the MDF test section wall, and the copper layer on the surface of the heaters. However, upon removing a heater from the test section, the copper layer is destroyed due to strong adhesion between the tape and the copper. This drawback was considered acceptable since it was critical for the heaters to remain attached to the test section walls during testing.

To mount the heater on the test section surface, multiple spanwise strips of tape were placed along the surface to cover the entire area of the heater being installed. One heater required 12 strips of tape to cover the entire base. To begin the attachment process, the liner on the strip of tape at the leading edge of the desired heater location was removed. The heater was then aligned with the first strip of tape and carefully pressed into place. Then a roller was used to apply consistent compression to ensure a good bond. Having aligned the heater with the first strip of tape, the liner was removed from the second strip. The heater was then gently pressed into place and rolled in a similar manner as with the first strip of tape. This cycle was repeated until the entire heater was attached to the test section wall. Installing the heater in small increments prevented air from being trapped under the surface of the heater.

Each downstream heater was powered by a Lambda EMI Model GEN100-15 DC power supply rated at $1500 \mathrm{~W}$. The Lambda power supplies delivered regulated DC output voltages with a ripple of $\pm 8 \mathrm{mV}$ [Lambda Americas Inc., 2005]. Since only two Lambda power supplies were available for testing, a combination of Staco Energy Products Model 3PN1210B variable autotransformers and full wave bridge rectifiers built in the VTExCCL laboratory were used to power the upstream heaters. Each autotransformer and rectifier combination had a power rating of $1440 \mathrm{~W}$. Due to the unregulated output from the autotransformers, manual adjustments were made throughout the experiments to ensure that a constant heat flux was being supplied to the upstream heaters. The autotransformer and rectifier power supplies were only used during the developing duct flow benchmark heat transfer tests since that was the only time that the upstream heaters were used in this study so far.

Figure 3-11 presents a diagram of the heater and power supply hookup. A $1 \Omega$ precision resistor with $1 \%$ uncertainty was placed in series with the power supply and the 
heater to obtain a more precise measurement of the supply current. While testing, the voltage across the precision resistor was measured. Using the known precision resistor and heater resistances along with the measured voltage, the heater power was calculated using Equation 3-2:

$$
\mathrm{P}_{\text {heater }}=\left(\frac{\mathrm{V}_{\text {prec }}}{\mathrm{R}_{\text {prec }}}\right)^{2} \mathrm{R}_{\text {heater }}
$$

The precision resistor voltages for all three geometries tested were in the range of $2.8<$ $\mathrm{V}_{\text {prec }}<7.5 \mathrm{~V}$. Heater resistances were typically about $9.3 \Omega$. Using the power calculated for each test, the net heat flux entering the channel was calculated accounting for heat loss using Equation 3-3,

$$
\mathrm{q}_{\text {net }}{ }^{\prime}=\frac{\mathrm{P}_{\text {heater, total }}-\mathrm{q}_{\text {loss }} "\left(2 \mathrm{~L}_{\text {heater }} \cdot \mathrm{W}\right)}{2 \mathrm{~L}_{\text {heater }} \cdot \mathrm{W}+0.5 \mathrm{~N} \pi \cdot \mathrm{d}^{2}}
$$

where $\mathrm{L}_{\text {heater }}$ is the heater length in the streamwise direction, $\mathrm{W}$ is the heater width, $\mathrm{N}$ is the number of pins in the channel, and $\mathrm{d}$ is the pin diameter. The denominator defines the wetted area inside the channel. The loss heat flux was calculated knowing the temperature difference between the heater wall and ambient temperatures, and the associated thermal resistance. The test section heater operating conditions for all endwall tests are given in Table 3-1.

Also note the grounding symbol in Figure 3-11. To obtain accurate temperature measurements, it was necessary to ground the power supplies to the data acquisition system ground. If the power supply ground was left floating, significant bias was input into the thermocouple signals.

Referring back to Figure 3-7, the pin fin endwall measurements were made at the cutaway region of the test section roof. The heater that served as the viewing endwall of the pin fin row crossed over the cutaway region mostly unsupported. Only the pin fins provided support. To provide a thermal barrier against losses from the cutaway region, a zinc selenide window was installed to fill the void while leaving an insulating air gap. 
Losses were estimated to be under $5 \%$ at $\mathrm{Re}=5000$, becoming less with increasing Reynolds number. Zinc selenide was desirable due to its near constant radiation transmissivity over the infrared portion of the electromagnetic spectrum.

A ThermaCam P20 infrared camera manufactured by FLIR Systems AB. was used to obtain a temperature map across the exposed test section surface. Figure 3-12 shows a photograph of the infrared camera. Although not shown in Figure 3-7, the camera was placed on top of an enclosure that blocked out the surrounding light when capturing images. Each pixel of an infrared image represented a temperature. Since predicting the radiative properties of the surrounding test area was difficult, obtaining accurate absolute temperatures with the infrared camera alone was feasible only through image calibration. However, the strength of using an infrared camera was the sensitivity to temperature gradients. To obtain the calibration, thermocouples were mounted on the surface of the heater with Omegabond thermally conductive cement. The calibration process is discussed in Section 4.1 in greater detail. Type E thermocouples were mounted on the outside of the MDF duct wall to allow loss corrections according to Equation 3-3.

To obtain reliable endwall heat transfer measurements, it was important to maintain thermal contact between the pin fins and the test section heaters. To do so, the copper pins were first attached to the test section roof heater in the proper configuration across the entire span at the cutaway region. This operation was done before attaching the test section roof to the floor. The pins were attached rigidly to the roof heater using Duralco 132 thermally conductive epoxy manufactured by the Cotronics Company. After the epoxy cured, Omegatherm thermally conductive silicone paste manufactured by Omega Engineering was applied to the opposite side of the pin fins. The silicone paste did not cure to form a rigid bond. Since the test section roof was removable, it was necessary for one side of the pin fin heater interface to be temporary. After applying the silicone paste, the test section roof was assembled to the floor. Figure 3-13 summarizes the pin fin attachment method. As shown in the figure, the conductive epoxy provided thermal contact on the viewing side of the pin fin while silicone paste provided thermal contact on the test section floor side. Figure 3-14 is a photograph of the pins attached to 
flow side of the test section roof before assembly. The geometry shown is the single row $\mathrm{S} / \mathrm{d}=4$ configuration.

The balsa wood pin fin measurement method involved wrapping a $25.4 \mu \mathrm{m}$ thick inconel foil around a balsa wood pin fin, with the foil serving as a resistance heater. Type E thermocouples were installed under the surface of the foil at the leading, side, and trailing edges of the pin fin. Figure 3-15 is a diagram showing all the components of a balsa wood pin fin. Figure 3-16 shows a photograph of a balsa wood pin to give a realistic perspective.

The first step to build a balsa wood measurement pin was to carve a piece of balsa wood into a cylinder with the correct height and diameter. The diameter of the balsa wood pin was slightly undersized to compensate for the thickness of the inconel foil and adhesive, giving a combined diameter of $0.95 \mathrm{~cm}$. The pin height was also $0.95 \mathrm{~cm}$, equaling the channel height. Grooves were carved into the side of the pin to allow the thermocouples to be placed flush with the surface of the pin. The thermocouples were attached to the balsa wood using Devcon 5 Minute Epoxy, with the beads being at the pin midplane. Thermally conductive, Omegatherm silicone paste was then applied to the surface of the thermocouple beads to give thermal contact with the inconel foil once installed. The inconel foil was sized and measured in order to wrap around the pin, while leaving a gap where the heater leads were installed. This forced the electrical current to pass through the inconel foil, around the circumference of the pin. The heater leads were soldered to both ends of the foil. Grooves were cut into the balsa wood for the leads to lay under the surface, giving a smoother fit between the foil and the balsa wood. Devcon 5 Minute Epoxy was used to attach the foil to the balsa wood.

Before assembling the test section, the balsa wood pins were attached to the roof using clear silicone adhesive manufactured by GE. Omegatherm silicone paste was applied to the other end of the pin to fill a possible air gap between the balsa pin and the test section floor. This attachment method is shown in Figure 3-17. The wires were attached to the test section wall using $68.5 \mu \mathrm{m}$ thick Kapton tape in a way to reduce flow disturbances. Figure 3-18 presents the wiring arrangement inside the channel. As shown in the figure, the heater leads were positioned $180^{\circ}$ opposite the side thermocouple. Using this arrangement, the leading, trailing, and left sides of the pin fin were used to 
gather temperature data. To check for measurement sensitivity to the wiring arrangement, sample measurements were taken with the bend in the upstream thermocouple wire 2.54 $\mathrm{cm}$, and $7.62 \mathrm{~cm}$ upstream of the pin fin. The measurements were insensitive to the placement of the bend.

Due to small variations in the size of the inconel foil strips, the electrical resistance had to be measured for each pin fin. Each balsa wood pin was hooked up in series with one of the Lambda GEN100-15 DC power supplies (power supplies that powered the test section heaters) and four $1 \Omega$ precision resistors, similar to the test section heater hookup shown in Figure 3-11. Four precision resistors instead of one were used to increase the voltage drop in the circuit to improve the power supply resolution. While running the power supply, the voltage was measured across one precision resistor (the others were checked for repeatability) and the inconel foil. Using both voltages and the known resistance of the precision resistor, the resistance of the inconel foil was calculated using Equation 3-4:

$$
\mathrm{R}_{\text {foil }}=\left(\frac{\mathrm{V}_{\text {foil }}}{\mathrm{V}_{\text {prec }}}\right) \mathrm{R}_{\text {prec }}
$$

To run pin fin heat transfer tests, the balsa pins were hooked up in exactly the same way as when measuring the inconel foil resistances. Using the measured precision resistor voltage and the known inconel foil and precision resistance values, the power supplied to the inconel foil was given by Equation 3-5:

$$
\mathrm{P}_{\text {foil }}=\left(\frac{\mathrm{V}_{\text {prec }}}{\mathrm{R}_{\text {prec }}}\right)^{2} \mathrm{R}_{\text {foil }}
$$

The inconel foil voltages measured during testing were in the range of $2<\mathrm{V}_{\text {prec }}<3.1 \mathrm{~V}$. Typical inconel foil resistances were about $0.12 \Omega$. Moreover, the heat flux was calculated using Equation 3-6: 


$$
\mathrm{q}^{\prime \prime}=\frac{\mathrm{P}_{\text {foil }}}{\mathrm{A}_{\text {foil }}}
$$

For the balsa wood pin fin tests, the test section was considered adiabatic. The typical inconel foil surface area was about $2.53 \times 10^{-4} \mathrm{~m}^{2}$. The inconel foil operating conditions for all pin fin heat transfer tests are given in Table 3-2.

It was not known whether or not mounting the balsa pins on the test section heaters would cause significant conduction loss to the thin copper layer deposited on the heater surface. To investigate this question, pin heat transfer measurements were taken from the $\mathrm{S} / \mathrm{d}=2$ geometry with the row located both up and downstream of the test section heaters. Tests were taken over the entire Reynolds number range for both cases. The results are shown in Figure 3-19 with $\mathrm{Nu}_{\mathrm{d}}$ plotted against $\mathrm{Re}_{\mathrm{d}}$. As shown in the figure, there is a noticeable difference in the results based on the pin row location, indicating a conduction error due to the copper on the surface of the test section heaters. As a result of this test, the pin fin row was placed downstream of the heated section for the rest of the balsa wood pin fin heat transfer tests.

All thermocouple signals for both endwall and pin fin heat transfer tests were captured using National Instruments signal conditioning hardware and software. The signal conditioner used was an SCXI 1102 with a built in $2 \mathrm{~Hz}$ low pass filter for measuring steady state temperatures. An SCXI 1303 terminal block was used to connect the thermocouples to the signal conditioner while providing cold junction compensation for the temperature measurements. Both the signal conditioner and terminal block were housed in an SCXI 1000 chassis, the same chassis used for capturing mass flow data. The conditioned analog temperature signals were digitized along with the mass flow rate measurement signals using a PCI-6034E 16 bit data acquisition card. LabView software was used to control the signal conditioning hardware. The infrared camera required no external equipment to capture data. However, the images did require post processing and this is discussed in detail in chapter 4.

Two alternative pin fin heat transfer measurement methods were examined that used thermally conducting copper pins instead of non-conducting balsa wood pins. Neither method yielded accurate results. Although this section of the thesis is focused on 
heat flux surfaces and instrumentation and not data analysis, the analysis methods were related to why the measurement methods failed and will be presented here along with instrumentation.

The first alternative pin surface measurement method involved mounting a thermocouple in the center of a copper pin fin to obtain an average temperature. These measurements were taken simultaneously with the endwall pin fin measurements with the infrared camera. Figure 3-20 diagrams the method in which the thermocouple was installed in the pin fin. First, a $1.6 \mathrm{~mm}$ hole was drilled in the center of the pin just past the midline point. Then, a slot $1.6 \mathrm{~mm}$ wide and $0.8 \mathrm{~mm}$ deep was machined on the base of the pin from the edge of the hole to the edge of the side wall of the pin fin. This combination of hole and slot gave room for the thermocouple to be placed in the center of the pin fin with the wire folded over to allow a snug fit between the pin fin and the test section roof and floor. To ensure thermal contact between the pin fin and the thermocouple, Omegabond thermally conductive cement was applied to the inside of the hole and along the slot. These pin fins were mounted to the heater surfaces the same way the other copper pin fins were installed.

Using the assumption that the copper pin was isothermal, pin heat transfer coefficients were calculated using Equation 3-7:

$$
\mathrm{h}=\frac{\mathrm{q}_{\text {pin }}}{\mathrm{T}_{\text {pin }}-\mathrm{T}_{\text {bulk }}}
$$

where $\mathrm{q}_{\text {pin }}$ " is the pin heat flux, $\mathrm{T}_{\text {pin }}$ is the pin temperature, and $\mathrm{T}_{\text {bulk }}$ is the bulk fluid temperature. Due to the pin wetted area exposed to the flow being different than the base area, the pin heat flux was not equal to the heat flux generated by the bounding test section endwall heaters. The pin heat flux was determined accounting for losses using Equation 3-8:

$$
\mathrm{q}_{\text {pin }} "=\frac{\mathrm{P}_{\text {heater, total }}-\mathrm{q}_{\text {loss }} "\left(2 \mathrm{~L}_{\text {heater }} \cdot \mathrm{W}\right)}{2 \mathrm{~L}_{\text {heater }} \cdot \mathrm{W}+0.5 \mathrm{~N} \pi \cdot \mathrm{d}^{2}}\left(\frac{\mathrm{A}_{\mathrm{b}}}{\mathrm{A}_{\text {wet, pin }}}\right)
$$


where $A_{b}$ is the cross-sectional area of the base of the pin, and $A_{w e t, p i n}$ is the wetted area of the pin exposed to the flow. This equation was based on the assumption that the heat entering the pin was due only to the heat generated by the test section heaters over the base area of the pin fins. Furthermore, all heat flux generated by the heaters surrounding the pins was assumed to enter the flow. To summarize, transverse heat conduction on the heater surface surrounding the pin fins was assumed negligible.

Pin surface measurements were taken for the $\mathrm{S} / \mathrm{d}=2$, single row geometry throughout the entire Reynolds number range. To investigate the validity of the measurement method, a comparison was made with data from the literature. Data from the first row of multiple row array studies were used. This comparison is shown in Figure 3-21. Comparing the results as $\mathrm{Nu}_{\mathrm{d}}$ versus $\mathrm{Re}_{\mathrm{d}}$, the embedded thermocouple technique severely under-predicted the pin surface heat transfer through most of the Reynolds number range. Even considering that the geometry in this study was somewhat different than the geometries from the literature, the results seemed unreasonable. All data from the literature represented in Figure 3-21 were average Nusselt number values around the circumference of the pin. Note that the data from Chyu et al. [1998a] was given as a corrrelation. The data from both Ames et al. [2004], and Metzger et al. [1982b], was originally presented in the literature in the form of circumferential midline heat transfer measurements. This circumferential data was numerically integrated to obtain the data points given in Figure 3-21.

An analytical method was also used to evaluate the pin surface heat transfer using data from copper pins. This method accounted for a temperature profile along the length of the pin, but assumed no radial gradients. Base temperatures of the pin fins were readily available from the calibrated infrared images captured during the pin fin array endwall tests. The analytical methodology was adopted from Incropera \& DeWitt [2002], for steady state heat transfer from extended surfaces of uniform cross-section with an adiabatic tip. The adiabatic tip assumption arose from symmetrically heating the pins from both endwalls, giving an adiabatic condition at the pin midplane.

The total heat rate entering the pin was given by Equation 3-9: 


$$
\mathrm{q}_{\mathrm{pin}}=\sqrt{\mathrm{hPk}_{\mathrm{pin}} \mathrm{A}_{\mathrm{b}}}\left(\mathrm{T}_{\mathrm{b}}-\mathrm{T}_{\text {bulk }}\right) \tanh \left(\mathrm{mL}_{\mathrm{pin}} / 2\right)
$$

where $\mathrm{P}$ is the pin perimeter, $\mathrm{k}_{\mathrm{pin}}$ is the pin thermal conductivity, $\mathrm{T}_{\mathrm{b}}$ is the temperature at the base of the pin, $\mathrm{L}_{\mathrm{pin}} / 2$ is half the pin height, and $\mathrm{m}$ is defined by Equation 3-10:

$$
\mathrm{m}=\sqrt{\frac{\mathrm{hP}}{\mathrm{k}_{\text {pin }} \mathrm{A}_{\mathrm{b}}}}
$$

Other terms have already been defined. In both Equations 3-9 and 3-10, all values were known from gathered data except $h$. Finding $h$ required iteration until the right hand side of Equation 3-9 matched the total rate of heat entering the pin, which was considered a known value. The basic assumption when determining the heat rate entering the pin fin was that only heat generated at the base of the pin, entered the pin. In a similar manner as with the embedded thermocouple measurement technique, this again assumed no transverse heat flow across the heater adjacent to the pin fin.

This method was used to re-analyze the pin surface data for the $\mathrm{S} / \mathrm{d}=2$ single row geometry at $\operatorname{Re}=13,000$. Since pin endwall and embedded thermocouple data were taken simultaneously for the $\mathrm{S} / \mathrm{d}=2$ geometry, it was convenient to make a direct comparison of the two analysis methods to check whether or not the new method improved the results. Unfortunately, the analytical method yielded results very similar to the embedded thermocouple method. For the $\mathrm{Re}=13,000$ case, the embedded thermocouple technique yielded $\mathrm{Nu}_{\mathrm{d}}=31.9$, while the analytical method gave $\mathrm{Nu}_{d}=29.7$. It was shown that both methods severely under-predicted pin surface heat transfer.

The assumptions used in determining the pin surface heat transfer were questioned due to poor agreement with data from the literature. In particular, it was questioned whether or not it was valid to assume zero transverse heat conduction across the heater when calculating the pin endwall heat rate from the test section heaters. To answer this question, a numerical investigation was done using ANSYS for four separate models. All four models examined half a pin fin with an adiabatic tip symmetry condition. This was considered valid due to symmetric heating from both pin endwalls. 
It must be noted that these models were intended to be used for qualitative purposes only, and the results are not considered accurate pin heat transfer predictions.

The first model served as a baseline for the other models. A single pin was modeled in this case along with a layer of Kapton on one endwall. A layer of copper was also modeled on the surface of the Kapton. This configuration simulated a single pin fin with the test section heater attached to the surface. The heater area surrounding the pin was not included for this model. However, the second model examined a rectangular section of a heater with a pin fin attached at the center. In this model, the heater area was five pin diameters long and two pin diameters wide. Two pin diameters represented one pin span for the $\mathrm{S} / \mathrm{d}=2$ single row geometry, a symmetry condition. Using five pin diameters for the heater length gave enough distance to see the temperature gradient up and downstream of the pin disappear. The third model had the same dimensions of the second model except the copper layer on the surface of the Kapton was not included. This model was used to check whether or not the copper on the surface of the Kapton was causing conduction effects. The fourth model was a replica of the second model, but the boundary conditions were different. The first three models used the same boundary conditions. The pin surface temperature was the variable of interest for all models. Figures 3-22 through 3-25 are three-dimensional contour plots of the results, but also indicate where the boundary conditions were applied and dimensions.

For all simulations, a constant heat flux boundary condition was applied to the outer heater surface. A convective boundary condition was applied to both the pin and endwall to simulate the flow. As already stated, the pin tip was adiabatic. Estimates for the pin and endwall heat transfer coefficients were based on correlations from Chyu et al. [1998a] at $\mathrm{Re}_{\mathrm{d}}=13,000$. Table 3-3 lists the boundary conditions, thermal properties, key dimensions, and resulting steady state pin surface temperatures for all four models.

The results of the first model are shown in Figure 3-22. The figure presents a surface temperature contour plot of the three-dimensional model. As mentioned already, the heater surrounding the pin was not included. The applied heat flux and convective boundary conditions resulted in a pin temperature of $26.4^{\circ} \mathrm{C}$. Due to the high thermal conductivity of copper, there was no apparent temperature gradient on the pin surface. 
Figure 3-23 shows the results from the second model, which included the heater surrounding the pin. With the same applied heat flux and pin heat transfer coefficient, the pin temperature was $30.5^{\circ} \mathrm{C}$. This elevated pin temperature indicated that additional heat was being added to the pin, most definitely from the surrounding heater area. Also note the temperature gradient on the heater surface, indicating heat flow towards the pin.

Figure 3-24 presents the results of model three, which excluded the copper layer on the heater. The pin temperature was $26.8^{\circ} \mathrm{C}$, which was almost equal to the pin temperature from model one. This indicated that significant heat was not flowing from the surrounding heater area into the pin. Since models two and three were nearly identical except for the copper layer, it followed that the additional heat flux flowing into the pin was indeed due to the copper layer on the surface of the heater.

Figure 3-25 presents the results of model four. This model was identical to model two except the heat transfer coefficients were iterated until the pin temperature matched the pin temperature from model one, which had no surrounding heater. Scaling both the pin and endwall heat transfer coefficients equally, it required a $60 \%$ increase to force the pin temperature to equal the model one pin temperature. This model gave insight into the possible magnitude of measurement errors when assuming no transverse heat conduction across the heater surface. Referring back to Figure 3-21, percent differences were consistent when comparing the embedded thermocouple measurement technique against data from the literature.

In summary, the first ANSYS model did not include the heater surrounding the pin fin. This served as a baseline for the other models. To check for transverse conduction effects, the second model included the heater surrounding the pin fin. The resulting pin fin temperature was higher, indicating significant conduction effects surrounding the pin. The third model also included the surrounding heater, but the copper layer on the heater was not included. The resulting pin temperature was nearly equivalent to the original baseline temperature from model one that did not model the surrounding heater. Thus, the conduction effects were isolated to the thin copper layer on the surface of the heater. Finally, the fourth model also included the heater surrounding the pin fin with the copper layer on the heater surface, but the boundary conditions were 
iterated till the pin temperature matched the original baseline temperature. This gave insight into the size of errors that might be expected due to conduction effects.

\subsection{Testing Procedure}

To perform pin fin endwall heat transfer experiments, the zero points on the pressure transducers were first checked and set to zero if necessary. Next, the heat exchanger water supply was turned on and the blower was started and set to the required flow setting. At this point, the zinc selenide window was not installed. The reason was that the pressure in the test section had to be checked. The pressure was checked visually and by feeling of the test section heater that crossed the cutaway region.

The test section pressure was important due to the heater crossing the unsupported span of the cutaway section. Because the heater was non-rigid, too much positive pressure in the test section caused the heater to push out and lift the pins off of the test section floor. This condition was most easily found by feeling of the test section but was also noticeable visually. In addition, the condition was noticeable with the infrared camera. Figure 3-26 is a sample of an infrared image with the pin fins lifted off. Notice in the image that the temperature patterns downstream of the pin row are not periodic across the span of the image. Instead, the downstream wake pattern is in the shape of an arc. To correct the problem, the regulator valves up and downstream of the blower were adjusted according to the method described in Section 3.1 until the pins were seated down on the test section floor. Figure 3-27 is a sample of an infrared image with proper test section pressure and the pins properly seated. In comparison with Figure 3-26, the flow uniformity was much improved across the span of the image.

After setting the flow and checking the test section pressure, the zinc selenide window was installed and the endwall heaters were turned on. The heaters were set so the minimum temperature difference between the heater and bulk flow in the channel was no less that $10^{\circ} \mathrm{C}$ to maintain low uncertainty when calculating heat transfer coefficients. Note that during pin endwall heat transfer tests, the upstream heaters were not turned on. This was done to be consistent with pin fin array testing procedures found in the literature, since most heated tests are performed with the thermal boundary layer beginning immediately upstream of the pin fin array. For these tests, the pin row was placed five 
hydraulic diameters downstream from the leading edge of the heaters as indicated in Figure 3-7.

The test section was then insulated with $5.1 \mathrm{~cm}$ thick extruded polystyrene insulation and the rig was given time to reach steady state. In Figure 3-7, no insulation was shown covering the infrared viewing area of the test section. However, during the transient period, the cutaway region was covered like the rest of the test section. Only during data collection was the insulating cover removed from the infrared viewing area. Starting from uniform ambient temperature, typical transient times were about 3.5 hours. All thermocouple measurements were charted continuously while testing using National Instruments LabView software. When the test was near steady state, temperature and flow measurement data was captured to check the Reynolds number and the flow was modified if necessary. After checking the flow, and when the temperatures stopped climbing and began alternating around a mean value, the test section was assumed to be at steady state.

Measurements were made upon reaching steady state. Flow measurement and temperature data was captured using LabView for approximately one minute before removing the insulation to take infrared images. Also after starting the data collection process, the precision resistor voltage was checked manually with a multimeter. For each test, five infrared images were taken to give reduced measurement uncertainty. It took approximately 30 seconds to obtain the five images while still capturing temperature and flow measurement data. Temperature changes with the insulation removed were negligible. After the infrared data was taken, the insulation across the infrared viewing area was replaced, and flow and temperature data was taken for approximately 1 more minute. After each data set, the flow and heater settings were reset, and the rig was allowed to reach steady state for a new case. However, after running the first case of the day, only about one hour of transient time was necessary to go to a new steady state when test cases were changed.

The testing procedure was different for the balsa pin heat transfer tests. To begin the tests, the pressure transducer zero points were checked and adjusted if necessary. The water supply for the heat exchanger and blower were then turned on, and the flow was set to the desired setting. Unlike the pin fin endwall tests, the balsa pin row was installed 
downstream of the test section heaters. As a result, the pin fin row was bounded by the rigid test section walls and the operating pressure was not critical as with the endwall tests.

After setting the flow, the inconel foil heaters surrounding the balsa wood pins were powered up and set to the required setting. These heaters were set to give at least a $10^{\circ} \mathrm{C}$ temperature difference between the pin surface and the bulk flow temperature.

Note that the test section endwall heaters were not turned on during these tests. The test section was then insulated with the same insulation used during the pin fin endwall tests, and the rig was given time to reach steady state. While reaching steady state, flow data was captured at different times in order to check the Reynolds number. Blower speed adjustments were made as needed for corrections.

Starting from uniform ambient temperature, the typical transient time was about 2.5 hours. All temperatures were charted continuously using LabView software. Steady state was assumed when the system temperatures stopped climbing and began alternating around mean values. Upon reaching steady state, both flow and temperature data was recorded for about two minutes using LabView. During this time, the precision resistor voltage was checked manually with a multimeter. After collecting data, the flow and inconel heater settings were adjusted for the next test case. Being about 30 minutes, transient times were much shorter between test cases for the balsa pin tests.

\subsection{Facility Benchmarking}

The facility was benchmarked to check the assumptions made during the design process. Inside the test section, it was desired to have a periodic, hydrodynamically fully developed flow entering the pin fin row. To verify fully developed flow in the channel, pressure measurements were taken along the centerline in the streamwise direction to see the point where the pressure gradient became linear, with a linear pressure gradient indicating fully developed flow. Using the fully developed pressure gradient for different flow settings, Moody friction factors were calculated across the entire flow range. The Moody friction factor is defined by Equation 3-11: 


$$
f=\frac{-\left(\frac{d p}{d x}\right) D_{h}}{0.5 \rho \cdot U^{2}}
$$

Pressure taps were installed across the span of the channel five hydraulic diameters upstream of the first set of heaters to check the spanwise flow uniformity. The plenum pressure was taken to be the reference pressure for all measurements. Line plots showing the spanwise endwall heat transfer distribution downstream of the pin row were obtained from the infrared data, and also were a good indicator of spanwise uniformity. As an additional check of the quality of the duct, developing Nusselt number profiles were measured along the streamwise length of the upstream heaters. The fully developed Nusselt number for each case was estimated using the last three thermocouple measurements along the heaters.

For the heat transfer benchmarking calculations, Nusselt numbers were defined by Equation 3-12:

$$
\mathrm{Nu}=\left(\frac{\mathrm{q}_{\text {net }} "}{\mathrm{~T}_{\text {corr }}-\mathrm{T}_{\text {bulk }}}\right) \frac{\mathrm{D}_{\mathrm{h}}}{\mathrm{k}}
$$

The heat flux value given in Equation 3-12 was calculated using the method of Equation 3-3. The variable $\mathrm{T}_{\text {corr }}$ represents the heater wall temperature that was corrected for conduction across the heater thickness. For the line plots showing the spanwise uniformity downstream of the pin row, the Nusselt numbers were normalized by Equation (3-13)

$$
\mathrm{Nu}_{0}=0.022 \mathrm{Re}^{0.8} \operatorname{Pr}^{0.5},
$$

a correlation given by Kays and Crawford [1980] predicting the turbulent fully developed heat transfer in an open channel or duct. Having a constant heat flux boundary condition, $\mathrm{T}_{\text {bulk }}$ was obtained from an energy balance in the duct according to Equation 3-14: 


$$
\mathrm{T}_{\text {bulk }}=\mathrm{T}_{\mathrm{in}}+\frac{\overline{\overline{\mathrm{Q}_{\text {net }}}}}{\overline{\mathrm{mC}_{\mathrm{p}}}}\left(\frac{\mathrm{x}}{\mathrm{L}_{\text {heater }}}\right)
$$

where $\overline{\overline{\mathrm{Q}_{\text {net }}}}$ is the average net heat entering the channel, $\mathrm{x}$ is the streamwise distance to the measurement location from the leading edge of the heaters, $\mathrm{L}$ is the streamwise heater length, and $\mathrm{T}_{\text {in }}$ is the channel inlet temperature.

Figure 3-28 is a plot that shows an example of a developing pressure profile along the length of the channel at $\mathrm{Re}=13,000$. All Reynolds numbers across the testing range had similar developing pressure distributions. As shown on the plot, the flow became fully developed well upstream of the first set of heaters. The second set of heaters where the pin fin rows were installed, were located downstream of the plotted area. Note that neither the upstream heaters nor the duct liners were in the channel during the pressure measurement tests. This was necessary for correct pressure tap installation.

The friction factor data obtained from the developing pressure profile tests are shown in Figure 3-29. In the figure, the friction factor results are compared with data from the literature. Two correlations were used for the comparison, one for both low and high Reynolds numbers as given by Kakac et al. [1987]. As shown in the figure, the measured friction factor data agreed quite well with the published correlations. Within the range where the two correlations overlapped, the measured data fell between them.

Figure 3-30 is a plot displaying the spanwise flow uniformity across the test section. The plot was produced by first obtaining the differential pressure measurements between the plenum and each spanwise pressure tap and calculating the mean value. Then, the difference between the mean differential pressure and the pressure differential at each tap location was normalized by the channel dynamic pressure, and plotted as a function of tap location. This test was repeated across the entire Reynolds number range. As shown in the figure, there was little variation across the span, indicating uniform flow entering the test section.

Figure 3-31 shows spanwise Nusselt number line plots taken one and five pin diameters downstream of the trailing edge of the pin row for the $\mathrm{S} / \mathrm{d}=2,4$, and 8 single row geometries at $\mathrm{Re}=13,000$. To produce the plots, data was taken over an equal span 
in physical dimensions for all three geometries with a pin fin in the center. However, fewer pins were in the image as the pin spacing increased. That is the reason the individual plots are shorter as the spacing increases. As shown in the figure, the data are periodic across the span, and the magnitudes are balanced between the right and left hand sides of the plots. These spanwise heat transfer measurements indicate periodic and uniform flow across the span of the test section downstream of the pin row.

Figure 3-32 is a plot of developing Nusselt numbers for two different flow cases on the upstream heaters. The results are compared with predictions from Equation 3-13. Although both trends are above the predicted values, they still have reasonable agreement, with the low flow case $7.8 \%$ and the high flow case $5.6 \%$ higher than the correlation. Also of interest when obtaining the Nusselt number profiles was the symmetry between the test section roof and floor. Although the plots were not smooth curves, there was no obvious trend of the roof producing higher Nusselt numbers than the floor of the test section, or vice versa.

This combination of flow and heat transfer tests was necessary to verify satisfactory conditions inside the test section. The data indicated that the flow became hydrodynamically fully developed well upstream of the pin row. Spanwise pressure and heat transfer measurements indicated uniform flow across the span of the channel. Thus, the test section design was considered validated.

\subsection{Experimental Uncertainty}

Uncertainty analyses were carried out to quantify how well the experimental data represent the actual heat transfer values. Due to the small number of experiments for each data set, the method described by Moffat [1985] for single sample measurement uncertainty was used to carry out the analyses. This method can best be described by examining Equation 3-15:

$$
\mathrm{u}_{\mathrm{R}}= \pm \sqrt{\sum_{\mathrm{i}=1}^{\mathrm{n}}\left(\frac{\partial \mathrm{R}}{\partial \mathrm{x}_{\mathrm{i}}} \mathrm{u}_{\mathrm{x}_{\mathrm{i}}}\right)^{2}}
$$


where $u_{R}$ is the uncertainty of the variable of interest, $R, x_{i}$ is one of the measured variables necessary to obtain the value of $R$, and $u_{x_{i}}$ is the uncertainty of $x_{i}$. The partial derivative term in equation 3-15 represents a sensitivity index of the output $R$ to the variable $x_{i}$. When the partial derivative term is evaluated at $x_{i}$ and multiplied by $u_{x_{i}}$, it represents the uncertainty of $\mathrm{R}$ due to the uncertainty of the measured variable $\mathrm{x}_{\mathrm{i}}$. For many experiments, multiple measurements are required to obtain a desired output. As shown in equation 3-15, the total uncertainty of the variable $\mathrm{R}$ is the square root of the sum of the individual uncertainty contributions squared. This accounts for the propagation of experimental error due to the uncertainty of several measured variables.

For the present experiments, each variable for which the uncertainty was desired was written in terms of the measured variables. The partial derivatives of Equation 3-15 were approximated using the sequential perturbation method. This method first involved computing the desired output based on the nominal measured values. Then, each measured variable was increased by its uncertainty while holding the other variables constant. The absolute value of the difference between the nominal and altered outputs was recorded. Similarly, each measured value was decreased by its uncertainty while holding the other measured values constant, again, recording the absolute value of the difference between the nominal and altered outputs. The average of the differences yielded the uncertainty of the desired output variable due to the uncertainty of each measured variable. The total uncertainty was calculated using the root-sum-square (RSS) method as shown in Equation 3-15.

The above described method was used to calculate the experimental uncertainty for the open channel Reynolds number, $\mathrm{Re}$, the pin fin Nusselt number, $\mathrm{Nu}_{\mathrm{d}}$, the open channel Nusselt Number on the endwalls, $\mathrm{Nu}$, and finally the heat transfer augmentation, $\mathrm{Nu} / \mathrm{Nu}_{0}$. The results are presented in Table 3-4. To obtain a range of uncertainty, the calculations were carried out at both low and high Reynolds numbers. Note that heat transfer measurements were taken at different locations on both the pin fins and endwalls for each data set. As a result, uncertainty calculations were carried out at both low and high Nusselt numbers to obtain a range of uncertainty for both low and high Reynolds numbers. Uncertainties of the measured variables used to obtain the data of Table 3-4 are 
presented in Appendix C, along with the uncertainty equations used for each measurement.

As shown in Table 3-4, the Reynolds number uncertainty was relatively low at $1.7 \%$ and $0.9 \%$ for $\operatorname{Re}=5013$ and 30,484 respectively. Most of the uncertainty arose from the flow meter calibration uncertainty and the differential pressure reading across the meter. Being less than 5\% at all cases examined, the pin fin uncertainty was considered acceptable. Also shown in Table 3-4, the endwall Nusselt numbers had higher uncertainty than the pin fin Nusselt numbers. The primary reason is that there were more measured variables required to calculate the endwall as opposed to the pin fin heat transfer. A significant part of the endwall Nusselt number uncertainty arose from IR image calibration, which was not necessary for the pin fin heat transfer experiments. Although higher than for the pin fins, the endwall uncertainty is still reasonable at a maximum of $7.5 \%$. As a final note, the uncertainty of the heat transfer augmentation was slightly higher than the endwall heat transfer uncertainty. The reason is that the Reynolds number, which also has uncertainty, was used to calculate $\mathrm{Nu}_{0}$, the fully developed open channel heat transfer prediction. Thus, when calculating the endwall heat transfer augmentation, $\mathrm{Nu} / \mathrm{Nu}_{0}$, the uncertainty must be greater than the uncertainty of $\mathrm{Nu}$ alone. 
Table 3-1 Heater Operating Conditions for Single Pin Row Endwall Tests

\begin{tabular}{|c|c|c|c|c|c|c|}
\hline \multirow{2}{*}{ Re } & \multicolumn{2}{|c|}{$\mathbf{S} / \mathbf{d}=\mathbf{2}$} & \multicolumn{2}{c|}{$\mathbf{S} / \mathbf{d}=\mathbf{4}$} & \multicolumn{2}{c|}{$\mathbf{S} / \mathbf{d}=\mathbf{8}$} \\
\cline { 2 - 7 } & $\mathbf{V}_{\text {prec}}, \mathbf{V}$ & $\mathbf{P}_{\text {heater, }} \mathbf{W}$ & $\mathbf{V}_{\text {prec}}, \mathbf{V}$ & $\mathbf{P}_{\text {heater }}, \mathbf{W}$ & $\mathbf{V}_{\text {prec}}, \mathbf{V}$ & $\mathbf{P}_{\text {heater }}, \mathbf{W}$ \\
\hline 5000 & 3.9 & 139 & 3.7 & 125 & 2.8 & 72 \\
\hline 7500 & 4.4 & 177 & 4.2 & 160 & 3.3 & 99 \\
\hline 10000 & - & - & 4.6 & 194 & 3.7 & 125 \\
\hline 13000 & 5.4 & 266 & 5.1 & 243 & 4.1 & 154 \\
\hline 17500 & 6.1 & 339 & 5.8 & 309 & 4.6 & 195 \\
\hline 25000 & 6.8 & 423 & 6.7 & 407 & 5.3 & 259 \\
\hline 30000 & 7.5 & 525 & 7.2 & 472 & 5.7 & 301 \\
\hline
\end{tabular}

Table 3-2 Inconel Foil Operating Conditions for Balsa Wood Pin Fin Tests

\begin{tabular}{|c|c|c|c|c|c|c|}
\hline \multirow{2}{*}{ Re } & \multicolumn{2}{|c|}{$\mathbf{S} / \mathbf{d}=\mathbf{2}$} & \multicolumn{2}{c|}{$\mathbf{S} / \mathbf{d}=\mathbf{4}$} & \multicolumn{2}{c|}{$\mathbf{S} / \mathbf{d}=\mathbf{8}$} \\
\cline { 2 - 7 } & $\mathbf{V}_{\text {prec }}, \mathbf{V}$ & $\mathbf{P}_{\text {foil }}, \mathbf{W}$ & $\mathbf{V}_{\text {prec }}, \mathbf{V}$ & $\mathbf{P}_{\text {foil }}, \mathbf{W}$ & $\mathbf{V}_{\text {prec }}, \mathbf{V}$ & $\mathbf{P}_{\text {foil }}, \mathbf{W}$ \\
\hline 5000 & 2 & 0.47 & 2 & 0.47 & 2 & 0.47 \\
\hline 7500 & 2 & 0.47 & 2 & 0.47 & 2 & 0.47 \\
\hline 10000 & 2.4 & 0.72 & 2.4 & 0.72 & 2.4 & 0.72 \\
\hline 13000 & 2.4 & 0.72 & 2.4 & 0.72 & 2.4 & 0.72 \\
\hline 17500 & 2.9 & 1.07 & 2.9 & 1.07 & 3.1 & 1.16 \\
\hline 25000 & 3.1 & 1.16 & 3.1 & 1.16 & 3.1 & 1.16 \\
\hline 30000 & 3.11 & 1.19 & 3.1 & 1.16 & 3.11 & 1.19 \\
\hline
\end{tabular}


Table 3-3 Summary of ANSYS Models with Pin Surface Temperature Results

\begin{tabular}{|c|c|c|c|c|}
\hline Model & $\mathbf{h}_{\text {endwall, }}, \mathbf{W} / \mathbf{m}^{2} \mathbf{K}$ & $h_{\text {pin }}, W / \mathbf{m}^{2} K$ & $\mathrm{~T}_{\text {bulk }},{ }^{\circ} \mathrm{C}$ & $\mathrm{T}_{\mathrm{pin}},{ }^{\circ} \mathrm{C}$ \\
\hline 1 - No surrounding heater & NA & 155 & 20 & 26.4 \\
\hline 2 - With surrounding heater & 135 & 155 & 20 & 30.5 \\
\hline $\begin{array}{l}3 \text { - With surrounding heater; nc } \\
\text { copper on the Kapton }\end{array}$ & 135 & 155 & 20 & 26.8 \\
\hline $\begin{array}{l}4-\text { With surrounding heater; } \\
\text { boundary conditions iterated to } \\
\text { match model-1 pin temperature }\end{array}$ & 216 & 248 & 20 & 26.4 \\
\hline \multicolumn{5}{|c|}{ Heater Material Properties and Dimensions } \\
\hline & \multicolumn{2}{|l|}{$\mathbf{k}, \mathbf{W} / \mathbf{m}^{2} \mathbf{K}$} & \multicolumn{2}{|c|}{ Thickness t, $\mathrm{m}$} \\
\hline Kapton & \multicolumn{2}{|l|}{0.12} & \multicolumn{2}{|l|}{$76.2 \times 10^{-6}$} \\
\hline Copper & \multicolumn{2}{|l|}{391} & \multicolumn{2}{|l|}{$50.8 \times 10^{-6}$} \\
\hline \multicolumn{5}{|c|}{ Copper Pin Material Properties and Dimensions } \\
\hline $\mathrm{k}, \mathrm{W} / \mathrm{m} 2 \mathrm{~K}$ & \multicolumn{2}{|l|}{ Diameter d, m } & \multicolumn{2}{|c|}{ Length $\mathrm{d} / 2, \mathrm{~m}$} \\
\hline 391 & \multicolumn{2}{|l|}{$9.53 \times 10^{-3}$} & \multicolumn{2}{|c|}{$4.76 \times 10^{-3}$} \\
\hline
\end{tabular}

Table 3-4 Summary of Experimental Uncertainties

\begin{tabular}{|c|c|c|c|c|}
\hline Variable & Condition & Value & Uncertainty & $\%$ Uncertainty \\
\hline \multirow[t]{2}{*}{$\operatorname{Re}$} & Low $\operatorname{Re}$ & 5013 & 85 & $1.7 \%$ \\
\hline & High Re & 30,484 & 273 & $0.9 \%$ \\
\hline \multirow[t]{4}{*}{$\mathbf{N u}_{\mathrm{d}}$, Pin Fins } & Low Re, High $\mathrm{Nu}_{\mathrm{d}}$ & 54.6 & 2.6 & $4.8 \%$ \\
\hline & Low $\mathrm{Re}$, Low $\mathrm{Nu}_{\mathrm{d}}$ & 31.3 & 1.3 & $4.1 \%$ \\
\hline & High Re, High $\mathrm{Nu}_{\mathrm{d}}$ & 144.4 & 6.5 & $4.5 \%$ \\
\hline & High $\mathrm{Re}$, Low $\mathrm{Nu}_{\mathrm{d}}$ & 86.1 & 3.5 & $4.1 \%$ \\
\hline \multirow[t]{4}{*}{ Nu, Endwall } & Low Re, High $\mathrm{Nu}$ & 49.9 & 3.8 & $7.5 \%$ \\
\hline & Low Re, Low Nu & 18.1 & 1.1 & $6.1 \%$ \\
\hline & High Re, High Nu & 154.5 & 8.5 & $5.5 \%$ \\
\hline & High $\mathrm{Re}$, Low $\mathrm{Nu}$ & 82.3 & 4.1 & $5.0 \%$ \\
\hline \multirow[t]{4}{*}{$\mathbf{N u} / \mathbf{N u}_{0}$} & Low Re, High Nu & 3.0 & 0.23 & $7.7 \%$ \\
\hline & Low $\mathrm{Re}$, Low $\mathrm{Nu}$ & 1.1 & 0.07 & $6.3 \%$ \\
\hline & High Re, High $\mathrm{Nu}$ & 2.2 & 0.12 & $5.6 \%$ \\
\hline & High Re, Low Nu & 1.2 & 0.06 & $5.1 \%$ \\
\hline
\end{tabular}




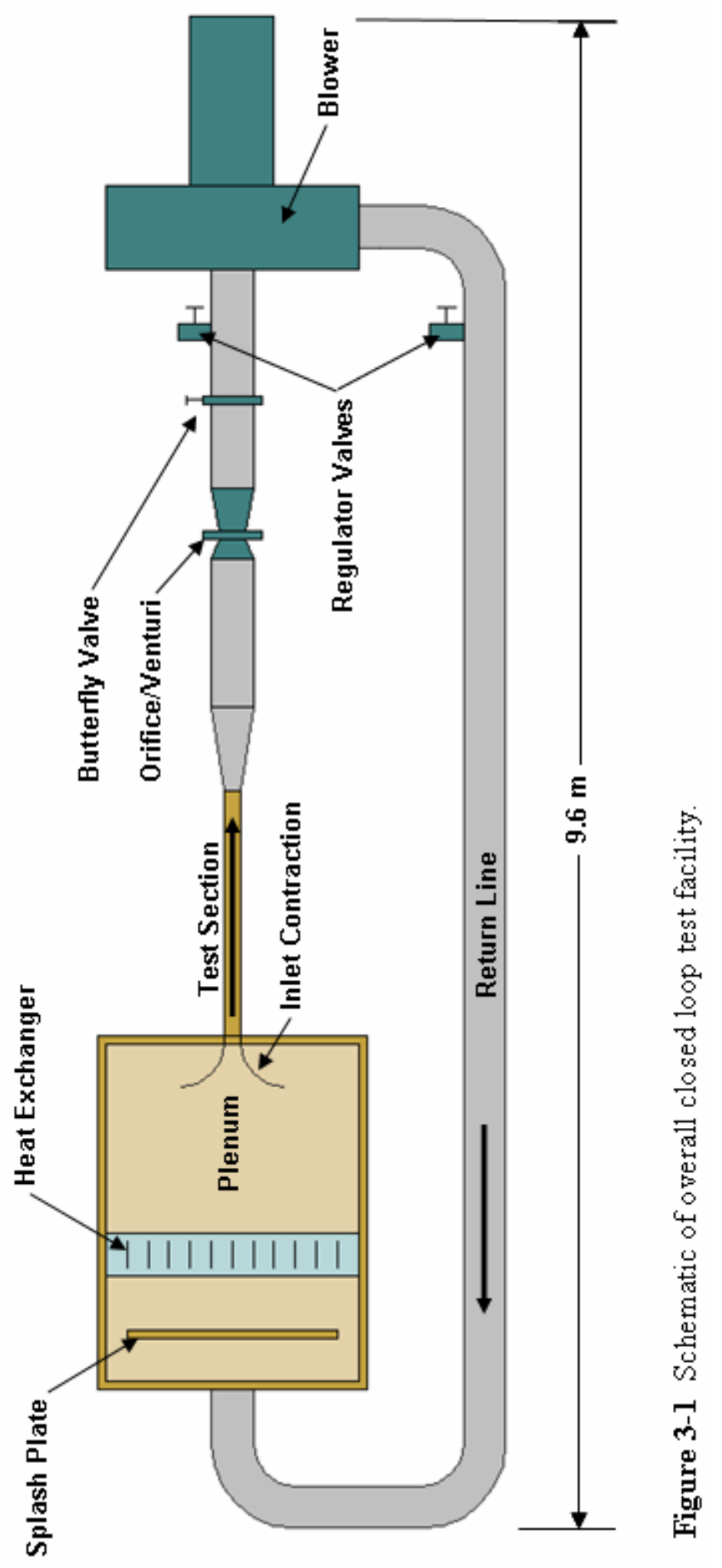




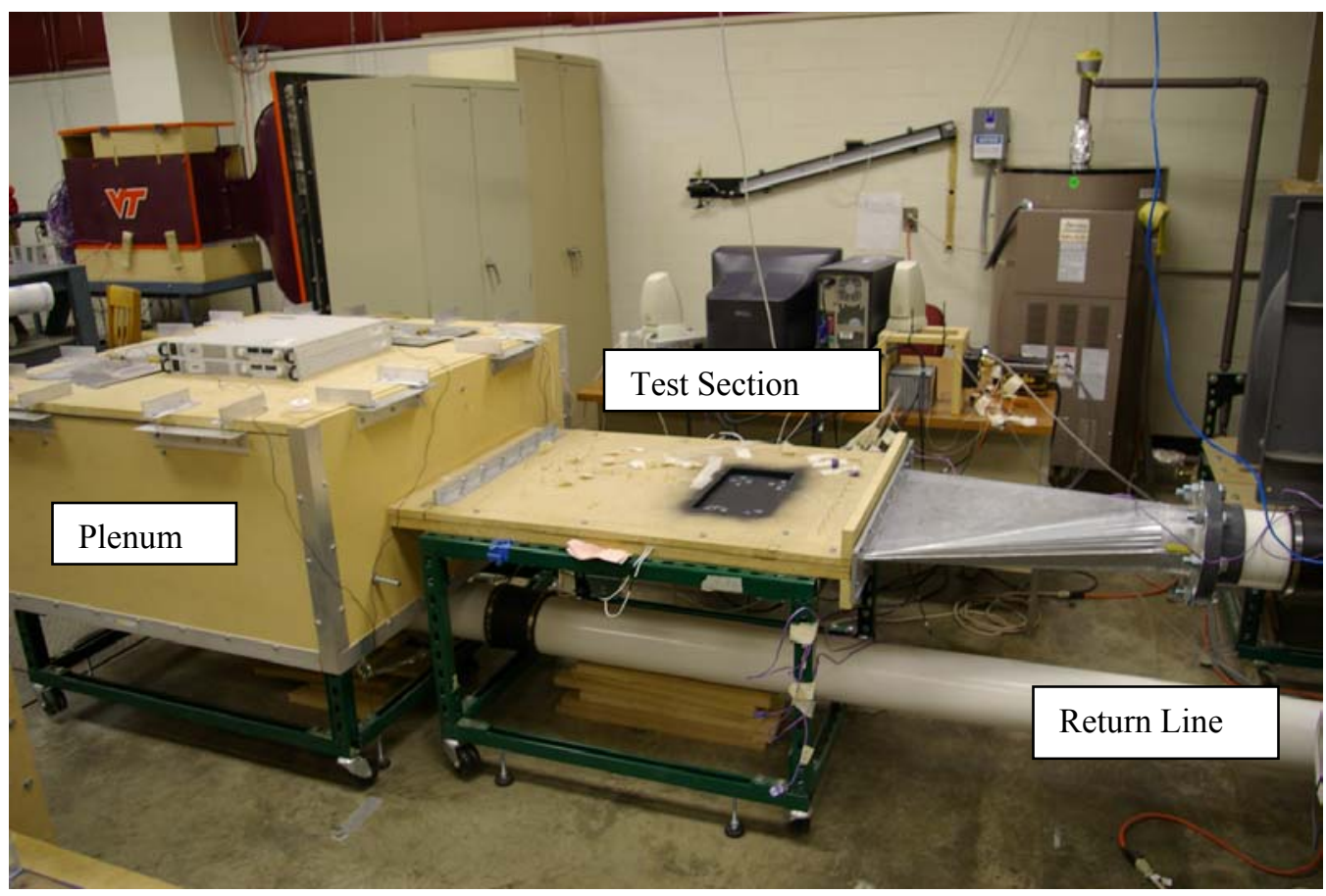

Figure 3-2 Photograph of the plenum and test section side of the test rig.

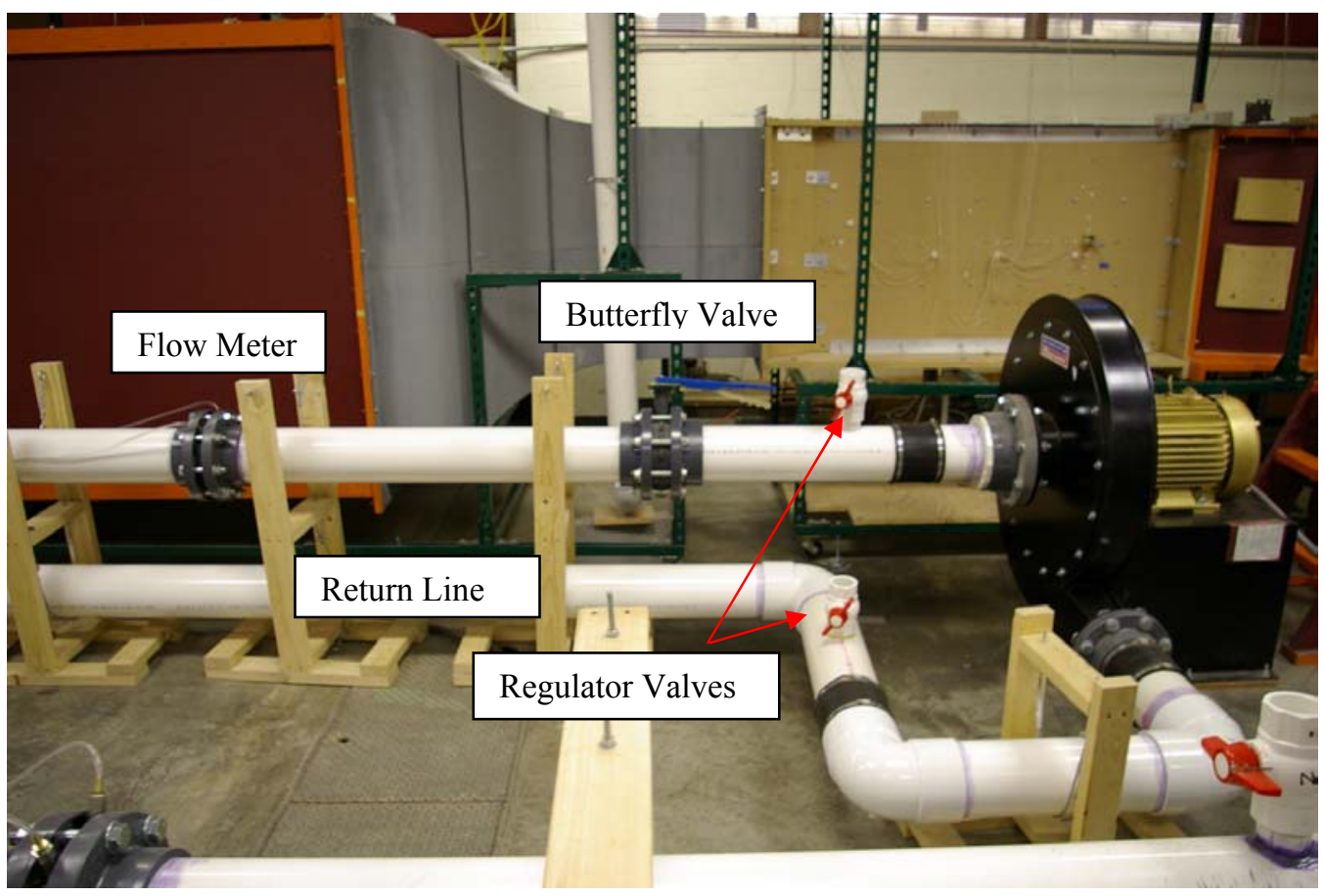

Figure 3-3 Photograph of the blower side of the test facility. 


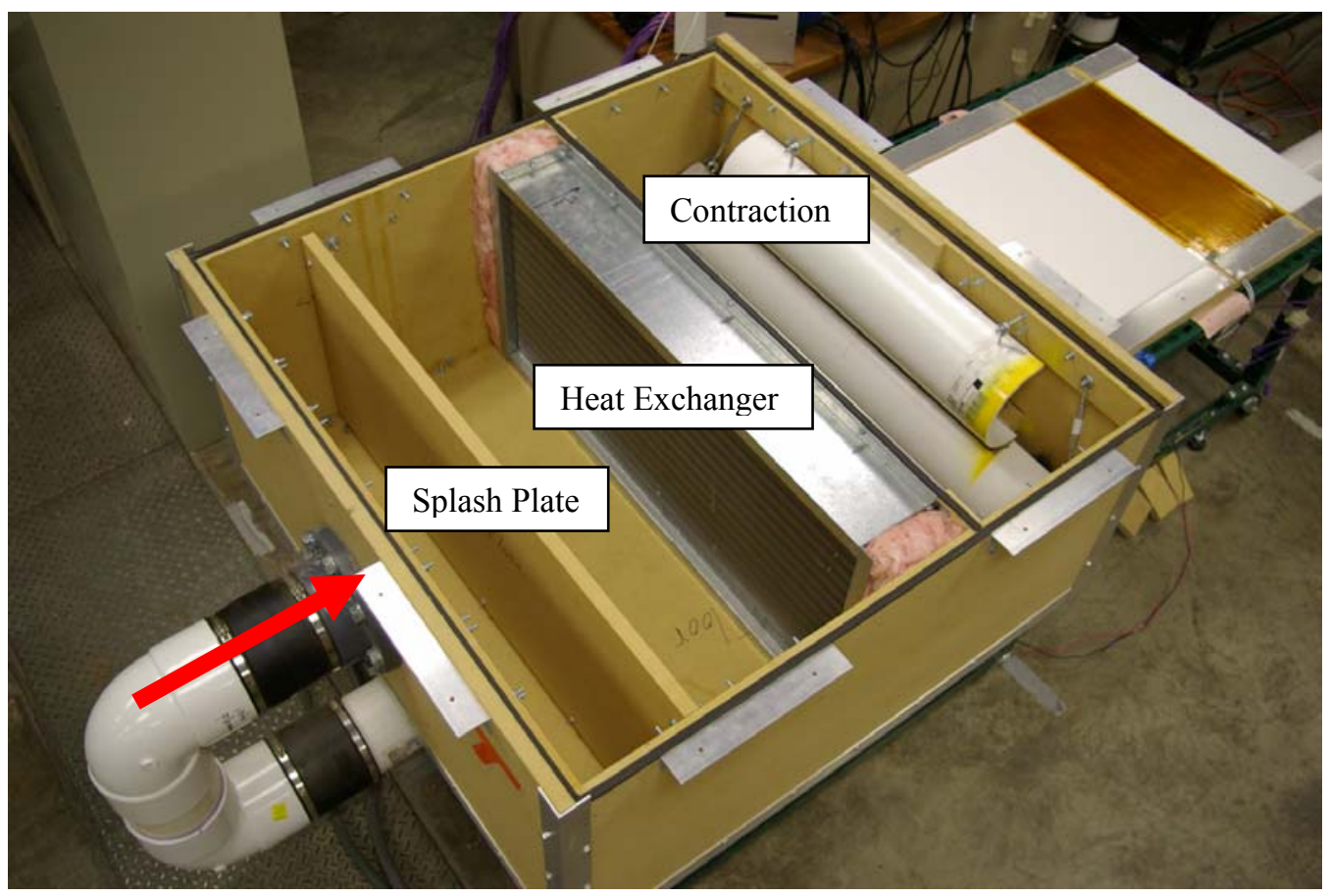

Figure 3-4 Photograph of the inside of the plenum.

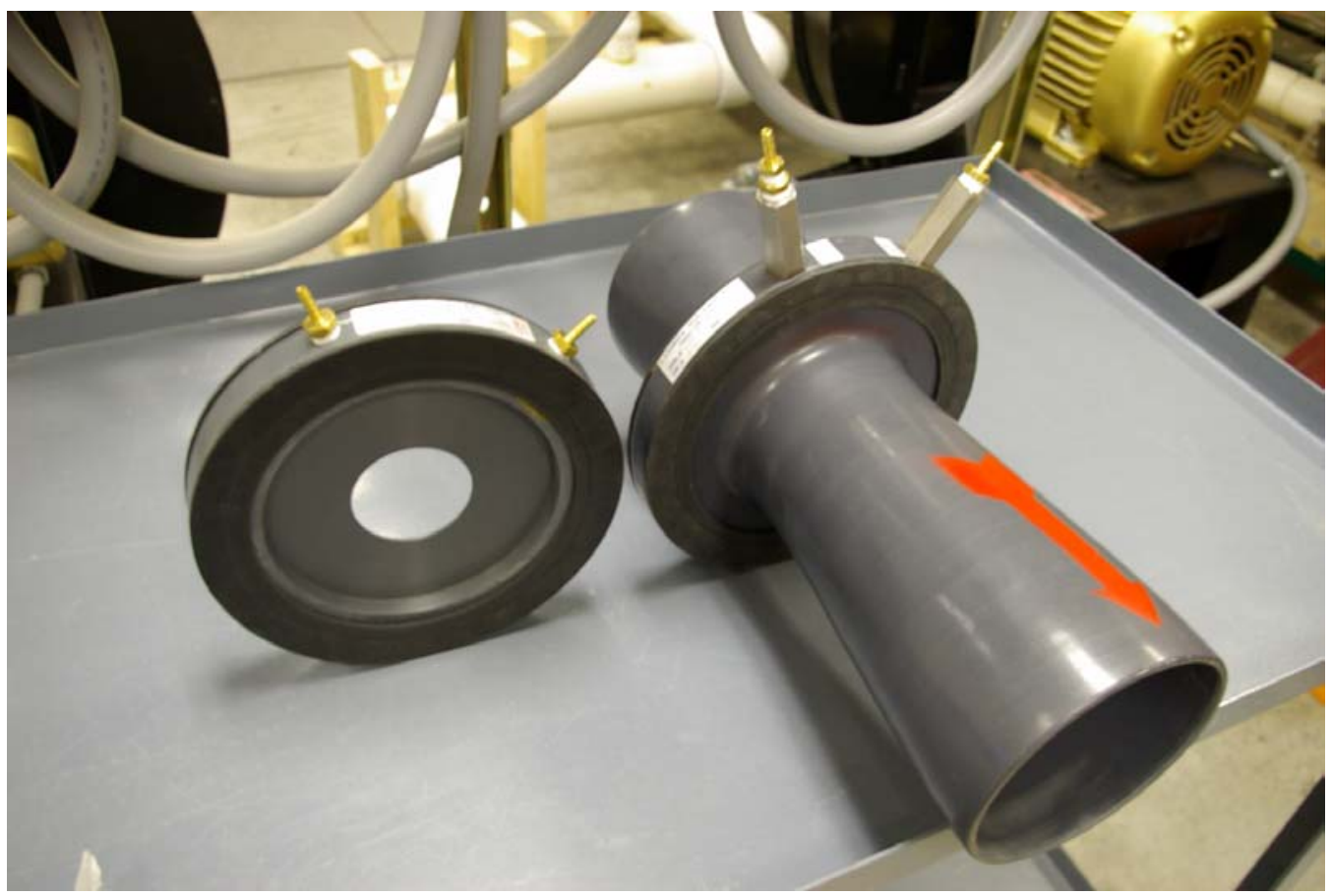

Figure 3-5 Photograph of the orifice and venturi flow meters. 


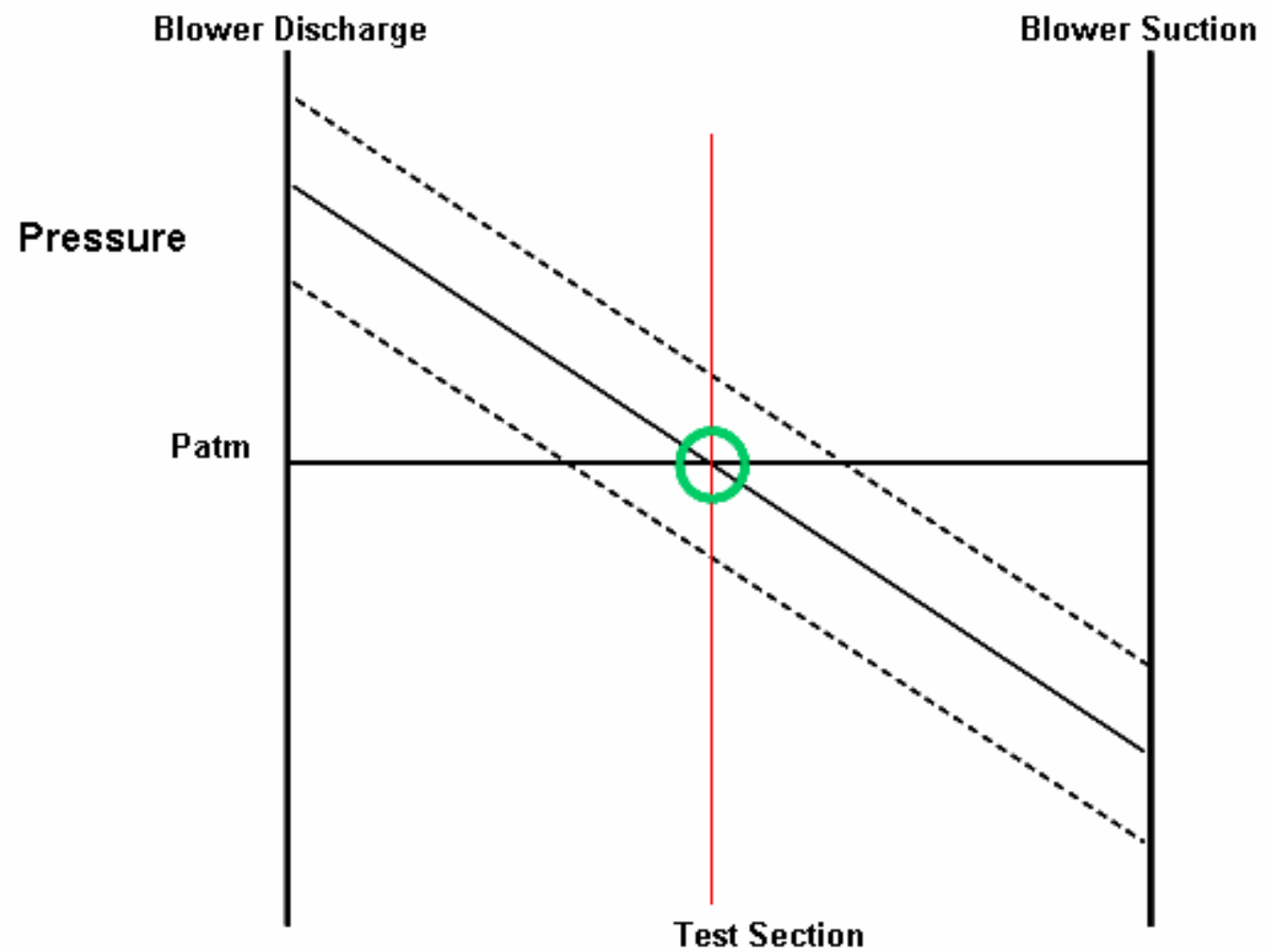

Figure 3-6 Diagram demonstrating the purpose of the regulator valves. The regulator valves adjusted the test section pressure to atmospheric. 


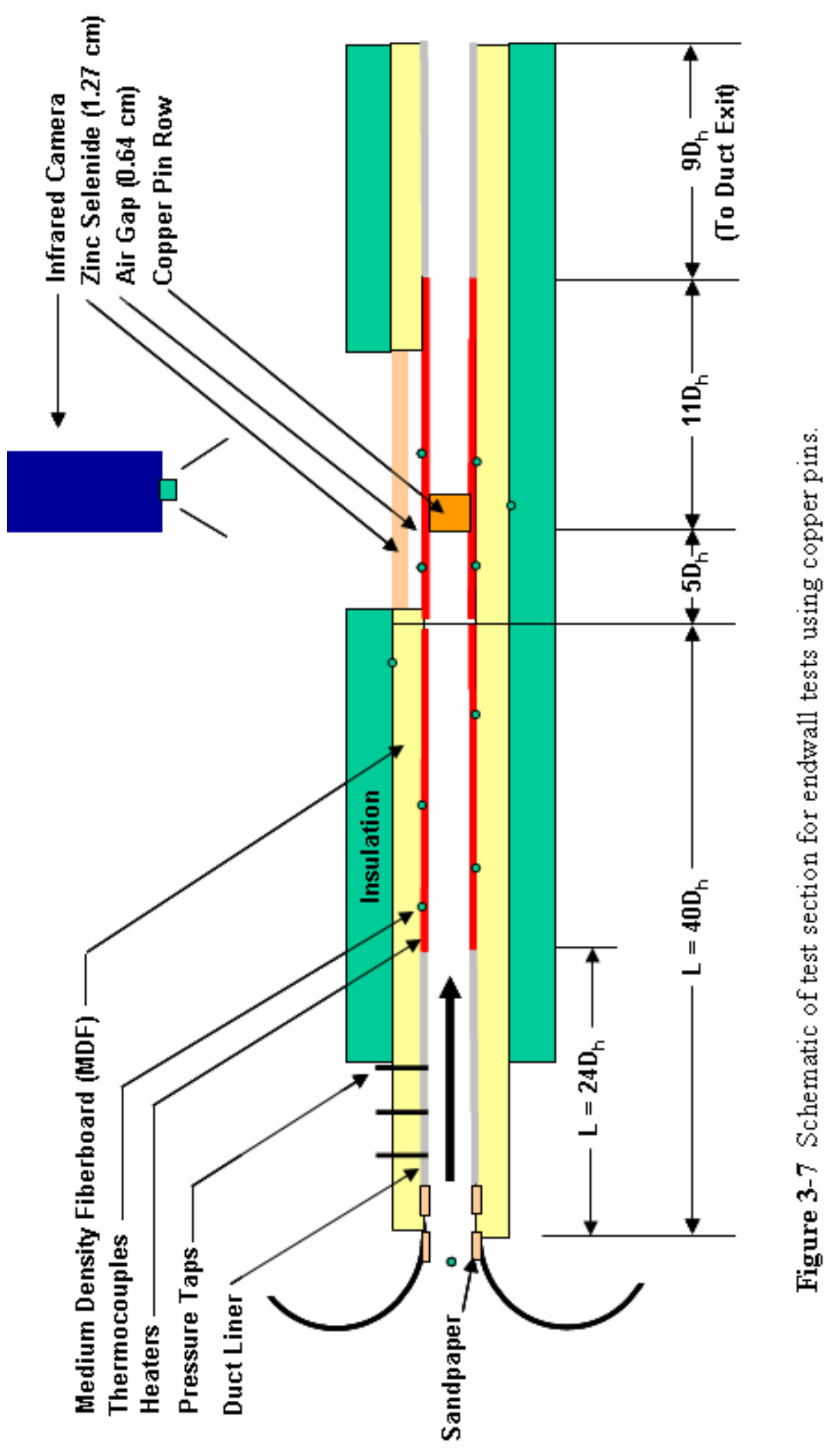




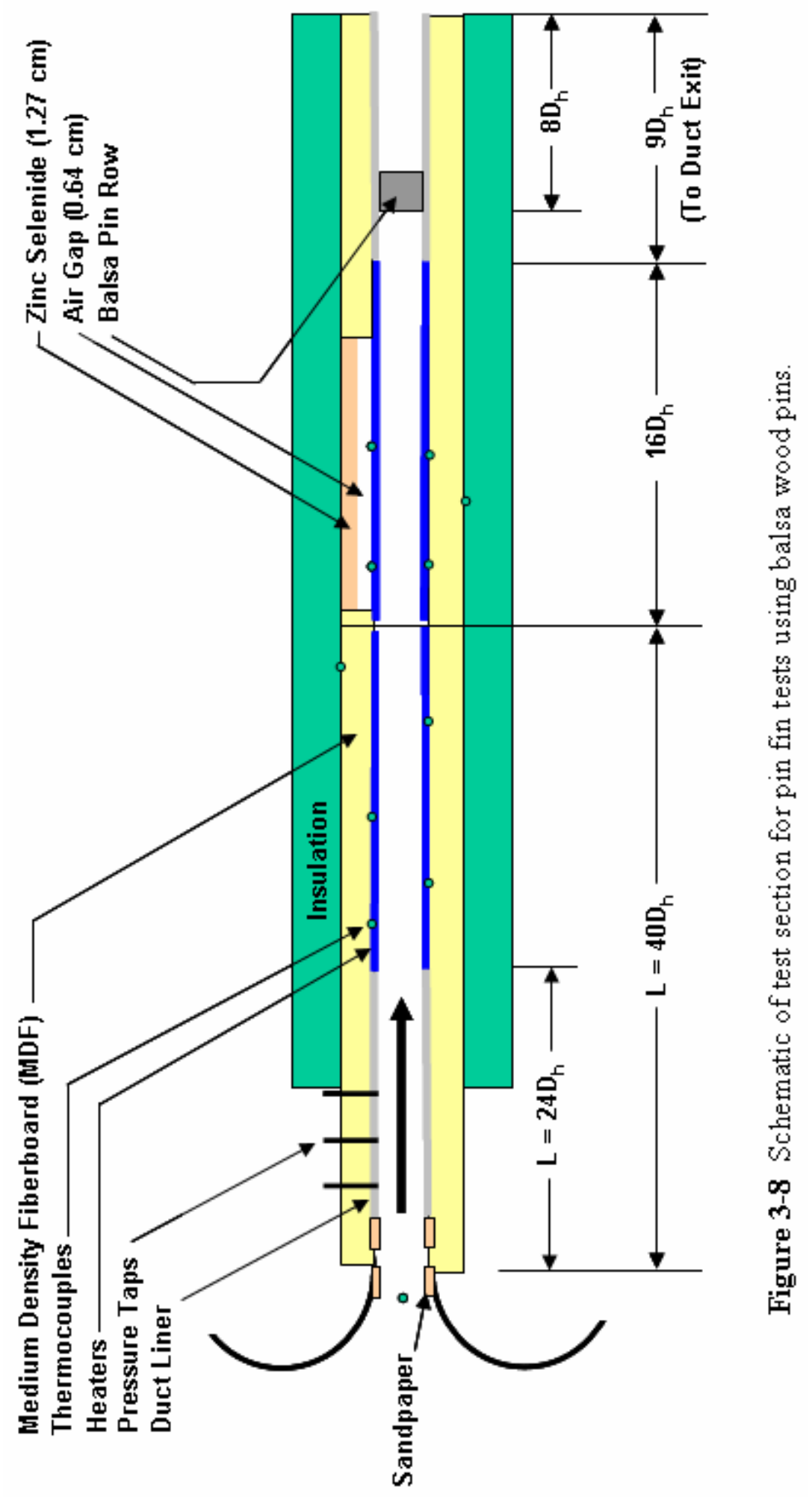




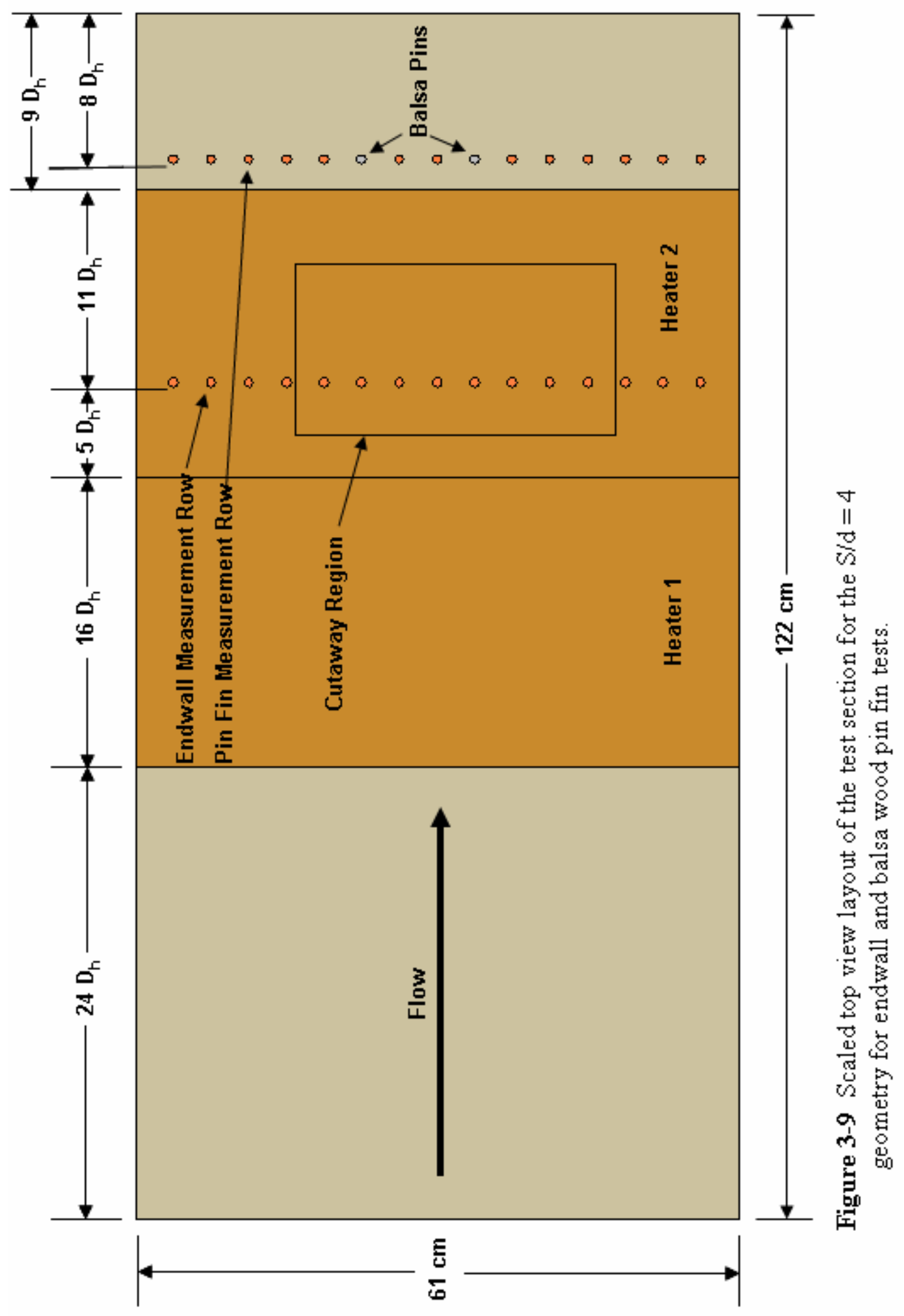




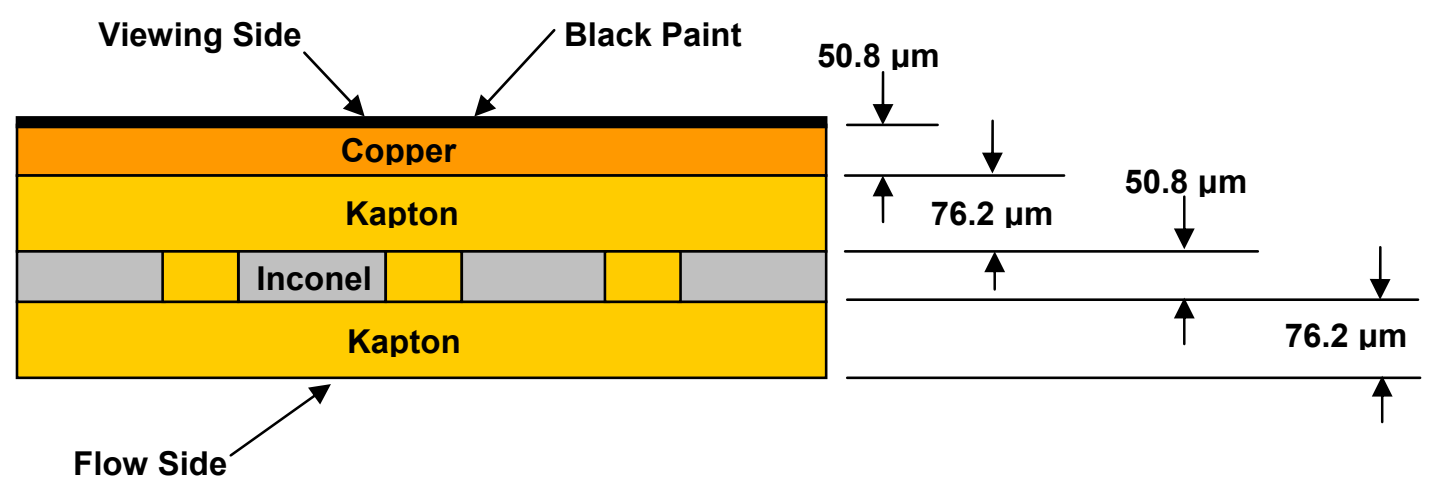

Figure 3-10 Sketch of heater cross-section (Not to scale).
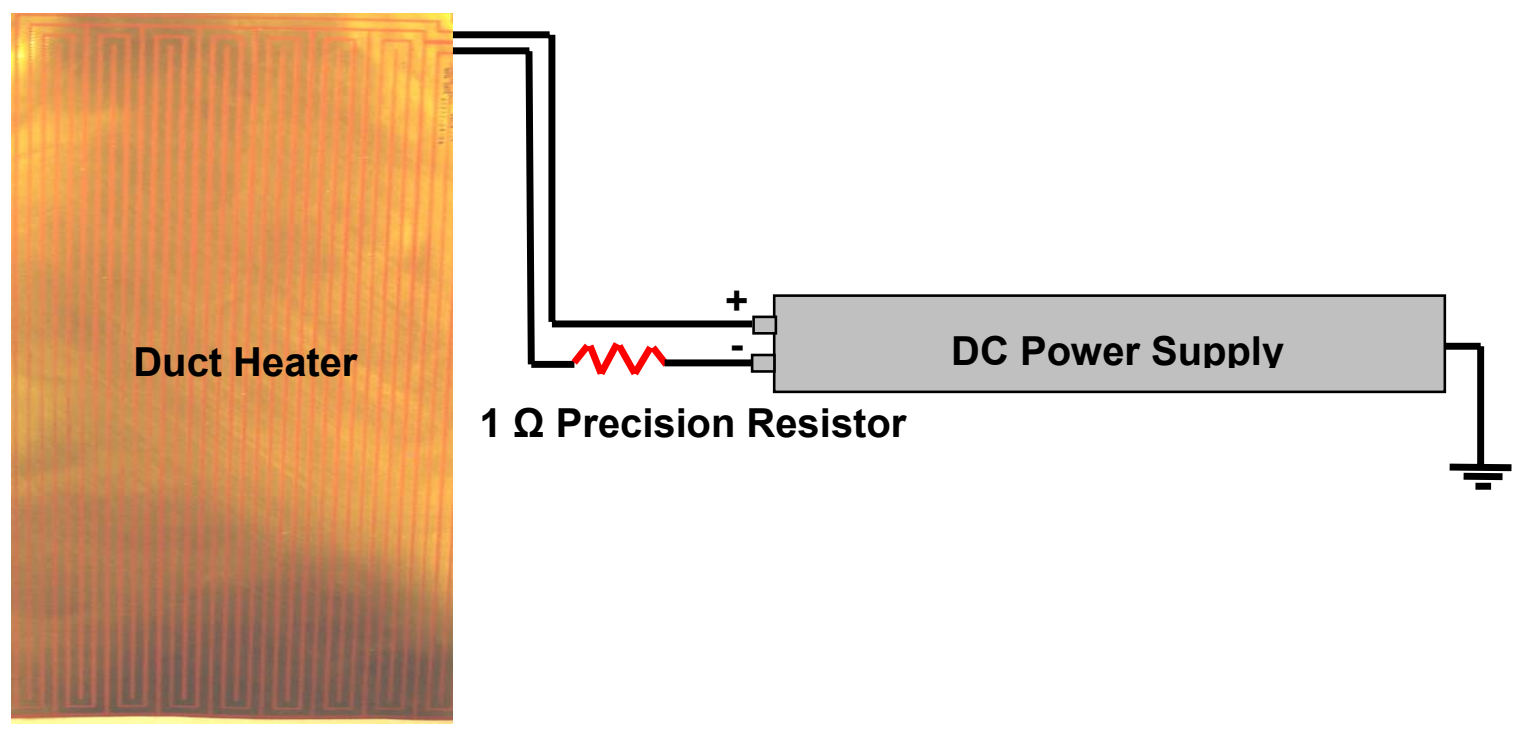

Figure 3-11 Diagram of heater and power supply hookup. On the heater, the serpentine inconel strips can be seen on the surface. 


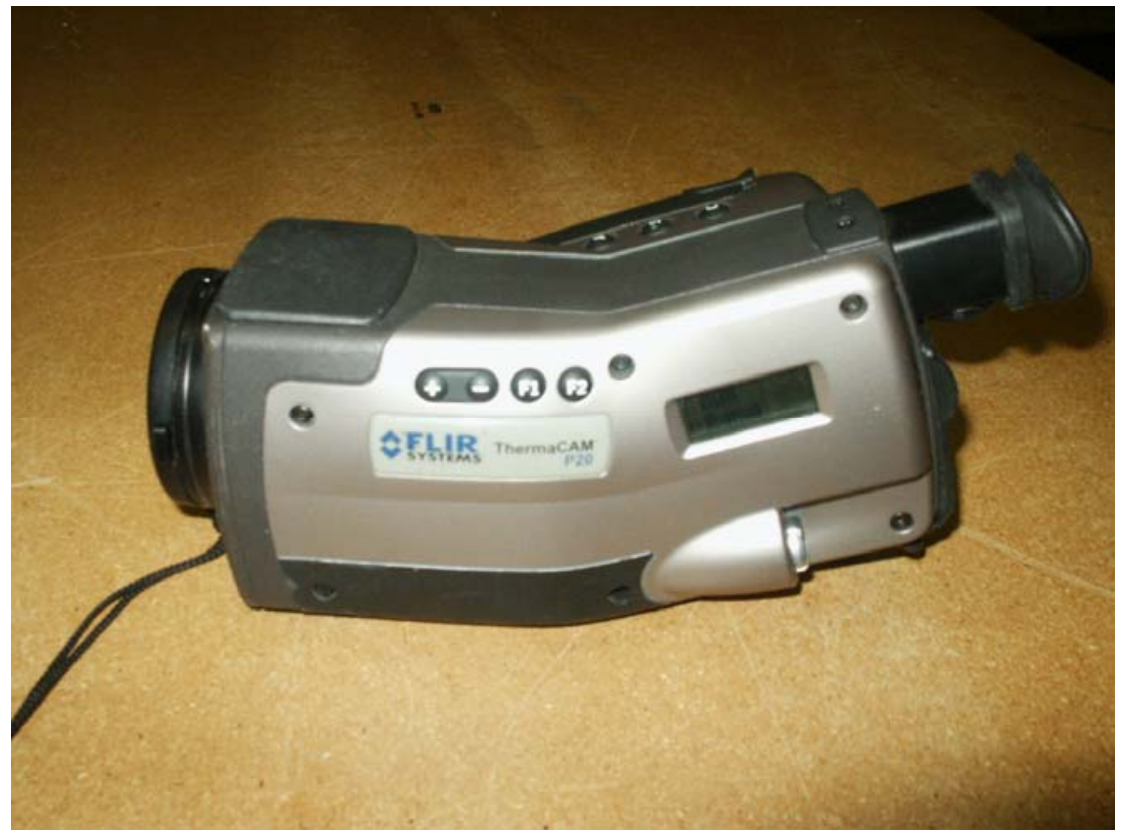

Figure 3-12 Photograph of ThermaCam P20 infrared camera manufactured by FLIR Systems AB.

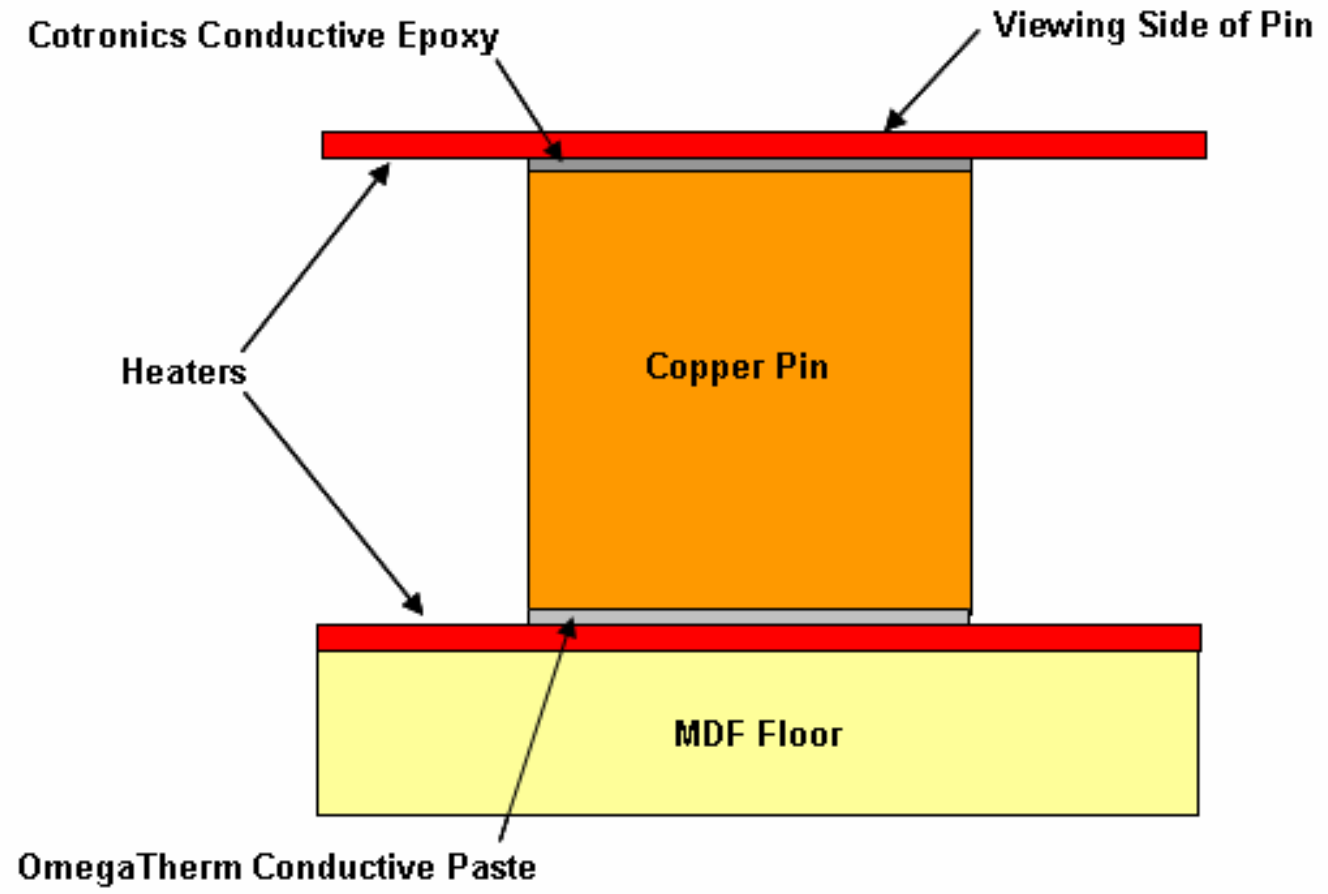

Figure 3-13 Diagram of pin fin attachment method. 


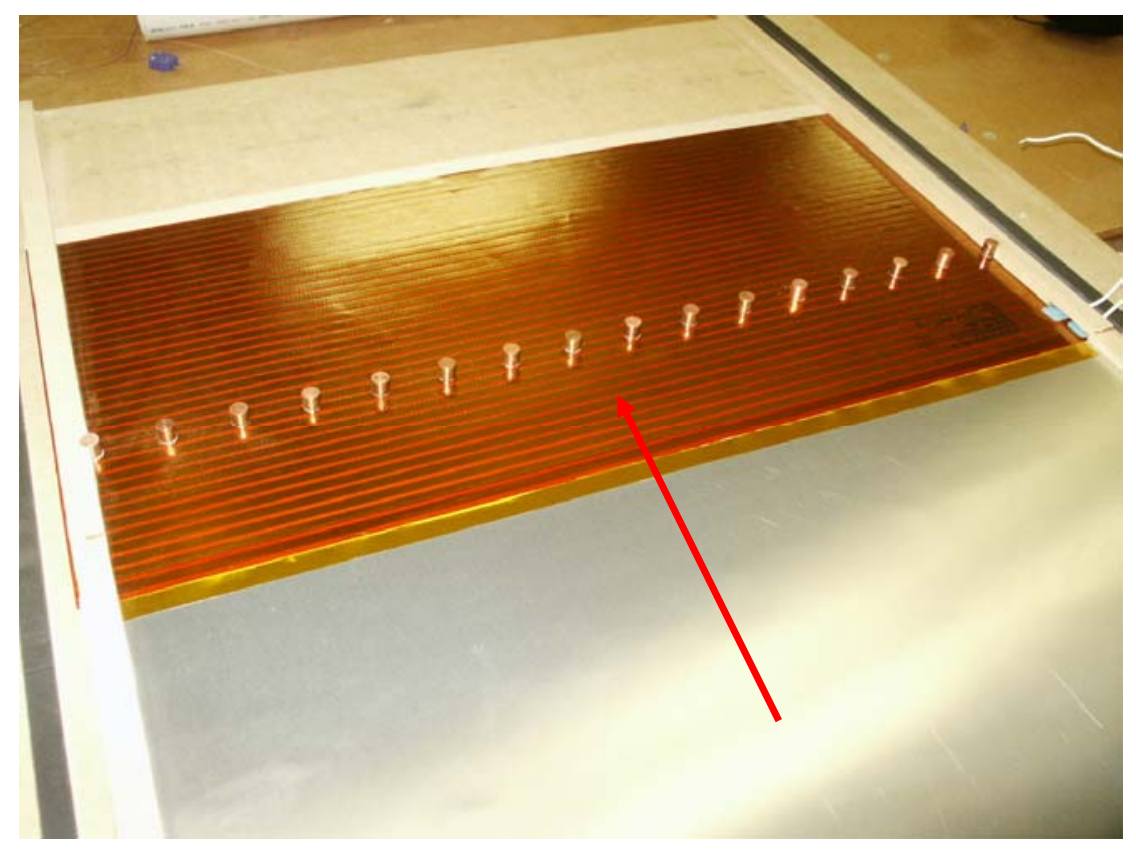

Figure 3-14 Photograph of the copper pins attached to the test section roof before assembly. The $\mathrm{S} / \mathrm{d}=4$ single row geometry is shown.

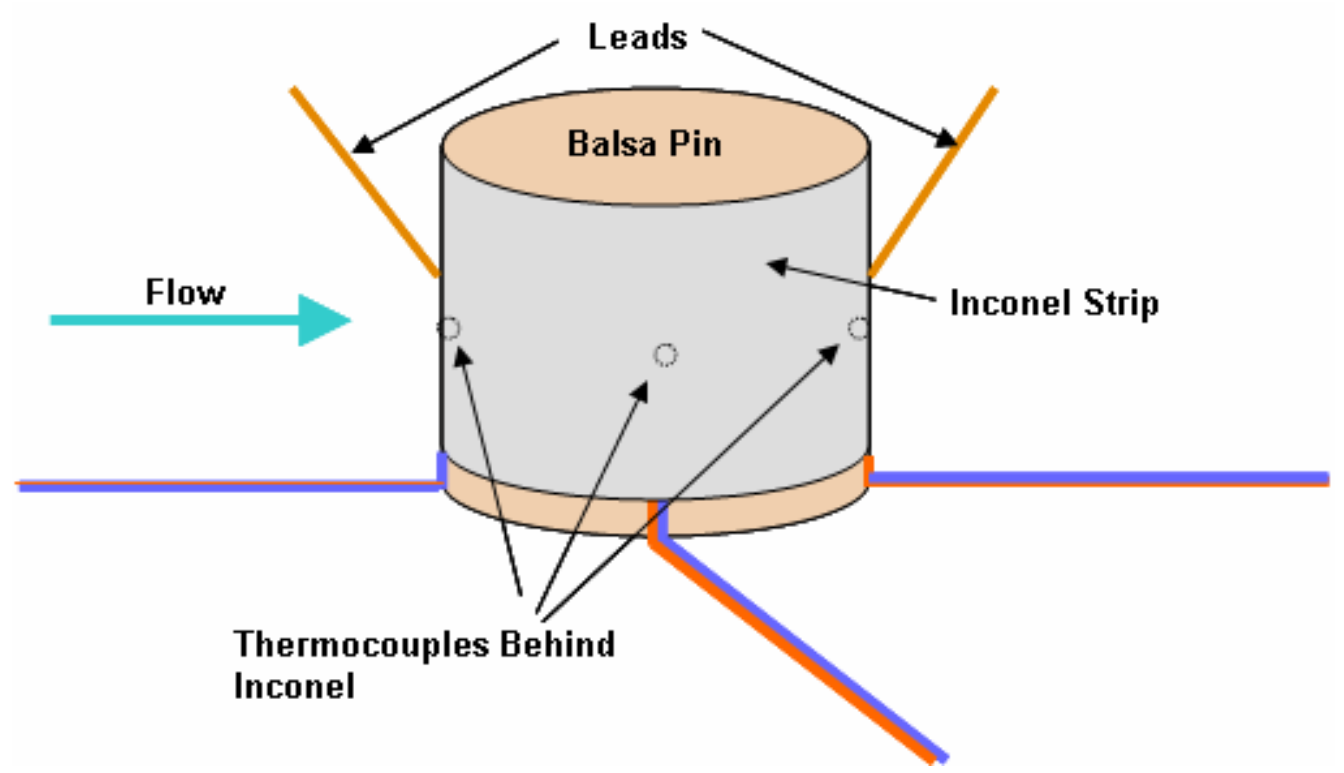

Figure 3-15 Diagram of balsa wood pin fin construction [Lawson, 2006]. 


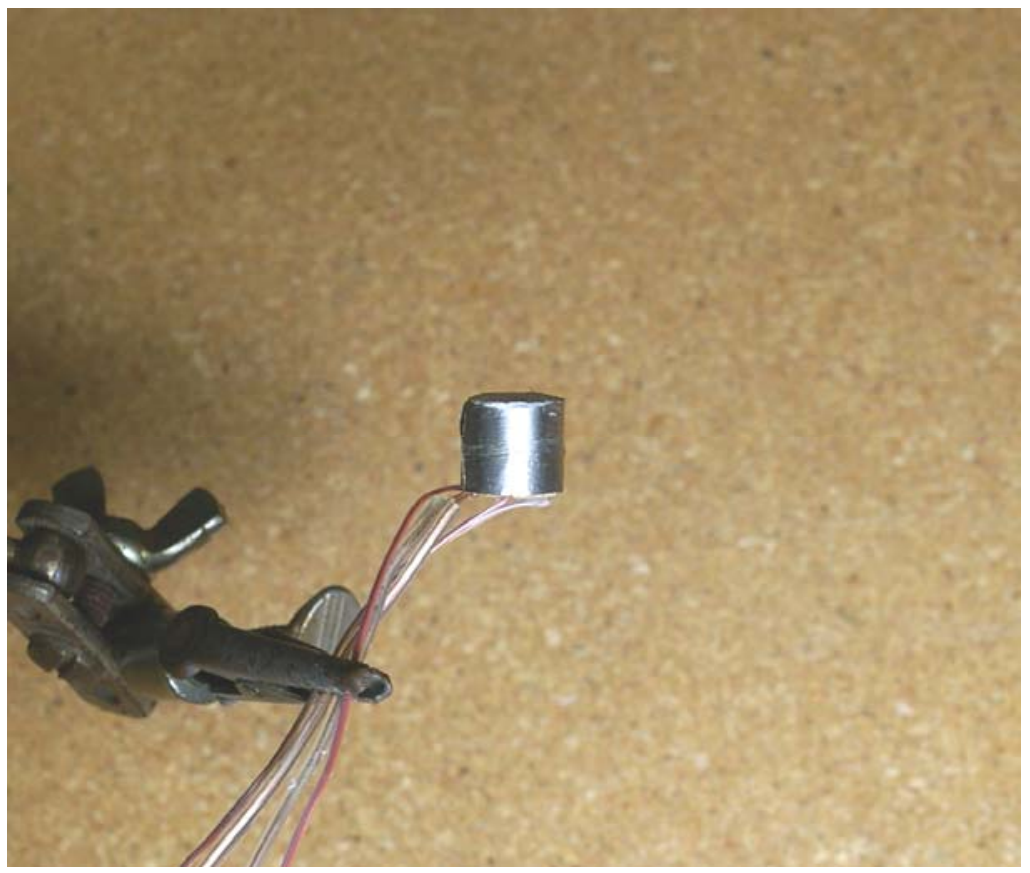

Figure 3-16 Photograph of completed balsa wood pin.

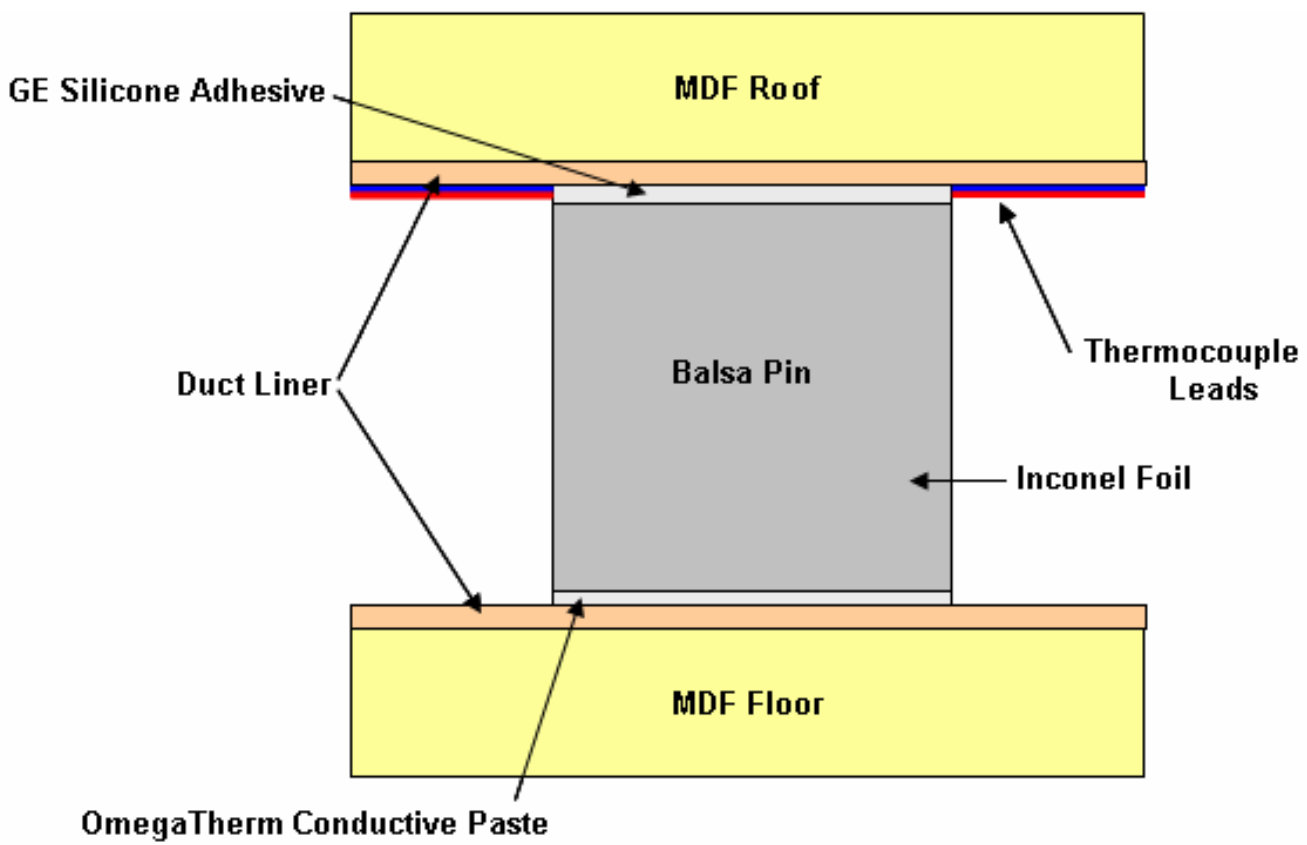

Figure 3-17 Diagram of balsa pin attachment method. 


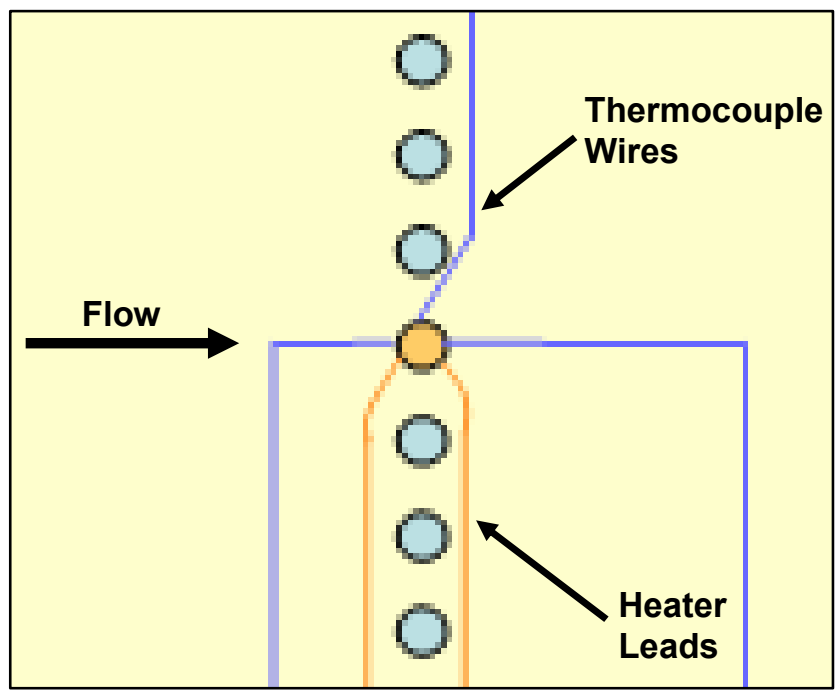

Figure 3-18 Diagram of balsa wood pin fin wiring arrangement inside the test section. This particular arrangement is for the $\mathrm{S} / \mathrm{d}=2$ single row array geometry [Lawson, 2006].

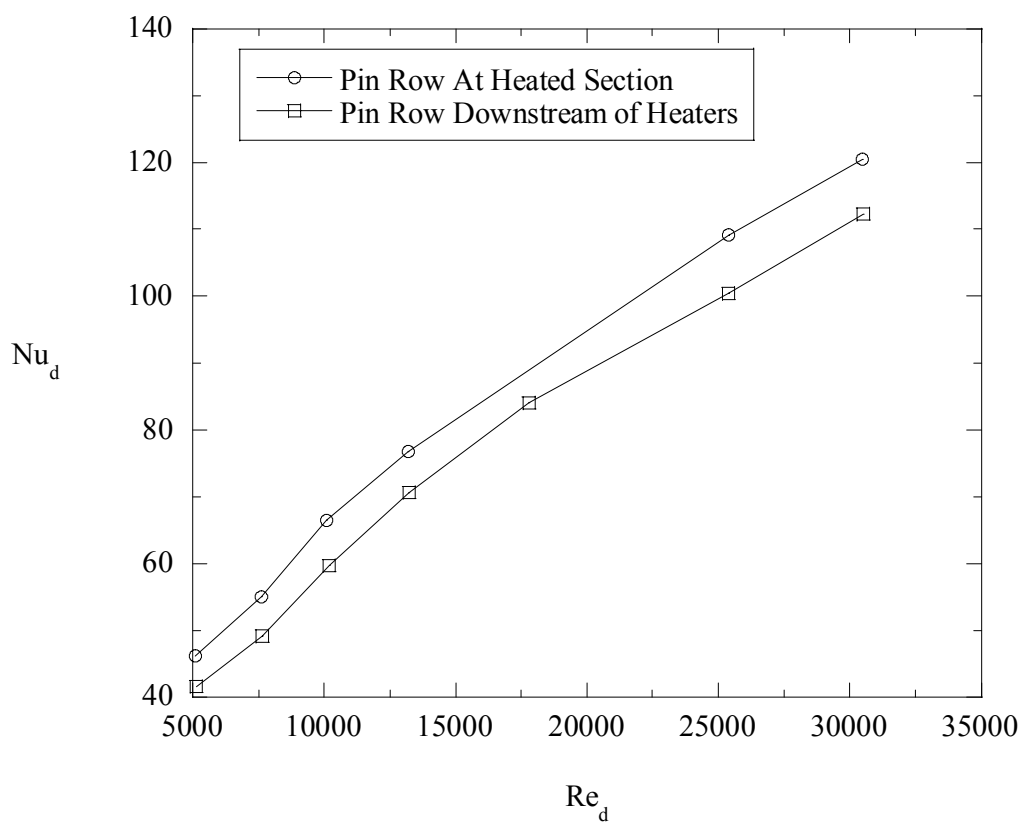

Figure 3-19 Comparison of balsa wood test results with the array on, and downstream of the test section heaters. The test results are based on the $\mathrm{S} / \mathrm{d}=2$ single row geometry. 


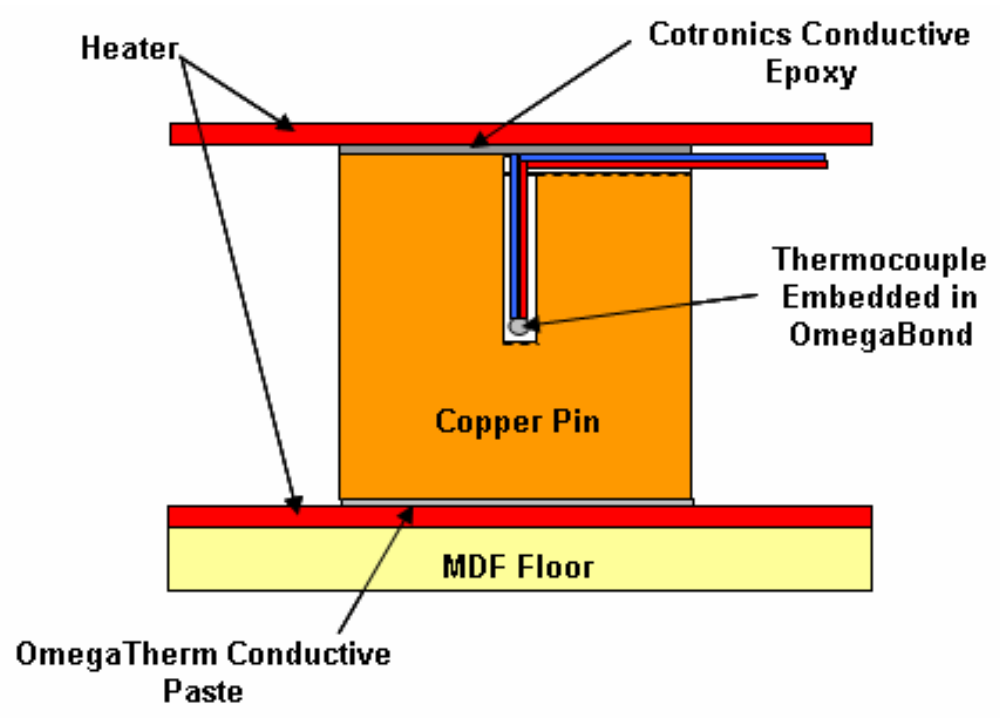

Figure 3-20 Diagram showing the method of installing a thermocouple in the center of a copper pin fin. The pin fin is attached to the heaters the same way as the other copper pin fins.

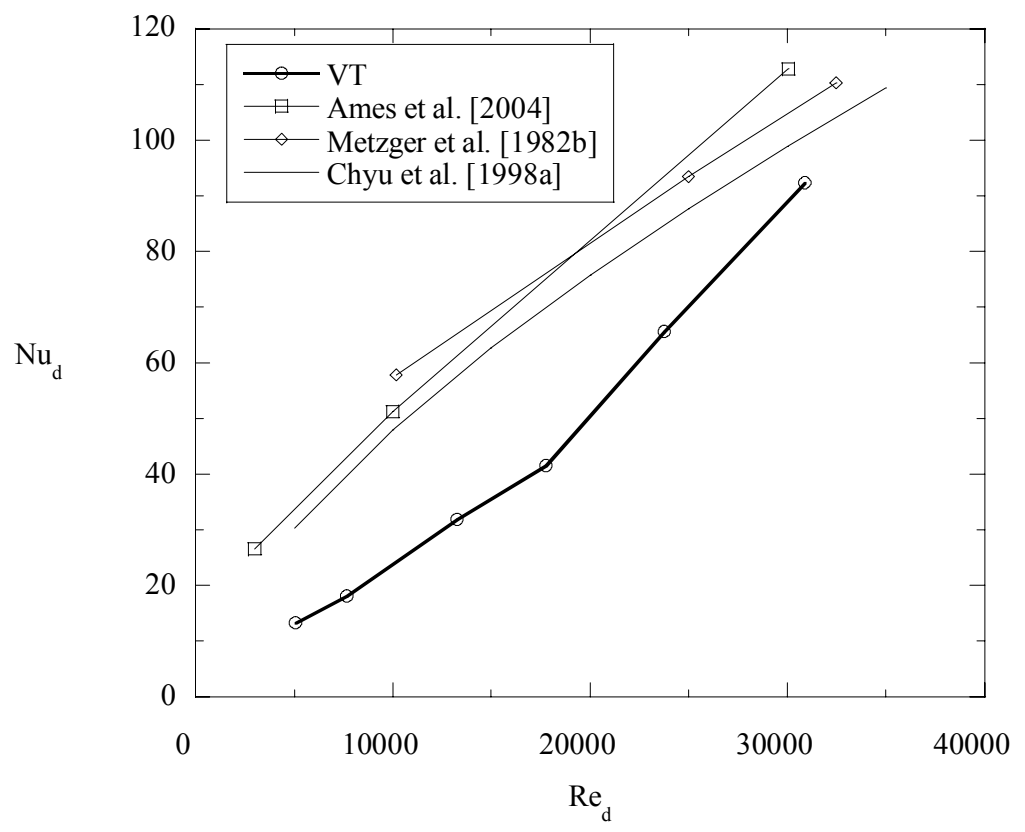

Figure 3-21 Comparison of the embedded thermocouple pin fin measurement technique with data from the literature. Ames used an $\mathrm{S} / \mathrm{d}=2.5, \mathrm{H} / \mathrm{d}=2$ geometry. Metzger used as $\mathrm{S} / \mathrm{d}=2.19, \mathrm{H} / \mathrm{d}=0.875$ geometry. Chyu used an $\mathrm{S} / \mathrm{d}=2.5, \mathrm{H} / \mathrm{d}=1$ geometry. 


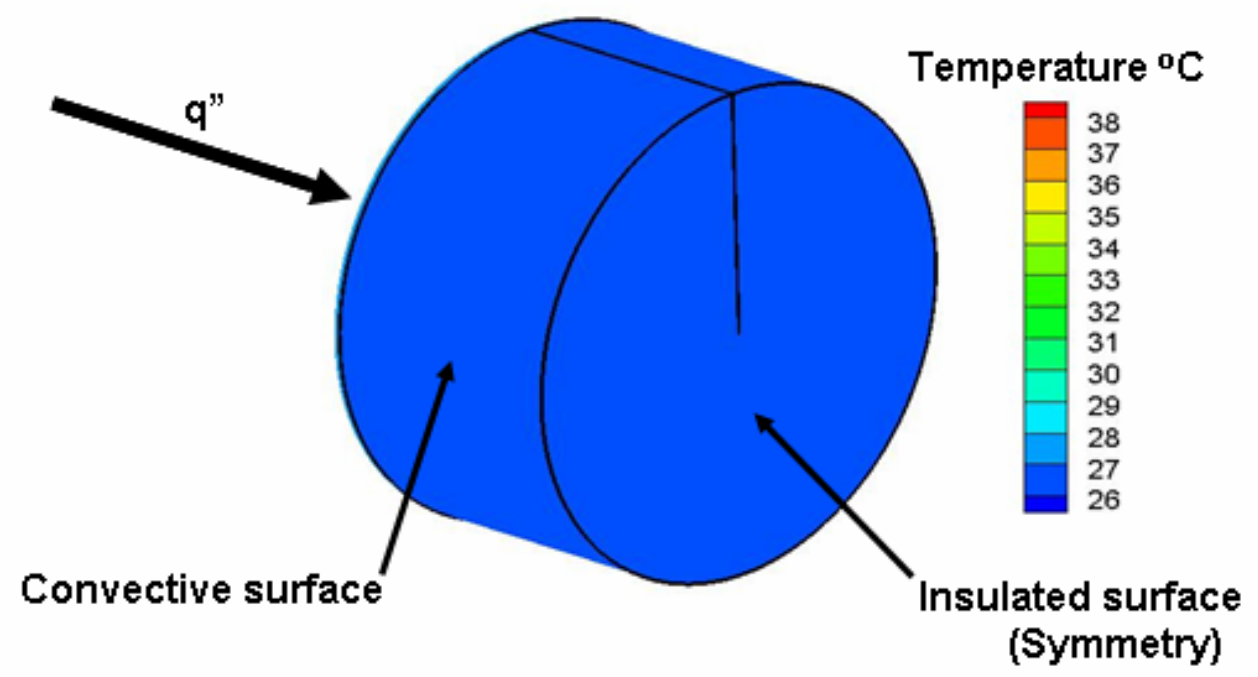

Figure 3-22 Model 1 results from ANSYS. Shown here is a surface temperature contour plot of the 3-dimensional model of a single pin with the surface heater attached. The surrounding heater has been excluded.

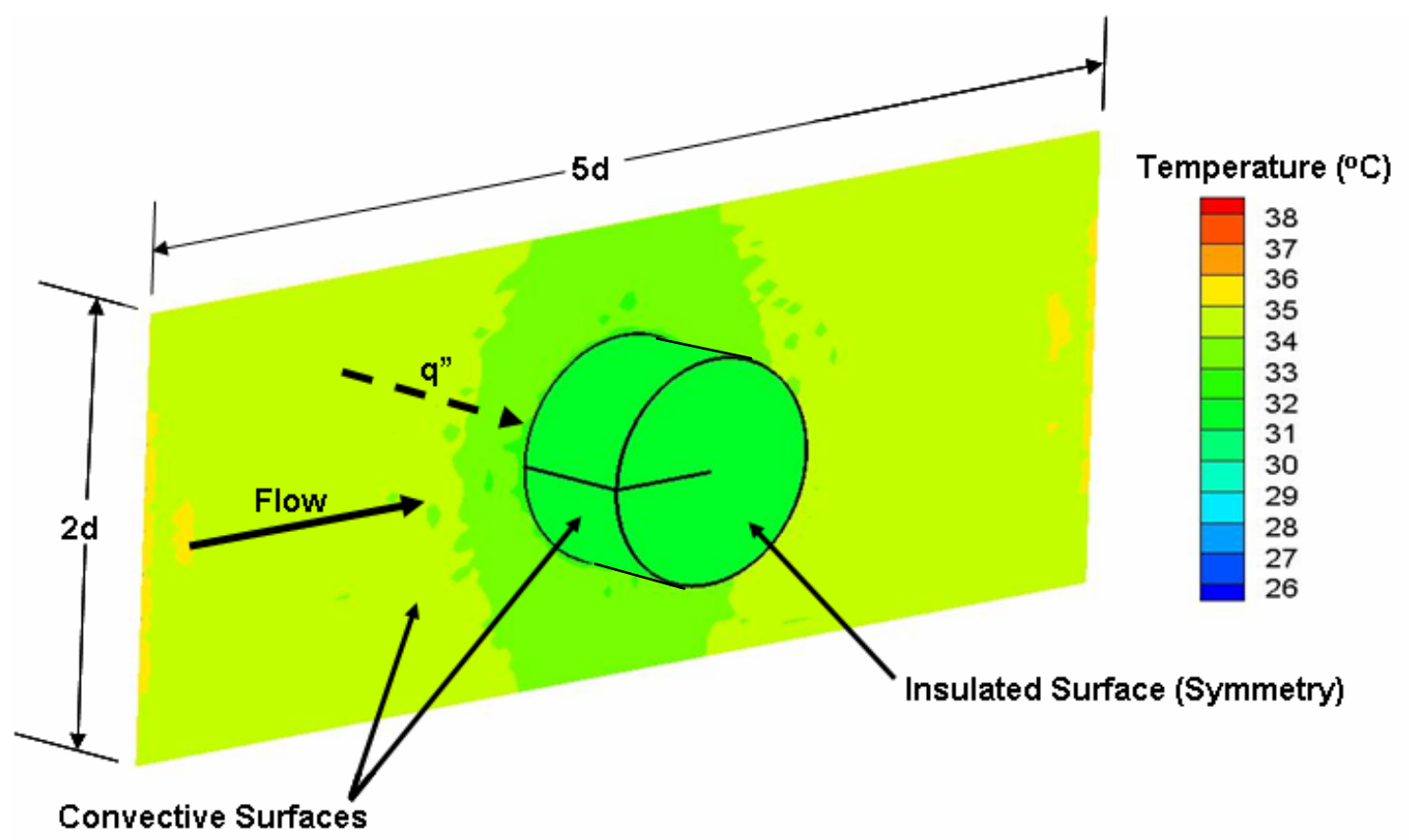

Figure 3-23 Model 2 results from ANSYS. Shown here is a surface temperature contour plot of the 3-dimensional model of a single pin including the surrounding heater area. 


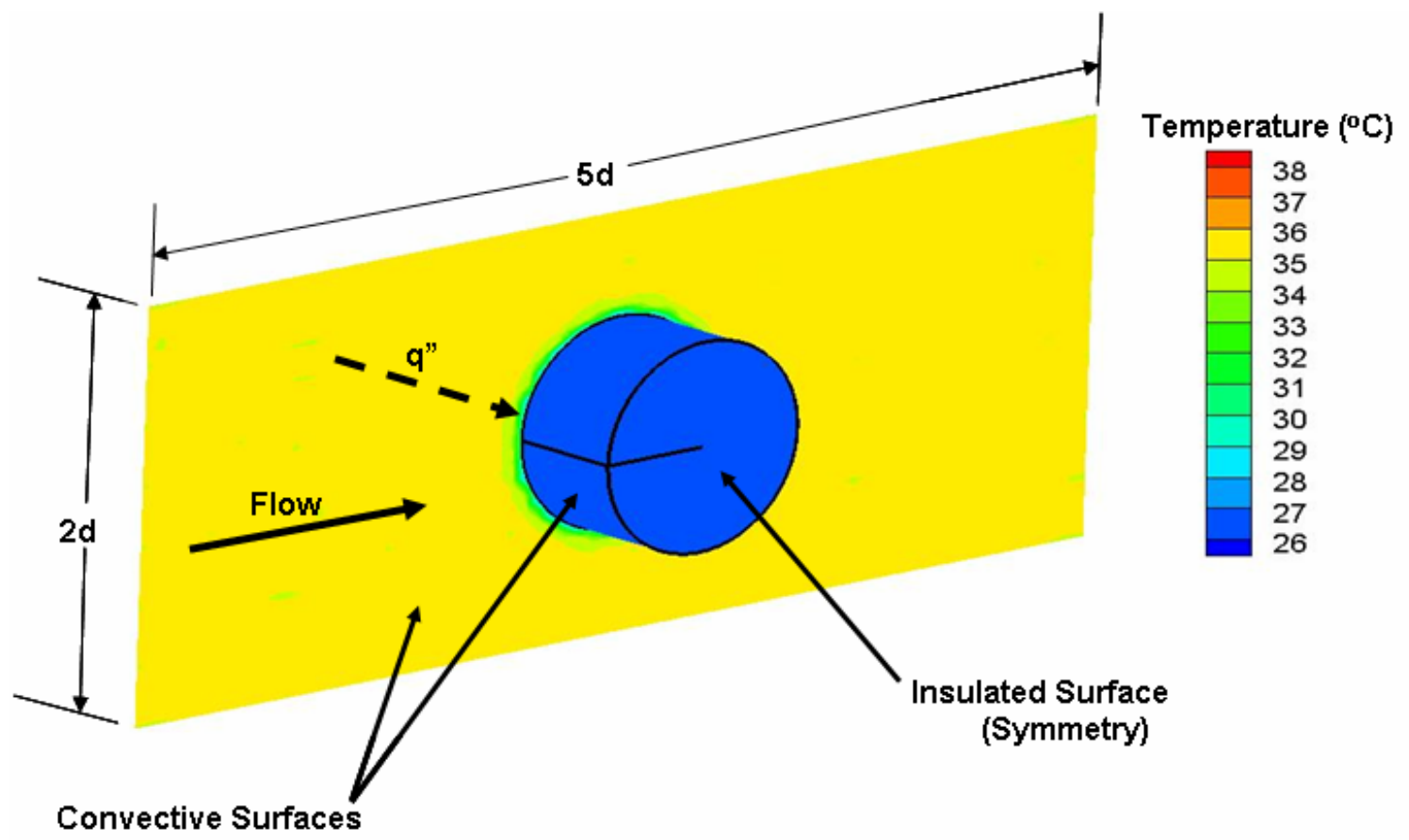

Figure 3-24 Model 3 results from ANSYS. Shown here is a surface temperature contour plot of the 3-dimensional model of a single pin including the surrounding heater area. Note that the copper layer on the heater surface was not included.

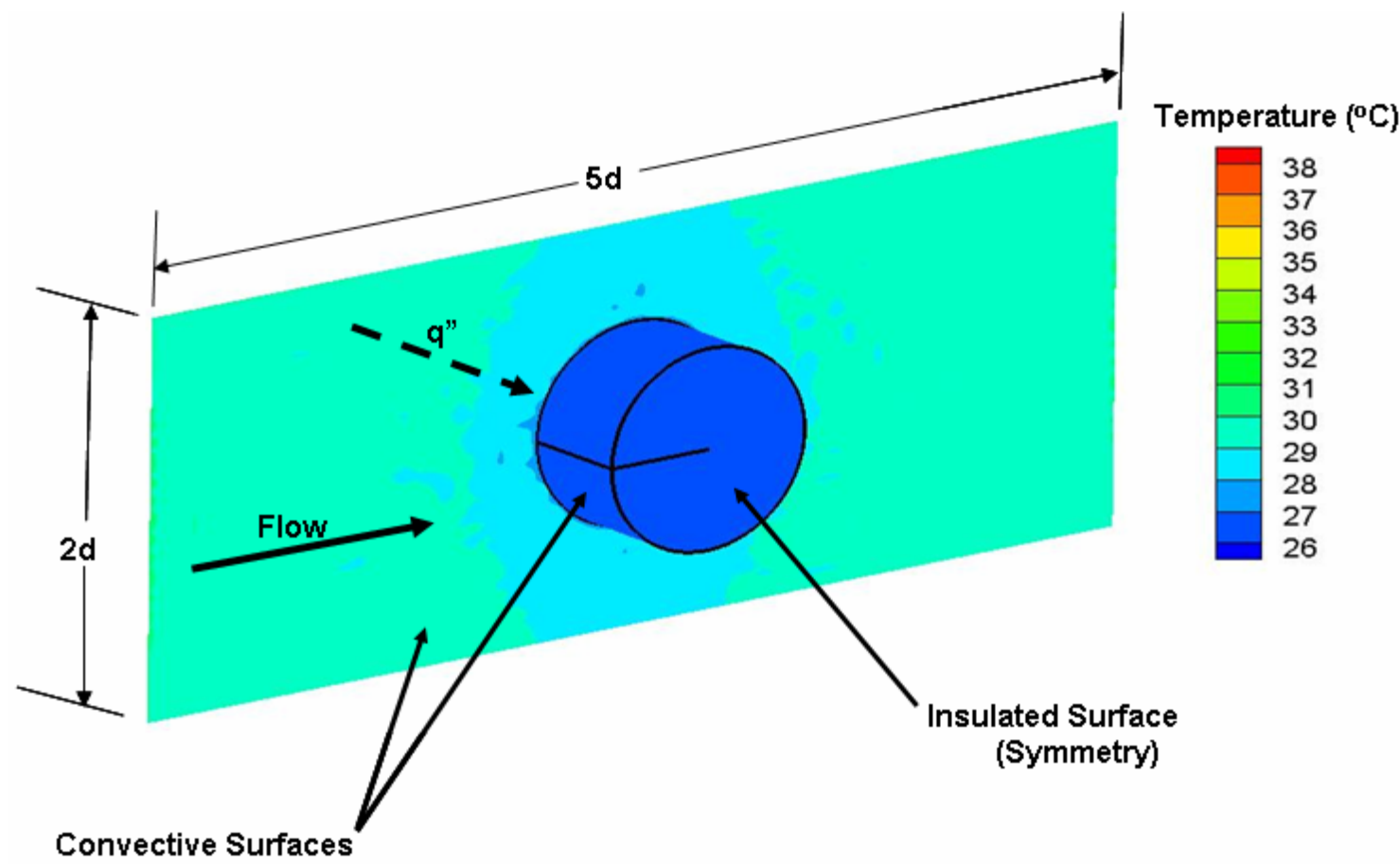

Figure 3-25 Model 4 results from ANSYS. Shown here is a surface temperature contour plot of the 3-dimensional model of a single pin including the surrounding heater area. The heat transfer coefficient was iterated to match the model 1 pin temperature. 


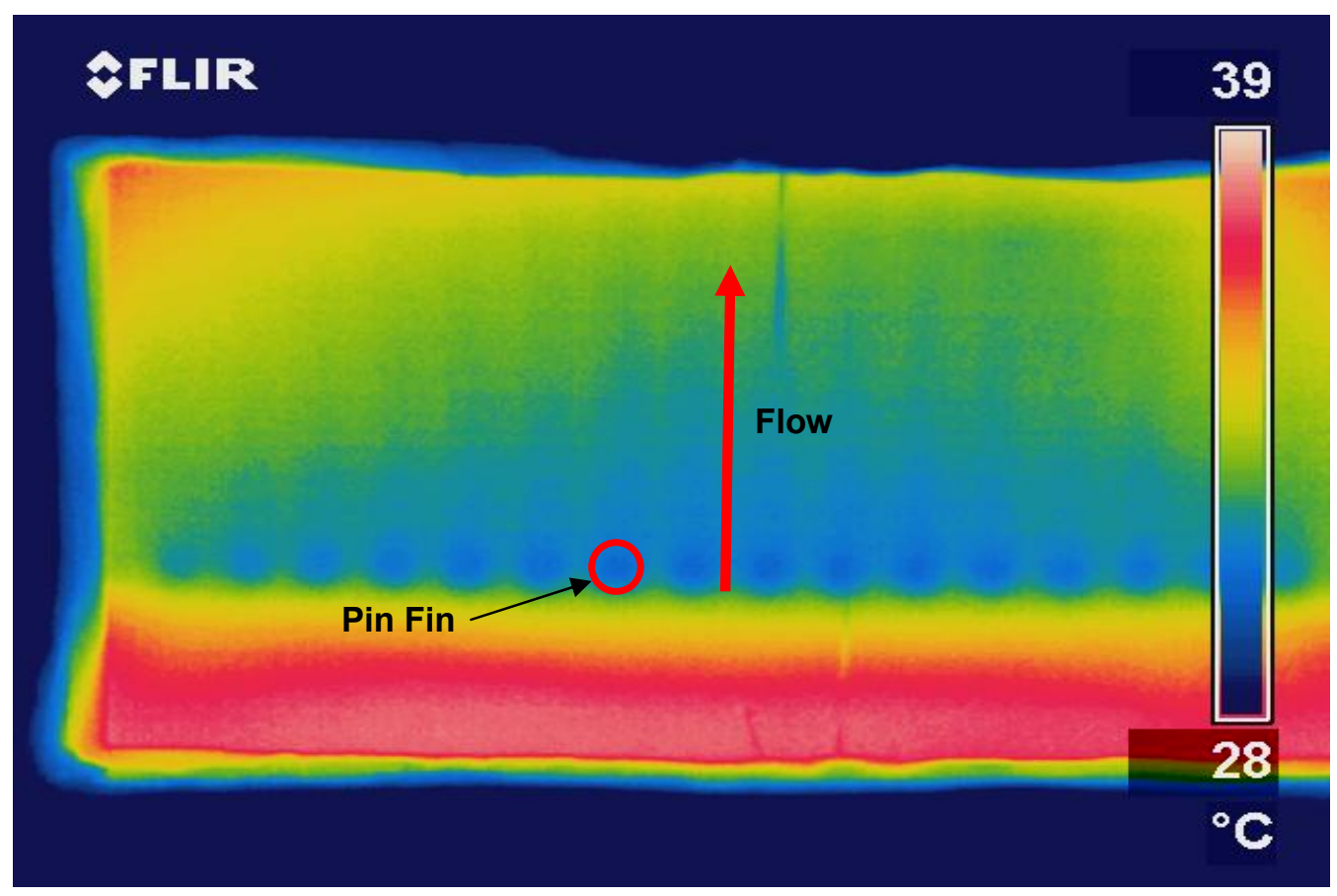

Figure 3-26 Infrared image with the pin fins lifted off of the test section floor.

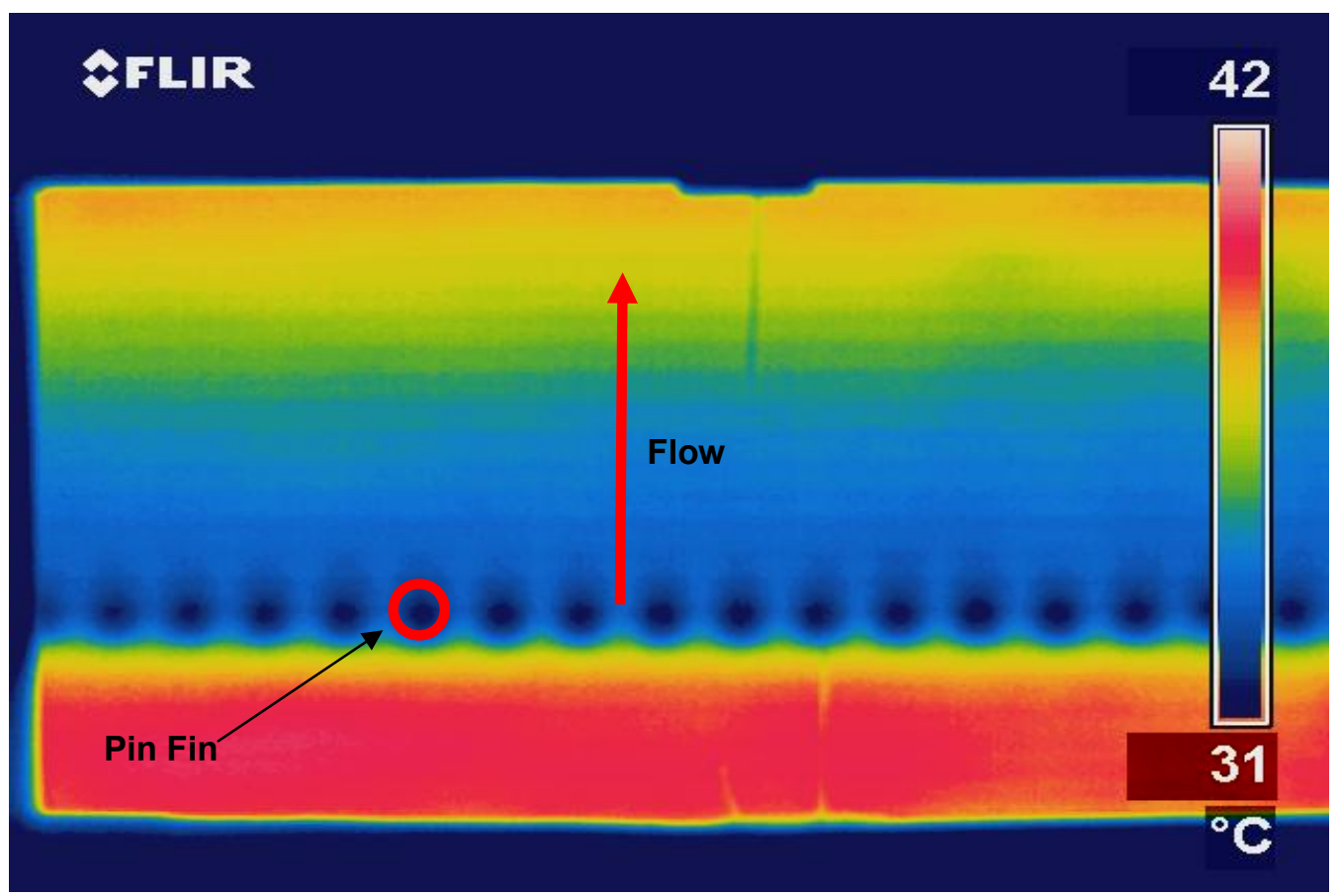

Figure 3-27 Infrared image with the pin fins properly seated on the test section floor. 


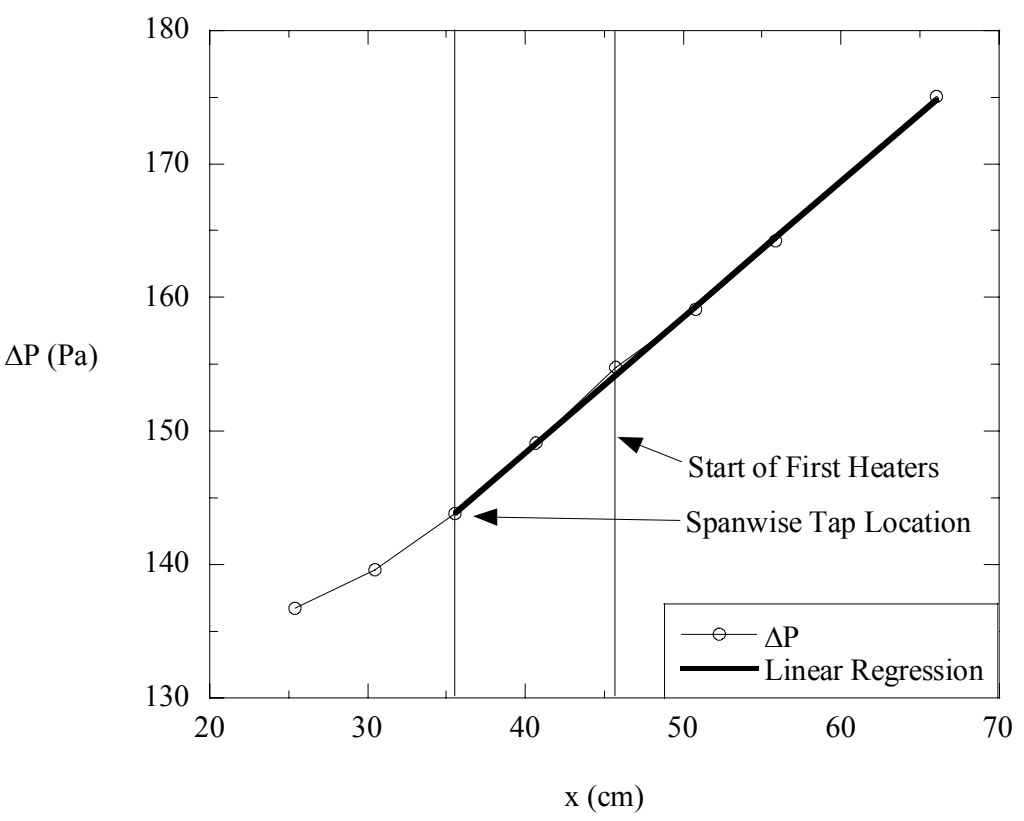

Figure 3-28 Developing pressure profile along the length of the channel $(\operatorname{Re}=13,000)$.

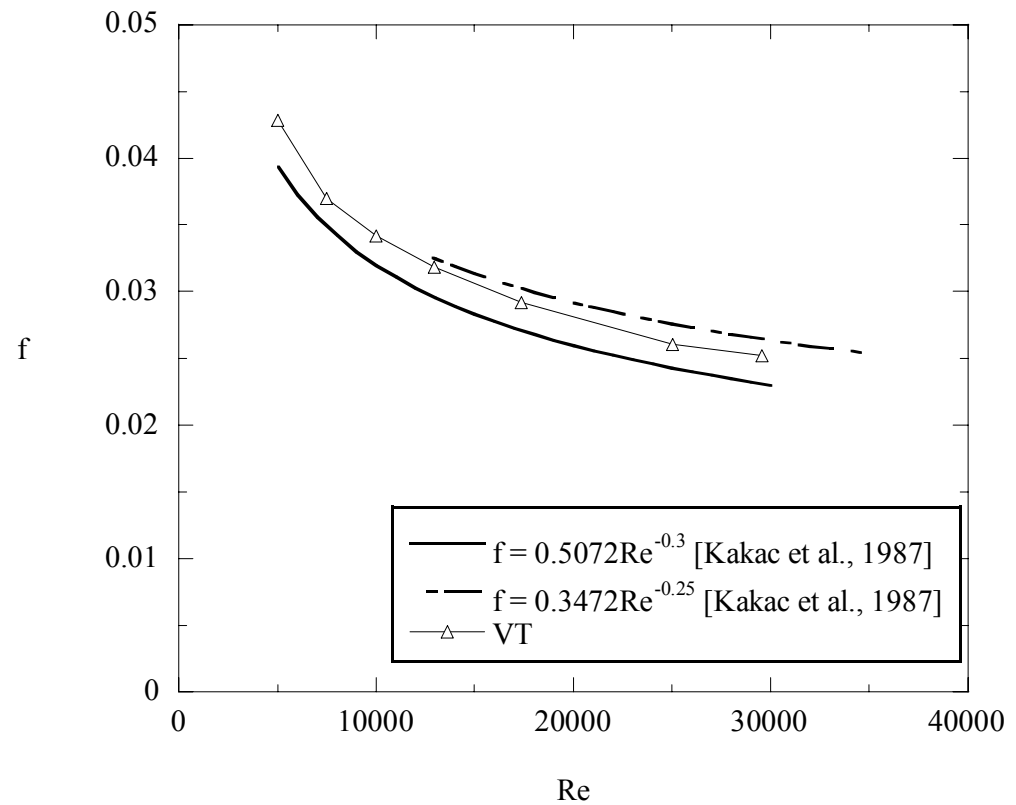

Figure 3-29 Friction factor results. 


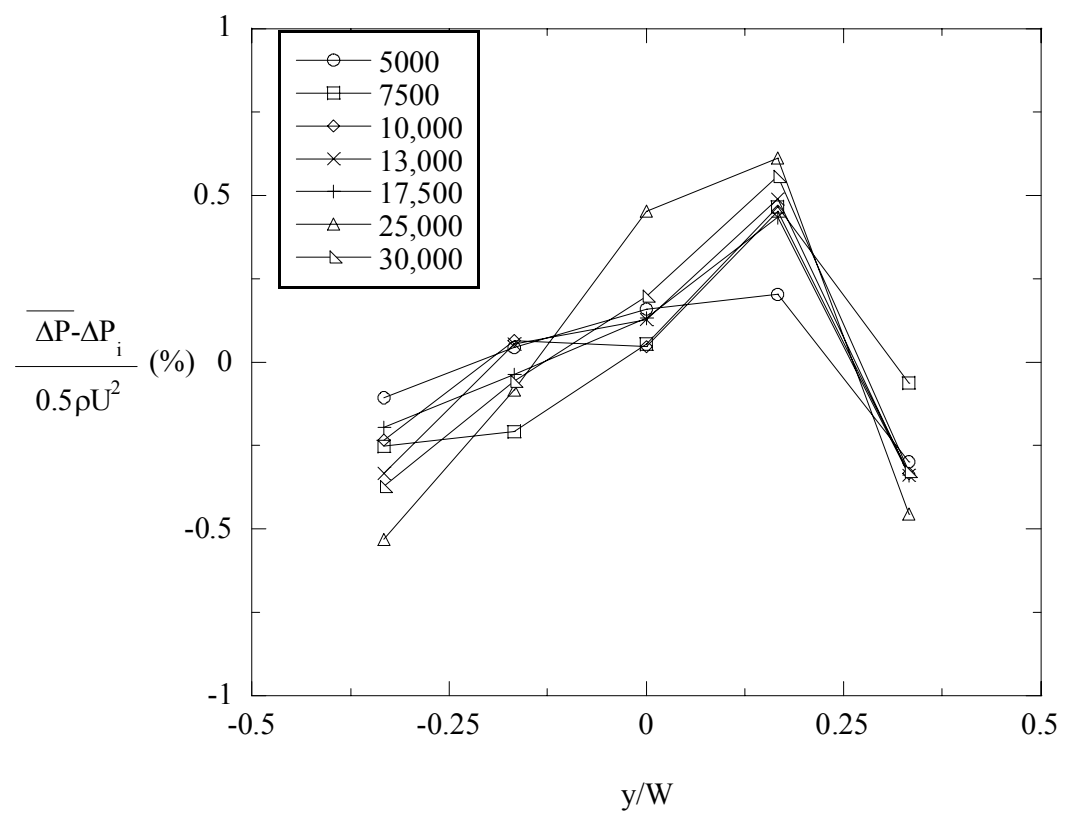

Figure 3-30 Test section spanwise uniformity plot.

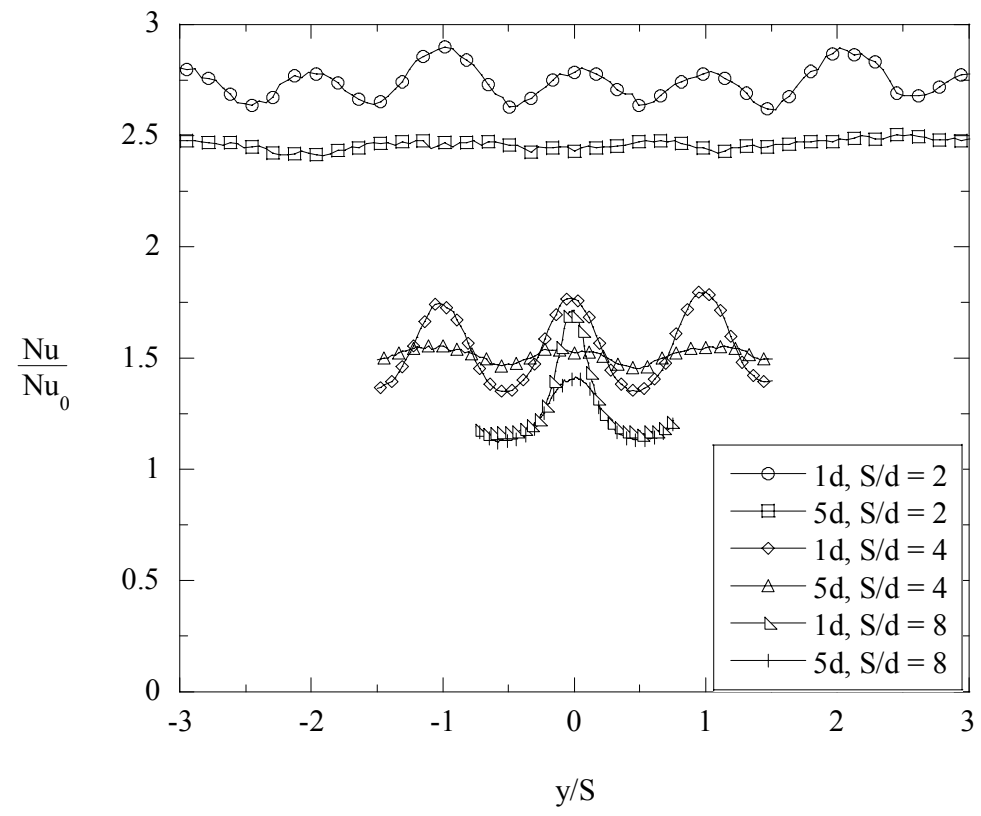

Figure 3-31 Spanwise Nusselt number line plots extracted from the endwall data one and five pin diameters (d) downstream of the trailing edge of the pin row for $\mathrm{S} / \mathrm{d}=2,4$, and 8 single row geometries. These results were produced for all three geometries at a nominal $\operatorname{Re}=13,000$. 


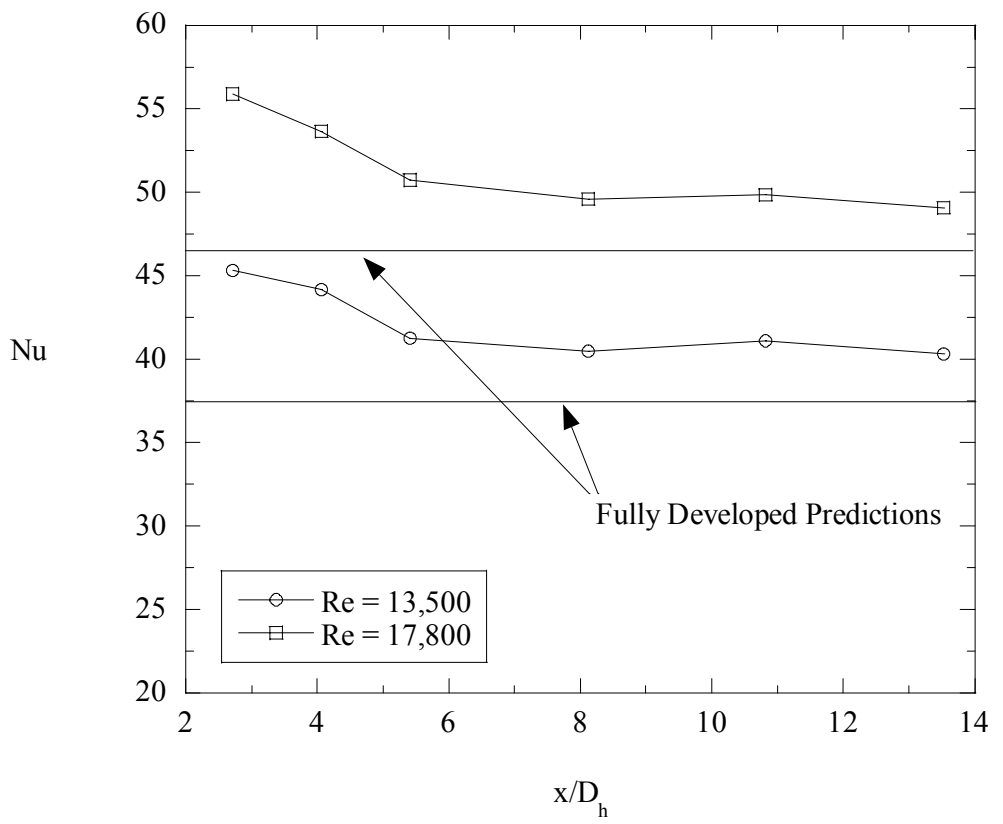

Figure 3-32 Developing Nusselt number profile along upstream heater surface. 


\section{Chapter 4}

\section{Data Reduction Methodology}

For the present study, temperatures were measured using thermocouples and an infrared camera. These measurements were used to calculate heat transfer coefficients on both the pin and endwall of a single row of pin fins. The endwall heat transfer measurements were made in this study using an infrared camera. The main strength of using an infrared camera is good spatial resolution. However, obtaining results requires post processing that is not required when using thermocouples. The infrared images were first calibrated using thermocouples on the endwall surface as standards. Due to capturing the data at an angle, the raw temperature images were skewed. As a result, the data were transformed back to an unskewed shape. Finally, the heat transfer coefficients were calculated, accounting for losses.

Three point measurements were made around the circumference of a single balsa wood pin fin for calculating the pin fin heat transfer. For increased resolution, two separate balsa wood pins were used at different rotation angles relative to the flow and the results were combined to calculate the average heat transfer of a single pin fin. Due to using point measurements on the pin fins with thermocouples, the analysis was relatively straightforward when calculating the heat transfer.

This chapter describes the data reduction procedure in detail. Section 4.1 first describes the endwall heat transfer analysis. Image post processing and the method of calculating endwall heat transfer coefficients accounting for losses are discussed in this section. Section 4.2 describes the method of computing the average heat transfer coefficients of the pin fins. Since knowing the combined pin and endwall heat transfer is important, Section 4.3 describes the way the separate pin and endwall data were analyzed to give the combined pin and endwall heat transfer results.

\subsection{Endwall Heat Transfer Analysis}

To begin the discussion of endwall heat transfer analysis, it is necessary to discuss the infrared image post processing. Figure 4-1 is a raw temperature image that shows the 
features which drove the post processing procedure. First note the thermocouple locations. To ensure that the calibration covered the temperature range, thermocouples were placed at locations with both high and low temperatures. Also note that the image is slightly skewed. The reason is that the camera had to be tilted to prevent reflection from the zinc selenide IR window surface back towards the camera. Figure 4-2 is a schematic that indicates the way the camera was reoriented to reduce the reflection problem. Placing the camera directly over head of the IR window as shown for position (a) caused a reflection in the center of the image, thus masking a large portion of the data. Moving the camera to position (b) greatly reduced the size of the reflection. As a result of reorienting the camera, only a small reflection is present in Figure 4-1. Finally, the marker locations outlined a rectangle on the heater surface. Although hard to see, in Figure 4-1, the rectangle outlined by the markers is slightly skewed. Matlab code written by Colban [2005] was used to transform the image back to a rectangular shape.

ThermaCam Researcher 2002 (ThermaCam) is the software that was used to calibrate the infrared images. To discuss image calibration, it was necessary to describe the way the infrared camera operates. The infrared camera senses radiation heat flux with wavelengths from the infrared band of the electromagnetic spectrum. According to Incropera and DeWitt [2002], the infrared band occurs in the range of $0.7<\lambda(\mu \mathrm{m})<100$, where $\lambda$ is the radiation wavelength. In addition, for a blackbody at temperatures within the range of the present experiments $\left(30\right.$ to $50^{\circ} \mathrm{C}$ ), the maximum emissive power for radiation heat transfer from the surface occurs at about a $10 \mu \mathrm{m}$ wavelength, which is well within the infrared band of the electromagnetic spectrum. The endwall which is viewed with the infrared camera is painted black to approximate the surface of a blackbody. Thus, the radiation emitted from the surface of the heater during testing is within the infrared band of the electromagnetic spectrum and measurable with the infrared camera.

The total radiation heat flux sensed by the camera from the surface of the heater is given by Equation 4-1:

$$
\mathrm{q}_{\mathrm{rad}}{ }^{\prime \prime}=\mathrm{E}+\rho \mathrm{G}
$$


where $\mathrm{E}$ is the total radiation generated from the surface, $\rho$ is the radiation reflectivity of the surface, and $G$ is the heat flux irradiated onto the surface of the heater from the surroundings or background. The product $\rho \mathrm{G}$ constitutes the radiation heat flux generated by the surroundings that is reflected from the heater surface towards the camera. Applying the Stefan-Boltzmann Law to E and G, and substituting (1- 1 ) for $\rho$ where $\varepsilon$ is the emissivity of the surface, Equation 4-1 can be recast as Equation 4-2:

$$
\mathrm{q}_{\mathrm{rad}}{ }^{\prime \prime}=\varepsilon \sigma \mathrm{T}_{\mathrm{w}}{ }^{4}+(1-\varepsilon) \sigma \mathrm{T}_{\mathrm{bg}}{ }^{4}
$$

where $\sigma$ is the Stefan-Boltzmann constant, $\mathrm{T}_{\mathrm{w}}$ is the heater temperature, and $\mathrm{T}_{\mathrm{bg}}$ is the background temperature. This assumes that the surroundings act as a blackbody, which is considered a valid assumption within enclosures. Substituting $\rho$ with $(1-\varepsilon)$ is considered valid since the heater is opaque. Rearranging Equation 4-2, the heater wall temperature is given by Equation 4-3:

$$
\mathrm{T}_{\mathrm{w}}=\left[\frac{1}{\varepsilon \sigma}\left(\mathrm{q}_{\mathrm{rad}}{ }^{\prime \prime}+(\varepsilon-1) \sigma \cdot \mathrm{T}_{\mathrm{bg}}{ }^{4}\right)\right]^{\frac{1}{4}}
$$

Using this relationship, the infrared camera converts the total radiation heat flux from the heater into surface temperatures.

In ThermaCam, each term in the right hand side of Equation 4-3 excluding $\sigma$ can be varied to achieve calibration. In all, seven parameters can be manipulated. These parameters are the emissivity, background temperature, atmospheric temperature, distance, relative humidity, and optics transmissivity and temperature. Both the emissivity of the surface and background temperature are direct inputs in Equation 4-3. The other five parameters in ThermaCam are used to manipulate the effective value of qrad" to calculate the temperatures on the heater. The atmospheric temperature, distance, and relative humidity were all used by the program to calculate the transmissivity of the air between the camera and the heater surface. Based on the ThermaCam results, the transmissivity of the air is always equal to one at room conditions. The optics 
transmission and temperature are used to calculate the radiation that is absorbed in an optical element between the measured surface and the camera. This scenario is directly related to the endwall measurement technique used in the present study, which incorporates a zinc selenide window.

Three thermocouples were used for each calibration. Two were placed upstream of the pin fins in a relatively warm region, and the other was placed within a pin wake, a relatively cool region. For a successful calibration, it was required that all measurement locations in the infrared image be within $\pm 1^{\circ} \mathrm{C}$ of the assigned calibration thermocouple, which is within the uncertainty of the infrared camera. Initially, the emissivity and background temperature were considered the primary variables to achieve calibration. However, attempts to match all three thermocouples generally failed. As a result, the optical transmissivity and temperature were taken into account. According to Rohm and Haas [1999], $8 \mathrm{~mm}$ thick zinc selenide has a transmissivity of approximately $70 \%$ over the range of $0.8<\lambda(\mu \mathrm{m})<14$, which is relevant to the present measurements. Although the zinc selenide window in the present experiments was $12.7 \mathrm{~mm}$ thick, the transmissivity was still assumed to be $70 \%$ as a starting point. Figure 4-3 is a plot that shows the transmissivity as a function of wavelength [Rohm and Haas, 1999].

As an example of the calibration results, Table 4-1 summarizes the calibration for the $\mathrm{S} / \mathrm{d}=2$ single row spacing at $\mathrm{Re}=13,072$. As a standard operating procedure, five images were taken for the data set to reduce the precision uncertainty. To obtain calibration for all five images, the optics temperature was varied between 22.6 and $23.6^{\circ} \mathrm{C}$. All other calibration parameters were held constant. As shown, the infrared images have reasonable agreement with the calibration thermocouples and are within the uncertainty of the infrared camera. In addition as shown in Table 4-1, the temperature differences between the heater wall and the bulk air temperature were above $10^{\circ} \mathrm{C}$ to maintain the heat transfer measurement uncertainty at a reasonable level. All calibrated images from ThermaCam were exported as temperature matrices in the form of Matlab data files for additional post processing. For a single data set, all five images were averaged to make one composite image.

Referring back to Figure 4-2, the infrared camera had to be placed at an angle to prevent errors in the data due to a reflection from the zinc selenide window. As a result, 
the composite infrared image had to be transformed back to the true rectangular shape. This transformation was carried out using a graphical user interface (GUI) Matlab program written by Colban [2005]. Figure 4-4 best describes how the program works. As shown, the markers for the skewed image do not form a rectangle, as indicated by the grey circles. Using the GUI program, the marker locations on the skewed image are selected. Then, the coordinates of the actual rectangle are input into the program. The program then moves the points from the skewed image to the appropriate corner locations and stretches the image to fit the new rectangular zone. This operation was done for each data set, completing the post processing of the endwall temperature data.

Before discussing how heat transfer coefficients were calculated, it is worth mentioning the losses that were considered when calculating the net heat flux entering the channel. Preliminary one-dimensional design calculations were carried out to estimate the losses to the atmosphere through the duct wall, and the insulated infrared window. The calculations were carried out assuming a bulk fluid temperature of $30^{\circ} \mathrm{C}$ and an ambient temperature of $20^{\circ} \mathrm{C}$. A free convection heat transfer coefficient of $5 \mathrm{~W} / \mathrm{m}^{2} \mathrm{~K}$ was assumed on the atmospheric side of the test rig. As a conservative estimate, the fully developed turbulent duct flow heat transfer prediction by Kays and Crawford [1980] given in Equation 3-13 was used to estimate the heat transfer coefficient inside the channel. A parallel resistance network was assumed. The details of the thermal resistances considered are given in Appendix C.

The preliminary results along with the measured heat loss of the $\mathrm{S} / \mathrm{d}=2,4$, and 8 pin spacings are shown in Figure 4-5. The loss represents the heat flux leaving the channel divided by the total heat flux generated, presented as a percentage. The loss is also presented as a function of the unobstructed duct Reynolds number, Re. The first point to notice is the similarity between the duct wall and the insulated IR window. This indicates that the thermal resistance through both are nearly equivalent, causing the same approximate losses. Based on this result, the array of heater wall temperatures obtained with the infrared camera for each test was used in conjunction with the room ambient temperature to calculate the heat loss. The actual losses out of the channel were calculated locally according to Equation 4-4: 


$$
\mathrm{q}_{\text {loss }} "=\frac{\mathrm{T}_{\mathrm{w}}-\mathrm{T}_{\mathrm{amb}}}{\frac{\mathrm{L}_{\mathrm{MDF}}}{\mathrm{k}_{\mathrm{MDF}}}+\frac{\mathrm{L}_{\text {ins }}}{\mathrm{k}_{\text {ins }}}+\frac{1}{\mathrm{~h}_{\text {amb }}}}
$$

where $T_{w}$ is the heater wall temperature at each pixel location, $T_{a m b}$ is the room ambient temperature, $\mathrm{L}_{\mathrm{MDF}}$ and $\mathrm{k}_{\mathrm{MDF}}$ are the thickness and thermal conductivity of the duct wall, $\mathrm{L}_{\mathrm{ins}}$ and $\mathrm{k}_{\mathrm{ins}}$ are the thickness and thermal conductivity of the insulation, and $\mathrm{h}_{\mathrm{amb}}$ is the ambient free convection heat transfer coefficient, assumed to be $5 \mathrm{~W} / \mathrm{m}^{2} \mathrm{~K}$. Due to nearly equivalent thermal resistances, this loss calculation was assumed to be representative of the loss through the duct wall and through the insulated IR window. Note that each measured data point in Figure 4-5 represents the average duct heat loss for each data set. All local loss measurements were averaged to obtain the overall duct heat loss.

The second main feature in Figure 4-5 is the magnitude of the loss percentages. As shown, the preliminary loss calculations are higher than the measured duct heat loss. The reason for the discrepancy is that the preliminary calculations were carried out with conservative estimates of the duct heat transfer coefficient and bulk fluid temperature to obtain estimates for the maximum heat loss from the channel. However, the measured heat loss from the experiments was lower due to reduced bulk fluid temperatures and higher heat transfer coefficients. As previously mentioned, a bulk fluid temperature of $30^{\circ} \mathrm{C}$, and the predicted fully developed unobstructed duct heat transfer coefficient were used for the preliminary loss calculations. For the actual experiments, the bulk temperatures ranged from approximately 10 to $20^{\circ} \mathrm{C}$ with duct wall heat transfer coefficients 1.5 to 3.2 times higher than the fully developed unobstructed duct heat transfer prediction. Only one measured data point is above $1 \%$.

The heated, wetted area inside the channel was used for calculating the net heat flux. Accounting for losses, the local net heat flux entering the channel is given by Equation 4-5:

$$
\mathrm{q}_{\text {net }} "=\frac{\mathrm{P}_{\text {heater, total }}-\mathrm{q}_{\text {loss }} "\left(2 \mathrm{~L}_{\text {heater }} \cdot \mathrm{W}\right)}{2 \mathrm{~L}_{\text {heater }} \cdot \mathrm{W}+0.5 \mathrm{~N} \pi \cdot \mathrm{d}^{2}}
$$


where $\mathrm{P}_{\text {heater, total }}$ is the total heater power, $\mathrm{L}_{\text {heater }}$ is the streamwise length of the heaters, $\mathrm{W}$ is the width of the heaters, $\mathrm{N}$ is the number of pin fins in the channel, and $\mathrm{d}$ is the pin diameter. The right hand term in the denominator of Equation 4-5 is used to subtract off the pin endwall area, and add on the pin surface area in contact with the flow. In this way, the denominator of Equation 4-5 gives the heated, wetted area inside the channel. For clarity, the power for each heater was calculated according to Equation 3-2:

$$
\mathrm{P}_{\text {heater }}=\left(\frac{\mathrm{V}_{\text {prec }}}{\mathrm{R}_{\text {prec }}}\right)^{2} \mathrm{R}_{\text {heater }}
$$

where $V_{\text {prec }}$ and $R_{\text {prec }}$ are the voltage and resistance respectively of a precision resistor placed in series with the heater, and $\mathrm{R}_{\text {heater }}$ is the electrical resistance of the heater. The precision resistor gives a more accurate estimate of the heater supply current.

The other loss consideration was a potential temperature drop across the thickness of the heater. Referring back to Figure 3-10, thin inconel foil situated between two layers of Kapton generated the endwall heater heat flux. As shown in Figure 4-5, almost all of the heat flux enters the channel flow. As a result, there is potential for a significant temperature drop across the layer of Kapton in contact with the flow. Using the properties of the Kapton layer and heat flux settings used for the $S / d=2$ endwall heat transfer tests in the Reynolds number range of $5000<\operatorname{Re}<30,000$, Figure 4-6 was produced to illustrate the potential temperature drop across the Kapton layer in contact with the flow. As shown, the temperature drop reaches nearly $2{ }^{\circ} \mathrm{C}$ at the highest heat flux setting. When considering a temperature difference of about $10{ }^{\circ} \mathrm{C}$ between the endwall and bulk flow, a $2{ }^{\circ} \mathrm{C}$ temperature drop across the heater will cause a $20 \%$ bias error when calculating heat transfer coeffients. As a result of this analysis, all endwall temperatures were corrected according to Equation 4-6:

$$
\mathrm{T}_{\text {corr }}=\mathrm{T}_{\mathrm{w}}-\mathrm{q}_{\text {net }}{ }^{\prime \prime}\left(\frac{\mathrm{L}_{\text {Kapton }}}{\mathrm{k}_{\text {Kapton }}}\right)
$$


where $T_{\mathrm{w}}$ is the measured endwall temperature, $\mathrm{L}_{\mathrm{Kapton}}$ is the thickness of the Kapton layer, and $\mathrm{k}_{\text {Kapton }}$ is the thermal conductivity of Kapton.

Using the loss corrections described above, a separate Matlab program was used to convert the endwall temperatures to heat transfer coefficients. Each pixel location of the images represented a temperature. Thus, for each individual temperature on the endwall, the heat transfer coefficient was defined as given by Equation 4-7:

$$
\mathrm{h}=\frac{\mathrm{q}_{\text {net }} "}{\mathrm{~T}_{\text {corr }}-\mathrm{T}_{\text {bulk }}}
$$

where $\mathrm{q}_{\text {net }}$ " is the net heat flux, $\mathrm{T}_{\text {corr }}$ gives the corrected wall temperature, and $\mathrm{T}_{\text {bulk }}$ is the bulk temperature of the fluid in the channel. The constant heat flux boundary condition imposed by the endwall heaters resulted in the bulk fluid temperature varying linearly along the streamwise direction of the channel. Applying an energy balance to the test section, the bulk fluid temperature was defined by Equation 4-8:

$$
\mathrm{T}_{\text {bulk }}=\mathrm{T}_{\text {in }}+\frac{\overline{\overline{\mathrm{Q}_{\text {net }}}}}{\overline{\mathrm{mC}_{\mathrm{p}}}}\left(\frac{\mathrm{x}}{\mathrm{L}_{\text {heater }}}\right)
$$

where $T_{i n}$ is the channel inlet temperature, $m$ is the mass flow rate, $C_{p}$ is the specific heat of air, $\mathrm{x}$ is the streamwise distance along the heaters where the bulk temperature is being evaluated, $L_{\text {heater }}$ is the streamwise length of the heaters, and $\overline{\overline{Q_{n e t}}}$ is the average net heat rate entering the channel. The net heat rate is defined by Equation 4-9:

$$
\overline{\overline{\mathrm{Q}_{\text {net }}}}=\overline{\overline{\mathrm{q}_{\text {net }}}} "\left(2 \mathrm{~L}_{\text {heater }} \cdot \mathrm{W}+0.5 \mathrm{~N} \pi \cdot \mathrm{d}^{2}\right)
$$

where $\overline{\overline{\mathrm{q}_{\text {net }}}}$ " is the average net heat flux entering the channel, and $\left(2 \mathrm{~L}_{\text {heater }} \cdot \mathrm{W}+0.5 \mathrm{~N} \pi \cdot \mathrm{d}^{2}\right)$ defines the total heated, wetted area inside the channel. 
For scaling purposes, heat transfer coefficients are most useful in nondimensional form. In the present study, the heat transfer coefficients were nondimensionalized as Nusselt numbers. Because the pin fin row and the endwall upstream and downstream of the pin fins were studied, two Nusselt number definitions were used. The first definition was based on the convention found in the pin fin array literature. This definition is given by Equation 4-10:

$$
\mathrm{Nu}_{\mathrm{d}}=\frac{\mathrm{hd}}{\mathrm{k}}
$$

where $\mathrm{h}$ is the heat transfer coefficient, $\mathrm{d}$ is the pin diameter, and $\mathrm{k}$ is the thermal conductivity of the air. It is also convention in the literature to present the heat transfer results as a function of Reynolds number as given in Equation 4-11:

$$
\operatorname{Re}_{\mathrm{d}}=\frac{\mathrm{U}_{\max } \mathrm{d}}{v}
$$

where $U_{\max }$ is the maximum average velocity between the pins, $d$ is the pin diameter, and $v$ is the kinematic viscosity of the air.

Since the endwall results were also compared to unobstructed duct flow heat transfer, the heat transfer coefficients were non-dimensionalized by Equation 4-12:

$$
\mathrm{Nu}=\frac{\mathrm{hD}_{\mathrm{h}}}{\mathrm{k}}
$$

where $\mathrm{h}$ is the heat transfer coefficient, $\mathrm{D}_{\mathrm{h}}$ is the channel hydraulic diameter, and again, $\mathrm{k}$ is the thermal conductivity of the air. The corresponding Reynolds number is given by Equation 4-13:

$$
\operatorname{Re}=\frac{U_{\mathrm{h}}}{v}
$$


where $\mathrm{U}$ is the average channel velocity, $\mathrm{D}_{\mathrm{h}}$ is the hydraulic diameter of the channel, and $v$ is the kinematic viscosity of the air. For the unobstructed duct flow comparisons, the turbulent, fully developed smooth duct correlation by Kays and Crawford [1980] was used as a baseline. This prediction is given as Equation 3-13:

$$
\mathrm{Nu}_{0}=0.022 \mathrm{Re}^{0.8} \operatorname{Pr}^{0.5}
$$

To make the smooth duct comparisons, the heat transfer results were presented as $\mathrm{Nu} / \mathrm{Nu}_{0}$, which yield the heat transfer augmentation over turbulent, fully developed smooth duct flow.

\subsection{Pin Fin Heat Transfer Analysis}

Calculating heat transfer coefficients on the pin fin surface was more straightforward than on the endwall. Referring back to Figure 3-15, the pin fin heat transfer measurements were made on a balsa wood pin fin wrapped with a heated inconel foil. Thermocouples were mounted under the inconel foil at the leading, side, and trailing edges of the pin fin at the pin mid-plane. The heat transfer coefficients for the pin fin at each location were calculated according to Equation 4-14:

$$
h_{\text {pin }}=\frac{\frac{P_{\text {foil }}}{A_{\text {foil }}}}{T_{\text {pin }}-T_{\text {bulk }}}
$$

where $\mathrm{P}_{\text {foil }}$ is the power of the inconel foil given by Equation 3-5, $\mathrm{A}_{\text {foil }}$ is the surface area

of the foil, $\mathrm{T}_{\text {pin }}$ the measured foil temperature at the desired location, and $\mathrm{T}_{\text {bulk }}$ is the bulk temperature of the flow. Due to the test section endwall heaters not operating during the pin fin tests, $\mathrm{T}_{\text {bulk }}$ was assumed to be equal to the test section inlet temperature.

The heat loss was assumed negligible for the pin fin tests. This assumption is justified when considering that the inconel heater was attached to the outside of the balsa wood pin fin. As shown for the endwall heat transfer tests, the heat loss out of the channel was measured to be less than $1 \%$ for nearly all flow cases. For the pin fin heat 
transfer tests, balsa wood which has a very low thermal conductivity $(0.055 \mathrm{~W} / \mathrm{m}-\mathrm{K})$ added an additional thermal resistance in comparison to the endwall heat transfer tests. In addition, the balsa wood pin fin tests were carried out with the pin rows downstream of the test section heaters, which prevented heat loss to the thin copper layer deposited on the heater surface. Considering these reasons, the negligible heat loss assumption seems justified.

Similar to the endwall tests, all pin fin heat transfer results were nondimensionalized as Nusselt numbers. Generally, the heat transfer coefficients were converted to $\mathrm{Nu}_{\mathrm{d}}$, which is based on the pin diameter. The corresponding Reynolds number was $\mathrm{Re}_{\mathrm{d}}$, which is based on the maximum velocity between the pins and the pin diameter. However as discussed in Section 4.3, the pin and endwall results were also combined to give overall averages. In this case, the pin fin heat transfer coefficients were also converted to $\mathrm{Nu}$, allowing comparisons with fully developed, unobstructed duct flow. In this scenario, the results were presented as $\mathrm{Nu} / \mathrm{Nu}_{0}$, which gives the augmentation over turbulent, fully developed smooth duct heat transfer. $\mathrm{Nu}_{0}$ was defined in Equation 3-13. To maintain consistent length and velocity scales, Re was the relevant Reynolds number when presenting the results as $\mathrm{Nu} / \mathrm{Nu}_{0}$.

For increased resolution, two balsa wood pins were installed in the pin fin row and the results from both pins were combined to give an overall average. Figure 4-7 is a schematic that shows how the two pins were oriented. As shown, the pin on the left is placed with the leading and trailing thermocouples in line with the flow. Using only one pin fin with this orientation gives $90^{\circ}$ measurement resolution around the circumference of one side. The pin fin on the right is rotated $45^{\circ}$ relative to the flow direction, giving additional measurement locations at $45^{\circ}$ and $135^{\circ}$ from the leading edge. The third thermocouple on the pin on the right was not used. Combining the heat transfer coefficients in order from one to five as shown in Figure 4-7 gave $45^{\circ}$ measurement resolution around one side of the pin fin.

Figure 4-8 is a sample of circumferential pin fin data for the $S / d=2$ pin spacing at $\mathrm{Re}_{\mathrm{d}}=30,514$ plotted with first row data from Ames et al. [2004] at $\operatorname{Re}_{\mathrm{d}}=30,047$. The goal of this project was not to resolve in detail the circumferential heat transfer variation, but obtain average values of pin fin heat transfer. To obtain the average, the heat transfer 
distribution was numerically integrated using the trapezoidal rule according to Equation 4-15:

$$
\mathrm{Nu}_{\mathrm{d}}=\frac{1}{2(\mathrm{n}-1)} \sum_{\mathrm{i}=1}^{\mathrm{n}-1}\left[\mathrm{Nu}_{\mathrm{d}}(\mathrm{i})+\mathrm{Nu}_{\mathrm{d}}(\mathrm{i}+1)\right]
$$

All pin fin data from the present study were analyzed in this manner.

The measurement resolution of $45^{\circ}$ was chosen after examining the first row circumferential pin fin data from Ames et al. [2004], which is also shown in Figure 4-8. The first row data were extracted from the plot and numerically integrated with full resolution according to Equation 4-15 to use as a baseline for comparison. Then, the data was integrated with fewer points to investigate the effect of less resolution on the overall average. Analyzing the data with $90^{\circ}$ resolution caused a percent difference of $+3.7 \%$. However, analyzing the data with $45^{\circ}$ resolution reduced the percent difference to only $+1.3 \%$. Considering that typical measurement uncertainties are on the order of $5 \%$ or more, $45^{\circ}$ measurement resolution was considered acceptable for calculating the average pin fin heat transfer.

\subsection{Method of Combining Pin and Endwall Results}

Of primary importance to a turbine designer are the combined pin and endwall heat transfer results, which give the overall cooling effectiveness of the pin fin row or array. In the present study, the pin and endwall data were gathered during separate tests. As a result, a method was developed to combine the results.

Since only single rows of pin fins were studied, the first question was how far upstream and downstream of the pin row to include the endwall data when calculating the combined pin and endwall heat transfer. To answer this question, pin fin array data reported by Metzger et al. [1982a] was examined. In their study, the combined pin and endwall heat transfer was reported on a row by row basis for two staggered arrays with streamwise spacings of $\mathrm{x} / \mathrm{d}=1.5$ and 2.5. All other geometric parameters were maintained constant. The pin fin rows were constructed as individual segments that were 
stacked end to end to form the entire array. Heat transfer results were reported for each segment.

For the streamwise spacing of $\mathrm{x} / \mathrm{d}=1.5$, the segments extended 0.25 pin diameters upstream and downstream of the pin fin row. For $\mathrm{x} / \mathrm{d}=2.5$, the segments extended 0.75 pin diameters upstream and downstream of the pin fin row. Metzger et al. [1982a] claimed that the first row results for both streamwise spacings were within experimental uncertainty, and gave a single correlation to represent the first row results. As a result of the findings reported by Metzger et al. [1982a], data 0.5 pin diameters upstream and downstream of the pin fin row were included for calculating the combined pin and endwall heat transfer for a single row of pin fins.

For arrays of short pin fins typically found in gas turbine airfoils, both the pins and endwalls make significant contributions to the total heat transfer area. To compute the combined pin and endwall heat transfer, area fractions were calculated to represent the amount of heat transfer due to the pins and endwalls separately. Figure 4-10 is a drawing of one pin pitch in the transverse direction extending 0.5 pin diameters upstream and downstream of the pin fins. Using the nomenclature as shown, the fraction of the heat transfer area due to the pin fins is given by Equation 4-16:

$$
\frac{\mathrm{A}_{\text {pin }}}{\mathrm{A}_{\text {total }}}=\frac{\pi \mathrm{d} \cdot \mathrm{H}}{4 \mathrm{~S} \cdot \mathrm{d}-0.5 \pi \cdot \mathrm{d}^{2}+\pi \mathrm{d} \cdot \mathrm{H}}
$$

Similarly, the fraction of the heat transfer area due to the endwall is given by Equation 417:

$$
\frac{\mathrm{A}_{\text {endwall }}}{\mathrm{A}_{\text {total }}}=\frac{4 \mathrm{~S} \cdot \mathrm{d}-0.5 \pi \cdot \mathrm{d}^{2}}{4 \mathrm{~S} \cdot \mathrm{d}-0.5 \pi \cdot \mathrm{d}^{2}+\pi \mathrm{d} \cdot \mathrm{H}}=1-\frac{\mathrm{A}_{\text {pin }}}{\mathrm{A}_{\text {total }}}
$$

Using these area fractions, the combined pin and endwall heat transfer was defined by Equation 4-18: 


$$
\mathrm{Nu}_{\mathrm{d}}=\mathrm{Nu}_{\mathrm{d} \text {,pin }} \frac{\mathrm{A}_{\text {pin }}}{\mathrm{A}_{\text {total }}}+\mathrm{Nu}_{\mathrm{d} \text {,endwall }} \frac{\mathrm{A}_{\text {endwall }}}{\mathrm{A}_{\text {total }}}
$$

The same area fractions were used whether calculating values of $\mathrm{Nu}_{\mathrm{d}}$ or $\mathrm{Nu}$. Table 4-2 gives the area fractions for the $\mathrm{S} / \mathrm{d}=2,4$, and 8 single row pin spacings. It must also be noted that the data underneath the pin fins were extracted when calculating the average endwall heat transfer across the pin row. Although the data were periodic across the span, the average heat transfer was calculated over three to five pin pitches to obtain a suitable average.

The last consideration when combining the pin and endwall data was calculating the Reynolds number. To simplify the process, both pin and endwall tests were carried out at the same approximate Reynolds numbers. As a result, it was considered acceptable to compute the mean Reynolds number between the pin and endwall data sets to use for presenting the combined results. In addition, using the same approximate Reynolds number is why it was considered acceptable to combine the pin and endwall results directly using Equation 4-18. 
Table 4-1 Calibration Results for $\mathrm{S} / \mathrm{d}=2, \mathrm{Re}=13,072, \mathrm{Re}_{\mathrm{d}}=13,274$

\begin{tabular}{|c|c|c|c|c|c|}
\hline & \multicolumn{5}{|c|}{ Image } \\
\hline & 1 & 2 & 3 & 4 & 5 \\
\hline Emissivity, $\varepsilon$ & 1.0 & 1.0 & 1.0 & 1.0 & 1.0 \\
\hline Background Temperature $\mathrm{T}_{\mathrm{bg},{ }^{\circ} \mathrm{C}}$ & 20.0 & 20.0 & 20.0 & 20.0 & 20.0 \\
\hline Optics Transmissivity $\tau$ & 0.7 & 0.7 & 0.7 & 0.7 & 0.7 \\
\hline Optics Temperature $\mathrm{T}_{\mathrm{opt},}{ }^{\circ} \mathrm{C}$ & 22.6 & 22.6 & 22.6 & 23.2 & 23.6 \\
\hline Distance L, $\mathrm{m}$ & 0.8 & 0.8 & 0.8 & 0.8 & 0.8 \\
\hline Atmospheric Temperature $T_{\text {atm }}{ }^{\circ} \mathrm{C}$ & 20.0 & 20.0 & 20.0 & 20.0 & 20.0 \\
\hline Relative Humidity, $\varphi$ & 0.3 & 0.3 & 0.3 & 0.3 & 0.3 \\
\hline \multicolumn{6}{|l|}{ Calibration Thermocouples, ${ }^{\circ} \mathrm{C}$} \\
\hline $\mathrm{T}_{1}$ & 41.3 & 41.3 & 41.3 & 41.3 & 41.3 \\
\hline $\mathrm{T}_{2}$ & 41.4 & 41.4 & 41.4 & 41.4 & 41.4 \\
\hline $\mathrm{T}_{3}$ & 33.3 & 33.3 & 33.3 & 33.3 & 33.3 \\
\hline \multicolumn{6}{|l|}{ Image Calibration Results, ${ }^{\circ} \mathrm{C}$} \\
\hline $\mathrm{T}_{1, \mathrm{cal}}$ & 41.8 & 41.8 & 41.8 & 41.7 & 41.8 \\
\hline $\mathrm{T}_{2, \mathrm{cal}}$ & 41.5 & 41.5 & 41.5 & 41.5 & 41.5 \\
\hline $\mathrm{T}_{3, \mathrm{cal}}$ & 32.8 & 32.8 & 32.7 & 32.7 & 32.7 \\
\hline \multicolumn{6}{|l|}{ Temperature Difference, ${ }^{\circ} \mathrm{C}$} \\
\hline $\mathrm{T}_{1, \mathrm{cal}}-\mathrm{T}_{1}$ & 0.5 & 0.5 & 0.5 & 0.4 & 0.5 \\
\hline $\mathrm{T}_{2, \mathrm{cal}}-\mathrm{T}_{2}$ & 0.1 & 0.1 & 0.1 & 0.1 & 0.1 \\
\hline $\mathrm{T}_{3, \mathrm{cal}}-\mathrm{T}_{3}$ & -0.5 & -0.5 & -0.6 & -0.6 & -0.6 \\
\hline \multicolumn{6}{|l|}{ Driving Potential, $\mathrm{T}_{\text {cal }}-\mathrm{T}_{\text {bulk }},{ }^{\circ} \mathrm{C}$} \\
\hline $\mathrm{T}_{1, \mathrm{cal}}-\mathrm{T}_{\text {bulk } 1}$ & 23.48 & 23.48 & 23.48 & 23.38 & 23.48 \\
\hline$T_{2, \text { cal }}-T_{\text {bulk } 2}$ & 23.18 & 23.18 & 23.18 & 23.18 & 23.18 \\
\hline $\mathrm{T}_{3, \mathrm{cal}}-\mathrm{T}_{\text {bulk } 3}$ & 12.67 & 12.67 & 12.57 & 12.57 & 12.57 \\
\hline
\end{tabular}

Table 4-2 Summary of Area Fractions for $\mathrm{S} / \mathrm{d}=2,4$, and 8 Pin Spacings

\begin{tabular}{|l|c|c|c|}
\hline & \multicolumn{3}{|c|}{ S/d } \\
\cline { 2 - 4 } & 2 & 4 & 8 \\
\hline $\mathrm{A}_{\text {pin }} / \mathrm{A}_{\text {total }}$ & 0.328 & 0.179 & 0.094 \\
\hline $\mathrm{A}_{\text {endwall }} / \mathrm{A}_{\text {total }}$ & 0.672 & 0.821 & 0.906 \\
\hline
\end{tabular}



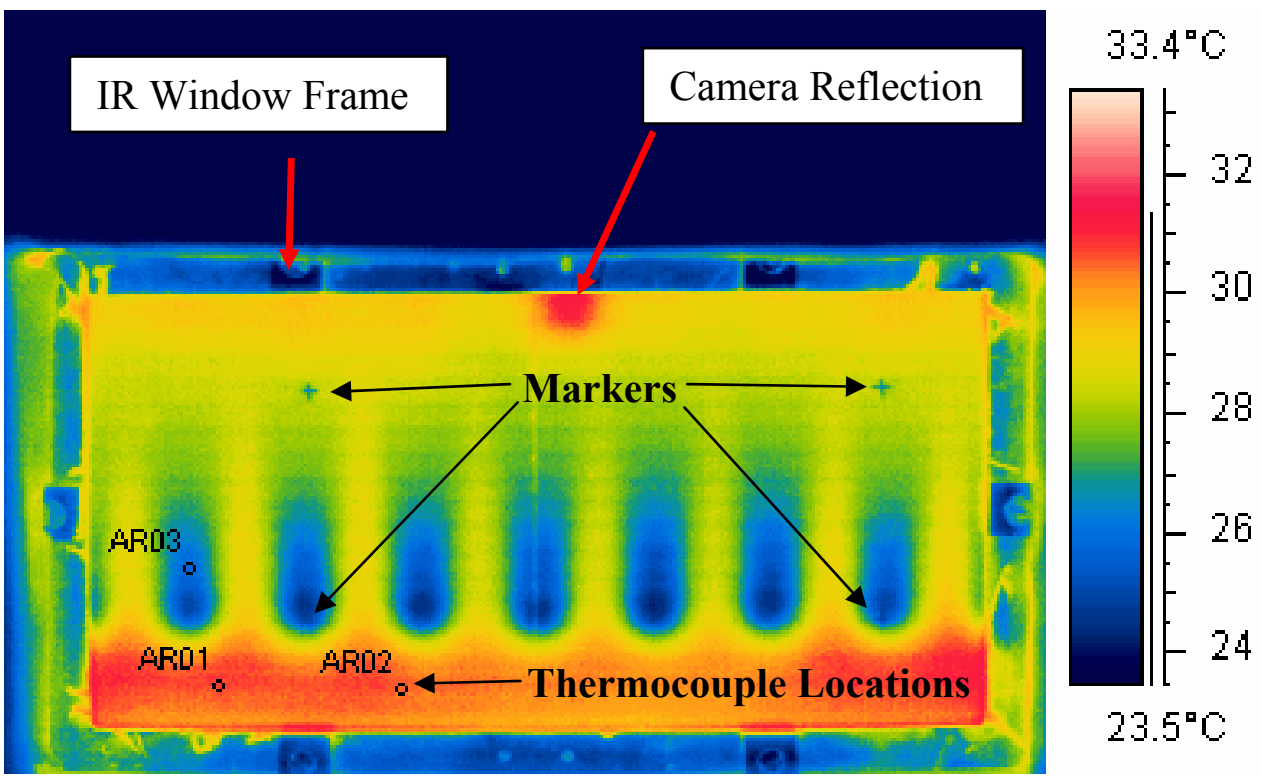

$23.5^{\circ} \mathrm{C}$

Figure 4-1 Raw infrared temperature image of the $S / d=4$ single row geometry at $R e=$ 12,964. The image was captured from ThermaCam, the IR image calibration software.

(a)

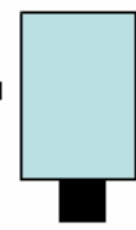

(b)

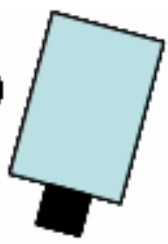

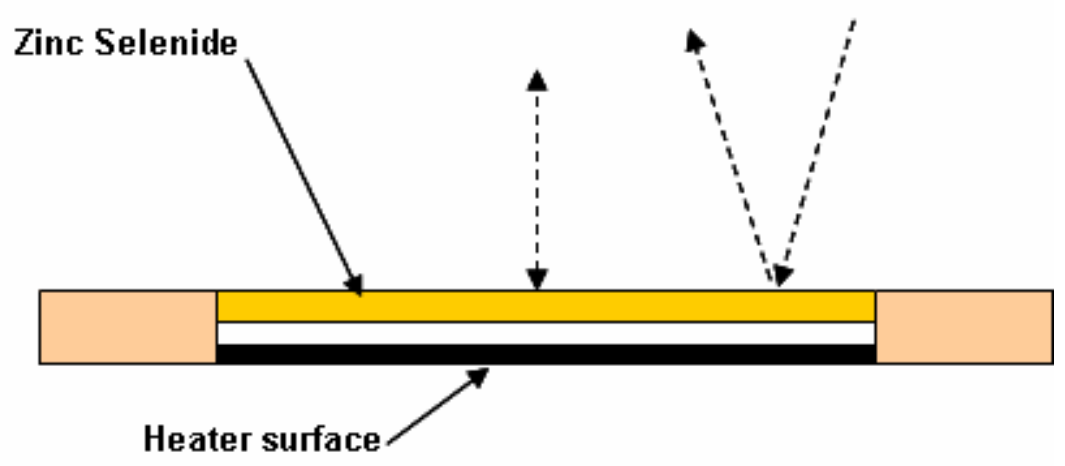

Figure 4-2 Schematic showing the camera orientation to prevent reflection. Camera position (a) causes reflection. Position (b) removes the reflection from most of the image. 
CVD ZINC SELENIDE Transmission

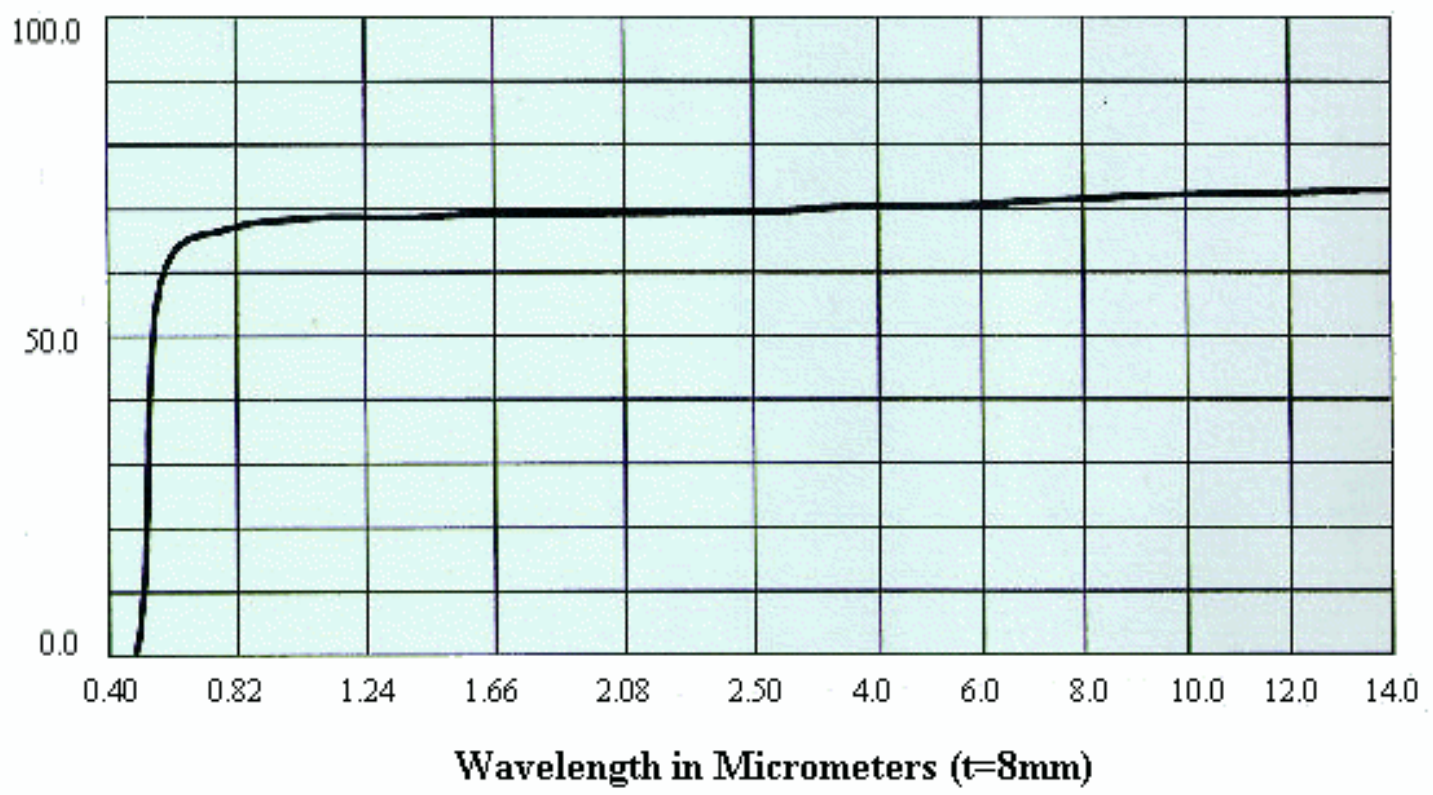

Figure 4-3 Zinc selenide transmissivity as a function of radiation wavelength [Rohm and Haas, 1999].

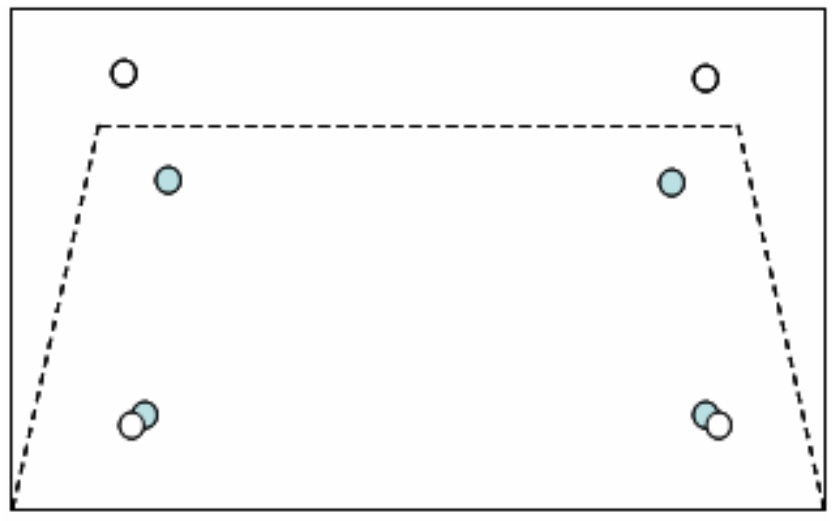

O Skewed Marker Location

O Transformed Marker Location

--- Skewed Image Outline

- Transformed Image Outline

Figure 4-4 Sketch showing the difference between a skewed and transformed image. 


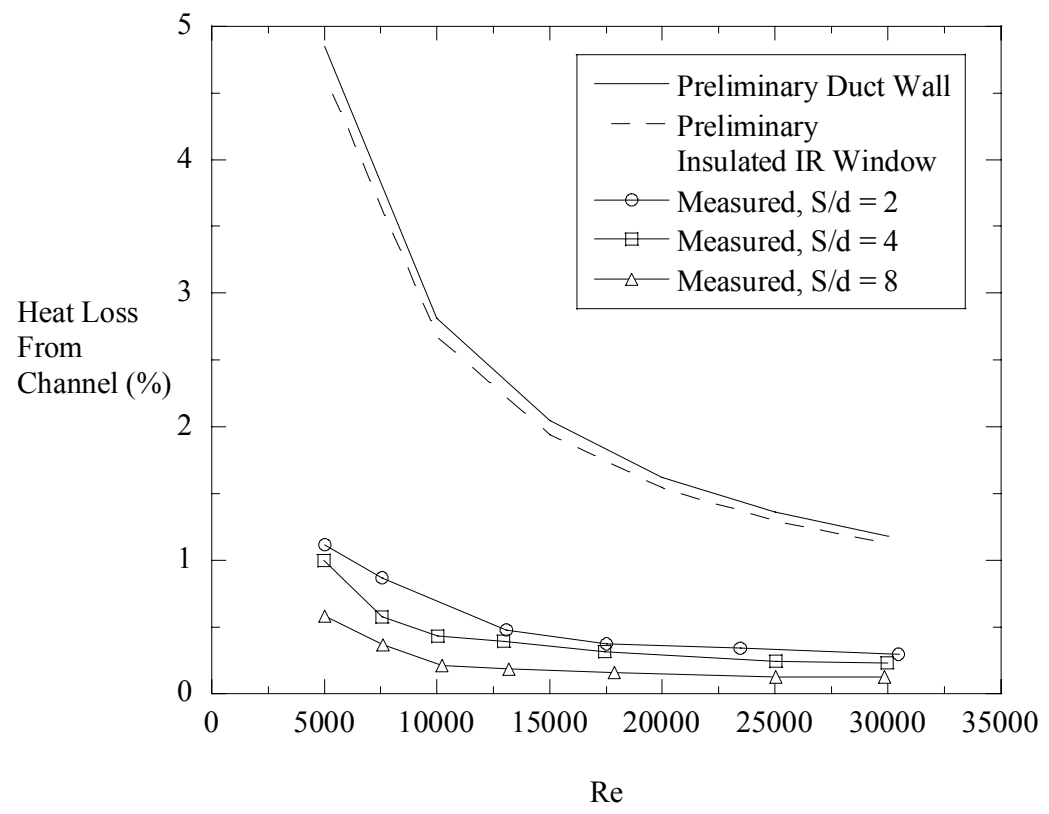

Figure 4-5 Estimated plain duct flow heat loss and measured channel heat loss for the three single row geometries.

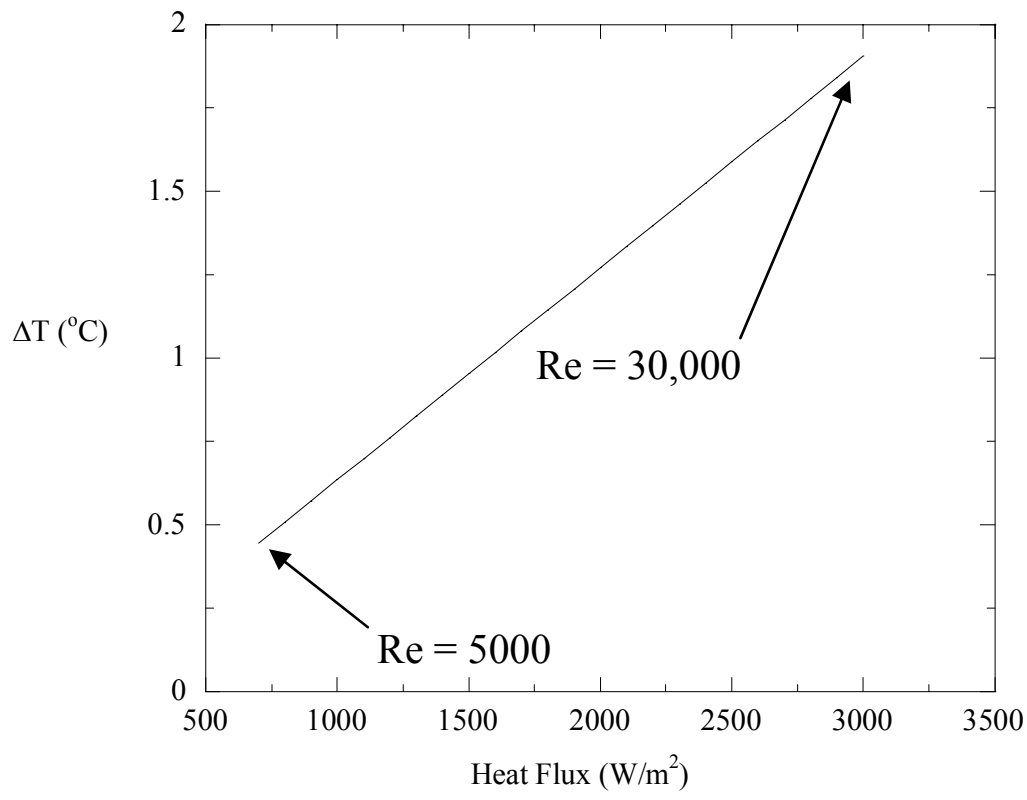

Figure 4-6 Estimated temperature drop across the heater as a function of heat flux over the range of $5000<\operatorname{Re}<30,000$ for the $\mathrm{S} / \mathrm{d}=2$ pin spacing. Because heat transfer coefficients increase with the Reynolds number, higher heat flux settings are required to maintain a reasonable difference between the wall and bulk temperatures. 


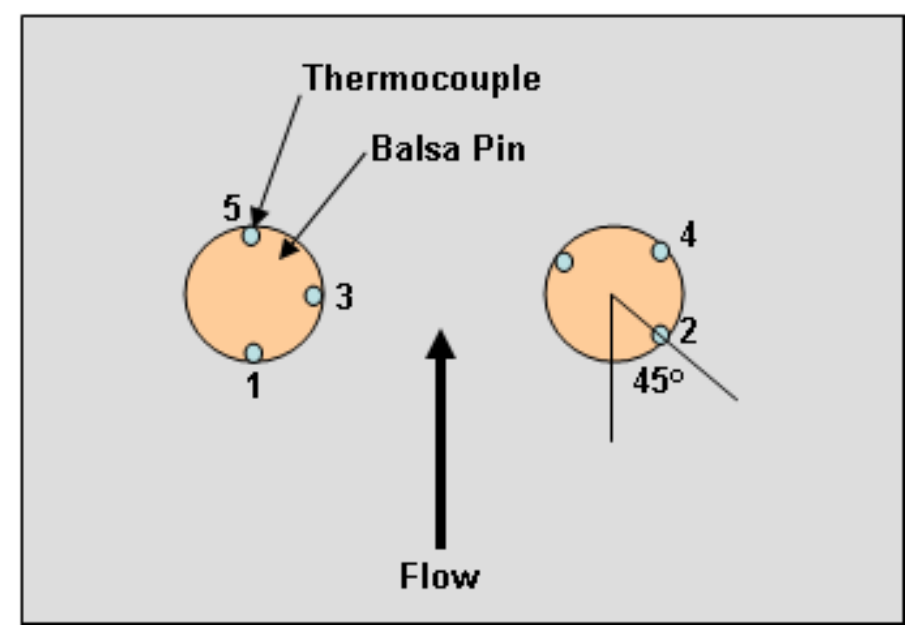

Figure 4-7 Schematic showing the balsa wood pin fin orientation for increased circumferential resolution. Note that this figure is not to scale and does not indicate the actual placement in the channel. It only points out the pin orientation for combining pin fin results.

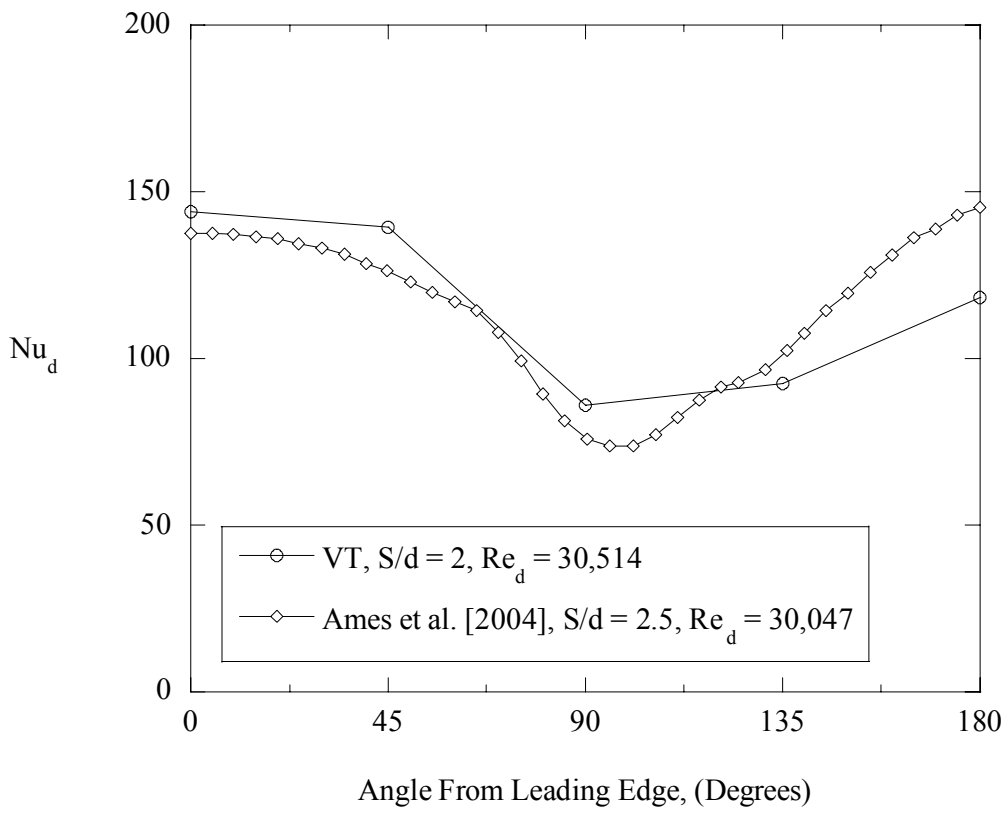

Figure 4-8 Plot of circumferential pin fin data for $\mathrm{S} / \mathrm{d}=2$ at $\mathrm{Re}_{\mathrm{d}}=30,514$ compared to first row circumferential data from Ames et al. [2004] at $\operatorname{Re}_{\mathrm{d}}=30,047$. 


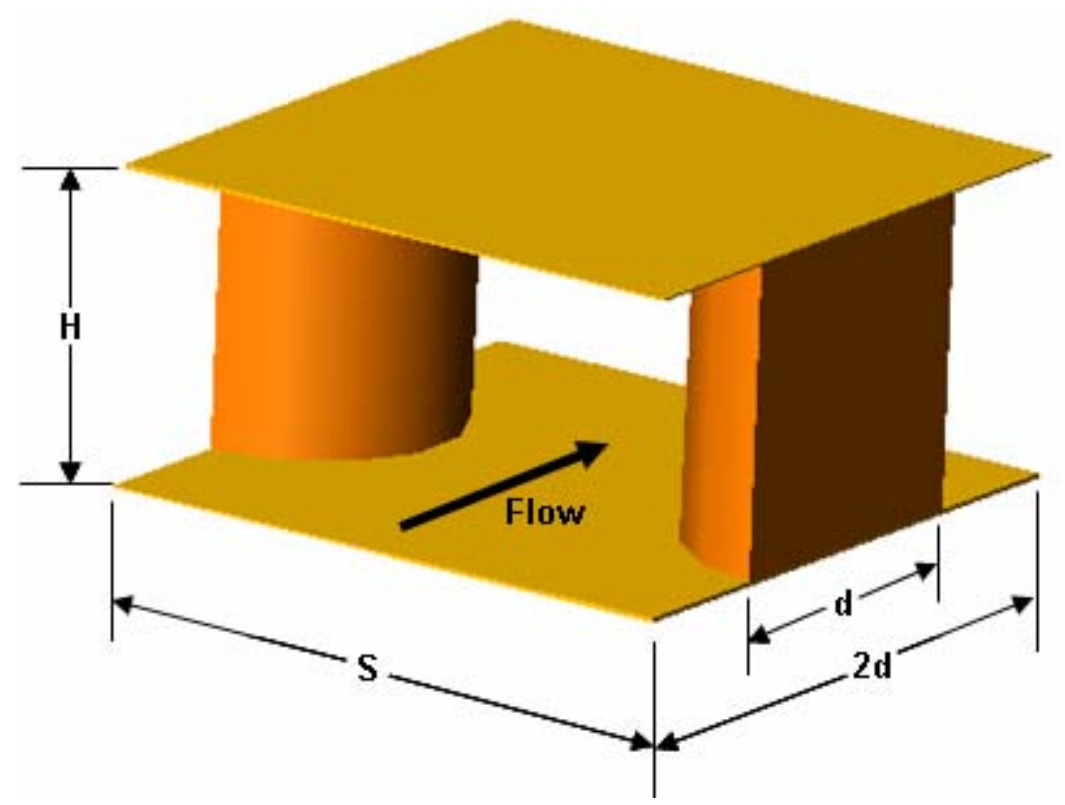

Figure 4-9 Drawing of one pin pitch transverse to the flow extending 0.5 pin diameters upstream and downstream of the pin fins. 


\section{Chapter 5}

\section{Experimental Results}

This chapter presents the experimental heat transfer results from the $\mathrm{S} / \mathrm{d}=2,4$, and 8 single pin fin row geometries. As mentioned earlier, tests were carried out over the range of $5000<\operatorname{Re}<30,000$. Measurements were made on both the pin and the endwall of the pin fin row. Heat transfer measurements were made on the endwall 3.5 pin diameters upstream and 6 pin diameters downstream of the pin fin row. Hence, the wake effects due to the pin fins were studied. Table 5-1 is a test matrix that gives a summary of the test cases.

To avoid confusion, it is worth mentioning the nomenclature used to present the heat transfer results. Two definitions of Nusselt number and Reynolds number are used. In the pin fin array literature, it is convention to define the Nusselt number as given by Equation 5-1:

$$
\mathrm{Nu}_{\mathrm{d}}=\frac{\mathrm{hd}}{\mathrm{k}}
$$

where the length scale is $\mathrm{d}$, the pin diameter. Similarly, the Reynolds number is defined as given by Equation 5-2:

$$
\operatorname{Re}_{\mathrm{d}}=\frac{\mathrm{U}_{\max } \mathrm{d}}{v}
$$

where $U_{\max }$ is the maximum average velocity between the pins. However in this study, many of the measurements were made outside of the pin fin row on the portion of the heater serving as the duct wall. As a result, the heat transfer results outside of the pin row are presented using the Nusselt number definition shown in Equation 5-3:

$$
\mathrm{Nu}=\frac{\mathrm{hD}_{\mathrm{h}}}{\mathrm{k}}
$$


where $D_{h}$, the hydraulic duct diameter is the length scale. This definition was used to allow comparison with the open duct fully developed turbulent heat transfer prediction, $\mathrm{Nu}_{0}$, given by Kays and Crawford [1980] in Equation 3-13 at the given duct Reynolds number, Re. Re is defined by Equation 5-4:

$$
\mathrm{Re}=\frac{\mathrm{UD}_{\mathrm{h}}}{v}
$$

where $\mathrm{U}$ is the average unobstructed duct velocity. Thus, endwall heat transfer results outside of the pin row are presented as $\mathrm{Nu} / \mathrm{Nu}_{0}$ at given values of Re to see the heat transfer augmentation over fully developed, unobstructed duct flow. In addition, the combined pin and endwall heat transfer of the pin rows are presented as both $\mathrm{Nu}_{\mathrm{d}}$ and $\mathrm{Nu} / \mathrm{Nu}_{0}$ for completeness.

Since the spanwise pin spacing and Reynolds number were the two primary variables in this study, this chapter is organized accordingly. Section 5.1 gives a brief discussion of pin and endwall heat transfer on a single row of pin fins in general. In this section, first row data from multiple pin row studies are used to make comparisons. Next, the effects of pin spacing are presented in Section 5.2. Finally in Section 5.3, the Reynolds number effects are presented. Comparisons are made with data from the literature where applicable.

\subsection{Heat Transfer From a Single Row of Pin Fins}

Pin fin heat transfer is a complex process. Upstream of the pin fins, there is ordinary duct flow, which may be laminar or turbulent depending on the duct Reynolds number, Re. According to Bejan [2004], duct flows are turbulent when the $\operatorname{Re}>2300$. In this study, only values of $\operatorname{Re}>5000$ were studied, so the duct flows for all test cases were considered turbulent. With a turbulent flow approaching the pin fin row, the flow is accelerated between the pin fins. This increased velocity between the pins increases heat exchange between the pin fin row and the fluid. Turbulent wakes are shed from the pin fins and enhance the duct wall heat transfer downstream of the pin fin row. The heat transfer is higher within the pin wakes as opposed to between the pins. As the flow 
proceeds farther downstream, the individual wakes from the pins tend to disperse and the flow begins to redevelop and become more uniform in the transverse direction to the bulk flow.

Throughout the pin row, heat transfer is significantly enhanced on both the pin fins and the bounding endwall. As an example, Table 5-2 gives sample results for the S/d $=2$ geometry at an approximate Reynolds number of $\operatorname{Re}_{\mathrm{d}}=10,000$ and is compared to different investigators found in the literature. For the literature comparison, first row heat transfer results were used from multiple row pin fin array studies. The geometries used by the other investigators are listed in the table. Note that all the other experimenters with the exception of Zukauskas [1972] studied arrays of short pin fins. Zukauskas [1972] compiled pin surface heat transfer results available at that time for long tubes and developed correlations predicting the tube surface heat transfer. The data points shown in Table 5-2 from Metzger and Haley [1982b] and Ames et al., [2004] were obtained from numerically integrating circumferential pin fin data at the given Reynolds numbers. The data from Yeh and Chyu [1998] was obtained directly from a plot. Finally, the data from Chyu et al. [1998a], and Metzger et al. [1982a] were obtained from correlations. Both pin fin and combined pin and endwall heat transfer results are shown in Table 5-2.

The present pin fin heat transfer results agree well with the long tube correlation by Zukauskas [1972] and Metzger and Haley [1982b]. Both Ames et al. [2004] and Chyu et al. [1998a] give lower results. The combined pin and endwall heat transfer result shown in Table 5-2 from my study agrees well with Metzger et al. [1982a]. The result from Yeh and Chyu [1998] is at a higher Reynolds number, but the Nusselt number is still in reasonable agreement.

Based on Table 5-2, a common feature is that the heat transfer on the pin fin is higher than the combined pin and endwall average. For pin fin arrays with small aspect ratio pin fins, both the pin fins and endwalls make significant contributions to the total heat transfer area. Thus, lower heat transfer on the endwall can significantly reduce the combined pin and endwall heat transfer.

As an example of the endwall heat transfer from a single row of pin fins, Figure 5-1 shows how the endwall heat transfer progresses from upstream, across and downstream of the pin row at a Reynolds number of $\mathrm{Re}=13,072$ for the $\mathrm{S} / \mathrm{d}=2$ single 
row geometry. The plot was obtained by averaging the Nusselt numbers calculated across the span of the viewing region at each streamwise measurement location across five pins. The data at the pin locations was extracted, so the results shown are only on the endwall. Also note that $\mathrm{x} / \mathrm{d}=0$ indicates the leading edge of the pin row. As shown, there is little augmentation upstream of the pins. However, there is a very high gradient across the pin row, with the maximum heat transfer one diameter downstream of the pins. The heat transfer augmentation then declines farther downstream of the pins but is still significantly higher than fully developed duct flow heat transfer. This trend is common to all results from the present study, but variations do exist depending on pin spacing and Reynolds number.

Shown in Figure 5-2 is the spanwise heat transfer augmentation for the $S / d=2$ geometry at one and five pin diameters downstream of the pin row for $\operatorname{Re}=13,072$. In the figure, $y / S=0$ indicates the center of the center pin in the image. Also note the good uniformity across the span. As shown, the wakes from the pin fins are prevalent one pin diameter downstream of the pin row. Farther downstream, the flow mixes and the heat transfer is reduced and becomes more uniform across the span. After the flow is disturbed by the pin fins, the additional turbulence increases the duct wall heat transfer a considerable distance downstream of the pin row.

The endwall effects mentioned above are best summarized by examining Nusselt number contour plots for the given cases. Figures 5-3 and 5-4 are contour plots of $\mathrm{Nu} / \mathrm{Nu}_{0}$ and $\mathrm{Nu}_{\mathrm{d}}$ respectively at $\mathrm{Re}=13,072$. The associated pin Reynolds number is $\mathrm{Re}_{\mathrm{d}}$ $=13,274$. As shown in both contours, the heat transfer measurements are mostly uniform across the span upstream of the pin row. A high gradient in heat transfer coefficients exists just upstream of the pin row. The maximum heat transfer coefficients occur on the endwall downstream of the pin fins. Also note the gradient between the pin wakes and the areas between the pins. This is the effect that was shown in the spanwise line plot of Figure 5-2. Also shown in the contour plots directly behind the pins in the wake region, there is high heat transfer augmentation. Farther downstream of the pins, the wakes disperse and the flow again becomes uniform across the span. Although there are differences depending on geometry and Reynolds number, these features are common to all the single pin row configurations that were studied. 


\subsection{Pin Spacing Effects}

Although many of the same heat transfer features were observed for all three pin spacings, there were significant differences in the data. To begin showing these differences, Figure 5-5 is a plot of $\mathrm{Nu}_{\mathrm{d}}$ versus $\mathrm{S} / \mathrm{d}$ at a nominal Reynolds number of $\mathrm{Re}_{\mathrm{d}}=$ 5000. Pin fin, endwall, and the combined pin and endwall heat transfer are shown in Figure 5-5. Before discussing the results, it is worth noting how the data was analyzed. Tests were ran for all three spacings based on duct Reynolds numbers in the range of $5000<\operatorname{Re}<30,000$. The same approximate duct Reynolds numbers were used for all three geometries. However, due to the different area blockages of the different spacings, the Reynolds numbers based on pin diameter and the maximum velocity between the pins, $\mathrm{Re}_{\mathrm{d}}$, were significantly different. As a result, the data for Figure 5-5 were obtained by interpolating between points from actual test data. Thus, Figure 5-5 is for qualitative purposes but displays the trends very well.

One key feature concerning Figure 5-5 is that the pin fin heat transfer is higher with larger pin spacing. This indicates that the pin fin heat transfer does not scale with $\mathrm{U}_{\max }$. Simoneau and VanFossen [1984] also reported this trend. This difference may be caused by stronger pin wake interactions with the $S / d=2$ pin spacing, but the effect is reduced with the $\mathrm{S} / \mathrm{d}=4$ and 8 pin spacings. Conversely, the endwall heat transfer decreases with increasing pin spacing. Similar to the pin fin heat transfer, this reduction is most likely attributed to reduced interaction between the pins as the spacing is increased. The difference is greater between the $\mathrm{S} / \mathrm{d}=2$ and 4 pin spacings than between $\mathrm{S} / \mathrm{d}=4$ and 8 . Due to the endwall being the larger contributor to the wetted area average, the combined pin and endwall heat transfer is reduced with increased pin spacing. Figure 5-6 is equivalent to Figure 5-5 except the results are based on a nominal Reynolds number of $\mathrm{Re}_{\mathrm{d}}=17,500$. The same trends are prevalent at the higher Reynolds number. However, the pin heat transfer relative to the endwall is higher at the low Reynolds number. This topic is discussed further in Section 5.3 with Reynolds number effects.

Figure 5-7 is a plot that compares the combined pin and endwall heat transfer with fully developed duct flow across the entire Reynolds number range for all three pin spacings. As shown in the figure, there is a significant reduction in heat transfer 
augmentation as $\mathrm{S} / \mathrm{d}$ increases. Again, the difference is smaller between $\mathrm{S} / \mathrm{d}=4$ and 8 than between $\mathrm{S} / \mathrm{d}=2$ and 4 . As the pin spacing becomes larger, the flow between the pins becomes more like plain duct flow with less influence by the pins. As the pin spacing increases, the combined pin and endwall heat transfer approaches plain duct flow heat transfer. How close the row average heat transfer approaches the fully developed duct flow value depends not only on pin spacing, but also on the thermal development length along the streamwise length of the channel.

This argument concerning pin spacing is supported by examining line plots that show the developing heat transfer normalized to fully developed duct flow downstream of the pin row both directly behind a pin and between two pins. Figure 5-8 shows such a plot for all three pin spacings at $\operatorname{Re}=5000$. Figure 5-9 is an identical plot except at $\operatorname{Re}=$ 30,000 . Note that in both plots, $x / d=1$ indicates the trailing edge of the pin row. As shown in Figure 5-8, the $\mathrm{S} / \mathrm{d}=2$ pin spacing has very similar developing heat transfer both within the pin wake and between the pins. However, the trends are much different for the $S / d=4$ and $S / d=8$ pin spacings. As shown for $S / d=4$, the heat transfer augmentation within the pin wake declines steadily, but the developing heat transfer between the pins is nearly constant, with only a slight increase along the streamwise direction. The $S / d=8$ pin spacing has a similar trend as the $S / d=4$ pin spacing. Within the pin wake, the heat transfer also declines steadily at the same approximate slope, differing only in magnitude. Between the pins for the $S / d=8$ pin spacing, there is no apparent change in heat transfer augmentation along the streamwise direction. The constant or nearly constant values of $\mathrm{Nu} / \mathrm{Nu}_{0}$ along the streamwise direction indicate that the pins have little influence on the area between the pins for wide pin spacing.

The results shown in Figure 5-9 also indicate less pin influence on the endwall between the pins with wide pin spacing. For the $S / d=2$ pin spacing, there is a smaller difference between the heat transfer within the pin wakes and between the pins than the other geometries. At $\mathrm{x} / \mathrm{d}=5$, the developing heat transfer within the pin wake and between the pins is essentially the same. As shown for the $\mathrm{S} / \mathrm{d}=4$ geometry, the developing heat transfer declines steadily along the streamwise direction within the pin wake. Between the pins, the developing heat transfer steadily rises indicating that the flow is remixing. At $x / d=7$, the heat transfer within the pin wake and between the pins 
are nearly equal, indicating that the flow has almost fully mixed across the span between the pins. The developing heat transfer within the pin wake for the $S / d=8$ pin spacing is similar to the $\mathrm{S} / \mathrm{d}=4$ developing heat transfer. The developing heat transfer between the pins is nearly constant as was seen in Figure $5-8$ for the $S / d=8$ pin spacing. This again indicates that as the pin spacing increases, less influence is exerted by the pins onto the endwall between the pins.

It is also of interest to see how the endwall heat transfer progresses from upstream, through, and downstream of the pin fin row. Spanwise averaged endwall heat transfer measurements at each streamwise location are shown in Figures 5-10 and 5-11 for all three geometries at $\mathrm{Re}=5000$ and $\mathrm{Re}=30,000$ respectively. Note that when producing these figures, the heat transfer data under the pins were extracted, leaving only the endwall data surrounding the pins. The leading edge of the pin row is at $\mathrm{x} / \mathrm{d}=0$. As shown in Figure 5-10, a large heat transfer gradient exists upstream of the pin row for all three pin spacings. Downstream of the pin row, the $\mathrm{S} / \mathrm{d}=2$ pin spacing gives the highest heat transfer enhancement, followed by $\mathrm{S} / \mathrm{d}=4$, and finally the $\mathrm{S} / \mathrm{d}=8$ pin spacing. One obvious feature is that $\mathrm{S} / \mathrm{d}=2$ gives much higher heat transfer enhancement than both the $\mathrm{S} / \mathrm{d}=4$ and $\mathrm{S} / \mathrm{d}=8$ pin spacings. The relative difference in heat transfer enhancement is greater between $\mathrm{S} / \mathrm{d}=2$ and $\mathrm{S} / \mathrm{d}=4$ than $\mathrm{S} / \mathrm{d}=4$ and $\mathrm{S} / \mathrm{d}=8$.

There are two noticeable features shown in Figure 5-10. The first is that the maximum spanwise averaged heat transfer for the $S / d=2$ pin spacing occurs several pin diameters downstream of the pin row. Conversely, the maximum spanwise heat transfer occurs at the trailing edge of the pin row for both $\mathrm{S} / \mathrm{d}=4$ and $\mathrm{S} / \mathrm{d}=8$. This difference may again be attributed to increased pin wake interaction as the pin spacing is decreased. The other major difference is upstream of the pins. Before reaching the pin fins, the flow is considered to be a plain duct flow. Even though the duct Reynolds numbers are about the same for all three geometries shown in the plot, there is significant variability in heat transfer enhancement upstream of the pins. The results indicate that this is both a spacing and Reynolds number effect.

The evidence of Reynolds number effects is shown in Figure 5-11. The spanwise averaged developing heat transfer data shown in Figure 5-11 does not have the same features that were observed in Figure 5-10. The data in Figure 5-10 is based on Re= 
5000 whereas Figure 5-11 is based on $\operatorname{Re}=30,000$. As shown in Figure 5-11, the maximum spanwise averaged heat transfer is located at the trailing edge of the pin row for all three spacings. In addition, the developing heat transfer upstream of the pins collapses to a single curve. Upstream of the pins, the flow has not encountered flow disturbances. Besides magnitude, the developing heat transfer enhancement along the flow direction is similar for the $\mathrm{S} / \mathrm{d}=4$ and 8 spacings at $\mathrm{Re}=30,000$. However, the $\mathrm{S} / \mathrm{d}$ $=2$ spacing follows a much steeper gradient upstream of the pins followed by a steep decrease in heat transfer downstream. The discrepancies shown in Figures 5-10 and 5-11 are discussed further in Section 5.3, which considers Reynolds number effects.

Considerable differences among pin spacing are also apparent when observing line plots of the endwall heat transfer across the span of a portion of the duct at different streamwise distances downstream of the pin row. Figure 5-12 is a collection of spanwise line plots at both one and five pin diameters downstream of the pin row for all three spacings at $\mathrm{Re}=5000$. The Nusselt numbers are normalized by $\mathrm{Nu}_{0}$, the prediction for open duct fully developed heat transfer. Also note that $y / S=0$ indicates the center of the center pin in the image where the data was extracted. For clarity, the original images from all three geometries that the data was extracted from were the same physical size. However, for a given size, fewer pin spans are present for larger pin spacing. This is why the line plots become shorter with increased pin spacing when the y-axis is nondimensionalized by $\mathrm{y} / \mathrm{S}$.

As shown in Figure 5-12, the $\mathrm{S} / \mathrm{d}=2$ pin spacing has little noticeable difference one and five pin diameters downstream of the pin row at $\mathrm{Re}=5000$. This again indicates strong interaction between the pins for the $S / d=2$ pin spacing. Both $S / d=4$ and $S / d=8$ show more distinct effects due to the pin fins. At one pin diameter downstream of the pin row, there is a large difference between the pin wake and the area between the pins. This difference is larger for $S / d=8$ than for the $S / d=4$ pin spacing. Five pin diameters downstream of the pin row, the peaks at the center of the pin wakes are significantly reduced due to mixing.

Figure 5-13 is equivalent to Figure 5-12 except it is based on $\operatorname{Re}=30,000$. As shown in the figure for the $\mathrm{S} / \mathrm{d}=2$ pin spacing, the individual pin wakes are much more noticeable one pin diameter downstream of the pin fin row as compared to the $S / d=5000$ 
case shown in Figure 5-12. However, the flow is nearly remixed five pin diameters downstream of the pin row at a significantly lower magnitude. There are also differences when comparing Figures 5-12 and 5-13 for the $S / d=4$ and $S / d=8$ pin spacings. One noticeable difference between cases for $\mathrm{S} / \mathrm{d}=4$, is that the heat transfer augmentation between the pin fins is shown to increase along the length of the channel. This same effect was shown in Figure 5-9 when presenting the streamwise developing heat transfer both within and outside of a pin wake at $\mathrm{Re}=30,000$. This again is an example of the mixing process. In this case, the peak heat transfer immediately downstream of the pin fins tends to decrease along the streamwise direction while the effects of wake shedding are diffused into the flow area between the pins, acting to increase the heat transfer along the streamwise direction. Besides having a larger decrease in peak heat transfer between one and five pin diameters downstream of the pin row at $\operatorname{Re}=30,000$, there are no major differences shown for the $\mathrm{S} / \mathrm{d}=8$ pin spacing in Figures 5-12 and 5-13. In both figures, the minimum heat transfer between the pins is nearly unchanged between one and five pin diameters downstream of the pin row. This is likely due to the wakes dissipating along the streamwise direction before spanwise diffusion can occur.

Contour plots are shown in Figures 5-14 and 5-15 to give an overall view of the endwall heat transfer. In Figure 5-14, the duct Nusselt number, $\mathrm{Nu}$, is normalized by the fully developed duct flow heat transfer prediction, $\mathrm{Nu}_{0}$. The Nusselt number contours shown in Figure 5-15 are based on $\mathrm{Nu}_{\mathrm{d}}$ to be consistent with the definition found in the literature for pin fin array studies. Contours of all three pin spacings are shown at approximate Reynolds numbers of $\operatorname{Re}=5000$ and $\operatorname{Re}=30,000$. Refer to the column for endwall tests in Table 5-1 for the desired geometry to the see the actual Re and $\operatorname{Re}_{\mathrm{d}}$ values for each test case.

As shown in Figure 5-14, it is clear that the $\mathrm{S} / \mathrm{d}=2$ pin spacing yields significantly higher heat transfer enhancement than $\mathrm{S} / \mathrm{d}=4$ and $\mathrm{S} / \mathrm{d}=8$. This increase appears to be caused not only by the increased velocity between the pins, but also due to increased pin wake interaction. Five pin diameters downstream of the pin row, the endwall heat transfer is nearly uniform, indicating that the flow is remixed. The wakes caused by the $\mathrm{S} / \mathrm{d}=4$ and $\mathrm{S} / \mathrm{d}=8$ pin spacings do not merge within the viewing region. In addition, the flow between the pins becomes more like unobstructed duct flow as the pin spacing is 
increased. This is evident when observing $\mathrm{S} / \mathrm{d}=8$. Along the streamwise direction of the viewing area, there is no apparent heat transfer gradient between the pins. The contours for the $\mathrm{S} / \mathrm{d}=4$ pin spacing do indicate that the flow between the pins is influenced by the pins, but the effect is not large.

Qualitatively, Figure 5-15 gives the same information when comparing the different geometries in terms of relative heat transfer across the endwall surface. Consequently, this figure will not be discussed in detail, but is still important when studying the data across the pin row. By convention Nusselt numbers based on pin diameter, $\mathrm{Nu}_{\mathrm{d}}$, are used when evaluating pin fin array heat transfer. Thus, Figure 5-15 is useful in estimating the endwall heat transfer coefficients surrounding the pin fins.

\subsection{Reynolds Number Effects}

As already mentioned, the pin and endwall heat transfer characteristics varied not only with pin spacing but also with Reynolds number. To begin the discussion, Figure 516 presents the $S / d=2,4$, and 8 pin fin heat transfer results as $\mathrm{Nu}_{\mathrm{d}}$ versus $\mathrm{Re}_{\mathrm{d}}$ and makes a comparison with data from the literature. As shown in the figure, the $\mathrm{S} / \mathrm{d}=2$ pin fin heat transfer results agree well with the long pin correlation given by Zukauskas [1972] and the data given by Metzger and Haley [1982b] for short pins. Chyu et al. [1998a] predicts $10 \%$ to $20 \%$ lower heat transfer over the present testing range. The results from Ames et al. [2004] are similar to Chyu et al. [1998a] at low Reynolds numbers, but agree quite well with the present results at the upper end of the range due to an apparently stronger Reynolds number dependence.

The S/d $=4$ and 8 pin spacings shown in Figure 5-16 yield higher heat transfer across the Reynolds number range than the $\mathrm{S} / \mathrm{d}=2$ pin spacing and the data given from the other researchers. It was shown in Section 5.2 that for a given value of $\operatorname{Re}_{\mathrm{d}}$, the pin fin heat transfer increases as the pin spacing increases. The Reynolds number dependency is also stronger for the $\mathrm{S} / \mathrm{d}=4$ and 8 pin spacings than geometries with narrower pin spacing. By inspection, the Reynolds number dependency for the $\mathrm{S} / \mathrm{d}=2$ geometry is similar to the predictions given by Zukauskas [1972], and Chyu et al. [1998a]. The Reynolds number dependency is unclear for Metzger and Haley [1982b] and Ames 
et al. [2004]. Both only presented three data points across the Reynolds number range. Deducing the trend requires higher resolution.

Figure 5-16 also indicates a different heat transfer mechanism for small and large pin spacings. As shown in Figure 5-16, the $\mathrm{S} / \mathrm{d}=4$ and 8 pin fin heat transfer data collapse, indicating the same heat transfer mechanism. As already mentioned, the $\mathrm{S} / \mathrm{d}=2$ heat transfer data fall below the $\mathrm{S} / \mathrm{d}=4$ and 8 results. It is of interest to investigate whether or not the pin Reynolds number, $R_{d}$, which uses $U_{\max }$ as the scaling velocity is the proper Reynolds number for presenting the pin fin heat transfer results. In Figure 517, the results are presented as $\mathrm{Nu}_{d}$ versus Re, the unobstructed duct Reynolds number which uses $U$ as the scaling velocity. Presented in this manner, the data from all three pin spacings do not collapse, and there is a clear trend that the pin fin heat transfer decreases with increased pin spacing. However, the differences are relatively small. As shown, the data fall within a $12 \%$ band across the entire Reynolds number range.

The conclusion to be drawn from this analysis is that velocity alone does not scale the pin fin heat transfer results. Increased knowledge of turbulence or a characteristic length including the effect of pin spacing may be required to collapse the pin fin heat transfer data. It is likely that this information can be obtained only from increased knowledge of the localized flow field adjacent to the pin fins.

A final point concerning pin fin heat transfer is that measurements on low aspect ratio pin fins are difficult to make. The proof of this is the variability among different researchers. Some differences may be attributed to measurement method, but there is no clear trend. As an example, Ames et al. [2004] used a heated foil technique and used fine wire thermocouples to obtain temperatures around the circumference of a pin fin midplane. Using the surface temperatures, he calculated the circumferential heat transfer. Chyu et al. [1998a] used a naphthalene sublimation technique to measure pin fin heat transfer. As shown in Figure 5-16, Ames et al. [2004] and Chyu et al. [1998a] had reasonable agreement at low Reynolds numbers but varied at the higher Reynolds numbers. More work is needed to better quantify heat transfer from low aspect ratio pin fins.

Figure 5-18 presents the combined pin and endwall heat transfer across the pin row for the $\mathrm{S} / \mathrm{d}=2,4$, and 8 pin spacings as $\overline{\mathrm{Nu}}_{\mathrm{d}}$ versus $\mathrm{Re}_{\mathrm{d}}$ and compares the data with 
results from the literature. As shown, the data for the $\mathrm{S} / \mathrm{d}=2$ pin spacing agrees well with Metzger et al. [1982a] over most of the Reynolds number range. However, at the higher Reynolds numbers, the $\mathrm{S} / \mathrm{d}=2$ Reynolds number dependence becomes weaker, increasing the discrepancy. The data reported by Yeh and Chyu [1998] are consistently lower than the present results and the predictions given by Metzger et al. [1982a]. Similar to the pin fin heat transfer data, there are significant differences in combined pin and endwall measurements reported by different investigators.

Referring back to Figure 5-16, the $\mathrm{S} / \mathrm{d}=4$ and 8 pin fin heat transfer is higher than the $S / d=2$ pin fin heat transfer for a given value of $R_{d}$. As shown in Figure 5-18, the opposite is true for the combined pin and endwall heat transfer. The $\mathrm{S} / \mathrm{d}=4$ and 8 pin spacings consistently give lower values of $\overline{\overline{\mathrm{Nu}}}_{\mathrm{d}}$ than the $\mathrm{S} / \mathrm{d}=2$ geometry for a given Reynolds number. This is true because of the large area contribution of the endwall to the entire wetted area exposed to the flow across the pin row. When computing the area average, the lower heat transfer value on the endwall outweighs the higher value on the pin fin. Also as shown in Figure 5-18, the Reynolds number dependence for all three pin spacings is similar.

Figure 5-19 shows the heat transfer augmentation over fully developed open duct flow plotted as $\overline{\overline{\mathrm{Nu}}} / \mathrm{Nu}_{0}$ versus $\mathrm{Re}$ for the $\mathrm{S} / \mathrm{d}=2,4$ and 8 pin spacings across the pin row. It has already been shown that the $\mathrm{S} / \mathrm{d}=2$ pin spacing augments heat transfer much more effectively than wider pin spacing. As shown in Figure 5-19 however, the $\mathrm{S} / \mathrm{d}=4$ and 8 pin spacings have less of a lower Reynolds number dependence than $S / d=2$ over most of the Reynolds number range. Note that for all three pin spacings, the Reynolds number dependence is strongest at low Reynolds numbers.

Figures 5-16 through 5-19 presented both pin fin and combined pin and endwall heat transfer results. It is also of interest to know the relative difference between the heat transfer on the pin fin as opposed to the endwall heat transfer. Figure 5-20 presents the pin to endwall heat transfer ratios as a function of pin Reynolds number, $\mathrm{Re}_{\mathrm{d}}$, for the $\mathrm{S} / \mathrm{d}$ $=2,4$, and 8 pin spacings. As shown, the ratio of pin to endwall heat transfer is strongly dependent on the Reynolds number. The trend is similar for all three geometries. The highest ratio occurs at the lowest Reynolds number. As the Reynolds number increases, the pin to endwall ratio follows a steep gradient and levels out at the higher Reynolds 
numbers. Also note that both the $\mathrm{S} / \mathrm{d}=4$ and 8 pin to endwall ratios are higher than those for $\mathrm{S} / \mathrm{d}=2$.

Metzger et al. [1984] reported results similar to those obtained for the $S / d=2$ pin spacing. Metzger et al. [1984] determined the pin to endwall ratio to be 1.8 and 2.1 for two separate multiple row arrays with geometries of $\mathrm{S} / \mathrm{d}=2.5, \mathrm{X} / \mathrm{d}=2.5$, and $\mathrm{H} / \mathrm{d}=1$, and $\mathrm{S} / \mathrm{d}=2.5, \mathrm{X} / \mathrm{d}=1.5$ and $\mathrm{H} / \mathrm{d}=1$ respectively. From the present results, the $\mathrm{S} / \mathrm{d}=2$ pin spacing yielded pin to endwall ratios of 2.0 at $\mathrm{Re}_{\mathrm{d}}=5109$ and 1.5 at $\mathrm{Re}_{\mathrm{d}}=30,735$. Metzger et al. [1984] did not consider Reynolds number dependence.

As mentioned in Section 5.2, the endwall heat transfer upstream and downstream of the pin row is dependant on the Reynolds number. Figure 5-21 presents the spanwise averaged developing heat transfer on the endwall for the $S / d=2$ pin spacing across the entire Reynolds number range. The leading edge of the pin row is at $x / d=0$. To focus only on the endwall, the data from the base of the pin fins were removed when computing the spanwise averages. As shown, the maximum heat transfer occurs downstream of the pin row at low Reynolds numbers. At $\mathrm{Re}=5013$, the maximum heat transfer augmentation occurs at about $\mathrm{x} / \mathrm{d}=4$. However, as the Reynolds number is increased, the peak heat transfer augmentation is moved closer to the trailing edge of the pin row. This condition is shown at the two highest Reynolds numbers of $\operatorname{Re}=23,434$ and $\operatorname{Re}=$ 30,484 , with the peak heat transfer augmentation occurring at the trailing edge.

The other major Reynolds number effect shown in Figure 5-21 is the variability upstream of the pin row. There is no clear trend, but the effect seems stronger at low Reynolds numbers. As shown, the gradients upstream of the pin row for the $\operatorname{Re}=5013$ and $\mathrm{Re}=7540$ test cases are noticeably positive, indicating stronger upstream effects. On the other hand, the upstream gradients are smaller at higher Reynolds numbers, which indicate weaker upstream effects.

Although there is a definite Reynolds number effect on the heat transfer upstream of the pins, the underlying cause may be due to the extreme flow blockage caused by the $\mathrm{S} / \mathrm{d}=2$ pin spacing. The mass-averaged velocity between the pins is twice the open duct velocity. This velocity ratio naturally causes large streamwise and spanwise velocity gradients upstream of the pin row, indicating large momentum changes with corresponding inertia forces. The upstream effects can be explained by interpreting the 
Reynolds number as the ratio of inertia to viscous forces. For the lower Reynolds number flows, viscous effects have a larger influence on the flow. Conversely at high Reynolds numbers, the inertia effects have a more significant role and the viscous effects have less of an influence upstream of the pin fins.

The upstream effects become less evident with larger pin spacings due to reduced flow blockage. This argument is supported by examining Figures 5-22 and 5-23, which show the spanwise averaged developing endwall heat transfer for the $\mathrm{S} / \mathrm{d}=4$ and 8 pin spacings respectively. Figures 5-22 and 5-23 were produced in the same manner as Figure 5-21. As shown in Figure 5-22, the data for the $S / d=4$ pin spacing upstream of the pin row are grouped much better than the $\mathrm{S} / \mathrm{d}=2$ pin spacing shown in Figure 5-21. However, there is still noticeable heat transfer variation upstream of the pin row. Finally for the $\mathrm{S} / \mathrm{d}=8$ pin spacing shown in Figure 5-23, the data collapse and there are no apparent viscous effects upstream of the pin row across the Reynolds number range. The reason is that the reduced flow blockage causes smaller velocity gradients upstream of the pin fins, which makes viscous effects less apparent. For the $\mathrm{S} / \mathrm{d}=8$ pin spacing, the ratio of maximum average velocity between the pins to the unobstructed average velocity is 1.14 , as compared to 2 for the $\mathrm{S} / \mathrm{d}=2$ pin spacing. Thus for wide pin spacings, the flow upstream, through, and downstream of the pin row behaves more like unobstructed duct flow.

Spanwise line plots based on data downstream of the pin row further demonstrate the Reynolds number effects. Figure 5-24 shows spanwise line plots one and five pin diameters downstream of the pin row for the $\mathrm{S} / \mathrm{d}=2$ geometry across the Reynolds number range. To avoid unnecessary clutter on the plot, only low, medium, and high Reynolds numbers are given. The main observation shown in Figure 5-24 is that pin interaction is increased at low Reynolds numbers. It has already been shown that decreasing the pin spacing gives increased pin interaction, but the data indicates that reducing the duct Reynolds number has the same effect for a given pin spacing. At one pin diameter downstream of the pin row in Figure 5-24 at $R e=5013$, there is little difference in heat transfer augmentation within and outside of the pin wakes. However, for both $\operatorname{Re}=17,504$ and $\operatorname{Re}=30,484$, there is a significant difference in heat transfer enhancement within and outside of the pin wakes. Five pin diameters downstream of the 
pin row, the flow is remixed at all Reynolds numbers. Furthermore, it is also shown in Figure 5-24 that the heat transfer augmentation relative to a plain duct flow is reduced with increasing Reynolds number. This indicates a stronger Reynolds number dependence for plain duct flow than for the pin fin row.

Figure 5-25 presents spanwise line plots one and five pin diameters downstream of the pin row for the $\mathrm{S} / \mathrm{d}=4$ pin spacing. Only low, medium, and high Reynolds numbers are shown. At both one and five pin diameters downstream of the pin row, the heat transfer augmentation is highest at $\operatorname{Re}=4986$. As shown for $\operatorname{Re}=17,454$ and $\operatorname{Re}=$ 29,973 , the heat transfer augmentation between the pin fins increases along the length of the channel while decreasing directly behind the pin fins along the streamwise direction. This is evidence of the wake effects diffusing into the flow between the pin fins. However, this effect is not as prevalent at $\operatorname{Re}=4986$. Although the heat transfer augmentation directly downstream of the pin fins decreases along the streamwise length of the channel, the heat transfer augmentation between the pin fins remains predominantly unchanged. At low Reynolds numbers, more streamwise distance is required for the flow to remix to give uniform spanwise heat transfer augmentation.

Figure 5-26 presents spanwise line plots one and five pin diameters downstream of the pin row for the $S / d=8$ pin spacing. Similar to Figures 5-24 and 5-25, only low, medium, and high Reynolds numbers are shown to avoid clutter. As shown, the major effect for the $\mathrm{S} / \mathrm{d}=8$ pin spacing is that the heat transfer augmentation directly downstream of the pin row increases with Reynolds number. However at five pin diameters downstream of the pin row, there are only small variations in heat transfer augmentation, indicating a weaker dependence on the Reynolds number. Also shown in Figure 5-26 is that between the pins, the heat transfer augmentation is independent of Reynolds number, indicating that the pin fins have little or no effect.

Contour plots of the endwall heat transfer measurements are given across the entire Reynolds number range for the $S / d=2,4$, and 8 pin spacings to give an overall view of the endwall heat transfer augmentation. Figure 5-27 presents the contour plots of the $\mathrm{S} / \mathrm{d}=2$ pin spacing plotted as $\mathrm{Nu} / \mathrm{Nu}_{0}$ to see the heat transfer augmentation over fully developed plain duct flow. All features from the previous discussion can be seen from a more qualitative viewpoint by examining the contour plots. 
The first point to note in Figure 5-27 is the location of the maximum heat transfer augmentation with respect to the pin row. At the low Reynolds numbers, the maximum heat transfer occurs well downstream of the row. As the Reynolds number is increased, the maximum heat transfer moves upstream towards the trailing edge of the pin row. The second main feature shown in Figure 5-27 is the pin wake interaction. Notice at both Re $=5004$ and $\operatorname{Re}=7604$, the heat transfer pattern immediately downstream of the pin row appears mixed. However at $\operatorname{Re}=13,184$ and above, the heat transfer patterns immediately downstream of the pin row are clearly distinct. The changing wake patterns from the pin fins are the cause of the maximum heat transfer augmentation occurring at different streamwise locations for different Reynolds numbers. The contour plots shown in Figure 5-27 also indicate the variation in duct wall heat transfer upstream of the pin row. As shown, the lowest heat transfer augmentation upstream of the pins occurs at Re $=5004$ and $\operatorname{Re}=7604$. At the higher Reynolds numbers, the upstream heat transfer augmentation is more consistent.

Figure 5-28 presents the contour plots of $\mathrm{Nu} / \mathrm{Nu}_{0}$ for the $\mathrm{S} / \mathrm{d}=4$ pin spacing across the entire Reynolds number range. The first notable feature is that upstream of the pin fins, the contour levels are more closely grouped than with the $\mathrm{S} / \mathrm{d}=2$ pin spacing, indicating that viscous effects have less of an influence upstream of the pin fins. It is also clear that between the pin fins in the streamwise direction, the heat transfer augmentation increases. Conversely, directly downstream of the pin fins the heat transfer augmentation decreases. This is evidence of the pin wake effects diffusing into the flow between the pin fins. It is also clear from the contours shown in Figure 5-28 that less distance is required in the streamwise direction for the flow to become fully mixed downstream of the pin fins for high Reynolds numbers. As shown for $\operatorname{Re}=4986$, the contour levels are different directly downstream and between the pin fins at $\mathrm{x} / \mathrm{d}>6$. However for $\mathrm{Re}=$ 29,973 at $\mathrm{x} / \mathrm{d}>6$, there is predominantly one heat transfer augmentation contour level, indicating that the flow is almost fully mixed.

Figure 5-29 presents contour plots of $\mathrm{Nu} / \mathrm{Nu}_{0}$ for the $\mathrm{S} / \mathrm{d}=8$ pin spacing across the entire Reynolds number range. The most obvious feature is that most of the area off to the side of the pin fin is at the same contour level for every case, indicating only a small dependence on Reynolds number on the duct wall heat transfer adjacent to the pins. 
In addition, upstream effects are not apparent. The second notable feature is the heat transfer augmentation immediately downstream of the pin fin. It is obvious that as the Reynolds number increases, the heat transfer augmentation downstream of the pin fin also increases. In addition, it is clear from the contour plots that effects from the pin fins are carried much farther downstream with wide pin spacing. This effect is more pronounced at high Reynolds numbers.

Figures 5-30 through 5-32 are contour plots of $\mathrm{Nu}_{\mathrm{d}}$ for the $\mathrm{S} / \mathrm{d}=2,4$, and 8 pin spacings across the entire Reynolds number range. These plots will not be discussed in detail because they give the same information concerning the heat transfer patterns on the endwall surface as shown in Figures 5-27 through 5-29. Since pin fin array heat transfer data is usually reported as $\mathrm{Nu}_{\mathrm{d}}$, Figures 5-30 through 5-32 are useful in estimating the heat transfer coefficients surrounding the pin fins.

As a final note, the contour data for the $\mathrm{S} / \mathrm{d}=4$ and 8 pin spacings at $\mathrm{Re}=10,000$ were not shown in the text, but are given in Appendix D. The reason for this is because endwall data were not collected for the $\mathrm{S} / \mathrm{d}=2$ pin spacing at $\mathrm{Re}=10,000$. Thus, the $\mathrm{S} / \mathrm{d}$ $=4$ and 8 contour data at $\operatorname{Re}=10,000$ were omitted within the text for consistency. 
Table 5-1 Test Matrix for the $\mathrm{S} / \mathrm{d}=2,4$, and 8 Single Row Geometries

\begin{tabular}{|c|c|c|c|c|c|c|c|c|c|c|c|}
\hline \multicolumn{4}{|c|}{ S/d = } & \multicolumn{4}{c|}{ S/d = 4 } & \multicolumn{4}{c|}{ S/d = } \\
\hline Pin Fin Tests & Endwall Tests & \multicolumn{2}{|c|}{ Pin Fin Tests } & Endwall Tests & Pin Fin Tests & \multicolumn{2}{|c|}{ Endwall Tests } \\
\hline Re & $\mathbf{R e}_{\mathbf{d}}$ & $\mathbf{R e}$ & $\mathbf{R e}_{\mathbf{d}}$ & $\mathbf{R e}$ & $\mathbf{R e}_{\mathbf{d}}$ & $\mathbf{R e}$ & $\mathbf{R e}_{\mathbf{d}}$ & $\mathbf{R e}$ & $\mathbf{R e}_{\mathbf{d}}$ & $\mathbf{R e}$ & $\mathbf{R e}_{\mathbf{d}}$ \\
\hline 5048 & 5127 & 5013 & 5090 & 5032 & 3407 & 4986 & 3376 & 5014 & 2910 & 5004 & 2904 \\
\hline 7512 & 7630 & 7540 & 7657 & 7538 & 5104 & 7563 & 5121 & 7487 & 4345 & 7604 & 4413 \\
\hline 10021 & 10178 & - & - & 9972 & 6808 & 10018 & 6784 & 9994 & 5800 & 10210 & 5925 \\
\hline 13017 & 13221 & 13072 & 13274 & 13014 & 8812 & 12964 & 8778 & 12997 & 7543 & 13184 & 7651 \\
\hline 17522 & 17796 & 17504 & 17775 & 17468 & 11828 & 17454 & 11818 & 17470 & 10139 & 17848 & 10358 \\
\hline 25016 & 25407 & 23434 & 23796 & 24961 & 16902 & 25018 & 16940 & 25077 & 14553 & 25018 & 14519 \\
\hline 30045 & 30514 & 30484 & 30956 & 29992 & 20308 & 29973 & 20295 & 29997 & 17409 & 29855 & 17327 \\
\hline
\end{tabular}

Table 5-2 Sample $\mathrm{S} / \mathrm{d}=2$ Results at $\mathrm{Re}_{\mathrm{d}}=10,000$ With Literature Comparison

\begin{tabular}{|l|c|c|c|c|c|c|c|}
\hline & \multicolumn{7}{|c|}{ Pin Fin Heat Transfer } \\
\hline Investigator & \multicolumn{1}{|l|}{ S/d } & X/d & H/d & Re & Red & Nud & \% Diff \\
\hline VT & 2 & - & 1 & 10021 & 10178 & 59.7 & - \\
\hline Ames et al. [2004] & 2.5 & 2.5 & 2 & - & 10028 & 51.3 & 16.4 \\
\hline Chyu et al. [1998] & 2.5 & 2.5 & 1 & - & 10000 & 49 & 21.8 \\
\hline Metzger and Haley [1982b] & 2.19 & 1.32 & 0.875 & - & 10200 & 57.9 & 3.1 \\
\hline Zukauskas [1972] & $1.3-2.6$ & $0.6-3.9$ & $>7$ & - & 10000 & 57.5 & 3.8 \\
\hline & \multicolumn{7}{|c|}{ Combined Pin and Endwall Heat Transfer } \\
\hline VT & 2 & - & 1 & 10000 & 10157 & 41.5 & - \\
\hline Metzger et al. [1982a] & 2.5 & 1.5 or 2.5 & 1 & - & 10000 & 38.9 & 6.7 \\
\hline Yeh and Chyu [1998] & 2.8 & 2.6 & 1 & - & 11400 & 39.1 & 6.1 \\
\hline
\end{tabular}




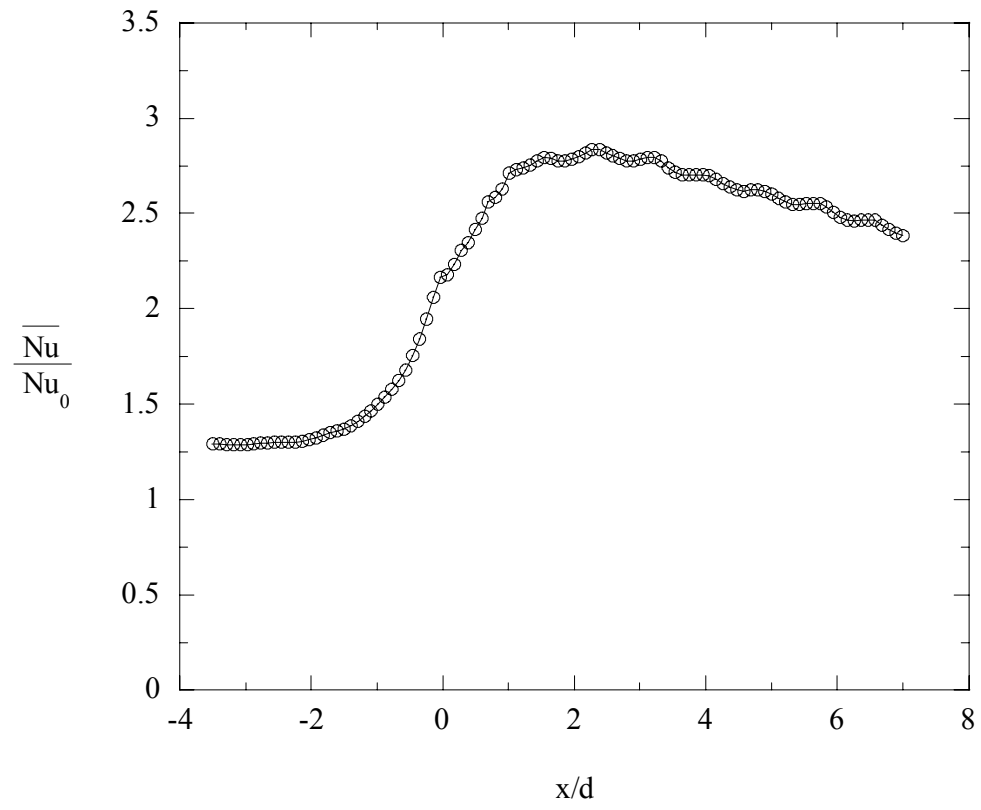

Figure 5-1 Spanwise average plot of the developing endwall heat transfer at $\operatorname{Re}=13,072$ for the $\mathrm{S} / \mathrm{d}=2$ geometry.

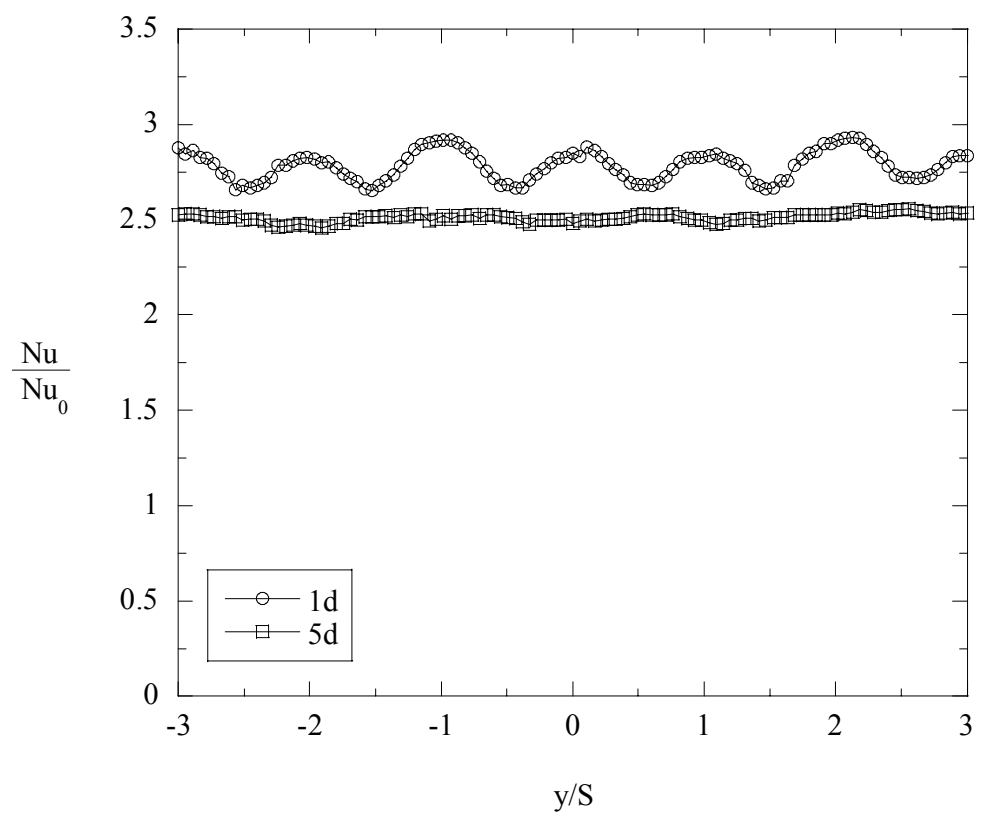

Figure 5-2 Spanwise line plots one and five pin diameters downstream of the pin row at $\operatorname{Re}=13,072$ for the $\mathrm{S} / \mathrm{d}=2$ geometry. 


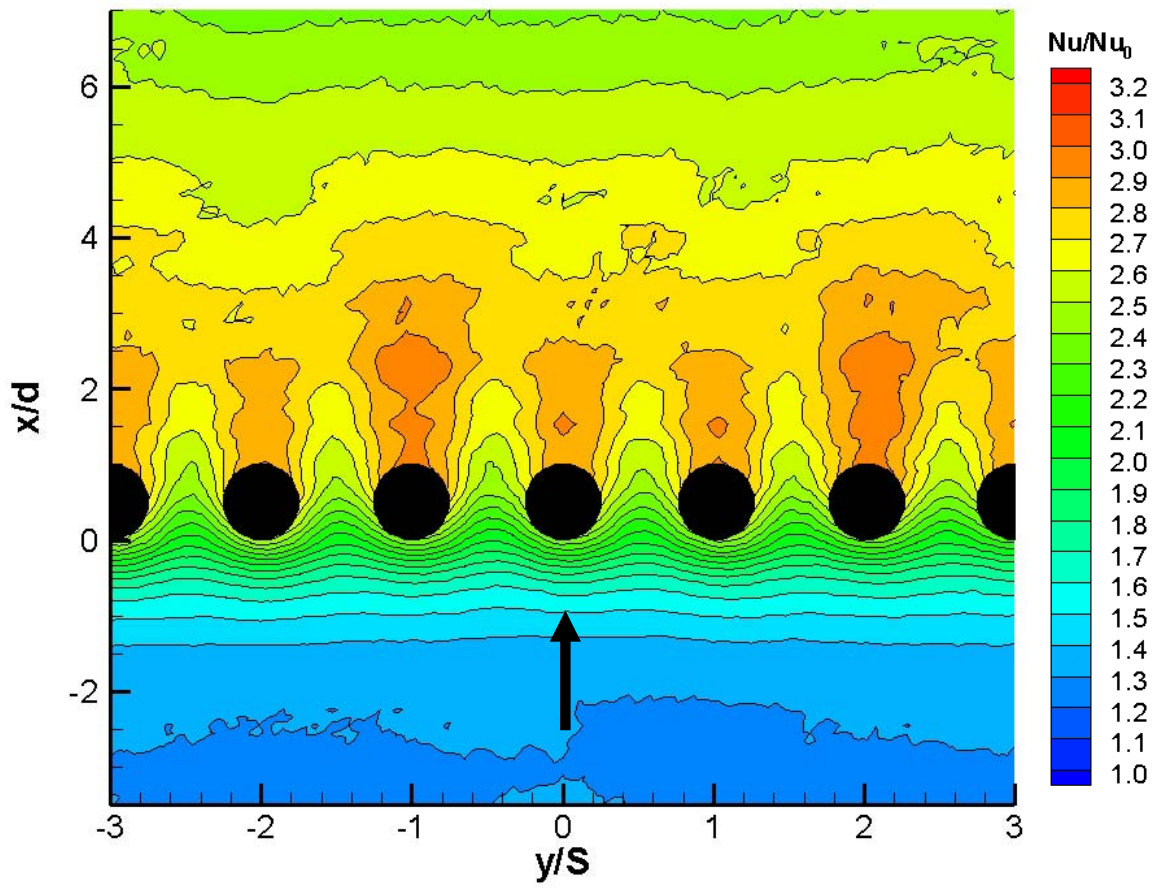

Figure 5-3 Contour of $\mathrm{Nu} / \mathrm{Nu}_{0}$ at $\mathrm{Re}=13,072$ and $\mathrm{Re}_{\mathrm{d}}=13,274$ for the $\mathrm{S} / \mathrm{d}=2$ geometry.

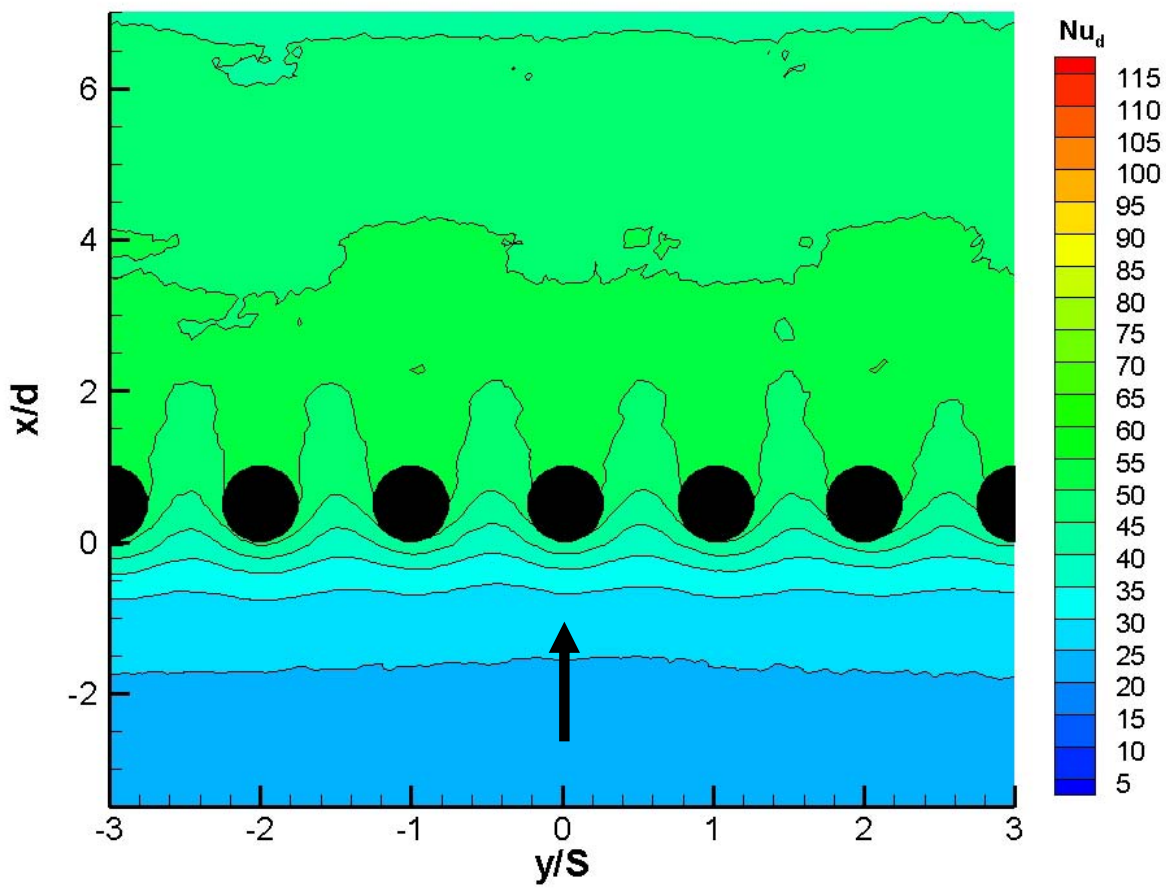

Figure 5-4 Contour of $\mathrm{Nu}_{\mathrm{d}}$ at $\mathrm{Re}=13,072$ and $\mathrm{Re}_{\mathrm{d}}=13,274$ for the $\mathrm{S} / \mathrm{d}=2$ geometry. 


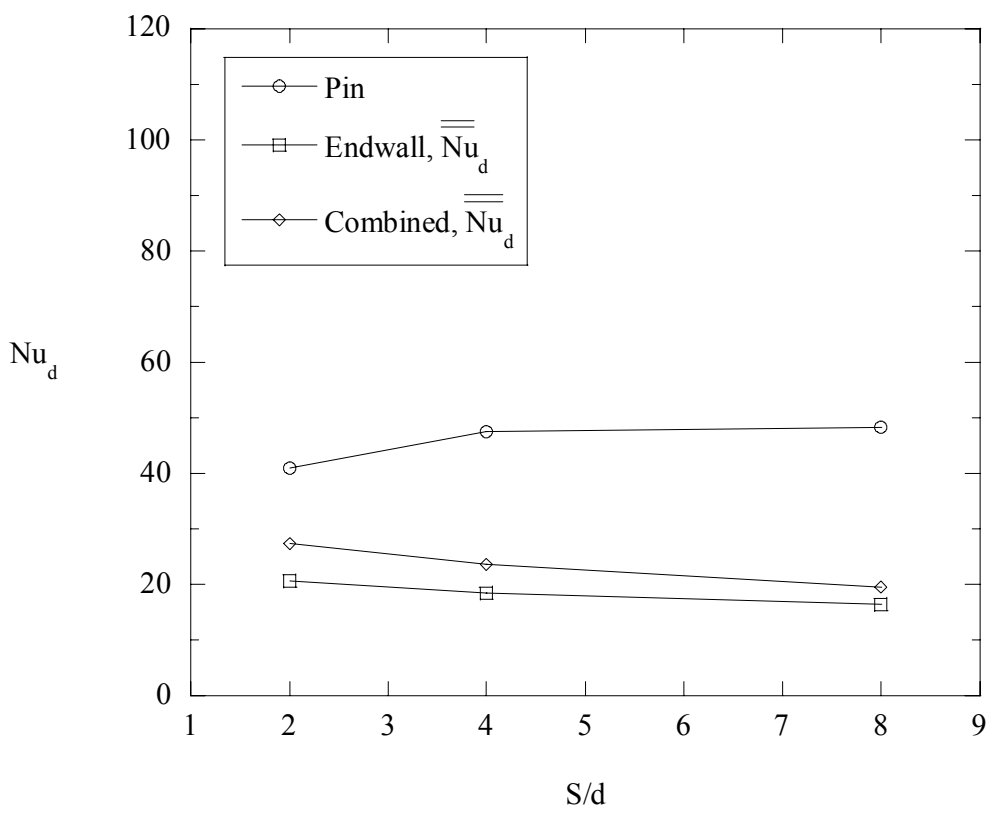

Figure 5-5 Plot showing the dependency of $\mathrm{Nu}_{d}$ on $\mathrm{S} / \mathrm{d}$ at a nominal Reynolds number of $\mathrm{Re}_{\mathrm{d}}=5000$.

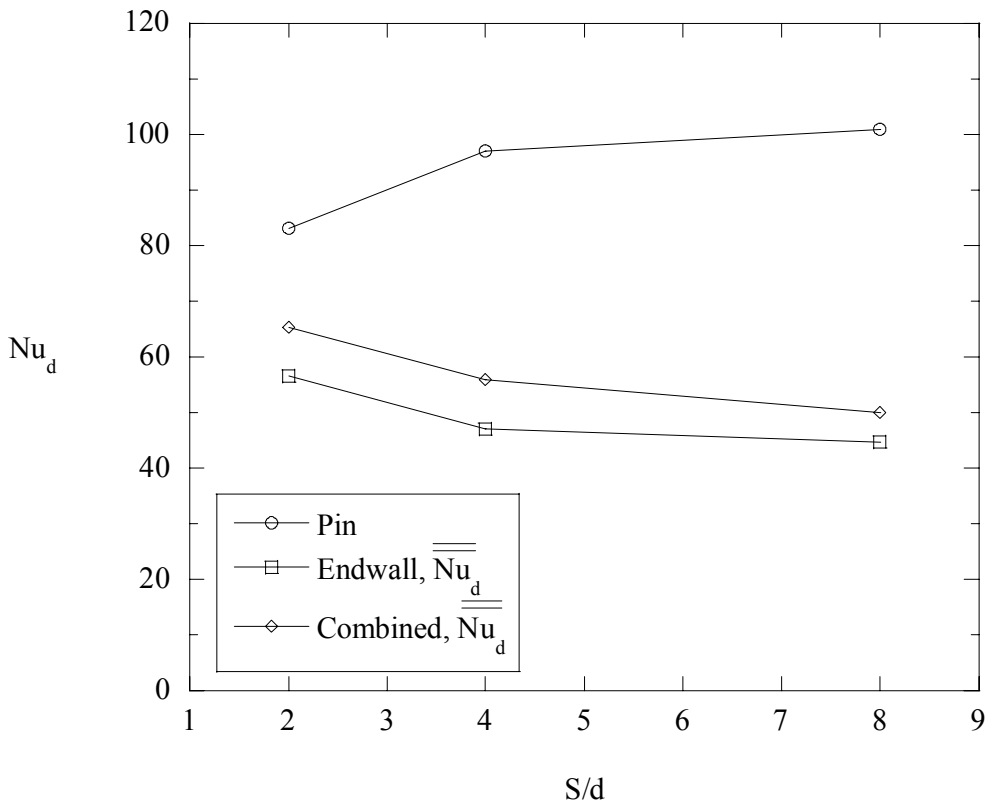

Figure 5-6 Plot showing the dependency of $\mathrm{Nu}_{\mathrm{d}}$ on $\mathrm{S} / \mathrm{d}$ at a nominal Reynolds number of $\mathrm{Re}_{\mathrm{d}}=17,500$. 


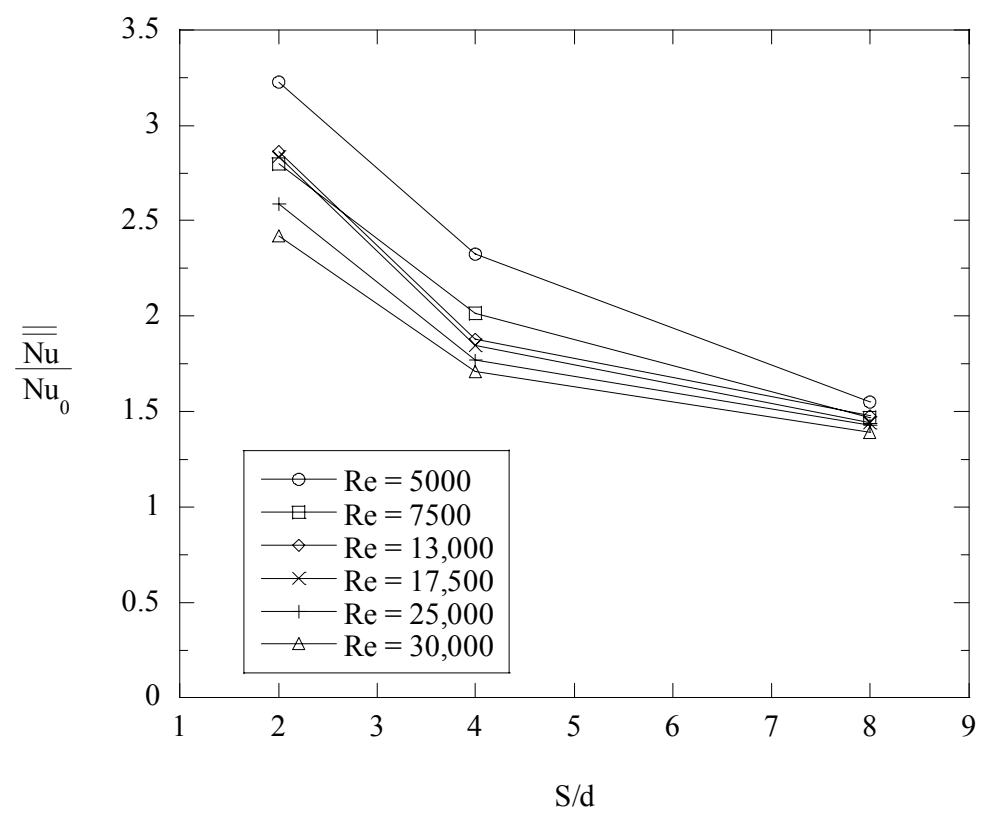

Figure 5-7 Normalized combined pin and endwall heat transfer versus the spanwise pin spacing.

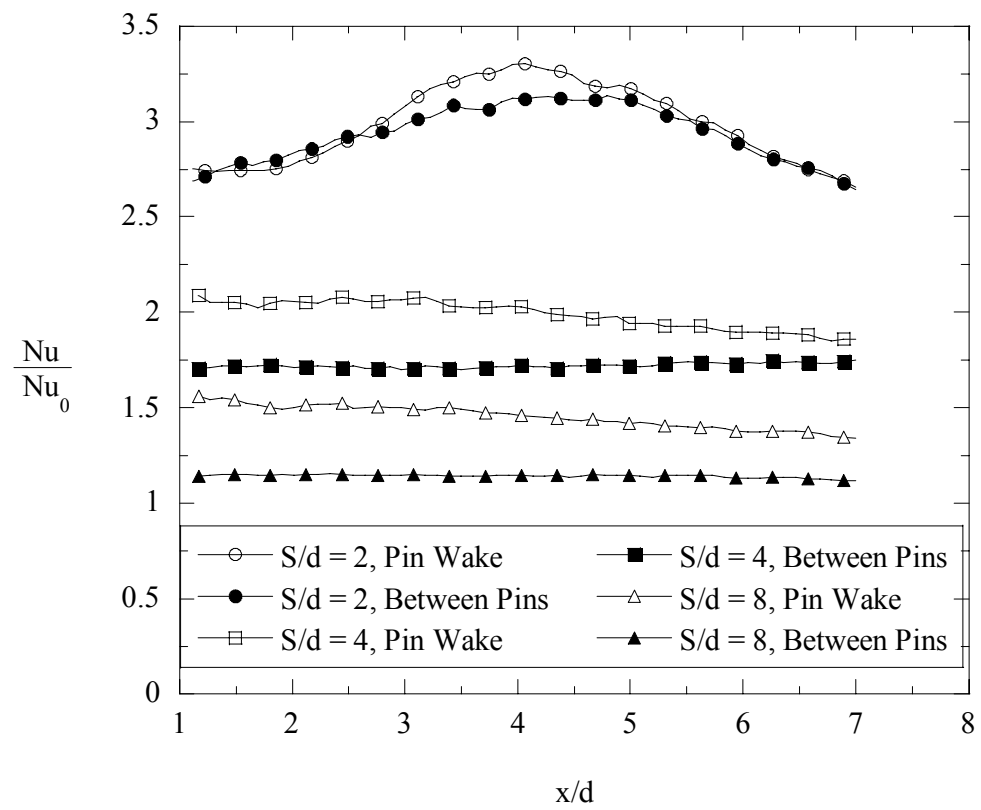

Figure 5-8 Normalized line plots showing the developing heat transfer downstream of the pin row both within a pin wake and between the pins for all three geometries at $\mathrm{Re}=$ 5000 . 


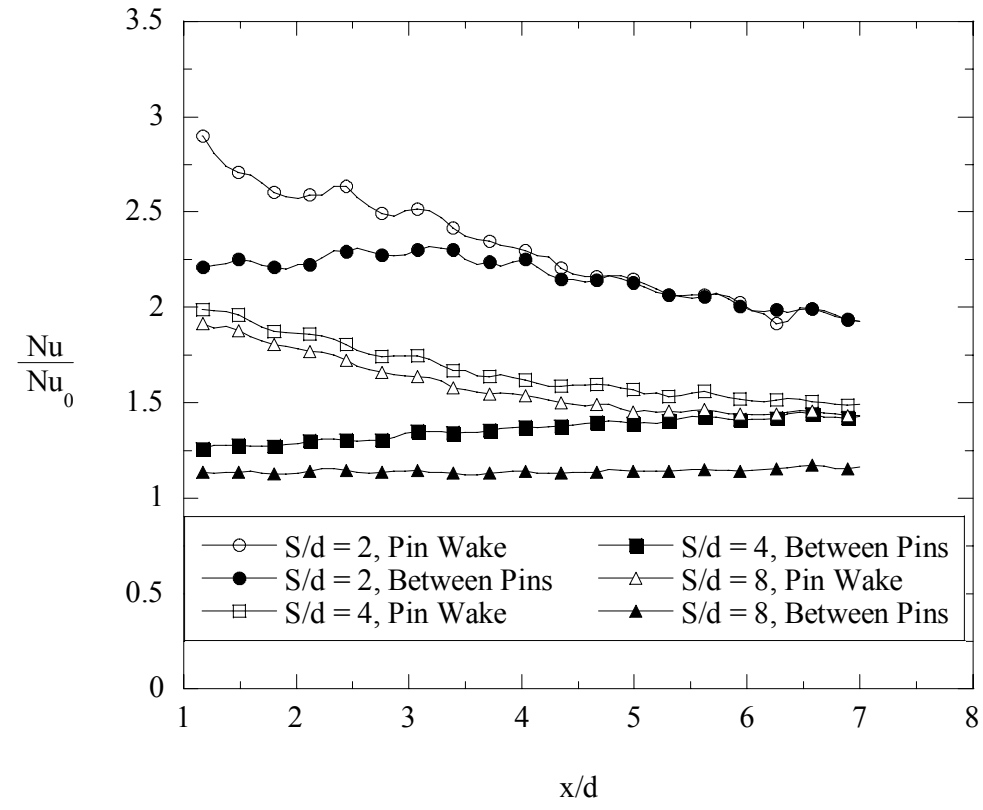

Figure 5-9 Normalized line plots showing the developing heat transfer downstream of the pin row both within a pin wake and between the pins for all three geometries at $\mathrm{Re}=$ 30,000 .

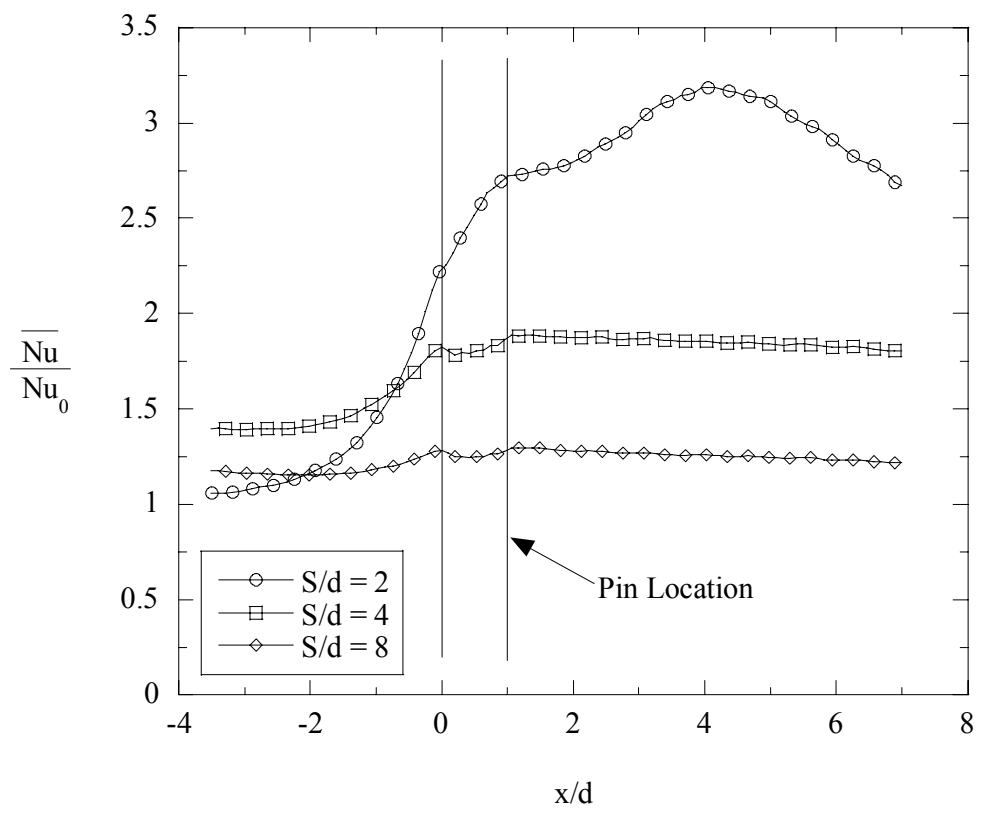

Figure 5-10 Spanwise averaged developing heat transfer along the streamwise direction for all three geometries at $\operatorname{Re}=5000$. 


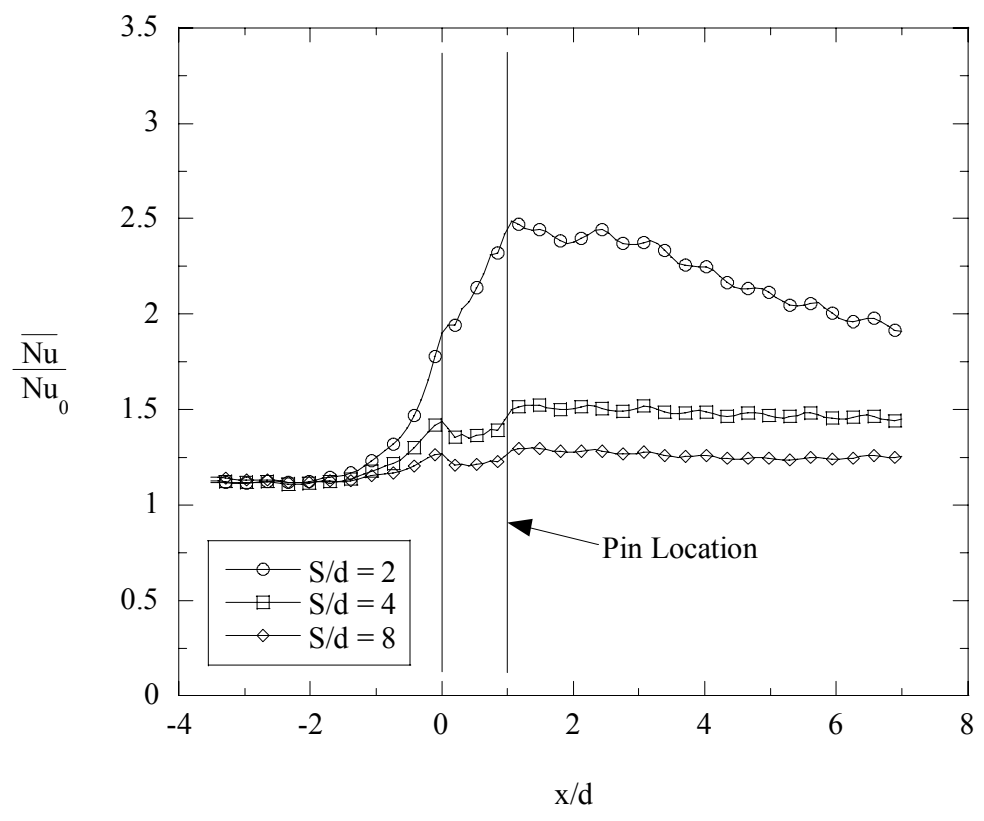

Figure 5-11 Spanwise averaged developing heat transfer along the streamwise direction for all three geometries at $\operatorname{Re}=30,000$.

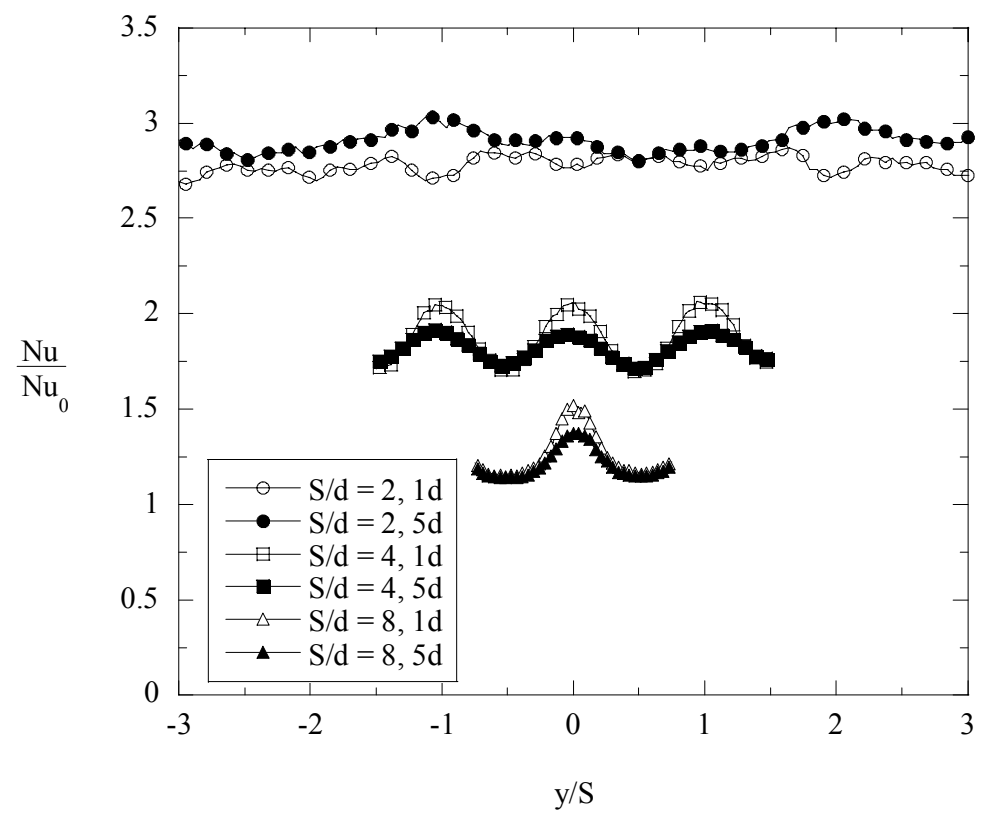

Figure 5-12 Spanwise line plots of normalized heat transfer one and five pin diameters downstream of the pin row for the $\mathrm{S} / \mathrm{d}=2,4$ and 8 geometries at $\mathrm{Re}=5000$. 


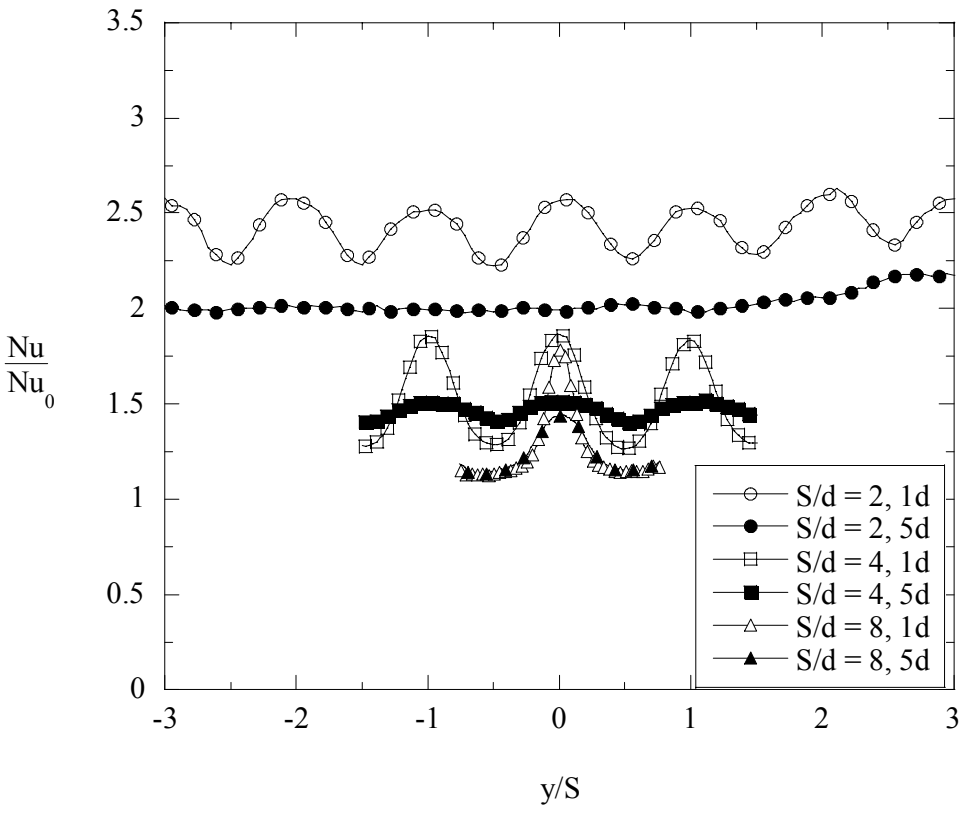

Figure 5-13 Spanwise line plots of normalized heat transfer one and five pin diameters downstream of the pin row for the $\mathrm{S} / \mathrm{d}=2,4$ and 8 geometries at $\operatorname{Re}=30,000$. 

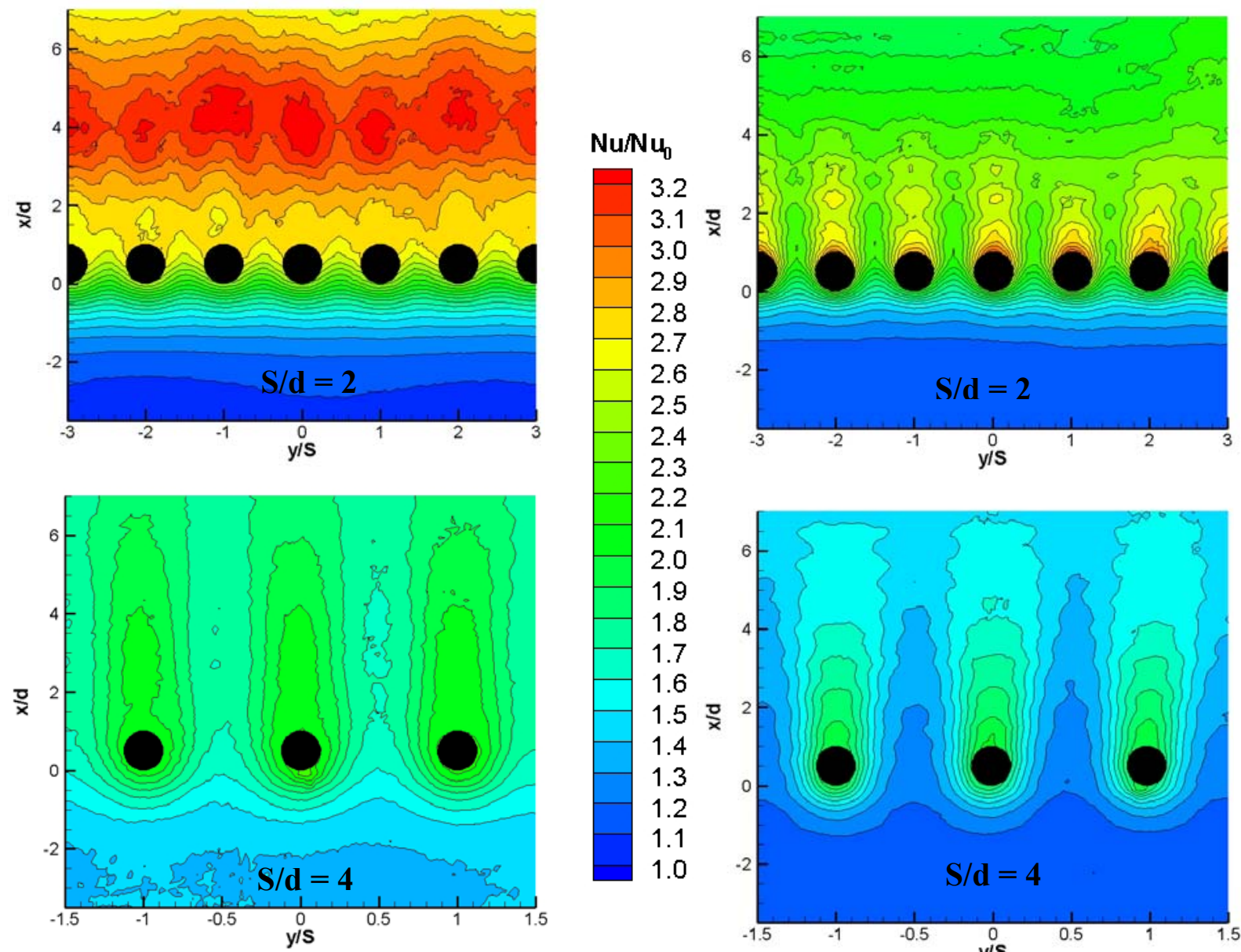

2.2
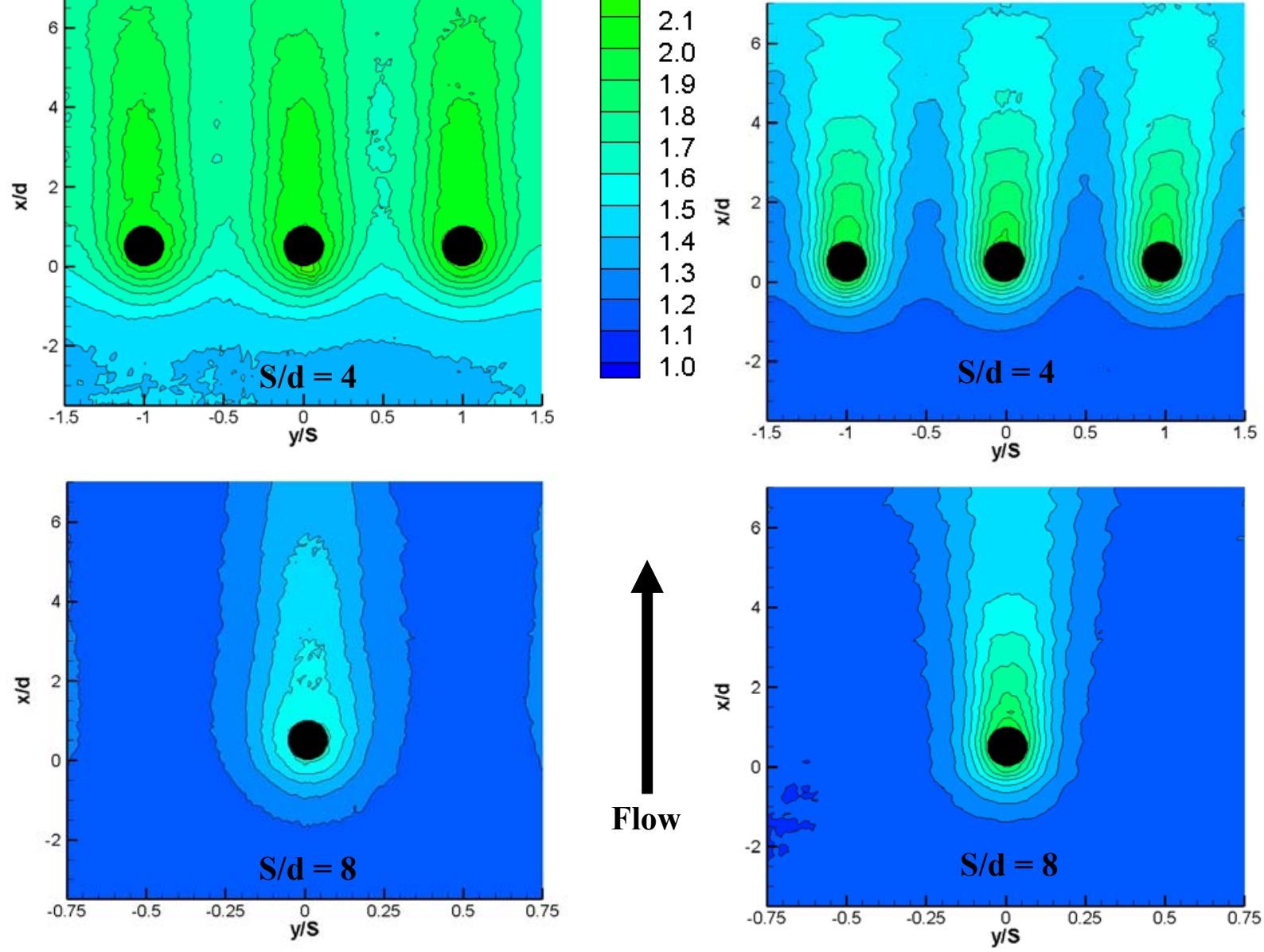

$$
\mathbf{R e}=\mathbf{5 0 0 0}
$$

$$
\operatorname{Re}=\mathbf{3 0 0 0 0}
$$

Figure 5-14 Contour plots of $\mathrm{Nu} / \mathrm{Nu}_{0}$ for all three geometries at $\mathrm{Re}=5000$ and $\mathrm{Re}=$ 30,000 . 

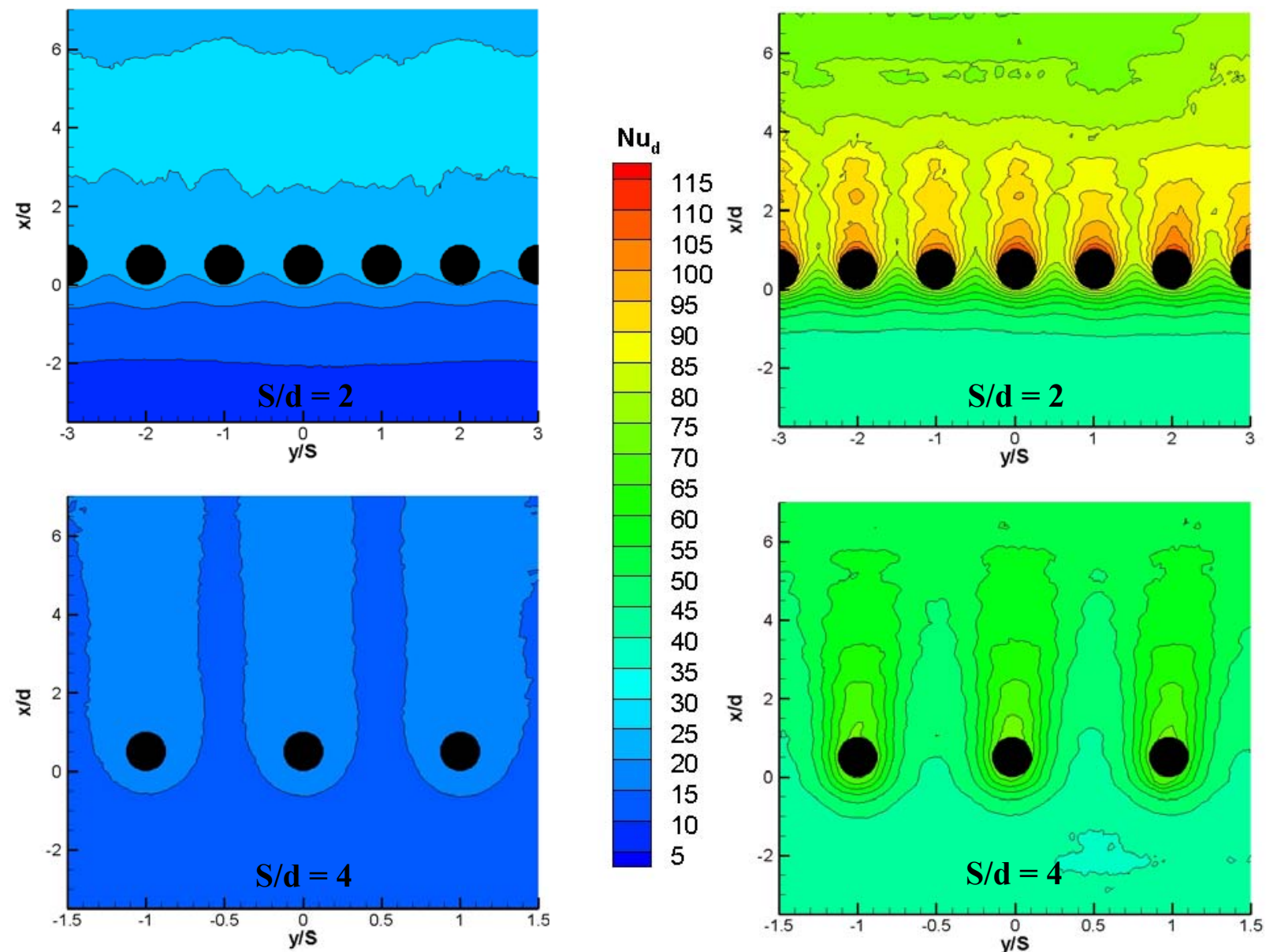

65

60

55

50

45

40

35

30

25

20

15

10

5
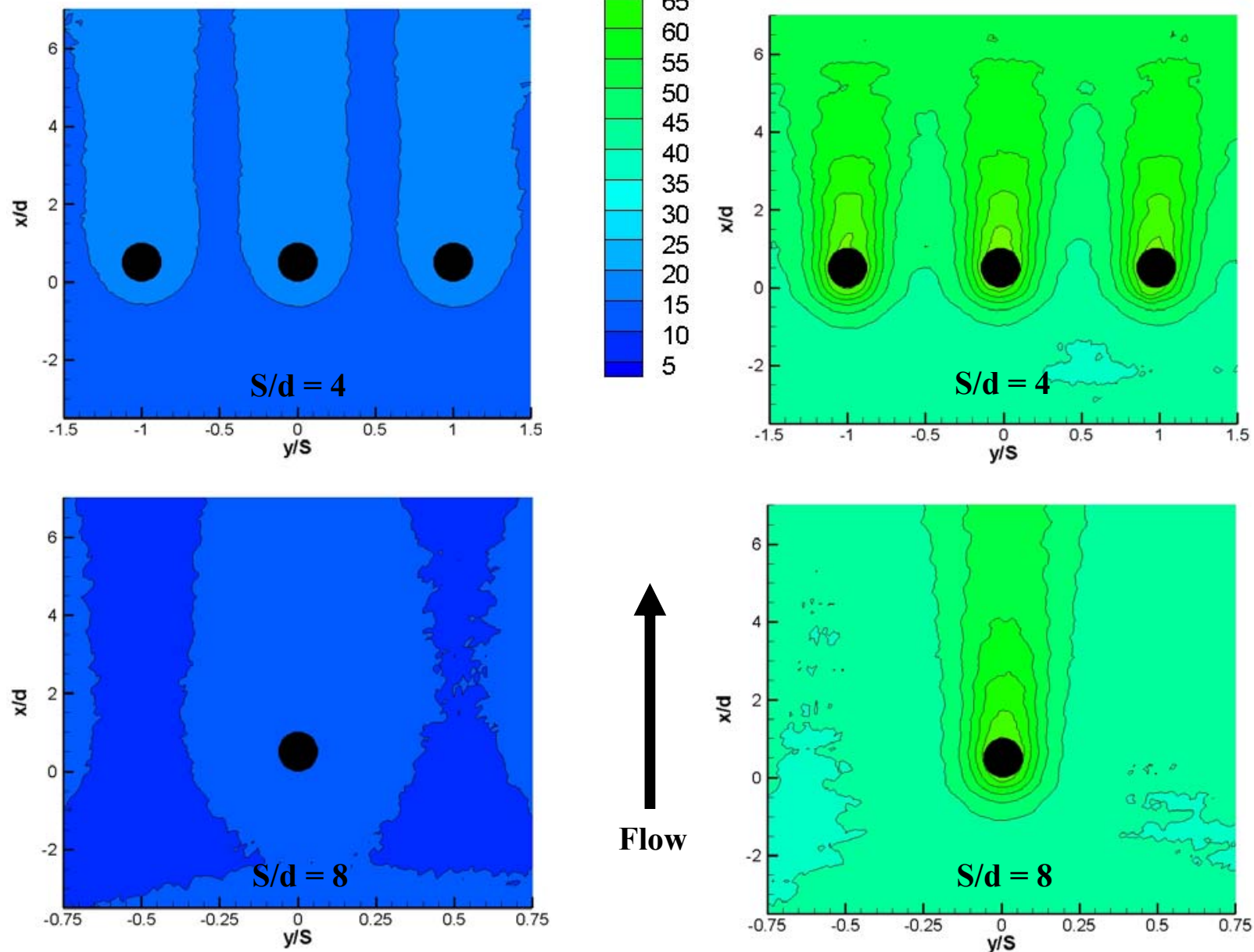

$$
\mathbf{R e}=\mathbf{5 0 0 0}
$$

$$
\operatorname{Re}=\mathbf{3 0 0 0 0}
$$

Figure 5-15 Contour plots of $\mathrm{Nu}_{\mathrm{d}}$ for all three geometries at $\mathrm{Re}=5000$ and $\mathrm{Re}=30,000$. 


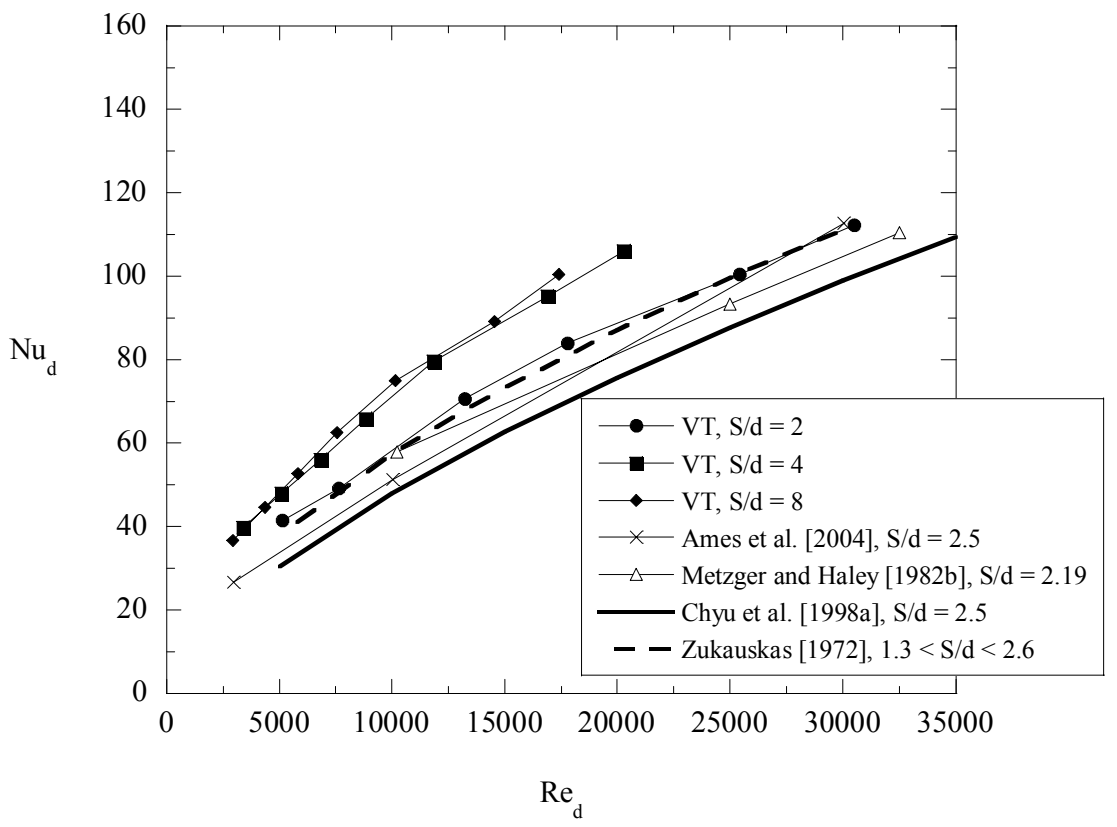

Figure 5-16 $\mathrm{S} / \mathrm{d}=2,4$, and 8 pin fin heat transfer results presented as $\mathrm{Nu}_{\mathrm{d}}$ versus $\mathrm{Re}_{\mathrm{d}}$ with a comparison with results from the literature.

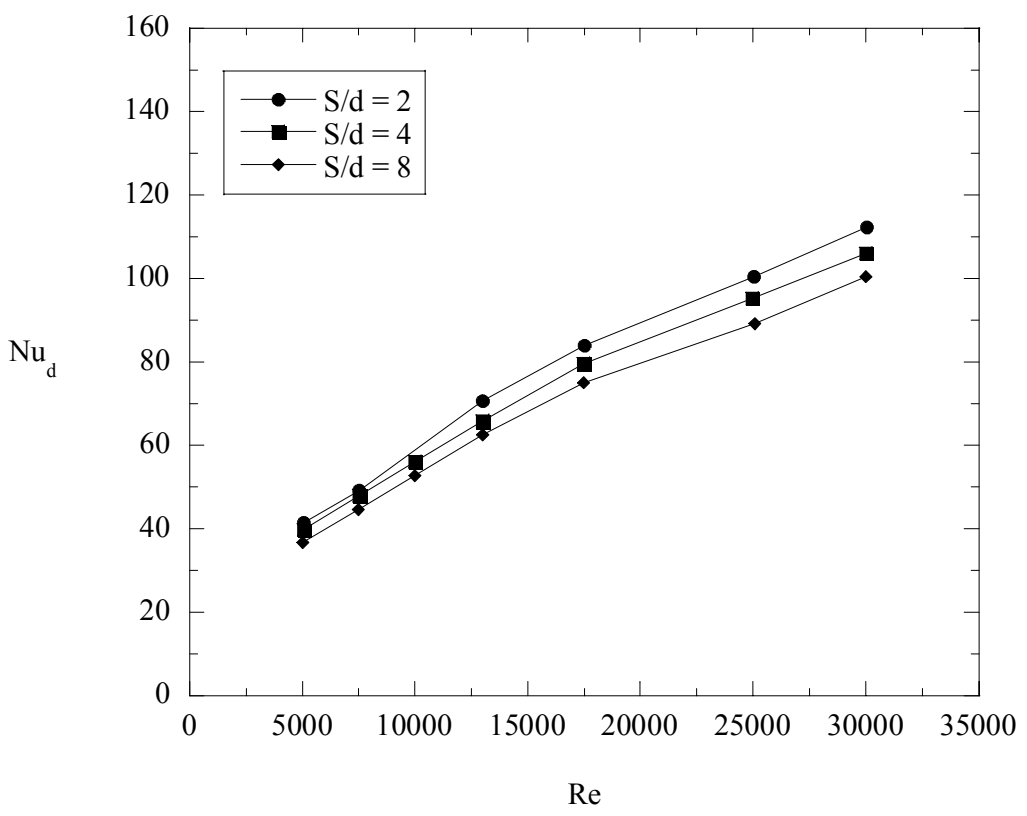

Figure 5-17 Comparison of pin fin heat transfer results showing the dependency of $\mathrm{Nu}_{\mathrm{d}}$ on $\operatorname{Re}$ to investigate different scaling possibilities. 


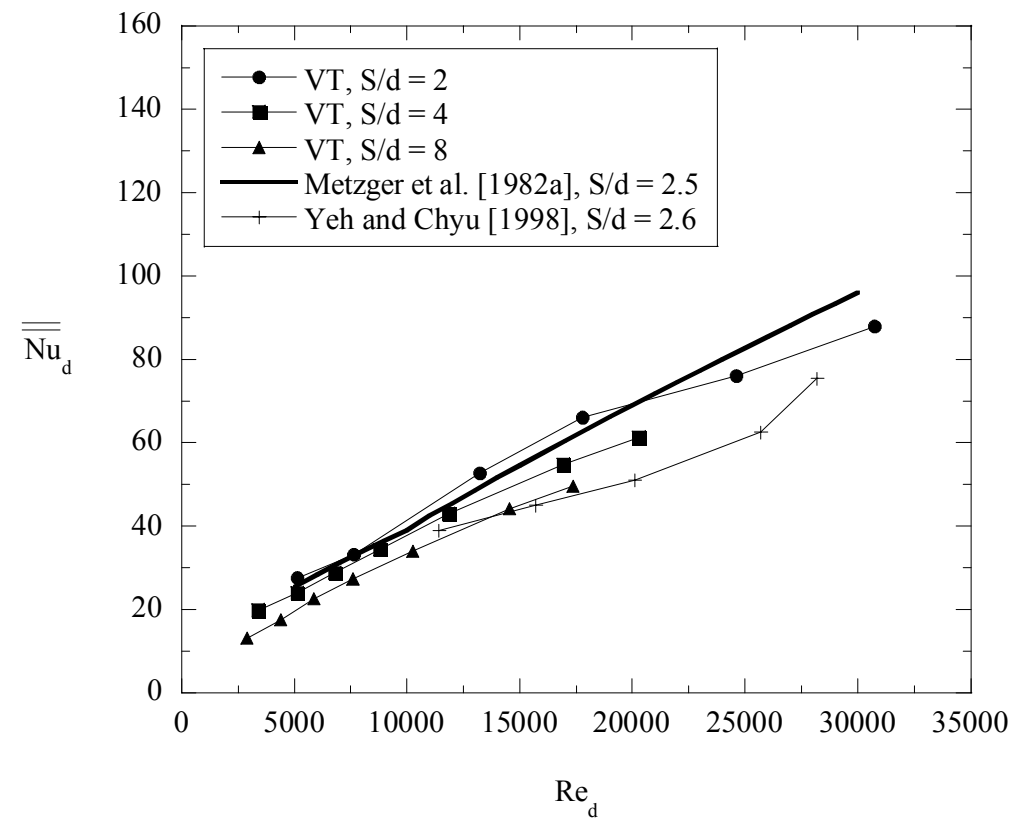

Figure 5-18 $\mathrm{S} / \mathrm{d}=2,4$, and 8 combined pin and endwall heat transfer results plotted as $\mathrm{Nu}_{\mathrm{d}}$ versus $\mathrm{Re}_{\mathrm{d}}$ and compared with data from the literature.

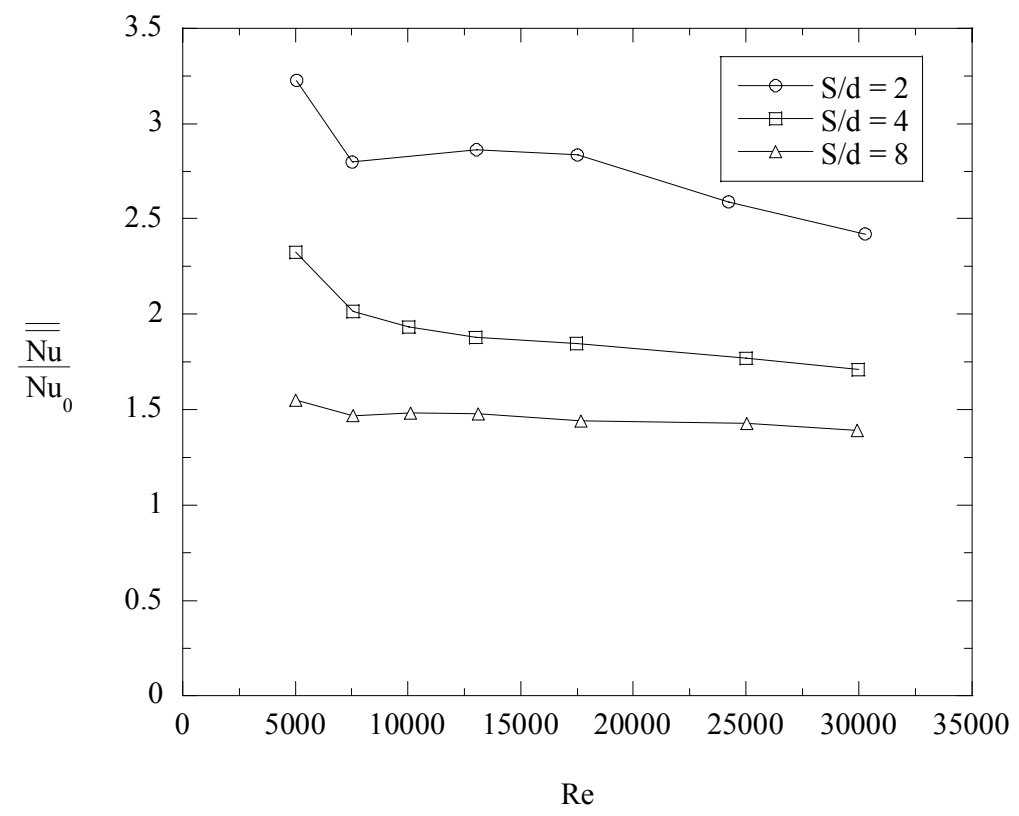

Figure 5-19 Combined pin and endwall heat transfer augmentation over fully developed open duct flow for the $\mathrm{S} / \mathrm{d}=2,4$, and 8 geometries as a function of Reynolds number, Re. 


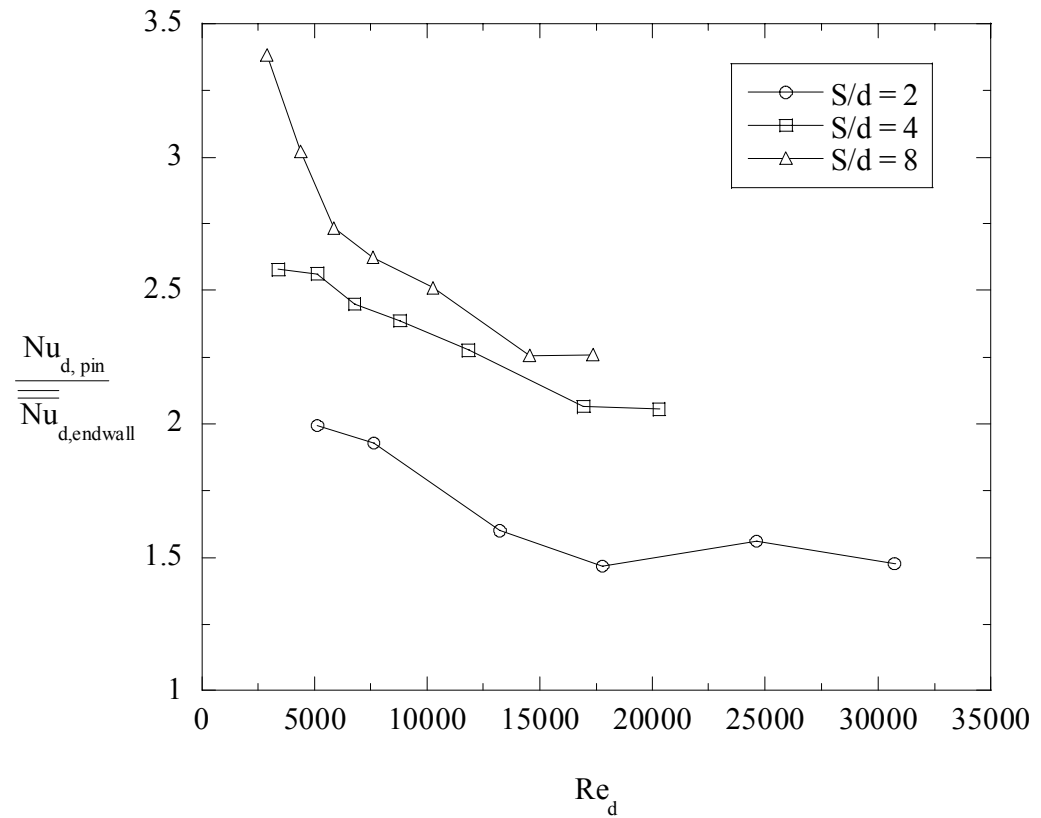

Figure 5-20 Pin to endwall heat transfer ratio as a function of $\mathrm{Re}_{\mathrm{d}}$.

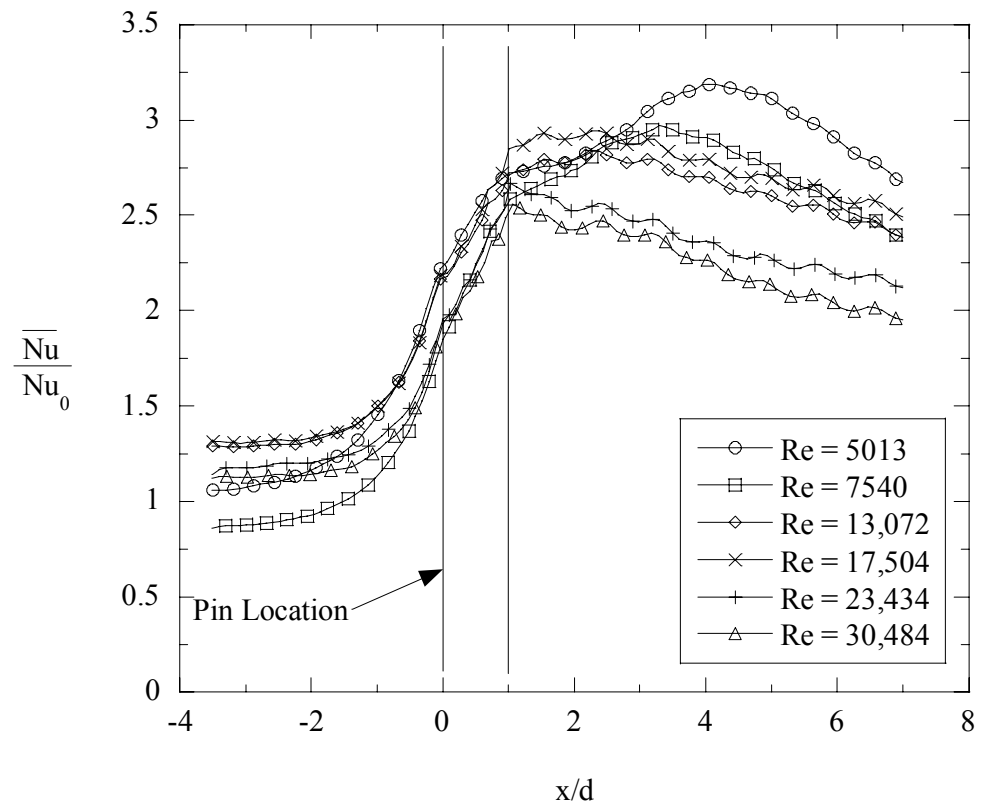

Figure 5-21 Developing endwall heat transfer for the $\mathrm{S} / \mathrm{d}=2$ geometry. 


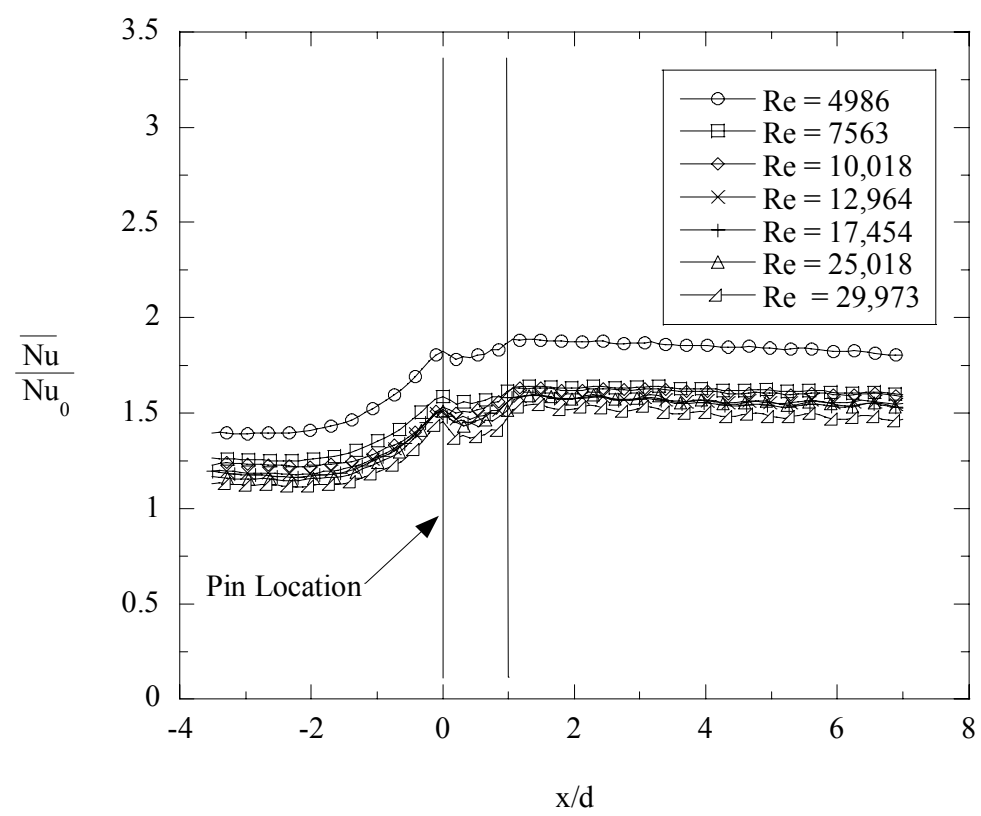

Figure 5-22 Developing endwall heat transfer for the $\mathrm{S} / \mathrm{d}=4$ geometry.

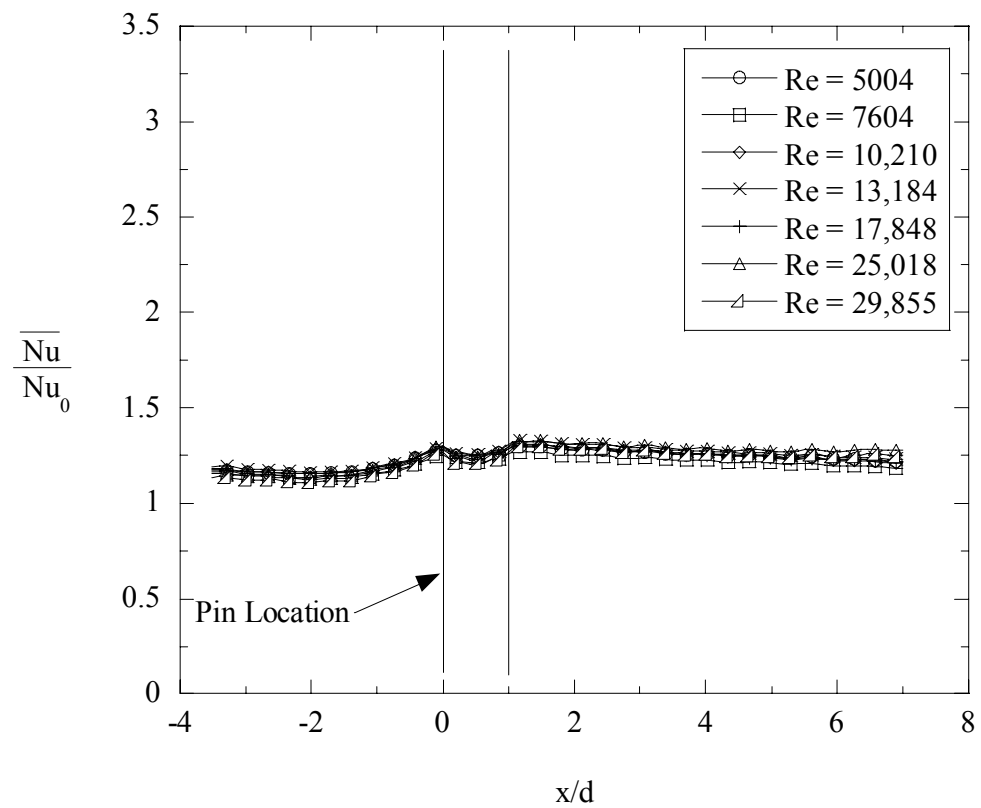

Figure 5-23 Developing endwall heat transfer for the $S / d=8$ geometry. 


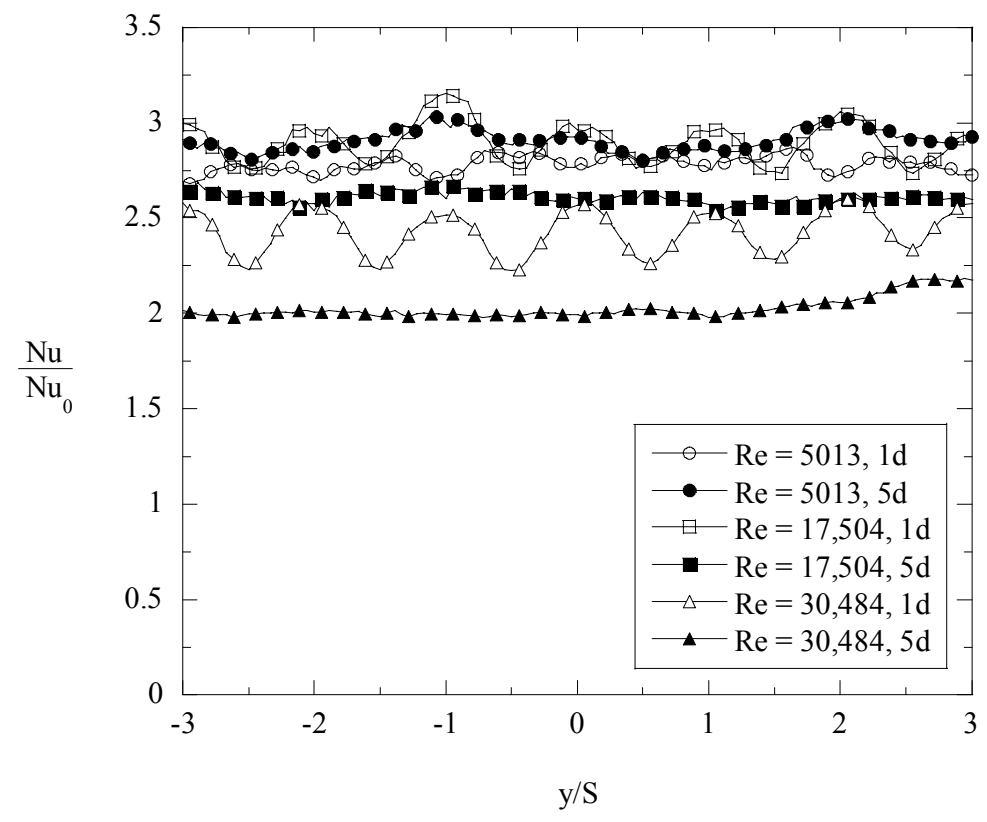

Figure 5-24 Spanwise line plots of endwall heat transfer downstream of the pin row for the $\mathrm{S} / \mathrm{d}=2$ geometry across the Reynolds number range.

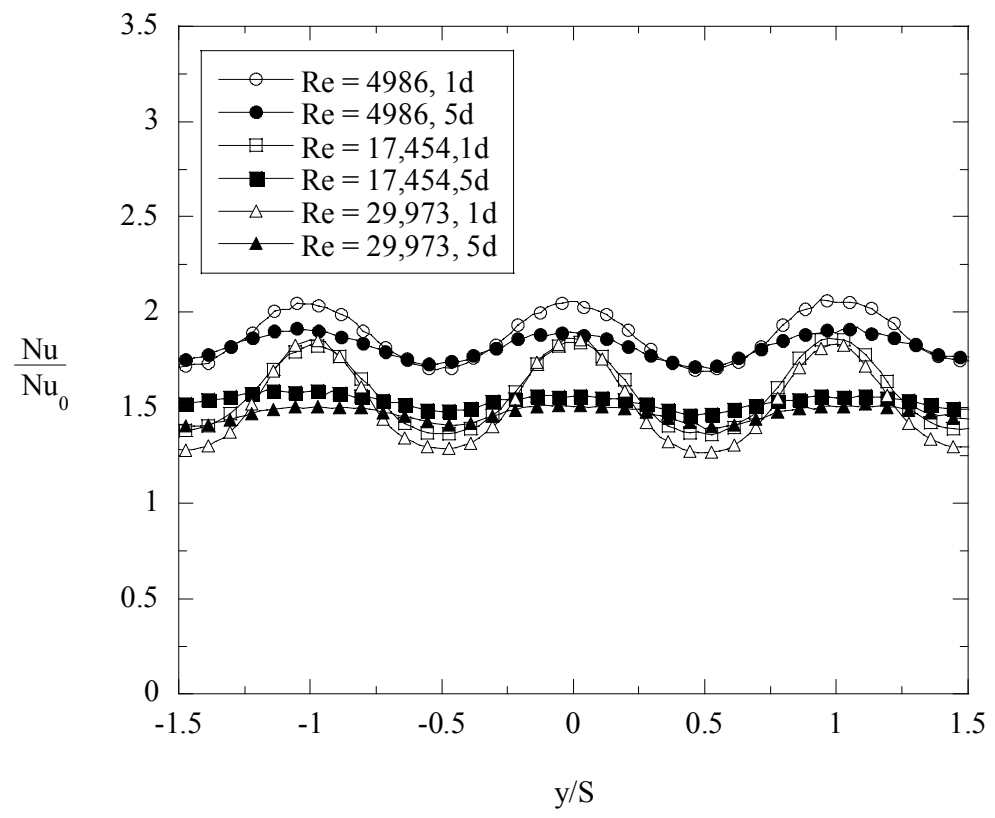

Figure 5-25 Spanwise line plots of endwall heat transfer downstream of the pin row for the $\mathrm{S} / \mathrm{d}=4$ geometry across the Reynolds number range. 


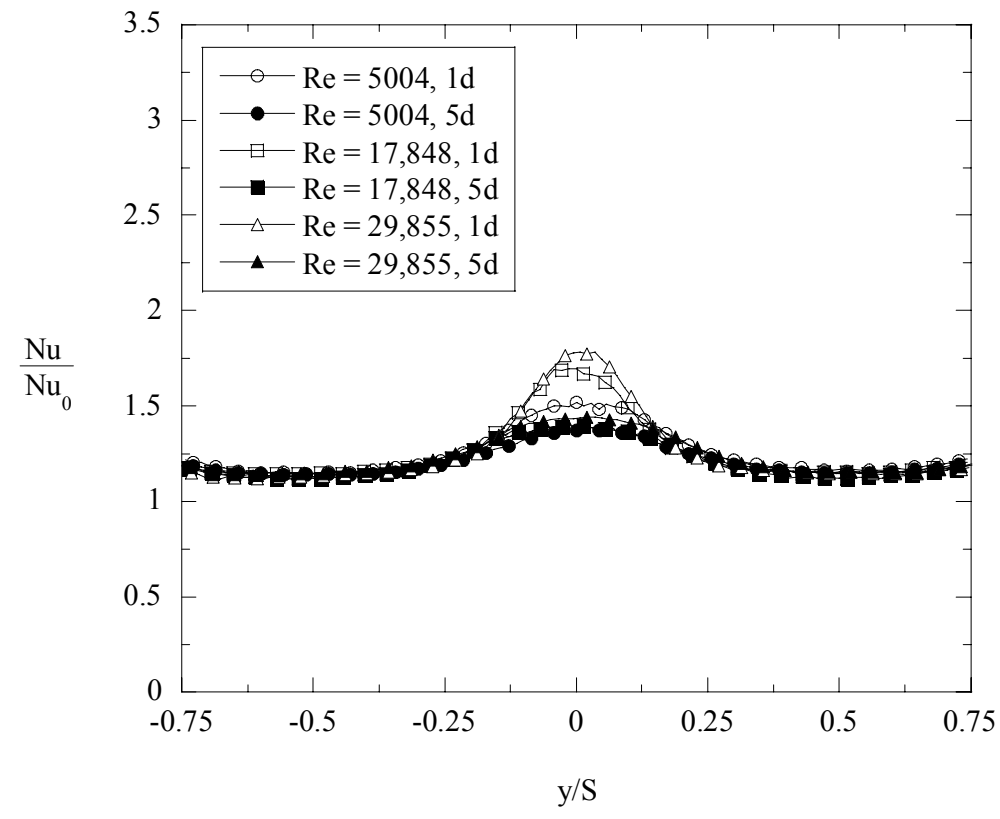

Figure 5-26 Spanwise line plots of endwall heat transfer downstream of the pin row for the $\mathrm{S} / \mathrm{d}=8$ geometry across the Reynolds number range. 

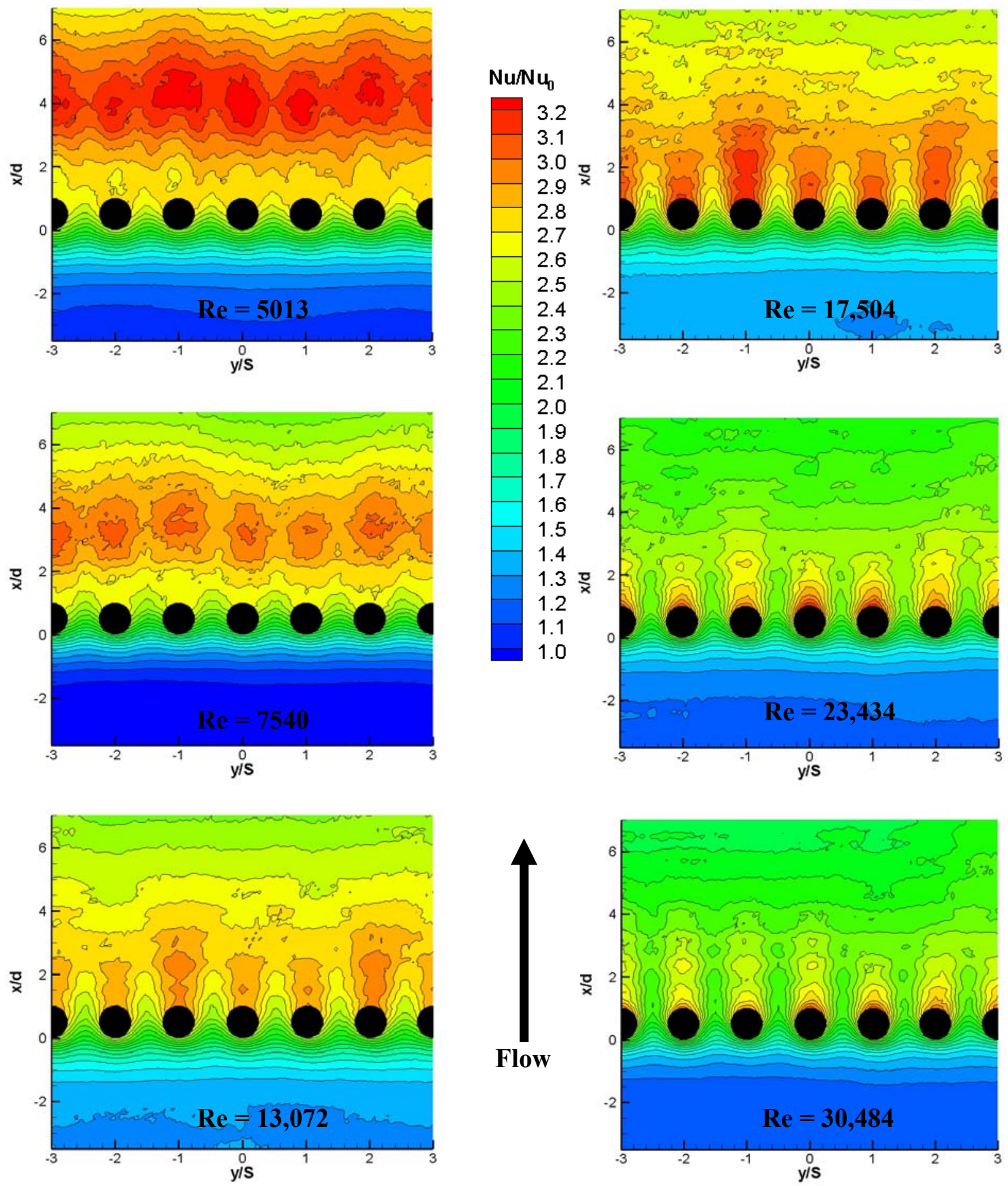

Figure 5-27 Contour plots of $\mathrm{Nu} / \mathrm{Nu}_{0}$ for the $\mathrm{S} / \mathrm{d}=2$ geometry. 

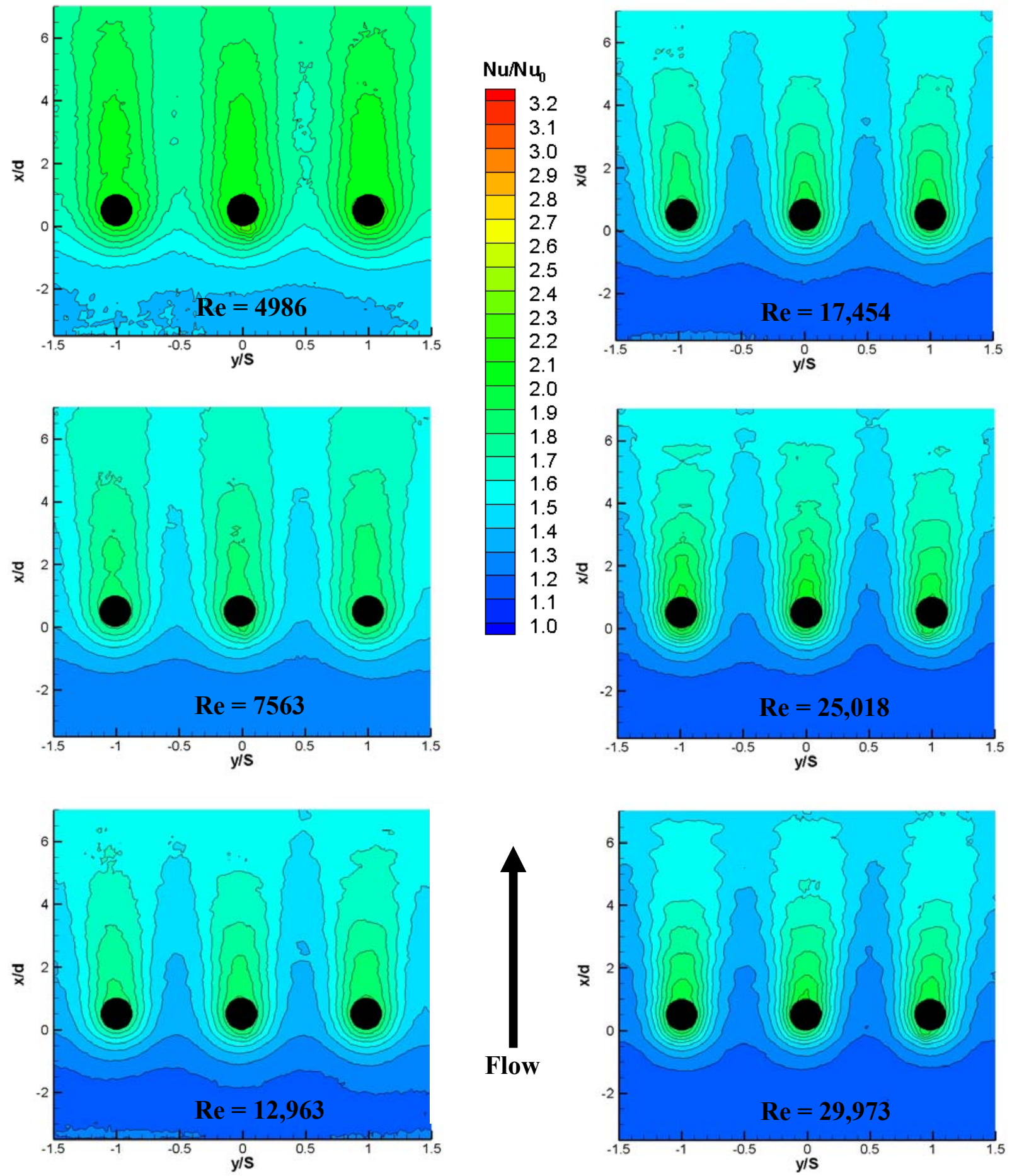

Figure 5-28 Contour plots of $\mathrm{Nu} / \mathrm{Nu}_{0}$ for the $\mathrm{S} / \mathrm{d}=4$ geometry. 

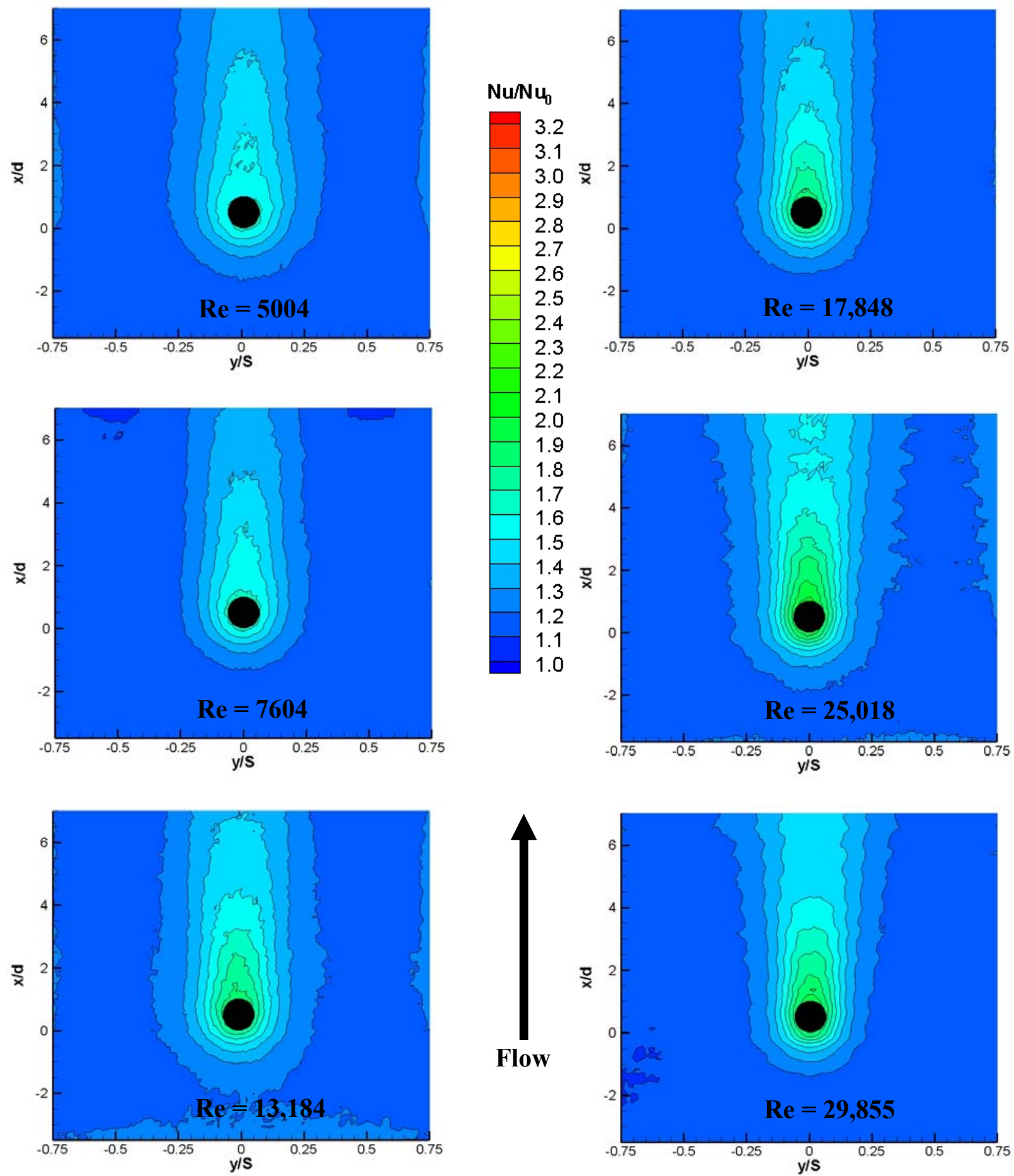

Figure 5-29 Contour plots of $\mathrm{Nu} / \mathrm{Nu}_{0}$ for the $\mathrm{S} / \mathrm{d}=8$ geometry. 

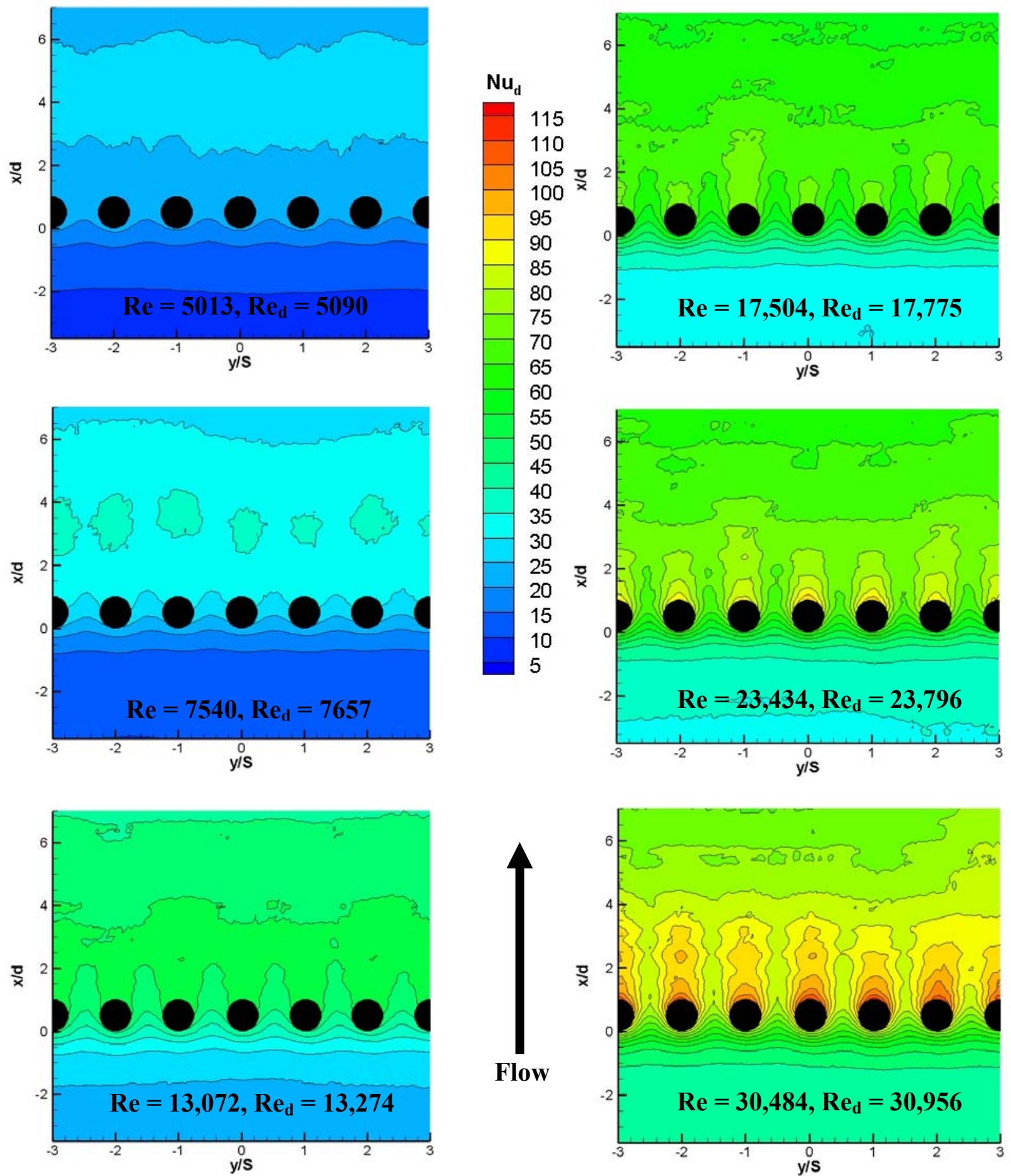

Figure 5-30 Contour plots of $\mathrm{Nu}_{\mathrm{d}}$ for the $\mathrm{S} / \mathrm{d}=2$ geometry. 

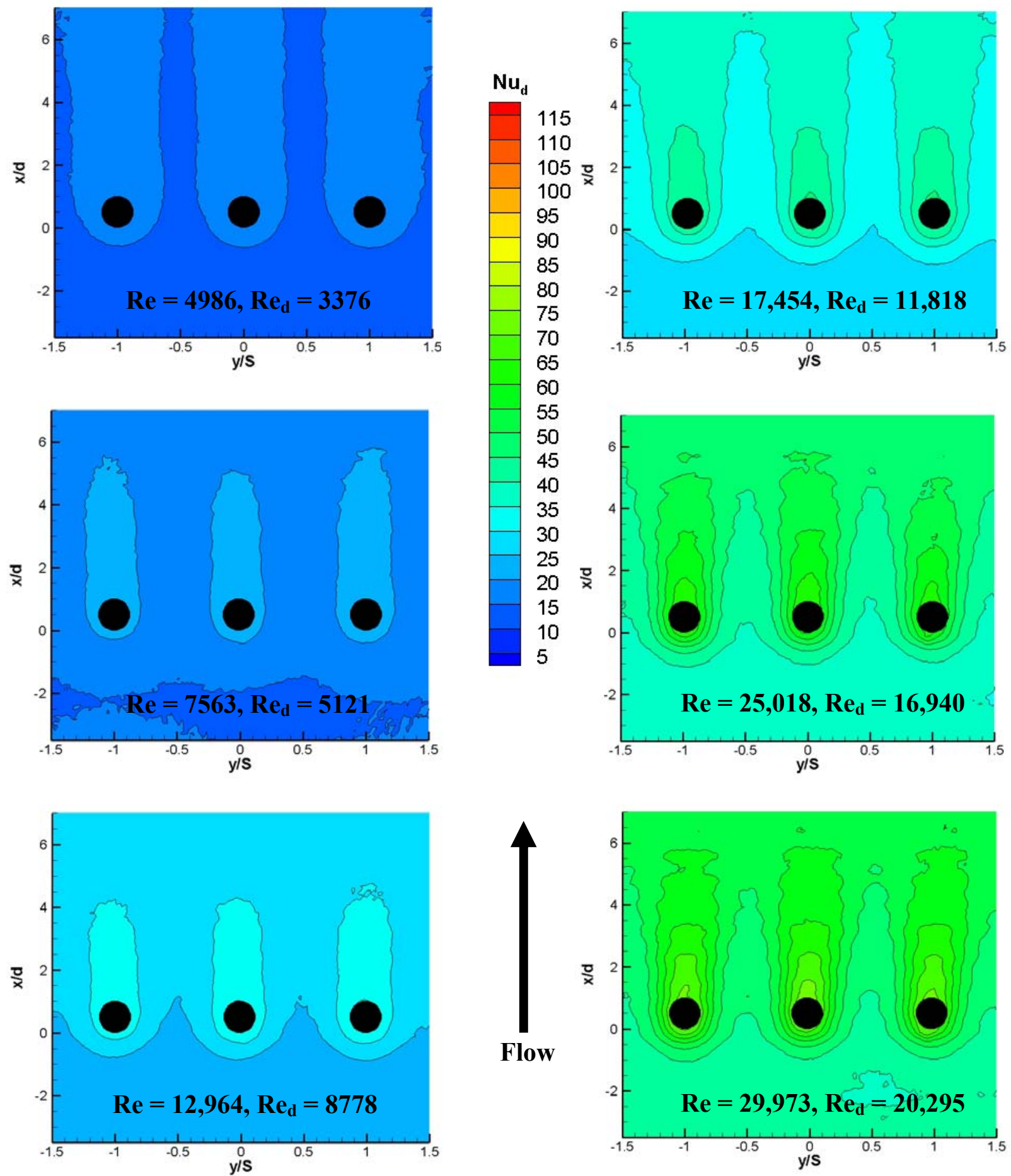

Figure 5-31 Contour plots of $\mathrm{Nu}_{\mathrm{d}}$ for the $\mathrm{S} / \mathrm{d}=4$ geometry. 

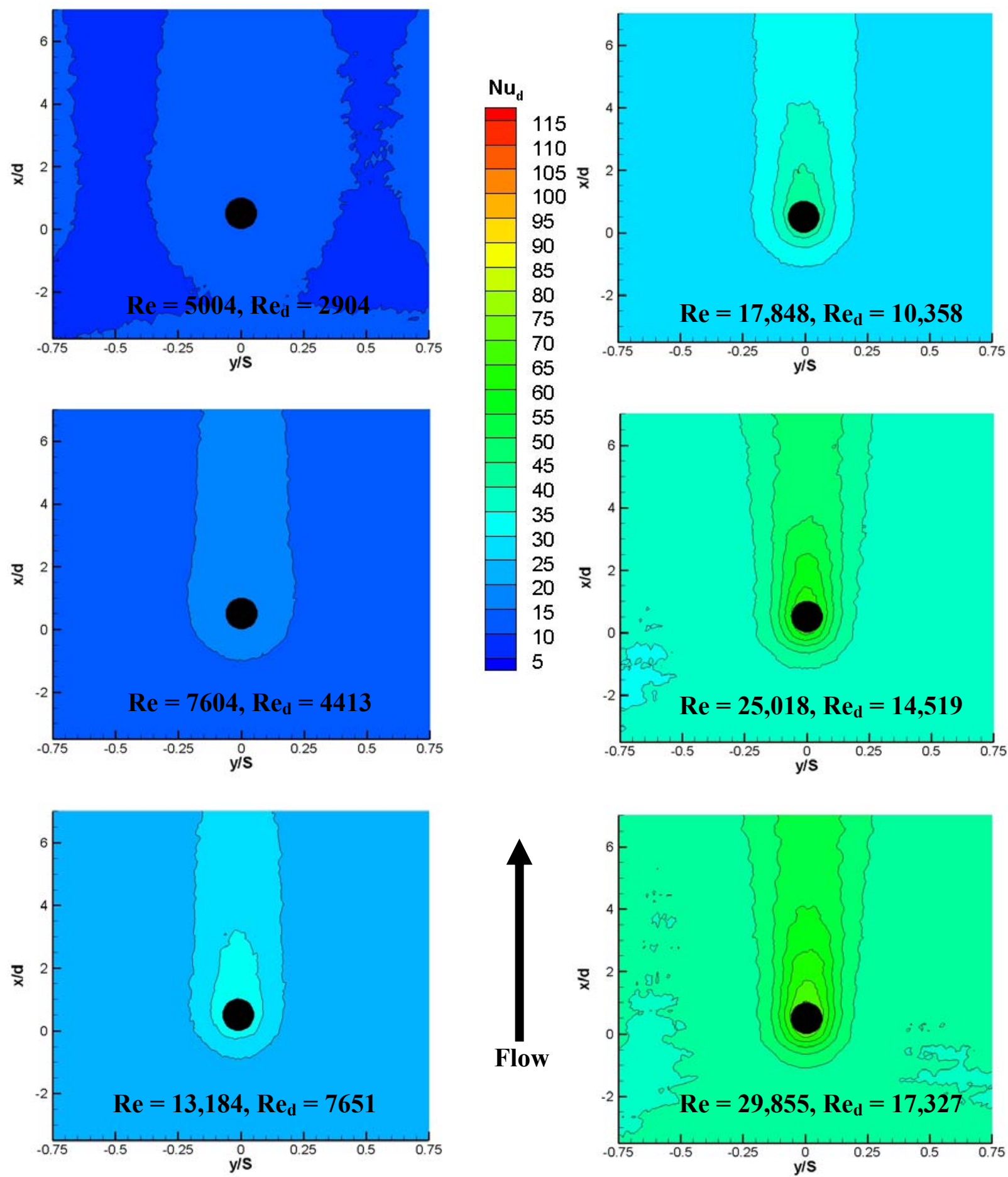

Figure 5-32 Contour plots of $\mathrm{Nu}_{\mathrm{d}}$ for the $\mathrm{S} / \mathrm{d}=8$ geometry. 


\section{Chapter 6}

\section{Conclusions}

The work presented in this thesis represents the beginning phase of a more comprehensive study to gain a more general knowledge base of pin fin array heat transfer. Pin fin arrays are typical cooling features found inside gas turbine airfoils. Pin and endwall heat transfer measurements were taken from single rows of pin fins oriented perpendicular to the flow. The spacings studied were $S / d=2,4$, and 8 , where $S$ is the center to center pin spacing transverse to the flow, and $\mathrm{d}$ is the pin diameter. The pin fins used for all three pin spacings had aspect ratios of $\mathrm{H} / \mathrm{d}=1$, where $\mathrm{H}$ is the pin height, and again $\mathrm{d}$ is the pin diameter.

A new test facility was designed and built to carry out the experiments. The chosen design was a closed loop, recirculating wind tunnel with an integral heat exchanger for maintaining a steady test section inlet temperature. In addition, two separate measurement methods were developed for the pin fin and endwall heat transfer measurements. The endwall measurement method involved using an infrared camera to obtain a temperature map of the pin fin row endwall. Heat transfer coefficients were calculated using the temperature map, giving high measurement resolution on the endwall surface. The pin fin heat transfer measurements were obtained using a heated inconel foil technique. The inconel foil was mounted around the circumference of a balsa wood pin fin. Thermocouples were mounted under the surface of the inconel, yielding temperatures required for calculating heat transfer coefficients on the pin fin surface.

The remainder of this chapter summarizes the major findings from this research. Since two variables, pin spacing and Reynolds number were studied in this project, this chapter is organized accordingly. Section 6.1 discusses pin spacing effects. In Section 6.2 , Reynolds number effects are presented. Finally, Recommendations for future work are made in Section 6.3. 


\subsection{Overview of Pin Spacing Effects}

Regarding the magnitude of the endwall heat transfer, the $\mathrm{S} / \mathrm{d}=2$ pin spacing provides much higher augmentation than the $\mathrm{S} / \mathrm{d}=4$ and 8 pin spacings. The trend is also clear, indicating that the endwall heat transfer decreases with increased pin spacing. However, it must be noted that the difference is much greater between the $\mathrm{S} / \mathrm{d}=2$ and 4 pin spacings than between $\mathrm{S} / \mathrm{d}=4$ and 8 .

The contour data indicate that these differences are caused by decreased pin wake interactions with increased pin spacing. For the $\mathrm{S} / \mathrm{d}=2$ pin spacing, distinct pin wakes are noticeable only for a few pin diameters downstream of the pin row. Four pin diameters downstream of the pins, the flow is fully mixed. For the $\mathrm{S} / \mathrm{d}=4$ pin spacing, it is clear from the contour data that less mixing occurs downstream of the pin fins than with the $S / d=2$ pin spacing. Six pin diameters downstream of the pins, the flow is almost but not fully mixed. However, the $\mathrm{S} / \mathrm{d}=8$ pin spacing produces wakes that remain distinct beyond six pin diameters, indicating that a much longer developing region is required for the flow to become fully mixed.

The pin spacing effects are considerably different for the pin fin heat transfer as opposed to the endwall heat transfer. For a given value of the pin Reynolds number, $\operatorname{Re}_{\mathrm{d}}$, which is based on the maximum average velocity between the pins, the pin fin heat transfer increases with increased pin spacing. However, there is little difference between the $\mathrm{S} / \mathrm{d}=4$ and 8 pin spacings. This is the opposite effect observed for the endwall heat transfer. Different trends of pin fin heat transfer for narrow and wide spacing indicate that the heat transfer mechanism on the pin fin surface changes as the pin spacing increases.

The combined pin and endwall heat transfer had a similar trend depending on pin spacing as the endwall heat transfer. Although the separate pin and endwall heat transfer measurements had different trends with respect to the pin spacing, the endwall carries more influence when considering the fraction of the total heat transfer area. As shown in Chapter 4 , the endwall contributes $67 \%, 82 \%$, and $91 \%$ of the total heat transfer area for the $\mathrm{S} / \mathrm{d}=2,4$, and 8 pin spacings respectively. Thus, the endwall heat transfer is more representative of the combined results than the pin fin heat transfer. 
The final notable feature concerning pin spacing is the pin heat transfer relative to the endwall. As the pin spacing increases, the ratio of pin to endwall heat transfer also increases. As already mentioned, the pin fin heat transfer increases with pin spacing while the endwall heat transfer decreases. The trend of the pin to endwall ratio is a direct effect of these two results. At $\mathrm{Re}_{\mathrm{d}}=5000$, the percent differences between the pin and endwall heat transfer for the $\mathrm{S} / \mathrm{d}=2,4$, and 8 pin spacings are $98 \%, 157 \%$, and $193 \%$ respectively. At $\operatorname{Re}_{\mathrm{d}}=17,500$, the percent differences are smaller at $47 \%, 106 \%$, and $126 \%$ for the $\mathrm{S} / \mathrm{d}=2,4$, and 8 pin spacings respectively. The pin fin heat transfer is significantly higher than the endwall heat transfer.

\subsection{Overview of Reynolds Number Effects}

The Reynolds number has a significant effect on the endwall heat transfer. This effect is most evident examining plots of the spanwise averaged developing heat transfer for all three pin spacings at both low and high Reynolds numbers. For all spanwise averaged plots, the endwall Nusselt numbers were normalized by the turbulent, fully developed duct flow heat transfer prediction by Kays and Crawford [1980]. The maximum heat transfer augmentation ranged from about 1.5 to 3.2 times the fully developed duct flow heat transfer, depending on Reynolds number and pin spacing. The highest augmentation occurs at low Reynolds numbers. Also at low Reynolds numbers, there is significant variability upstream of the pin fins among the three spacings, although no obstructions have been encountered. At high Reynolds numbers, the curves for all three spacings collapse upstream of the pin row. This effect is reasonable when considering the interpretation of the Reynolds number. Generally, the Reynolds number is understood to represent the ratio of inertia to viscous forces. At lower Reynolds number flows, viscous effects play a larger role, causing effects farther upstream of the pin row.

In addition, Reynolds number effects are most prevalent for tight pin spacings. Plots of the spanwise averaged developing heat transfer for the $S / d=2$ pin spacing indicate significant variability upstream of the pins throughout the Reynolds number range. However, the Reynolds numbers effects are less apparent for the $S / d=4$ pin spacing. For $\mathrm{S} / \mathrm{d}=8$, the spanwise averaged developing heat transfer is predominantly 
independent of Reynolds number when the Nusselt numbers are normalized by the turbulent fully developed duct flow heat transfer prediction. It is likely that wide pin spacing reduces the pin fin wake effects between the pins, forcing the endwall heat transfer to behave more like unobstructed duct flow heat transfer.

The ratio of pin fin to endwall heat transfer is also strongly dependent on the Reynolds number, at low Reynolds numbers in particular. Although the magnitudes are different, the trend is the same for all three pin spacings. The ratio of pin to endwall heat transfer decreases as the Reynolds number increases. However, the ratios decrease to an apparent asymptotic value, where the ratio is no longer dependent on the Reynolds number.

It has already been stated that increasing the pin spacing increases the pin fin heat transfer, indicating different heat transfer mechanisms for narrow and wide spacings. The argument of a different heat transfer mechanism is supported by examining plots of the pin fin Nusselt numbers as a function of the pin Reynolds number, $\operatorname{Re}_{\mathrm{d}}$. The $\mathrm{S} / \mathrm{d}=4$ and 8 data collapse, indicating similar heat transfer mechanisms. However, the trend for the $\mathrm{S} / \mathrm{d}=2$ pin spacing falls noticeably below $\mathrm{S} / \mathrm{d}=4$ and 8 . Thus, it is clear that the pin fin heat transfer does not scale with the maximum velocity between the pins.

In an attempt to determine the proper scaling velocity to use in computing the Reynolds number, the pin fin heat transfer results were also plotted as a function of Re, the duct Reynolds number. Although the data for all three pin spacings does not collapse, they are more closely grouped. When presenting the results as a function of the duct Reynolds number, Re, the pin fin heat transfer decreases with increased spacing. The data for all three pin spacings are within an approximate $12 \%$ band across the Reynolds number range. It is apparent that velocity alone does not scale the pin fin heat transfer results.

The pin fin data also indicate that the $\mathrm{S} / \mathrm{d}=4$ and 8 pin spacings have slightly stronger Reynolds number dependencies than $\mathrm{S} / \mathrm{d}=2$. However, the combined pin and endwall heat transfer for all three pin spacings have about the same Reynolds number dependency. As already mentioned, the endwall is the dominant contributor of heat transfer area across the pin fin row. As a result, the combined pin and endwall heat transfer follows the trend of the endwall heat transfer more closely. 


\subsection{Recommendations for Future Work}

After reviewing the pin fin array literature and analyzing the data from this research project, it is apparent that pin fin heat transfer for small aspect ratio pin fins is still a debatable topic. Although researchers have measured the circumferential heat transfer around the pin midline, I am unaware of any data available that fully characterizes the heat transfer distribution on the pin fin surface. I propose creating a heat transfer map on the surface of a pin fin using infrared thermography, similar to the method used in my study of the endwall heat transfer for rows of pin fins.

This experiment can be carried out by using a large scale, low thermal conductivity pin fin, possibly made of insulating foam. The pin fin can be fitted with a thin foil resistance heater that completely covers the pin fin surface. A zinc selenide window with near constant radiation transmissivity can be used to form the endwall adjacent to the pin fin to allow measurements with an infrared camera. Using this method, it may be possible to obtain a map of the pin fin heat transfer around the circumference of the pin for all locations along the length of the pin.

To accompany the heat transfer measurements, it would also be beneficial to measure the flow field adjacent to a pin fin. The results from my study indicate different heat transfer mechanisms on the pin fin as the spacing is increased. Performing experiments using smaller increments of pin spacing may better indicate when the transition occurs between the different heat transfer mechanisms. Laser doppler velocimetry (LDV) is a method of resolving the flow field in three dimensions and is likely to yield suitable results. 


\section{References}

Ames, F.E., Dvorak, L.A., and Morrow, M.J., 2004, "Turbulent Augmentation of Internal Convection Over Pins in Staggered Pin Fin Arrays,” ASME Paper GT2004-53889.

Armstrong, J., and Winstanley, D., 1988, “A Review of Staggered Array Pin Fin Heat Transfer for Turbine Cooling Applications,” ASME Journal of Turbomachinery, vol. 110, pp. 94-103.

Bejan, A., 2004, “Convection Heat Transfer," $3{ }^{\text {rd }}$ Edition. Hoboken, New Jersey: John Wiley and Sons, Inc.

Brigham, B.A., and VanFossen, G.J., 1984, "Length-to-Diameter Ratio and Row Number Effects in Short Pin Fin Heat Transfer," ASME Journal of Engineering for Gas Turbines and Power, vol. 106, pp. 241-245.

Chyu, M.K., 1990, "Heat Transfer and Pressure Drop for Short Pin-Fin Arrays with PinEndwall Fillet," ASME Journal of Heat Transfer, vol. 112, pp. 926-932.

Chyu, M.K., Hsing, Y.C., Shih, T.I.-P., and Natarajan, V., 1998a, "Heat Transfer Contributions of Pins and Endwall in Pin-Fin Arrays: Effects of Thermal Boundary Condition Modeling," ASME Paper 98-GT-175.

Chyu, M.K., Hsing, Y.C., and Natarajan, V., 1998b, "Convective Heat Transfer of Cubic Fin Arrays in a Narrow Channel," ASME Journal of Turbomachinery, vol. 120, pp. 362367.

Clifford, R.J., 1985, "Rotating Heat Transfer Investigations on a Multipass Cooling Geometry,” AGARD CP 390.

Colban, W.F., 2005, “A Detailed Study of Fan-Shaped Film-Cooling for a Nozzle Guide Vane for an Industrial Gas Turbine," Doctor of Philosophy Dissertation, Department of Mechanical Engineering, Virginia Polytechnic Institute and State University.

Elder, E.N., 2005, "Internal Heat Transfer and External Effectiveness Measurements for a Novel Turbine Blade Cooling Design," Master's Thesis, Department of Mechanical Engineering, Virginia Polytechnic Institute and State University.

Faulkner, F.E., 1971, “Analytical Investigation of Chord Size and Cooling Methods on Turbine Blade Cooling Requirements,” NASA CR-120882-Bk.-1.

Hill, P.G., and Peterson, C.R., 1992, "Mechanics and Thermodynamics of Propulsion," $2^{\text {nd }}$ Edition. Reading, Massachusetts: Addison-Wesley Publishing Company Inc. 
Incropera, F.P., and DeWitt, D.P., 2002, "Fundamentals of Heat and Mass Transfer," $5^{\text {th }}$ Edition. New York, New York: John Wiley and Sons, Inc.

Kakac, S., Shah, R.K., and Aung, W., 1987, "Handbook of Single Phase Convective Heat Transfer," New York, New York: John Wiley and Sons, Inc.

Kays, W.M., Crawford, M.E., 1980, “Convective Heat and Mass Transfer," $2^{\text {nd }}$ Edition. New York, New York: McGraw-Hill Book Company, Inc.

Lambda Americas Inc., "Model GEN100-15," http://www.lambdaemi.com/product html/genesyslu.htm (Neptune, New Jersey: Lambda Americas Inc., 2005).

Lang, R., "Venturi Quotation \#044110," Facsimile from Lambda Square Inc., March 24, 2005.

Lau, S.C., Kim, Y.S., and Han, J.C., 1985, "Effects of Fin Configuration and Entrance Length on Local Endwall Heat/Mass Transfer in a Pin Fin Channel," ASME Paper 85WA/HT-62.

Lawson, S.A., 2006, "Drawing for teleconference with Pratt and Whitney.”

Meriam Process Technologies, "2100 Series Smart Gauge,"

http://www.meriam.com/downloads/pdf/DataSheets/smartgauges_datasheet.pdf

(Cleveland, Ohio: Meriam Process Technologies, 2004).

Metzger, D.E., Berry, R.A., and Bronson, J.P., 1982a, "Developing Heat Transfer in Rectangular Ducts with Staggered Arrays of Short Pin Fins," ASME Journal of Heat Transfer, vol. 104, pp. 700-706.

Metzger, D.E., and Haley, S.W., 1982b, "Heat Transfer Experiments and Flow Visualization for Arrays of Short Pin Fins,” ASME Paper 82-GT-138.

Metzger, D.E., Fan, Z.X., Shepard, W.B., 1982c, "Pressure Loss and Heat Transfer Through Multiple Rows of Short Pin Fins," Heat Transfer 1982, vol. 3, U. Grigull et al., eds., Hemisphere, Washington, pp. 137-142.

Metzger, D.E., Fan, C.S., Haley, S.W., 1984, "Effects of Pin Shape and Array Orientation on Heat Transfer and Pressure Loss in Pin Fin Arrays," ASME Journal of Engineering for Gas Turbines and Power, vol. 106, pp. 252-257.

Moffat, R.J., 1985, "Uncertainty Analysis in the Planning of an Experiment," Jounal of Fluids Engineering, vol. 107, pp. 173-181.

Munson, B.R., Young, D.F., and Okiishi, T.H., 2002, "Fundamentals of Fluid Mechanics," $4^{\text {th }}$ Edition. New York, New York: John Wiley and Sons, Inc. 
Panton, R.L., 1996, "Incompressible Flow," $2^{\text {nd }}$ Edition. New York, New York: John Wiley and Sons, Inc.

Prausa, J.N., 2004, "Heat Transfer Coefficient and Adiabatic Effectiveness Measurements for an Internal Turbine Vane Cooling Feature," Master's Thesis, Department of Mechanical Engineering, Virginia Polytechnic Institute and State University.

Rohm and Haas, "CVD Zinc Selenide," http://www.cvdmaterials.com/znse.htm\#Transmission (Woburn, Massachusetts: Rohm and Haas Company, 1999).

Saravanamuttoo, H.I.H., Rogers, G.F.C, and Cohen, H., 2001, “Gas Turbine Theory," $5^{\text {th }}$ Edition. Harlow, England: Pearson Education Limited.

Setra Systems, "Model 370 Ultra-High Accuracy Setraceram" ${ }^{\mathrm{TM}}$ Digital Barometric Pressure Gage," http://www.setra.com/tra/pro/p ba 370.htm, (Boxborough, Massachusetts: Setra Systems Inc., 1998a).

Setra Systems, "Model 264 Very Low Differential Pressure Tansducer," http://www.setra.com/tra/pro/pdf/264.pdf, (Boxborough, Massachusetts: Setra Systems Inc. 1998b).

Simoneau, R.J., and VanFossen, G.J., 1984, "Effect of Location in an Array on Heat Transfer to a Short Cylinder in Crossflow," ASME Journal of Heat Transfer, vol. 106, pp. $42-48$.

Uzol, O., and Camci, C., 2005, "Heat Transfer, Pressure Loss and Flow Field Measurements Downstream of Staggered Two-Row Circular and Elliptical Pin Fin Arrays," ASME Journal of Heat Transfer, vol. 127, pp. 458-471.

VanFossen, G.J., 1981, “Heat Transfer Coefficients for Staggered Arrays of Short Pin Fins," ASME Paper 81-GT-75.

Yeh, J.J., and Chyu, M.K., 1998, "Heat Transfer of Staggered Pin Fin Arrays," Masters Presentations/Papers and Bennett Poster Competition, Carnegie Mellon University.

Zukauskas, A.A., 1972, "Heat Transfer from Tubes in Crossflow," Advances in Heat Transfer, vol. 8, pp. 93-160. 


\section{Appendix A: Test Facility Component Information}

This appendix presents the data sheets and general information for the major components of the test facility. These components include the heat exchanger, the blower, and the flow meters. Due to the importance of properly calculating the mass flow rate for experiments, the flow meter equations are presented with an explanation of how to properly perform the calculations.

\begin{tabular}{|c|c|c|c|}
\hline $\begin{array}{l}\text { Customer: } \\
\text { Job Ref.: } \\
\text { Job Item: }\end{array}$ & $\begin{array}{l}\text { Virginia Tech } \\
\text { High Flow }\end{array}$ & $\begin{array}{l}\text { Date: } \\
\text { By: } \\
\text { Record: }\end{array}$ & $\begin{array}{l}3 / 8 / 2005 \\
\text { Jeff Spaeth }\end{array}$ \\
\hline Dry Water Coil & Units (SI) & & \\
\hline \multicolumn{4}{|l|}{ AirSide: } \\
\hline Air Flow & m3/hr. (Std.) & 1,397 & \\
\hline Required Capacity & kW & 13.45 & \\
\hline Entering Air Temp. & ${ }^{\circ} \mathrm{C}$ & 54.4 & \\
\hline Required Air Temp. & ${ }^{\circ} \mathrm{C}$ & 26.0 & \\
\hline Airside Pressure & $\mathbf{k P a}$ & 101.329 & \\
\hline \multicolumn{4}{|l|}{ Tubeside: } \\
\hline Fluid ID & & WATER & \\
\hline Fluid Flow Rate & LMin. & 15.14 & \\
\hline Entering Fluid Temp. & ${ }^{\circ} \mathrm{C}$ & 21.11 & \\
\hline \multicolumn{4}{|l|}{ Coil Selection: } \\
\hline Model Number & & $18.75 \times 42-4 R-12 / 120$ & \\
\hline Die Surface & & $1 / 2-1-1 / 4 \times 1.083$ Stag.(Sine-\#16) & \\
\hline Die Number \& Location & & 16 (All Plants) & \\
\hline Face Area & $m^{\wedge} 2$ & 0.51 & \\
\hline Face Velocity & m/sec. & 0.8 & \\
\hline Number of Cireuits & & 3 & \\
\hline Tube Velocity & $\mathrm{m} / \mathrm{sec}$ & 0.7 & \\
\hline Configuration & & Thermal Counterflow & \\
\hline Tube Material & & $\mathrm{CU}$ & \\
\hline Tube Wall Thickness & $\mathrm{mm}$ & 0.406 & \\
\hline Fin Material & & AL & \\
\hline Fin Thickness & mm & 0.1397 & \\
\hline Header Diam. & mm & 22.225 & \\
\hline \multicolumn{4}{|l|}{ Capacity: } \\
\hline Rating & $\mathbf{k W}$ & 13.73 & \\
\hline Leaving Air Temp. & ${ }^{\circ} \mathrm{C}$ & 25.4 & \\
\hline Leaving Fluid Temp. & ${ }^{\circ} \mathrm{C}$ & 34.1 & \\
\hline Fluid Press. Drop & kPa. & 20.9 & \\
\hline Air Friction & $\mathrm{kPa}$. & 0.01 & \\
\hline
\end{tabular}

Figure A-1 Performance specifications of the heat exchanger quoted by Jeff Spaeth of Super Radiator Coils [Spaeth, 2004]. 


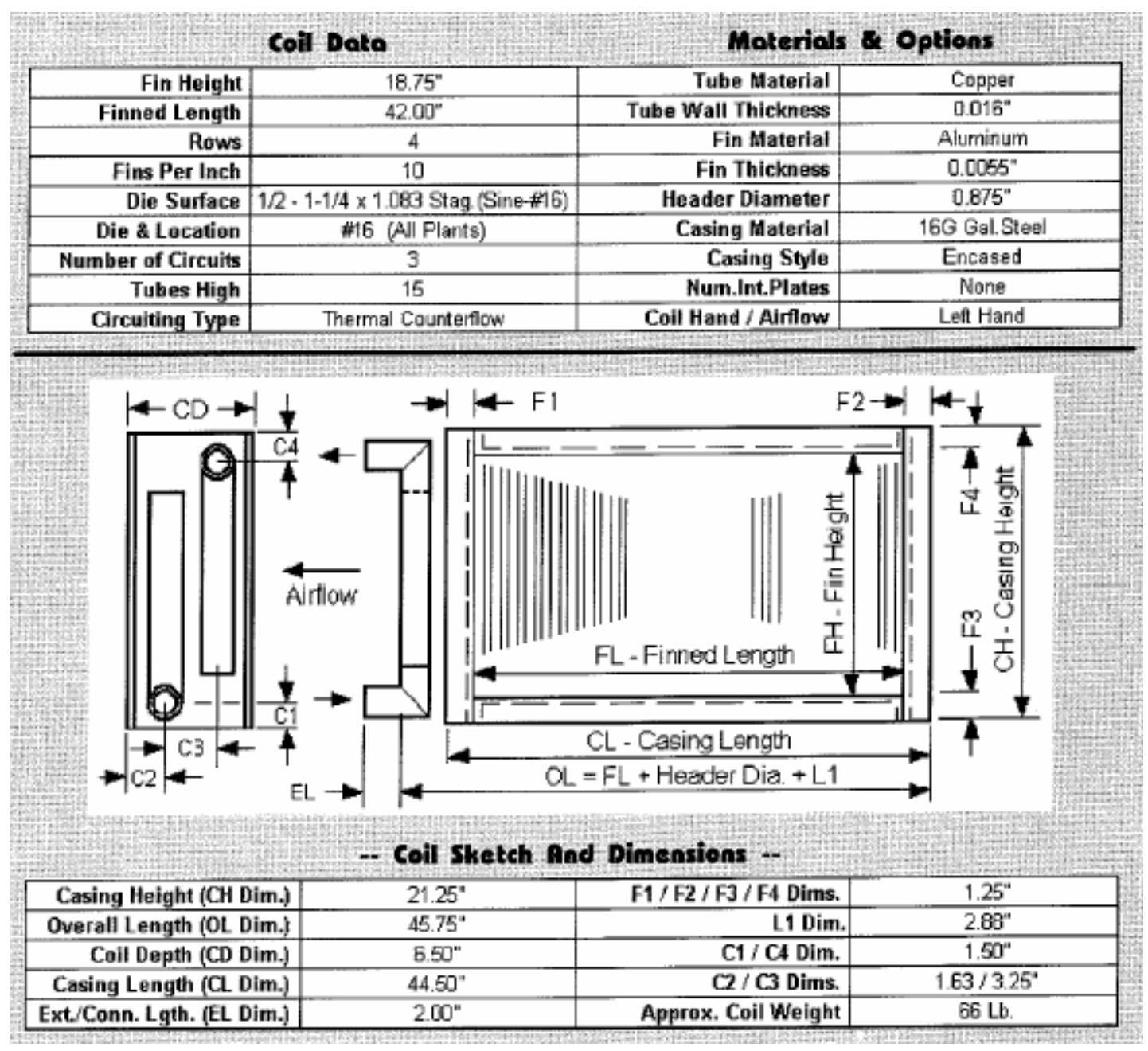

Figure A-2 Schematic drawing of the heat exchanger showing relevant dimensions [Spaeth, 2004]. 


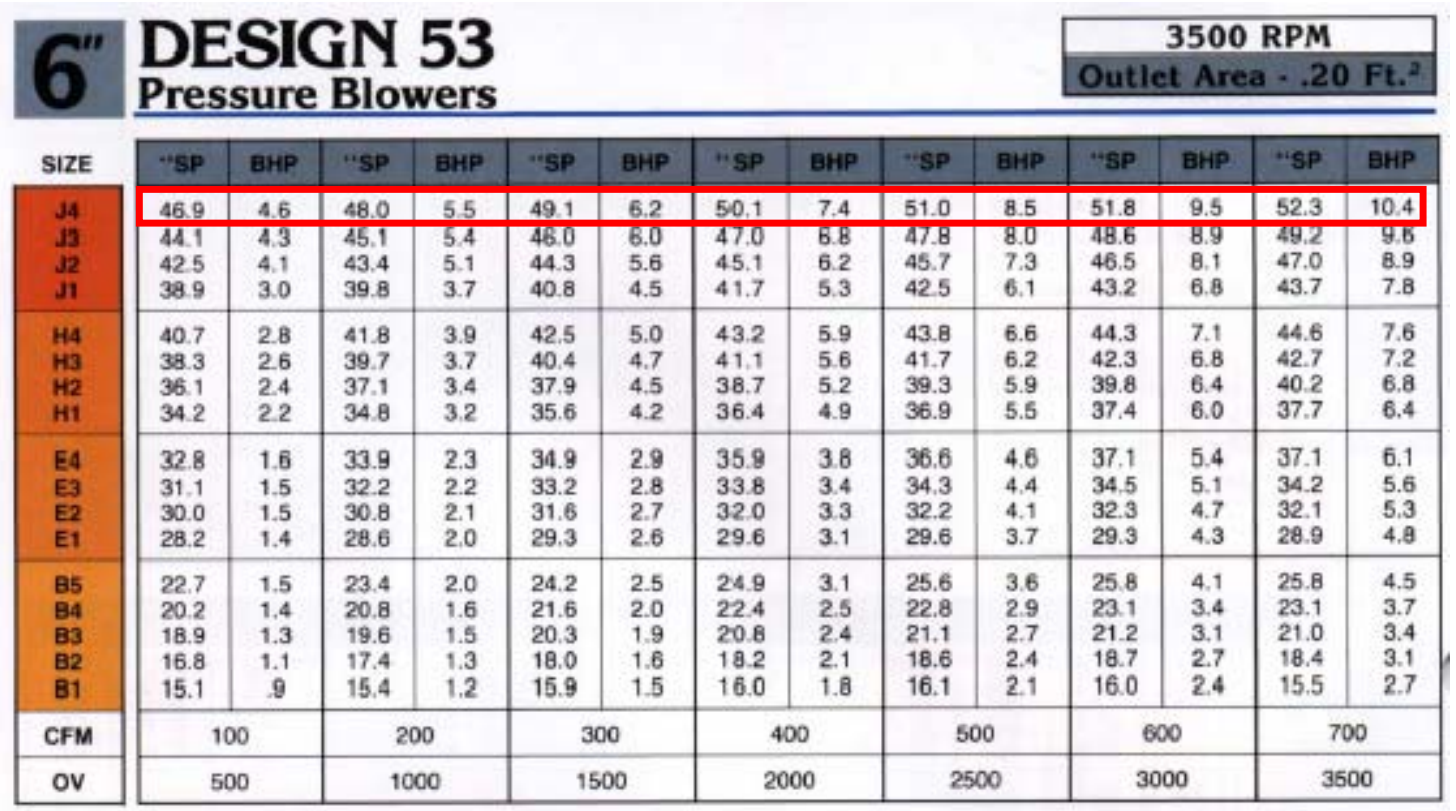

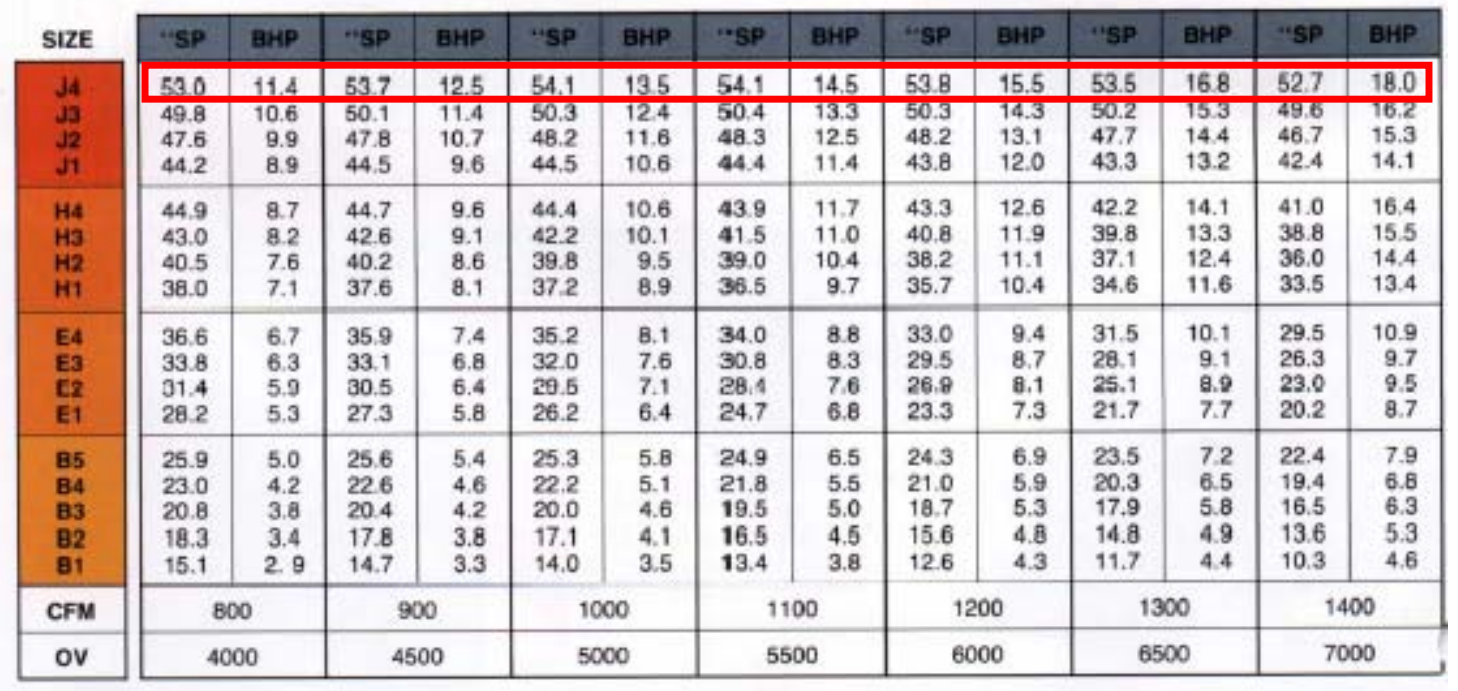

Figure A-3 Operating curve data for the J4 Design 53 pressure blower [Chicago Blower Corporation, 1998]. 


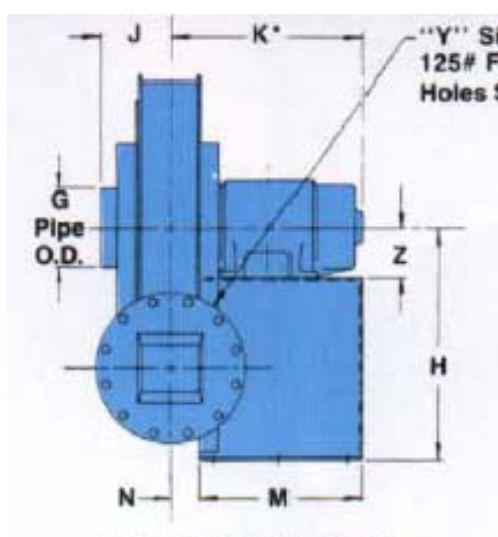

FRONT ELEVATION

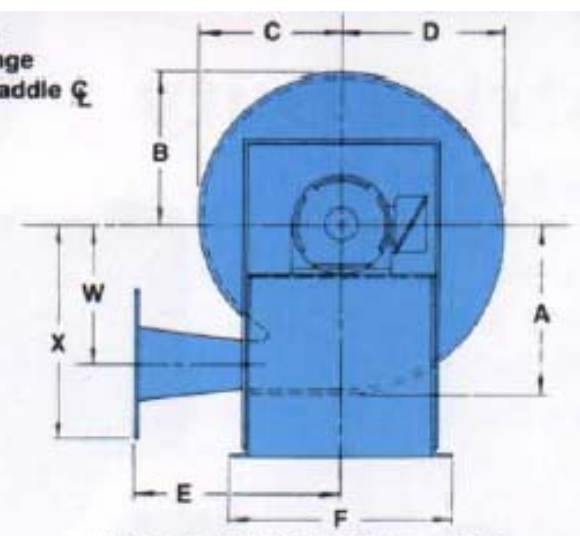

SIDE ELEVATION (drive side)

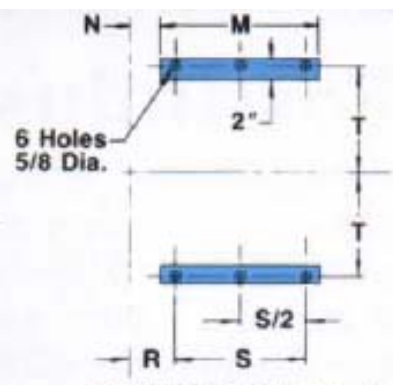

FOUNDATION (plan)

Do not use for construction purposes.

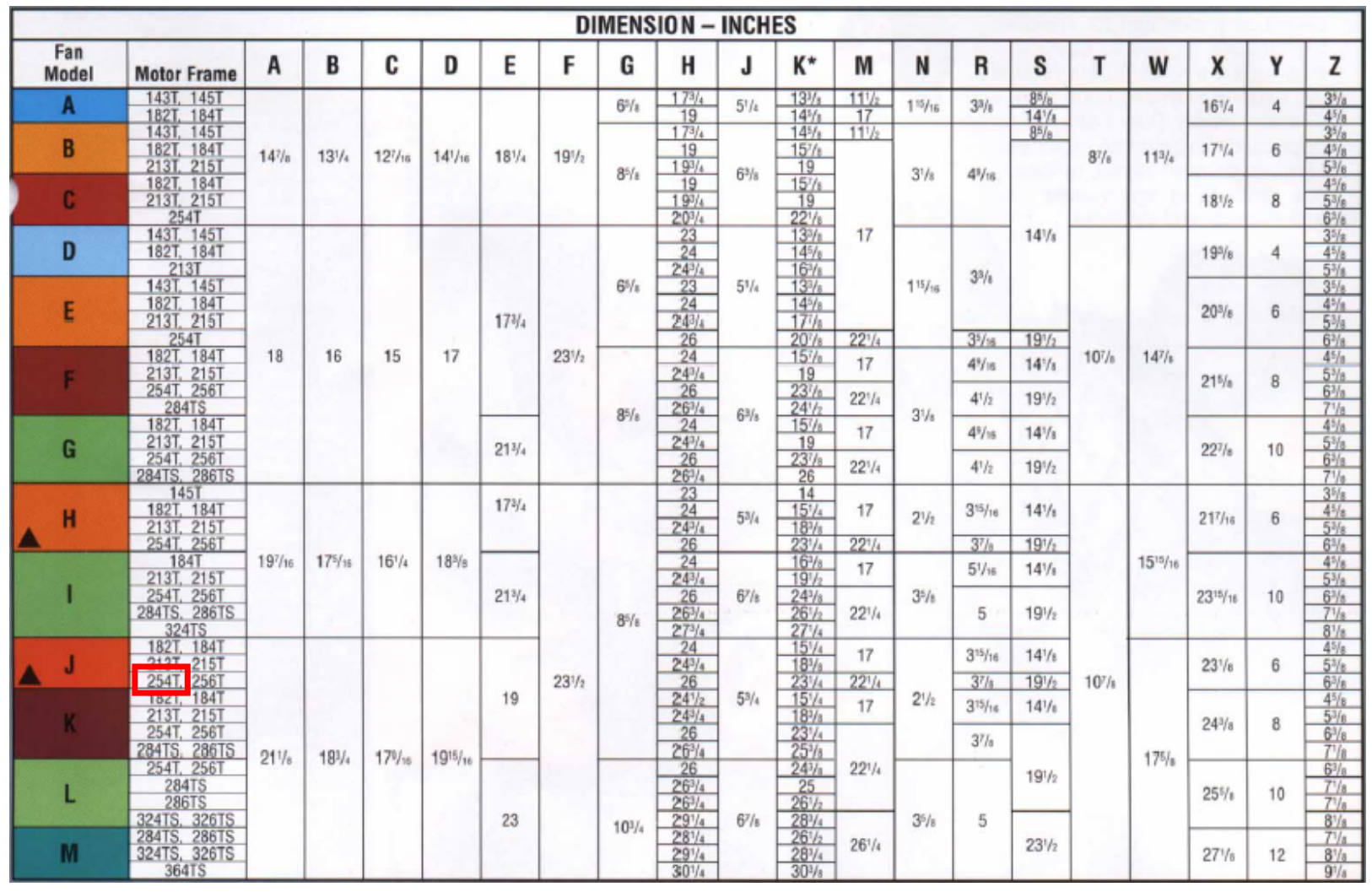

Figure A-4 Relevant dimensions for the J4 Design 53 pressure blower [Chicago Blower Corporation, 1998]. 


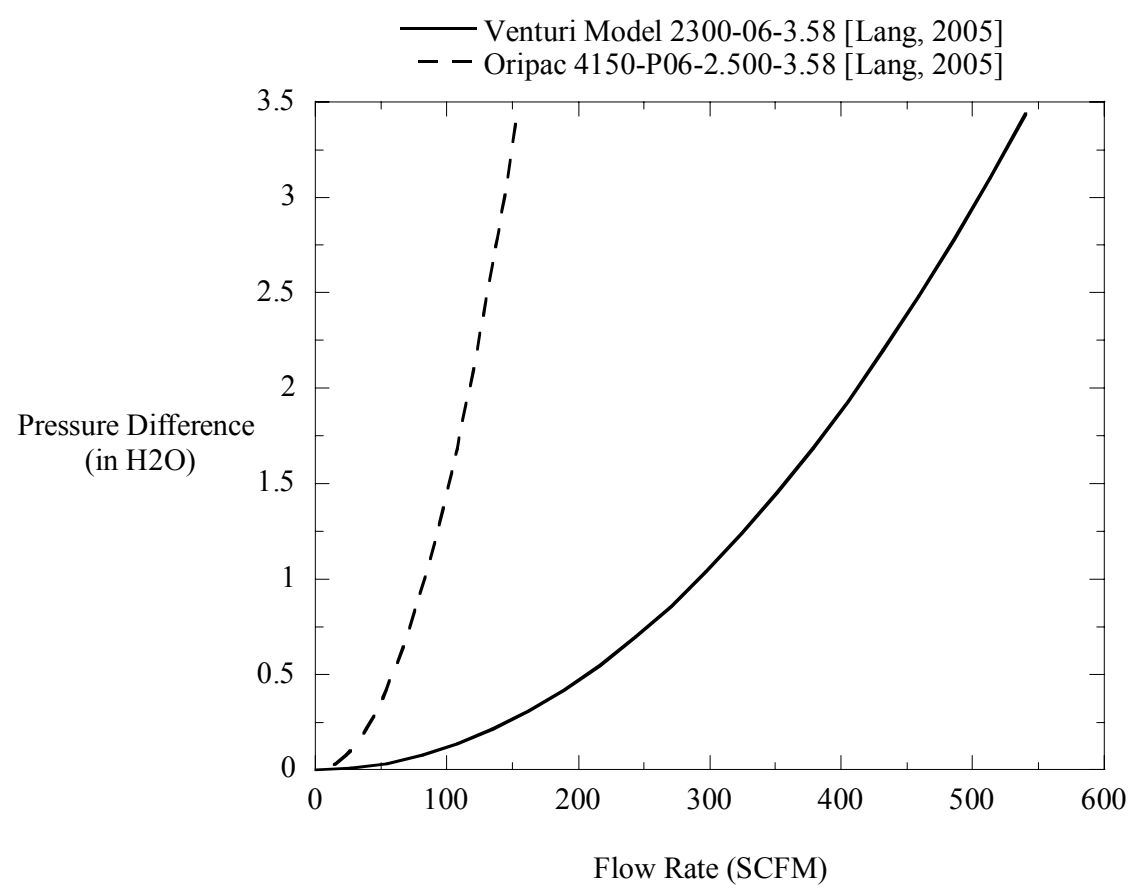

Figure A-5 Typical characteristic curves for the orifice and venturi flow meters [Lang, 2005]. Due to higher pressure drop, the orifice flow meter is used at low flow rates to give improved measurement resolution.

The general equation for calculating the volumetric flow rate at standard conditions for either the orifice or venturi meters is given as follows:

$$
\mathrm{Q}_{\text {std }}(\mathrm{SCFM})=\frac{5.9816 \cdot \mathrm{d}^{2} \cdot \mathrm{K} \cdot \mathrm{Y} \cdot \sqrt{\mathrm{dp}} \cdot \sqrt{\frac{2.703 \cdot \mathrm{P}_{\mathrm{L}}}{460+\mathrm{T}_{\mathrm{L}}}}}{\frac{2.703 \cdot 14.7 \cdot \mathrm{SG}}{460+\mathrm{T}_{\mathrm{b}}}}
$$

where $\mathrm{d}$ (in) is the bore, $\mathrm{K}$ is the flow coefficient, $\mathrm{Y}$ is the expansion factor, dp $\left(\mathrm{in}-\mathrm{H}_{2} \mathrm{O}\right)$ is the differential pressure across the meter, $\mathrm{P}_{\mathrm{L}}(\mathrm{psia})$ is the absolute line pressure, $\mathrm{T}_{\mathrm{L}}\left({ }^{\circ} \mathrm{F}\right)$ is the line temperature, $\mathrm{SG}$ (air $=1.0)$ is the specific gravity, and $\mathrm{T}_{\mathrm{b}}\left(60^{\circ} \mathrm{F}\right)$ is referred to as the base temperature at standard conditions. The flow rate output is in SCFM, which refers to standard cubic feet per minute. The flow coefficient is defined by:

$$
K=\frac{C}{\sqrt{1-\beta^{4}}}
$$

where $\mathrm{C}$ is referred to as the discharge coefficient, and $\beta$ is the ratio of the throat diameter to the open pipe diameter. Both $C$ and $\beta$ are given in Table $A-1$ for the orifice and venturi meters. The expansion factor for the orifice is written as follows: 
$\mathrm{Y}=1-\left(0.41+0.35 \beta^{4}\right) \frac{0.0361 \mathrm{dp}}{1.4 \mathrm{P}_{\mathrm{L}}}$

where all the inputs have already been defined. The expansion factor for the venturi meter is assumed to remain constant and is given in Table A-1.

Table A-1

\begin{tabular}{|r|c|c|}
\hline \multicolumn{3}{|c|}{ Flow Meter Parameters } \\
\hline & Orifice & Venturi \\
\hline \hline bore, $d,(i n):$ & 2.5 & 3.58 \\
\hline discharge coefficient, C: & 0.6084 & 0.995 \\
\hline expansion factor, $\mathrm{Y}=$ & & 0.9971 \\
\hline$\beta:$ & 0.4122 & 0.5903 \\
\hline
\end{tabular}

The primary variable of interest obtained from the flow meters is the mass flow rate. However, the equations given for the orifice and venturi meters give a volumetric flow rate output in SCFM. Providing the output in SCFM actually simplifies the mass flow rate calculation. To obtain the mass flow rate, multiply the volumetric flow rate at standard conditions by the fluid density at standard conditions. By definition, the density at standard conditions is a constant. Standard conditions for these particular flow meters are $60^{\circ} \mathrm{F}$ and $14.7 \mathrm{psia}$. The primary concern is to have consistency with the units. 


\section{Appendix B: Experimental Uncertainty Calculations}

This appendix outlines the equations used to calculate the experimental uncertainty for the pin fin Nusselt number $\mathrm{Nu}_{\mathrm{d}}$, the endwall Nusselt number, $\mathrm{Nu}$, the open channel Reynolds number, $\mathrm{Re}$, and the heat transfer augmentation, $\mathrm{Nu} / \mathrm{Nu}_{0}$.

\section{Uncertainty for the open channel Reynolds number, Re}

The open channel Reynolds number may be written as follows:

$$
\operatorname{Re}=\frac{2 Q_{\text {std }} \cdot \rho_{\text {std }}}{\mu(W+H)}
$$

The variables $Q_{\text {std }}$ and $\rho_{\text {std }}$ are the volume flow rate and density at standard conditions, where the density is a constant by definition. The formula for the volume flow rate in $\mathrm{m}^{3} / \mathrm{s}$ is written as follows:

$$
\mathrm{Q}_{\mathrm{std}}=\frac{5.9816 \cdot \mathrm{d}^{2} \cdot \mathrm{K} \cdot \mathrm{Y} \cdot \sqrt{\mathrm{dp}} \cdot \sqrt{\frac{2.703 \cdot \mathrm{P}_{\mathrm{L}}}{460+\mathrm{T}_{\mathrm{L}}}}}{\frac{2.703 \cdot 14.7}{460+60}} \cdot \frac{4.71936 \cdot 10^{-4} \frac{\mathrm{m}^{3}}{\mathrm{~s}}}{1 \mathrm{SCFM}}
$$

The uncertainty for the volume flow rate is computed first using the root-sum-square method.

$$
\mathrm{u}_{\mathrm{Q}_{\text {std }}}=\sqrt{\left(\frac{\partial \mathrm{Q}_{\text {std }}}{\partial \mathrm{dp}} \mathrm{u}_{\mathrm{dp}}\right)^{2}+\left(\frac{\partial \mathrm{Q}_{\text {std }}}{\partial \mathrm{T}_{\mathrm{L}}} \mathrm{u}_{\mathrm{T}_{\mathrm{L}}}\right)^{2}+\left(\frac{\partial \mathrm{Q}_{\text {std }}}{\partial \mathrm{P}_{\mathrm{L}}} \mathrm{u}_{\mathrm{P}_{\mathrm{L}}}\right)^{2}+\mathrm{u}_{\text {meter }}^{2}}
$$

Now, the uncertainty of the Reynolds number is calculated as follows:

$$
\mathrm{u}_{\mathrm{Re}}=\sqrt{\left(\frac{\partial \mathrm{Re}}{\partial \mathrm{Q}_{\mathrm{std}}} \mathrm{u}_{\mathrm{Q}_{\text {std }}}\right)^{2}+\left(\frac{\partial \mathrm{Re}}{\partial \mathrm{W}} \mathrm{u}_{\mathrm{w}}\right)^{2}+\left(\frac{\partial \mathrm{Re}}{\partial \mathrm{H}} \mathrm{u}_{\mathrm{H}}\right)^{2}}
$$

Presented in the following tables are uncertainty results at both low and high Reynolds numbers. 


Re $=5013$
\begin{tabular}{|c|c|c|c|c|}
\hline Variable & Value & $\begin{array}{c}\text { Precision } \\
\text { Uncertainty }\end{array}$ & $\begin{array}{c}\text { Bias } \\
\text { Uncertainty }\end{array}$ & $\begin{array}{c}\text { Total } \\
\text { Uncertainty }\end{array}$ \\
\hline $\mathrm{Re}$ & 5013 & - & - & $85(1.7 \%)$ \\
\hline $\mathrm{Q}_{\mathrm{std}}, \mathrm{m}^{3} / \mathrm{s}$ & $2.34 \mathrm{E}-02$ & - & - & $3.98 \mathrm{E}-04$ \\
\hline $\mathrm{P}_{\mathrm{L}}, \mathrm{kPa}$ & 94.6 & - & - & $1.10 \mathrm{E}-02$ \\
\hline $\mathrm{T}_{\mathrm{L}},{ }^{\circ} \mathrm{C}$ & 26.6 & 0.028 & 0.200 & 0.202 \\
\hline $\mathrm{dP}, \mathrm{Pa}$ & 97.9 & - & - & 3.11 \\
\hline $\mathrm{W}, \mathrm{cm}$ & 61.0 & - & - & $7.94 \mathrm{E}-02$ \\
\hline $\mathrm{H}, \mathrm{cm}$ & 0.95 & - & - & $3.97 \mathrm{E}-02$ \\
\hline
\end{tabular}

Re $=\mathbf{3 0 , 4 8 4}$
\begin{tabular}{|c|c|c|c|c|}
\hline Variable & Value & $\begin{array}{c}\text { Precision } \\
\text { Uncertainty }\end{array}$ & $\begin{array}{c}\text { Bias } \\
\text { Uncertainty }\end{array}$ & $\begin{array}{c}\text { Total } \\
\text { Uncertainty }\end{array}$ \\
\hline $\mathrm{Re}$ & 30484 & - & - & $273(0.90 \%)$ \\
\hline $\mathrm{Q}_{\mathrm{std}}, \mathrm{m}^{3} / \mathrm{s}$ & $1.42 \mathrm{E}-01$ & - & - & $1.26 \mathrm{E}-03$ \\
\hline $\mathrm{P}_{\mathrm{L}}, \mathrm{kPa}$ & 94.6 & - & - & $1.10 \mathrm{E}-02$ \\
\hline $\mathrm{T}_{\mathrm{L}},{ }^{\circ} \mathrm{C}$ & 23.0 & 0.018 & 0.200 & 0.201 \\
\hline $\mathrm{dP}, \mathrm{Pa}$ & 313 & - & - & 3.11 \\
\hline $\mathrm{W}, \mathrm{cm}$ & 61.0 & - & - & $7.94 \mathrm{E}-02$ \\
\hline $\mathrm{H}, \mathrm{cm}$ & 0.95 & - & - & $3.97 \mathrm{E}-02$ \\
\hline
\end{tabular}


Uncertainty for the pin fin Nusselt $\mathrm{Number}, \mathrm{Nu}_{\mathrm{d}}$

In terms of the measured variables, $\mathrm{Nu}_{\mathrm{d}}$ is written as follows:

$\mathrm{Nu}_{\mathrm{d}}=\frac{\left(\frac{\mathrm{V}_{\text {prec }}}{\mathrm{R}_{\text {prec }}}\right)^{2} \mathrm{R}_{\text {foil }} \cdot \mathrm{d}}{\mathrm{k} \cdot \mathrm{A}_{\text {foil }}\left(\mathrm{T}_{\text {pin }}-\mathrm{T}_{\text {bulk }}\right)}$

According to the root-sum-square method, the uncertainty is written as:

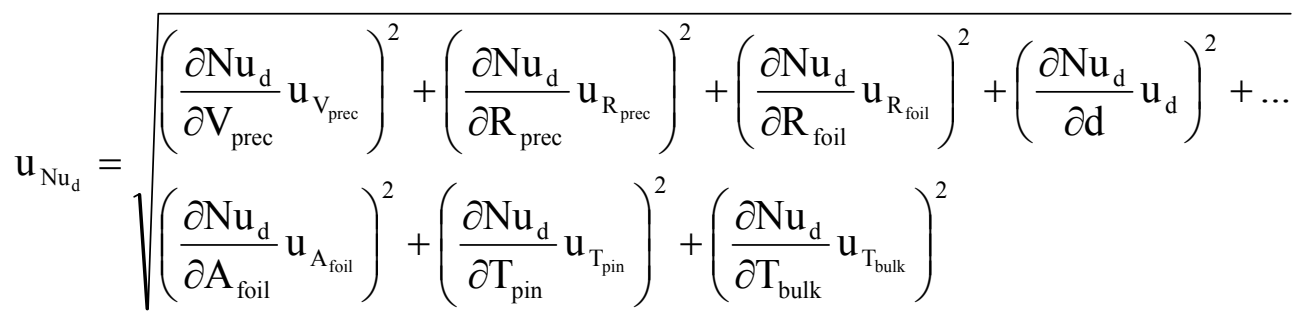

The following tables present the results of the pin fin heat transfer uncertainty analyses.

$\operatorname{Re}=5013$, High $\mathrm{Nu}_{\mathrm{d}}$

\begin{tabular}{|c|c|c|c|c|}
\hline Variable & Value & $\begin{array}{c}\text { Precision } \\
\text { Uncertainty }\end{array}$ & $\begin{array}{c}\text { Bias } \\
\text { Uncertainty }\end{array}$ & $\begin{array}{c}\text { Total } \\
\text { Uncertainty }\end{array}$ \\
\hline $\mathrm{Nu}_{\mathrm{d}}$ & 54.56 & - & - & $2.60(4.77 \%)$ \\
\hline $\mathrm{V}_{\text {prec }}$ & 2.01 & - & - & 0.006 \\
\hline $\mathrm{R}_{\text {prec }}, \Omega$ & 1 & - & - & 0.01 \\
\hline $\mathrm{d}, \mathrm{m}$ & $9.53 \mathrm{E}-03$ & - & - & $2.55 \mathrm{E}-04$ \\
\hline $\mathrm{R}_{\text {foil }}, \Omega$ & 0.117 & - & - & 0.002 \\
\hline $\mathrm{A}_{\text {foill }}, \mathrm{m}^{2}$ & $2.53 \mathrm{E}-04$ & - & - & $8.29 \mathrm{E}-07$ \\
\hline $\mathrm{T}_{\text {pin }},{ }^{\circ} \mathrm{C}$ & 22.76 & 0.046 & 0.200 & 0.205 \\
\hline $\mathrm{T}_{\text {bulk }},{ }^{\circ} \mathrm{C}$ & 10.02 & 0.220 & 0.200 & 0.300 \\
\hline
\end{tabular}


$\operatorname{Re}=5013$, Low $\mathrm{Nu}_{\mathrm{d}}$

\begin{tabular}{|c|c|c|c|c|}
\hline Variable & Value & $\begin{array}{c}\text { Precision } \\
\text { Uncertainty }\end{array}$ & $\begin{array}{c}\text { Bias } \\
\text { Uncertainty }\end{array}$ & $\begin{array}{c}\text { Total } \\
\text { Uncertainty }\end{array}$ \\
\hline $\mathrm{Nu}_{\mathrm{d}}$ & 31.31 & - & - & $1.28(4.08 \%)$ \\
\hline $\mathrm{V}_{\text {prec }}$ & 1.9 & - & - & 0.0057 \\
\hline $\mathrm{R}_{\text {prec }}, \Omega$ & 1 & - & - & 0.01 \\
\hline $\mathrm{d}, \mathrm{m}$ & $9.53 \mathrm{E}-03$ & - & - & $2.55 \mathrm{E}-04$ \\
\hline $\mathrm{R}_{\text {foil }}, \Omega$ & 0.131 & - & - & 0.002 \\
\hline $\mathrm{A}_{\text {foil }}, \mathrm{m}^{2}$ & $2.53 \mathrm{E}-04$ & - & - & $8.29 \mathrm{E}-07$ \\
\hline $\mathrm{T}_{\text {pin }},{ }^{\circ} \mathrm{C}$ & 32.23 & 0.044 & 0.200 & 0.205 \\
\hline $\mathrm{T}_{\text {bulk }},{ }^{\circ} \mathrm{C}$ & 10.02 & 0.220 & 0.200 & 0.300 \\
\hline
\end{tabular}

$\mathrm{Re}=30,484$, High $\mathrm{Nu}_{\mathrm{d}}$

\begin{tabular}{|c|c|c|c|c|}
\hline Variable & Value & $\begin{array}{c}\text { Precision } \\
\text { Uncertainty }\end{array}$ & $\begin{array}{c}\text { Bias } \\
\text { Uncertainty }\end{array}$ & $\begin{array}{c}\text { Total } \\
\text { Uncertainty }\end{array}$ \\
\hline $\mathrm{Nu}_{\mathrm{d}}$ & 144.36 & - & - & $6.55(4.53 \%)$ \\
\hline $\mathrm{V}_{\text {prec }}$ & 3.194 & - & - & 0.014 \\
\hline $\mathrm{R}_{\text {prec }}, \Omega$ & 1 & - & - & 0.01 \\
\hline $\mathrm{d}, \mathrm{m}$ & $9.53 \mathrm{E}-03$ & - & - & $2.55 \mathrm{E}-04$ \\
\hline $\mathrm{R}_{\text {foil }}, \Omega$ & 0.117 & - & - & 0.002 \\
\hline $\mathrm{A}_{\text {foil }}, \mathrm{m}^{2}$ & $2.53 \mathrm{E}-04$ & - & - & $8.29 \mathrm{E}-07$ \\
\hline $\mathrm{T}_{\text {pin }},{ }^{\circ} \mathrm{C}$ & 23.50 & 0.034 & 0.200 & 0.203 \\
\hline $\mathrm{T}_{\text {bulk }},{ }^{\circ} \mathrm{C}$ & 11.35 & 0.032 & 0.200 & 0.203 \\
\hline
\end{tabular}


$\mathrm{Re}=30,484$, Low $\mathrm{Nu}_{\mathrm{d}}$

\begin{tabular}{|c|c|c|c|c|}
\hline Variable & Value & $\begin{array}{c}\text { Precision } \\
\text { Uncertainty }\end{array}$ & $\begin{array}{c}\text { Bias } \\
\text { Uncertainty }\end{array}$ & $\begin{array}{c}\text { Total } \\
\text { Uncertainty }\end{array}$ \\
\hline $\mathrm{Nu}_{\mathrm{d}}$ & 86.09 & - & - & $3.55(4.12 \%)$ \\
\hline $\mathrm{V}_{\text {prec }}$ & 3.194 & - & - & 0.014 \\
\hline $\mathrm{R}_{\text {prec }}, \Omega$ & 1 & - & - & 0.01 \\
\hline $\mathrm{d}, \mathrm{m}$ & $9.53 \mathrm{E}-03$ & - & - & $2.55 \mathrm{E}-04$ \\
\hline $\mathrm{R}_{\text {foil }}, \Omega$ & 0.117 & - & - & 0.002 \\
\hline $\mathrm{A}_{\text {foil }}, \mathrm{m}^{2}$ & $2.53 \mathrm{E}-04$ & - & - & $8.29 \mathrm{E}-07$ \\
\hline $\mathrm{T}_{\text {pin }},{ }^{\circ} \mathrm{C}$ & 31.73 & 0.034 & 0.200 & 0.203 \\
\hline $\mathrm{T}_{\text {bulk }},{ }^{\circ} \mathrm{C}$ & 11.35 & 0.032 & 0.200 & 0.203 \\
\hline
\end{tabular}




\section{Uncertainty for the endwall Nusselt number, $\mathrm{Nu}$}

Due to the many inputs, the uncertainties of the individual variables used in calculating the endwall Nusselt numbers were computed separately. To summarize, the uncertainties of the net heat loss, qloss ", net heat flux entering the channel, $\mathrm{q}_{\text {net }}$ ", conduction corrected wall temperature, $\mathrm{T}_{\text {corr }}$, and the bulk temperature, $\mathrm{T}_{\text {bulk }}$, were calculated before calculating the uncertainty of the endwall Nusselt numbers. The defining equations for each, including the endwall Nusselt Number are written as follows:

$$
\begin{aligned}
& \mathrm{Nu}=\frac{2 \mathrm{q}_{\text {net }}^{\prime \prime} \cdot \mathrm{W} \cdot \mathrm{H}}{\mathrm{k}(\mathrm{W}+\mathrm{H})\left(\mathrm{T}_{\text {corr }}-\mathrm{T}_{\text {bulk }}\right)} \\
& \mathrm{T}_{\text {bulk }}=\mathrm{T}_{\text {in }}+\frac{\overline{\overline{\mathrm{Q}_{\text {net }}}}}{\mathrm{mC}_{\mathrm{p}}}\left(\frac{\mathrm{x}}{\mathrm{L}}\right) \\
& \mathrm{T}_{\text {corr }}=\mathrm{T}_{\mathrm{w}}-\mathrm{q}_{\text {net }}^{\prime \prime}\left(\frac{\mathrm{L}_{\text {Kapton }}}{\mathrm{k}_{\text {Kapton }}}\right) \\
& \mathrm{q}_{\text {net }}^{\prime \prime}=\frac{\mathrm{P}_{\text {total }}-\mathrm{q}_{\text {loss }}^{\prime \prime}\left(2 \mathrm{~A}_{\text {heater }}\right)}{2 \mathrm{~A}_{\text {heater }}+0.5 \mathrm{~N} \cdot \pi \cdot \mathrm{d}^{2}} \\
& \mathrm{q}_{\text {loss }}^{\prime \prime} \frac{\mathrm{T}_{\mathrm{w}}-\mathrm{T}_{\text {amb }}}{\frac{\mathrm{L}_{\mathrm{MDF}}}{\mathrm{k}_{\mathrm{MDF}}}+\frac{\mathrm{L}_{\text {ins }}}{\mathrm{k}_{\text {ins }}}+\frac{1}{\mathrm{~h}_{\mathrm{amb}}}}
\end{aligned}
$$

Using the above five equations, the endwall Nusselt number uncertainty is calculated using the root-sum-square method as given below:

$$
\begin{aligned}
& \mathrm{u}_{\mathrm{Nu}}=\sqrt{\left(\frac{\partial \mathrm{Nu}}{\partial \mathrm{q}_{\text {net }}^{\prime \prime}} \mathrm{u}_{\mathrm{q}_{\text {net }}}\right)^{2}+\left(\frac{\partial \mathrm{Nu}}{\partial \mathrm{W}} \mathrm{u}_{\mathrm{W}}\right)^{2}+\left(\frac{\partial \mathrm{Nu}}{\partial \mathrm{H}} \mathrm{u}_{\mathrm{H}}\right)^{2}+\left(\frac{\partial \mathrm{Nu}}{\partial \mathrm{T}_{\text {corr }}} \mathrm{u}_{\mathrm{T}_{\text {corr }}}\right)^{2}+\left(\frac{\partial \mathrm{Nu}}{\partial \mathrm{T}_{\text {bulk }}} \mathrm{u}_{\mathrm{T}_{\text {bulk }}}\right)^{2}} \\
& \mathrm{u}_{\mathrm{T}_{\text {bulk }}}=\sqrt{\left(\frac{\partial \mathrm{T}_{\text {bulk }}}{\partial \mathrm{T}_{\text {in }}} \mathrm{u}_{\mathrm{T}_{\text {in }}}\right)^{2}+\left(\frac{\partial \mathrm{T}_{\text {bulk }}}{\partial \overline{\overline{\mathrm{Q}_{\text {net }}}}} \mathrm{u}_{\overline{\overline{\mathrm{Q}_{\text {net }}}}}\right)^{2}+\left(\frac{\partial \mathrm{T}_{\text {bulk }}}{\partial \mathrm{m}} \mathrm{u}_{\mathrm{m}}\right)^{2}+\left(\frac{\partial \mathrm{T}_{\text {bulk }}}{\partial \mathrm{x}} \mathrm{u}_{\mathrm{x}}\right)^{2}+\left(\frac{\partial \mathrm{T}_{\text {bulk }}}{\partial \mathrm{L}} \mathrm{u}_{\mathrm{L}}\right)^{2}} \\
& \mathrm{u}_{\mathrm{T}_{\text {corr }}}=\sqrt{\left(\frac{\partial \mathrm{T}_{\text {corr }}}{\partial \mathrm{T}_{\mathrm{w}}} \mathrm{u}_{\mathrm{T}_{\mathrm{w}}}\right)^{2}+\left(\frac{\partial \mathrm{T}_{\text {corr }}}{\partial \mathrm{q}_{\text {net }}^{\prime \prime}} \mathrm{u}_{\mathrm{q}_{\text {net }}}\right)^{2}}
\end{aligned}
$$




$$
\begin{aligned}
& \mathrm{u}_{\mathrm{q}_{\text {net }}}=\sqrt{\left(\frac{\partial \mathrm{q}_{\text {net }}^{\prime \prime}}{\partial \mathrm{P}_{\text {total }}} \mathrm{u}_{\mathrm{P}_{\text {total }}}\right)^{2}+\left(\frac{\partial \mathrm{q}_{\text {net }}^{\prime \prime}}{\partial \mathrm{q}_{\text {loss }}^{\prime \prime}} \mathrm{u}_{\mathrm{q}_{\text {loss }}}\right)^{2}+\left(\frac{\partial \mathrm{q}_{\text {net }}^{\prime \prime}}{\partial \mathrm{A}_{\text {heater }}} \mathrm{u}_{\mathrm{A}_{\text {heater }}}\right)^{2}+\left(\frac{\partial \mathrm{q}_{\text {net }}^{\prime \prime}}{\partial \mathrm{d}} \mathrm{u}_{\mathrm{d}}\right)^{2}} \\
& \mathrm{u}_{\mathrm{q}_{\text {loss }}^{\prime \prime}}=\sqrt{\left(\frac{\partial \mathrm{q}_{\text {loss }}^{\prime \prime}}{\partial \mathrm{T}_{\mathrm{w}}} \mathrm{u}_{\mathrm{T}_{\mathrm{w}}}\right)^{2}+\left(\frac{\partial \mathrm{q}_{\text {loss }}^{\prime \prime}}{\partial \mathrm{T}_{\text {amb }}} \mathrm{u}_{\mathrm{T}_{\text {amb }}}\right)^{2}}
\end{aligned}
$$

The results of the uncertainty analyses are presented in the following tables.

\begin{tabular}{|c|c|c|c|c|}
\hline Variable & Value & $\begin{array}{c}\text { Precision } \\
\text { Uncertainty }\end{array}$ & $\begin{array}{c}\text { Bias } \\
\text { Uncertainty }\end{array}$ & $\begin{array}{c}\text { Total } \\
\text { Uncertainty }\end{array}$ \\
\hline $\mathrm{Nu}$ & 49.91 & - & - & $3.76(7.54 \%)$ \\
\hline $\mathrm{q}_{\text {net }}{ }^{\prime}, \mathrm{W} / \mathrm{m}^{2}$ & 765.43 & - & - & 29.03 \\
\hline $\mathrm{W}, \mathrm{m}$ & $6.10 \mathrm{E}-01$ & - & - & $7.62 \mathrm{E}-04$ \\
\hline $\mathrm{H}, \mathrm{m}$ & $9.53 \mathrm{E}-03$ & - & - & 3.97E-04 \\
\hline $\mathrm{T}_{\text {corr },}{ }^{\circ} \mathrm{C}$ & 33.27 & - & - & 0.49 \\
\hline $\mathrm{T}_{\text {bulk }}{ }^{\circ} \mathrm{C}$ & 22.04 & - & - & 0.29 \\
\hline $\mathrm{T}_{\text {in }}{ }^{\circ} \mathrm{C}$ & 17.158 & 0.008 & 0.200 & 0.200 \\
\hline $\mathrm{Q}_{\text {net,bar, }} \mathrm{W}$ & 275.4 & - & - & 10.44 \\
\hline m_dot, $\mathrm{kg} / \mathrm{s}$ & $2.86 \mathrm{E}-02$ & - & - & $4.87 \mathrm{E}-04$ \\
\hline $\mathrm{x}$, in & 5.875 & - & - & 0.039 \\
\hline $\mathrm{L}$, in & 11.5 & - & - & 0.03 \\
\hline $\mathrm{P}_{\text {total }}, \mathrm{W}$ & 278.5 & - & - & 10.44 \\
\hline $\mathrm{q}_{\mathrm{loss}} ", \mathrm{~W} / \mathrm{m} 2$ & 6.81 & - & - & 0.32 \\
\hline$A_{\text {heater }}, m^{2}$ & $1.78 \mathrm{E}-01$ & - & - & $5.15 \mathrm{E}-04$ \\
\hline $\mathrm{d}, \mathrm{m}$ & $9.53 \mathrm{E}-03$ & - & - & $2.54 \mathrm{E}-05$ \\
\hline $\mathrm{T}_{\mathrm{w}},{ }^{\circ} \mathrm{C}$ & 33.76 & 0.410 & 0.270 & 0.490 \\
\hline $\mathrm{T}_{\mathrm{amb},}{ }^{\mathrm{o}} \mathrm{C}$ & 22 & 0.157 & 0.200 & 0.250 \\
\hline
\end{tabular}

Re = 5013, High Nu 
$\mathrm{Re}=5013$, Low Nu

\begin{tabular}{|c|c|c|c|c|}
\hline Variable & Value & $\begin{array}{c}\text { Precision } \\
\text { Uncertainty }\end{array}$ & $\begin{array}{c}\text { Bias } \\
\text { Uncertainty }\end{array}$ & $\begin{array}{c}\text { Total } \\
\text { Uncertainty }\end{array}$ \\
\hline $\mathrm{Nu}$ & 18.08 & - & - & $1.11(6.15 \%)$ \\
\hline $\mathrm{q}_{\text {net }}{ }^{\prime}, \mathrm{W} / \mathrm{m}^{2}$ & 756.03 & - & - & 29.03 \\
\hline $\mathrm{W}, \mathrm{m}$ & $6.10 \mathrm{E}-01$ & - & - & $7.62 \mathrm{E}-04$ \\
\hline $\mathrm{H}, \mathrm{m}$ & $9.53 \mathrm{E}-03$ & - & - & $3.97 \mathrm{E}-04$ \\
\hline $\mathrm{T}_{\text {corr }}{ }^{\circ} \mathrm{C}$ & 49.72 & - & - & 0.73 \\
\hline $\mathrm{T}_{\text {bulk }}{ }^{\circ} \mathrm{C}$ & 19.08 & - & - & 0.22 \\
\hline $\mathrm{T}_{\text {in }}{ }^{\circ} \mathrm{C}$ & 17.158 & 0.008 & 0.200 & 0.200 \\
\hline $\mathrm{Q}_{\text {net, }, \mathrm{bar}}, \mathrm{W}$ & 275.4 & - & - & 10.44 \\
\hline $\mathrm{m}_{\mathrm{d} \text { dot}, \mathrm{kg} / \mathrm{s}}$ & $2.86 \mathrm{E}-02$ & - & - & $4.87 \mathrm{E}-04$ \\
\hline $\mathrm{x}, \mathrm{in}$ & 2.31 & - & - & 0.039 \\
\hline $\mathrm{L}, \mathrm{in}$ & 11.5 & - & - & 0.03 \\
\hline $\mathrm{P}_{\text {total }}, \mathrm{W}$ & 278.5 & - & - & 10.44 \\
\hline $\mathrm{q}_{\text {loss }}{ }^{\circ}, \mathrm{W} / \mathrm{m} 2$ & 16.33 & - & - & 0.45 \\
\hline $\mathrm{A}_{\text {heater }}, \mathrm{m}{ }^{2}$ & $1.78 \mathrm{E}-01$ & - & - & $5.15 \mathrm{E}-04$ \\
\hline $\mathrm{d}, \mathrm{m}$ & $9.53 \mathrm{E}-03$ & - & - & $2.54 \mathrm{E}-05$ \\
\hline $\mathrm{T}_{\mathrm{w}},{ }^{\circ} \mathrm{C}$ & 50.2 & 0.680 & 0.250 & 0.730 \\
\hline $\mathrm{T}_{\text {amb }}{ }^{\circ} \mathrm{C}$ & 22 & 0.157 & 0.200 & 0.250 \\
\hline
\end{tabular}


$\mathrm{Re}=30,484$, High $\mathrm{Nu}$

\begin{tabular}{|c|c|c|c|c|}
\hline Variable & Value & $\begin{array}{c}\text { Precision } \\
\text { Uncertainty }\end{array}$ & $\begin{array}{c}\text { Bias } \\
\text { Uncertainty }\end{array}$ & $\begin{array}{c}\text { Total } \\
\text { Uncertainty }\end{array}$ \\
\hline $\mathrm{Nu}$ & 154.55 & - & - & $8.53(5.52)$ \\
\hline $\mathrm{q}_{\text {net }} ", \mathrm{~W} / \mathrm{m}^{2}$ & 2900.73 & - & - & 72.40 \\
\hline $\mathrm{W}, \mathrm{m}$ & $6.10 \mathrm{E}-01$ & - & - & $7.62 \mathrm{E}-04$ \\
\hline $\mathrm{H}, \mathrm{m}$ & $9.53 \mathrm{E}-03$ & - & - & $3.97 \mathrm{E}-04$ \\
\hline $\mathrm{T}_{\text {corr }}{ }^{\circ} \mathrm{C}$ & 33.40 & - & - & 0.30 \\
\hline $\mathrm{T}_{\text {bulk }}{ }^{\circ} \mathrm{C}$ & 19.65 & - & - & 0.22 \\
\hline $\mathrm{T}_{\text {in }}{ }^{\circ} \mathrm{C}$ & 16.5994 & 0.016 & 0.200 & 0.201 \\
\hline $\mathrm{Q}_{\text {net,bar, }} \mathrm{W}$ & 1046 & - & - & 25.94 \\
\hline $\mathrm{m}_{\mathrm{d} \text { dot, } \mathrm{kg} / \mathrm{s}}$ & $1.74 \mathrm{E}-01$ & - & - & $1.54 \mathrm{E}-03$ \\
\hline $\mathrm{x}, \mathrm{in}$ & 5.875 & - & - & 0.039 \\
\hline $\mathrm{L}, \mathrm{in}$ & 11.5 & - & - & 0.03 \\
\hline $\mathrm{P}_{\text {total }}, \mathrm{W}$ & 1048.97 & - & - & 25.94 \\
\hline $\mathrm{q}_{\text {loss }}{ }^{\circ}, \mathrm{W} / \mathrm{m} 2$ & 7.67 & - & - & 0.23 \\
\hline $\mathrm{A}_{\text {heater }}, \mathrm{m}^{2}$ & $1.78 \mathrm{E}-01$ & - & - & $5.15 \mathrm{E}-04$ \\
\hline $\mathrm{d}, \mathrm{m}$ & $9.53 \mathrm{E}-03$ & - & - & $2.54 \mathrm{E}-05$ \\
\hline $\mathrm{T}_{\mathrm{w}},{ }^{\circ} \mathrm{C}$ & 35.24 & 0.212 & 0.209 & 0.300 \\
\hline $\mathrm{T}_{\text {amb }}{ }^{\circ} \mathrm{C}$ & 22 & 0.157 & 0.200 & 0.250 \\
\hline
\end{tabular}




\begin{tabular}{|c|c|c|c|c|}
\hline Variable & Value & $\begin{array}{c}\text { Precision } \\
\text { Uncertainty }\end{array}$ & $\begin{array}{c}\text { Bias } \\
\text { Uncertainty }\end{array}$ & $\begin{array}{c}\text { Total } \\
\text { Uncertainty }\end{array}$ \\
\hline $\mathrm{Nu}$ & 82.33 & - & - & $4.14(5.03 \%)$ \\
\hline$q_{\text {net }} ", W / m^{2}$ & 2894.92 & - & - & 72.40 \\
\hline $\mathrm{W}, \mathrm{m}$ & $6.10 \mathrm{E}-01$ & - & - & 7.62E-04 \\
\hline $\mathrm{H}, \mathrm{m}$ & $9.53 \mathrm{E}-03$ & - & - & 3.97E-04 \\
\hline $\mathrm{T}_{\text {corr },}{ }^{\mathrm{O}} \mathrm{C}$ & 43.56 & - & - & 0.32 \\
\hline $\mathrm{T}_{\text {bulk }},{ }^{\mathrm{o}} \mathrm{C}$ & 17.80 & - & - & 0.20 \\
\hline $\mathrm{T}_{\text {in }},{ }^{\circ} \mathrm{C}$ & 16.5994 & 0.016 & 0.200 & 0.201 \\
\hline$Q_{\text {net,bar, }}$ W & 1046 & - & - & 25.94 \\
\hline $\mathrm{m} \_$dot, $\mathrm{kg} / \mathrm{s}$ & $1.74 \mathrm{E}-01$ & - & - & $1.54 \mathrm{E}-03$ \\
\hline$x$, in & 2.31 & - & - & 0.039 \\
\hline $\mathrm{L}$, in & 11.5 & - & - & 0.03 \\
\hline $\mathrm{P}_{\text {total }}, \mathrm{W}$ & 1048.97 & - & - & 25.94 \\
\hline$q_{\text {loss }} ", W / m 2$ & 13.55 & - & - & 0.24 \\
\hline $\mathrm{A}_{\text {heater }}, \mathrm{m}^{2}$ & $1.78 \mathrm{E}-01$ & - & - & $5.15 \mathrm{E}-04$ \\
\hline $\mathrm{d}, \mathrm{m}$ & $9.53 \mathrm{E}-03$ & - & - & $2.54 \mathrm{E}-05$ \\
\hline $\mathrm{T}_{\mathrm{w}},{ }^{\circ} \mathrm{C}$ & 45.4 & 0.233 & 0.224 & 0.320 \\
\hline $\mathrm{T}_{\mathrm{amb},}{ }^{\mathrm{o}} \mathrm{C}$ & 22 & 0.157 & 0.200 & 0.250 \\
\hline
\end{tabular}




\section{Uncertainty for the heat transfer augmentation, $\mathrm{Nu} / \mathrm{Nu}_{0}$}

As a result of the Reynolds number and endwall heat transfer uncertainty already being known, calculating the heat transfer augmentation uncertainty was relatively straightforward and is given in the following equation:

$$
\frac{\mathrm{Nu}}{\mathrm{Nu}_{0}}=\frac{\mathrm{Nu}}{0.022 \mathrm{Re}^{0.8} \operatorname{Pr}^{0.5}}
$$

In a similar manner as before, the uncertainty is calculated using the root-sum-square method as given below:

$$
\mathrm{u}_{\frac{\mathrm{Nu}}{\mathrm{Nu}_{0}}}=\sqrt{\left(\frac{\partial \frac{\mathrm{Nu}}{\mathrm{Nu} u_{0}}}{\partial \mathrm{Nu}} \mathrm{u}_{\mathrm{Nu}}\right)^{2}+\left(\frac{\partial \frac{\mathrm{Nu}}{\mathrm{Nu} u_{0}}}{\partial \mathrm{Re}} \mathrm{u}_{\mathrm{Re}}\right)^{2}}
$$

The uncertainty results are given in the following tables.

$\mathrm{Re}=5013, \mathrm{High} \mathrm{Nu} / \mathrm{Nu}_{0}$

\begin{tabular}{|l|r|r|}
\hline Variable & Value & \multicolumn{1}{c|}{$\begin{array}{c}\text { Total } \\
\text { Uncertainty }\end{array}$} \\
\hline $\mathrm{Nu} / \mathrm{Nu}_{0}$ & 2.96 & $0.227(7.66 \%)$ \\
\hline $\mathrm{Nu}$ & 49.91 & 3.76 \\
\hline $\mathrm{Re}$ & 5013 & 85 \\
\hline
\end{tabular}

$\mathrm{Re}=5013$, Low Nu$/ \mathrm{Nu}_{0}$

\begin{tabular}{|l|r|r|}
\hline \multicolumn{1}{|c|}{ Variable } & \multicolumn{1}{c|}{ Value } & \multicolumn{1}{c|}{$\begin{array}{c}\text { Total } \\
\text { Uncertainty }\end{array}$} \\
\hline $\mathrm{Nu} / \mathrm{Nu}_{0}$ & 1.07 & $.067(6.30 \%)$ \\
\hline $\mathrm{Nu}$ & 18.08 & 1.11 \\
\hline $\mathrm{Re}$ & 5013 & 85 \\
\hline
\end{tabular}




Re $=30,484$, High $\mathbf{N u} / \mathbf{N u}_{\mathbf{0}}$
\begin{tabular}{|l|r|r|}
\hline Variable & Value & $\begin{array}{c}\text { Total } \\
\text { Uncertainty }\end{array}$ \\
\hline $\mathrm{Nu} / \mathrm{Nu}_{0}$ & 2.16 & $0.120(5.57 \%)$ \\
\hline $\mathrm{Nu}$ & 154.55 & 8.53 \\
\hline $\mathrm{Re}$ & 30484 & 273 \\
\hline
\end{tabular}

Re $=30,484$, Low Nu/Nu $\mathbf{~}$
\begin{tabular}{|l|r|r|}
\hline Variable & Value & $\begin{array}{c}\text { Total } \\
\text { Uncertainty }\end{array}$ \\
\hline $\mathrm{Nu} / \mathrm{Nu}_{0}$ & 1.15 & $0.058(5.09 \%)$ \\
\hline $\mathrm{Nu}$ & 82.33 & 4.14 \\
\hline $\mathrm{Re}$ & 30484 & 273 \\
\hline
\end{tabular}




\section{Appendix C: Duct Heat Loss Calculations}

This appendix presents the method used to account for heat loss from the channel for preliminary design calculations and also during testing. Figure $\mathrm{C}-1$ is a schematic that shows all materials that contribute to the total thermal resistance. Table $\mathrm{C}-1$ lists the dimensions and properties used for calculating the heat loss.

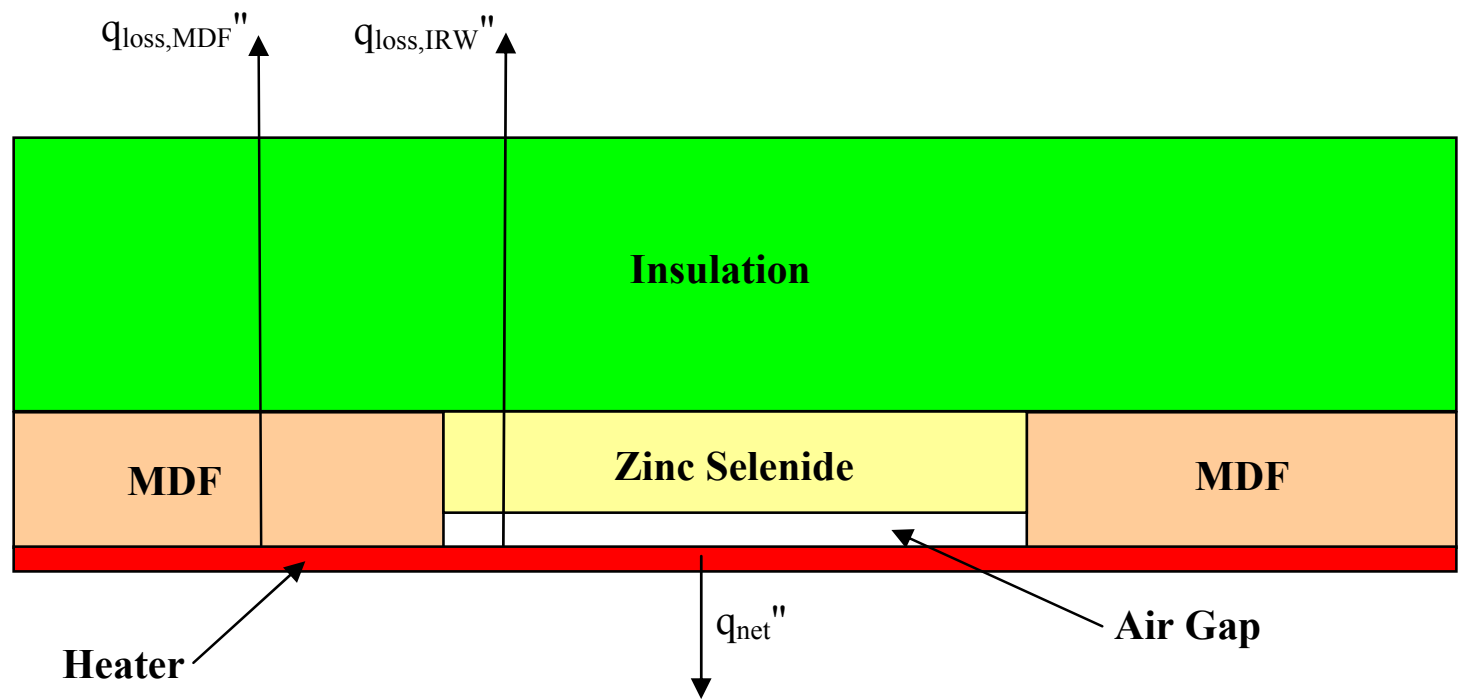

Flow

Figure C-1 Schematic showing the thermal resistances to heat loss from the channel.

As shown in Figure C-1, there are two basic paths for the heat transfer leaving the channel. The first is through the zinc selenide infrared window (IRW), and the other is through the MDF duct wall to the atmosphere. The thermal resistance through the IRW can be written as follows:

$\mathrm{R}_{\text {IRW }}^{\prime \prime}=\frac{\mathrm{L}_{\text {air }}}{\mathrm{k}_{\text {air }}}+\frac{\mathrm{L}_{\text {IRW }}}{\mathrm{k}_{\text {IRW }}}+\frac{\mathrm{L}_{\text {ins }}}{\mathrm{k}_{\text {ins }}}+\frac{1}{\mathrm{~h}_{\text {amb }}}$

Similarly, the thermal resistance through the MDF duct wall to the atmosphere can be written as:

$$
\mathrm{R}_{\mathrm{MDF}}^{\prime \prime}=\frac{\mathrm{L}_{\mathrm{MDF}}}{\mathrm{k}_{\mathrm{MDF}}}+\frac{\mathrm{L}_{\text {ins }}}{\mathrm{k}_{\text {ins }}}+\frac{1}{\mathrm{~h}_{\mathrm{amb}}}
$$

Substituting the given values and assuming $\mathrm{h}_{\mathrm{amb}}=5 \mathrm{~W} / \mathrm{m}^{2} \mathrm{~K}$, the resistances are calculated to be $\mathrm{R}_{\mathrm{IRW}}^{\prime \prime}=1.815 \mathrm{~m}^{2}-\mathrm{K} / \mathrm{W}$ and $\mathrm{R}_{\mathrm{MDF}}^{\prime \prime}=1.727 \mathrm{~m}^{2}-\mathrm{K} / \mathrm{W}$, which are only about 
$5 \%$ different. When considering that the heat loss from the channel is small in comparison to the total heat generated, the difference in thermal resistance to heat leaving the channel through either the duct wall or the IR window imparts only a small influence on the net heat flux entering the channel. Thus, the heat loss out of the channel through the MDF duct wall will be approximately equal to the heat loss through the IR window out of the channel. Due to the MDF wall providing the largest surface area for heat loss, and also due to the similarity between the MDF duct wall and IR window heat transfer paths, the path through the MDF duct wall was chosen to be the representative heat transfer path out of the channel when analyzing the experimental data. It is understood that the heat transfer coefficient, which is dependent on flow conditions within the channel is the primary resistance to heat transfer entering the channel. Higher heat transfer coefficients give less thermal resistance.

It is worth mentioning how the thermal resistance through the air gap was considered. The IR window was set in place leaving an air gap to prevent conduction errors on the heater surface when measuring the endwall heat transfer. Being heated from the bottom side by the endwall heater, it was questioned whether or not there would be free convection flows generated within the air gap. To answer this question, the estimated Rayleigh number was computed to determine whether assuming a simple onedimensional thermal resistance was valid or not. The Rayleigh number is defined as follows:

$\mathrm{Ra}_{\mathrm{t}}=\frac{\mathrm{g} \cdot \beta\left(\mathrm{T}_{\mathrm{w}}-\mathrm{T}_{\text {air }}\right) \mathrm{t}^{3}}{\alpha \cdot v}$

where $g$ is the acceleration due to gravity, $\beta$ is the volume expansion coefficient, $T_{w}$ is the heater wall temperature, $T_{\text {air }}$ is the air temperature within the air gap, $t$ is the thickness of the air gap, $\alpha$ is the thermal diffusivity, and $v$ is the momentum diffusivity. To prevent free convection, it is required that $\mathrm{Ra}_{\mathrm{t}}<1708$. After substituting the required parameters into the Rayleigh number equation and assuming a conservative temperature difference of $30^{\circ} \mathrm{C}$ between the heater wall and the air gap, it was found that $\mathrm{Ra}_{\mathrm{t}}<700$. This calculation validates the assumption of assuming one-dimensional conduction through the air gap.

Table C1 Heat Loss Parameters

\begin{tabular}{|l|l|l|l|l|}
\hline & MDF & Insulation & Air Gap & IR Window \\
\hline $\mathbf{L}(\mathbf{c m})$ & 1.91 & 5.08 & 0.635 & 1.27 \\
\hline $\mathbf{k}(\mathbf{W} / \mathbf{m}-\mathbf{k})$ & 0.124 & 0.037 & 0.026 & 18.0 \\
\hline
\end{tabular}




\section{Appendix D: Endwall Heat Transfer Contour Plots for the $S / d=4$ and 8 Pin Spacings}

This appendix presents the contour plots that were not shown within Chapter five when presenting the experimental results.

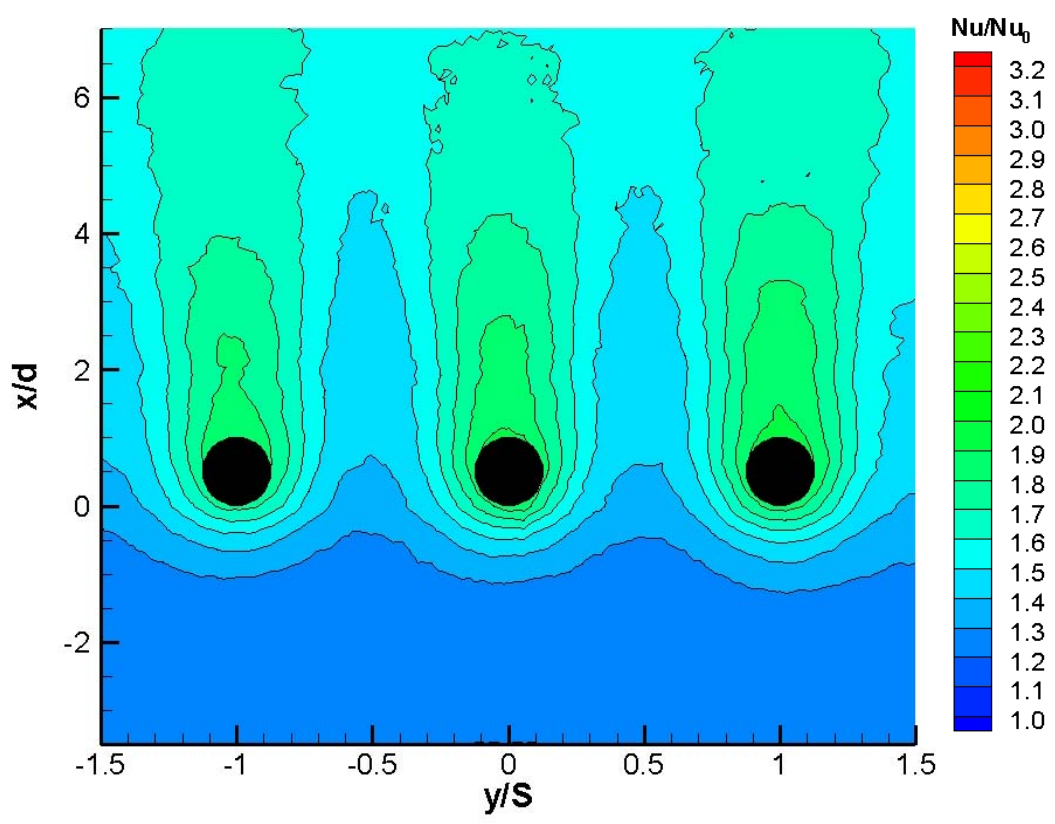

Figure D-1 Heat transfer augmentation contour for the $\mathrm{S} / \mathrm{d}=4$ pin spacing at $\mathrm{Re}=$ 10,018 and $\mathrm{Re}_{\mathrm{d}}=6784$.

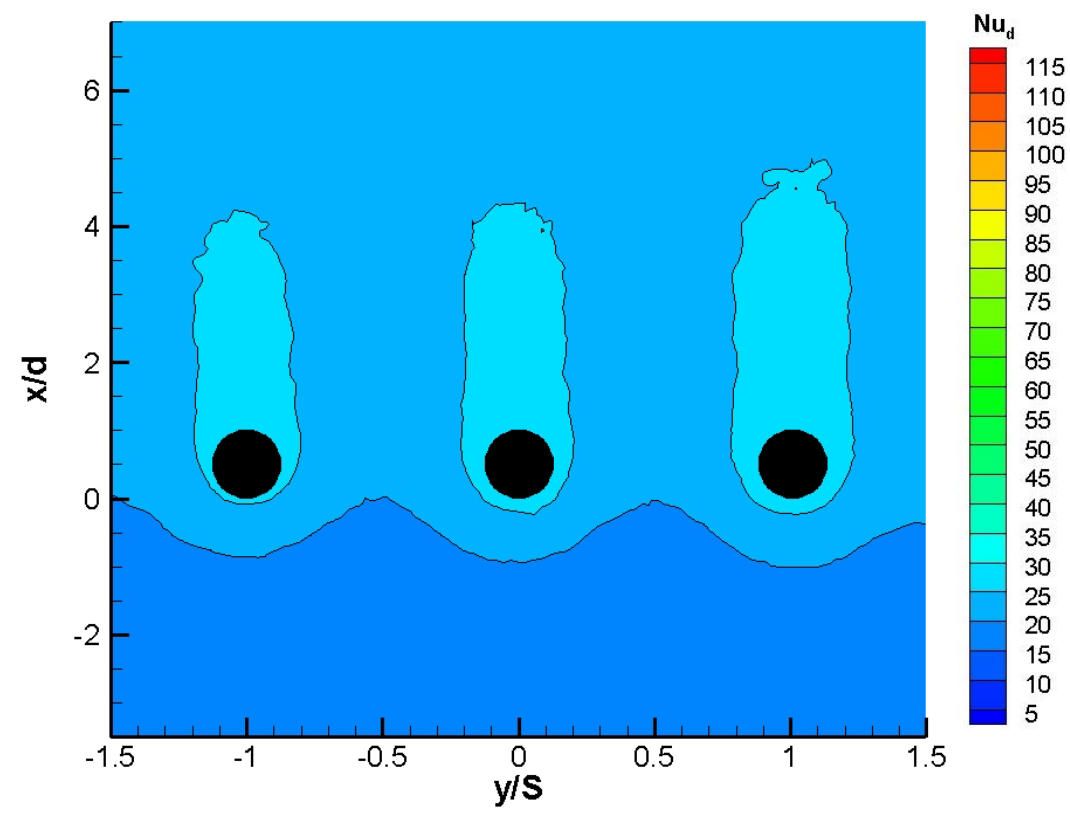

Figure D-2 Contour plot of $\mathrm{Nu}_{d}$ for the $\mathrm{S} / \mathrm{d}=4$ pin spacing at $\mathrm{Re}=10,018$ and $\mathrm{Re}_{\mathrm{d}}=$ 6784. 


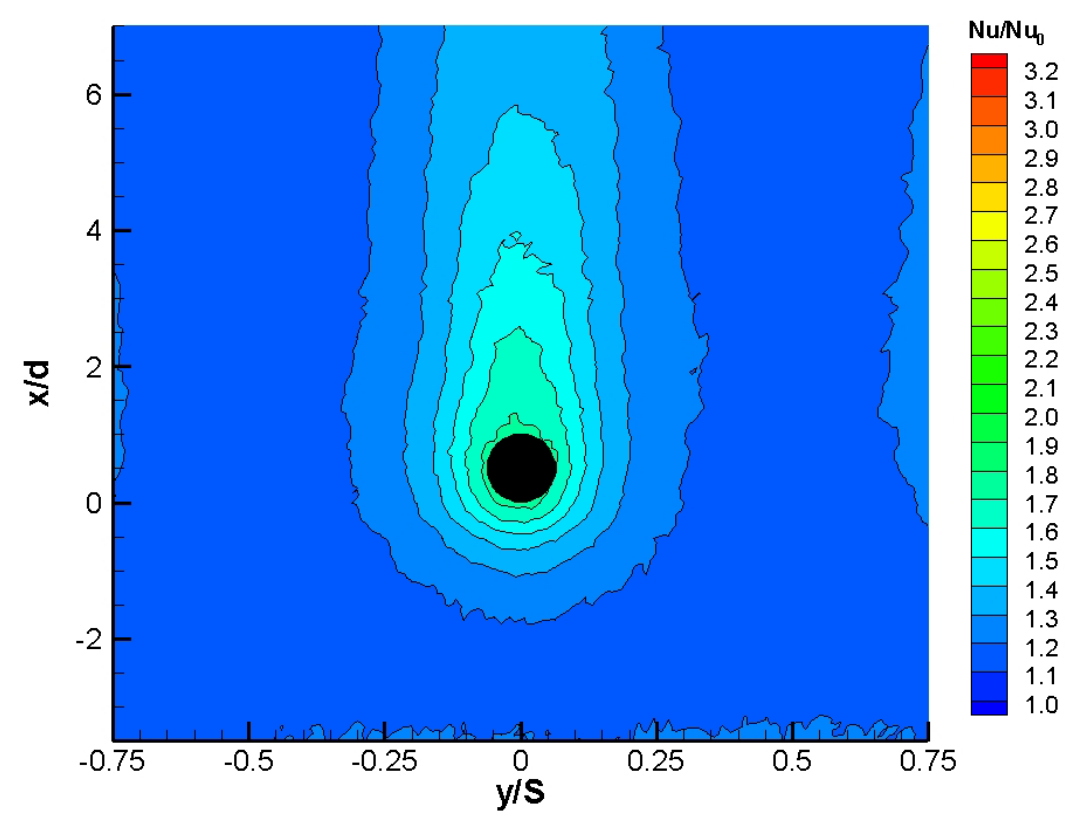

Figure D-3 Heat transfer augmentation contour for the $\mathrm{S} / \mathrm{d}=8$ pin spacing at $\mathrm{Re}=$ 10,210 and $\mathrm{Re}_{\mathrm{d}}=5925$.

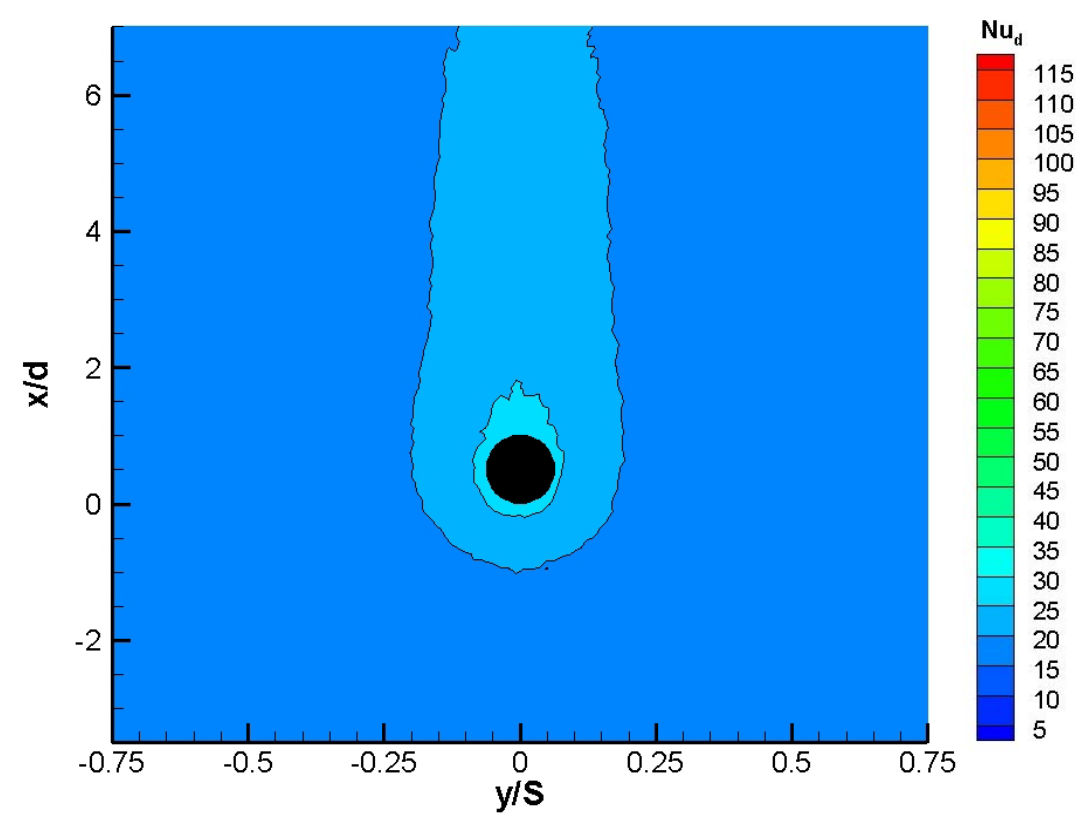

Figure D-4 Contour plot of $\mathrm{Nu}_{\mathrm{d}}$ for the $\mathrm{S} / \mathrm{d}=8$ pin spacing at $\mathrm{Re}=10,210$ and $\mathrm{Re}_{\mathrm{d}}=$ 5925. 